\title{
UNIVERSIDAD PONTIFICIA DE SALAMANCA
}

Facultad de Ciencias Políticas y Sociología

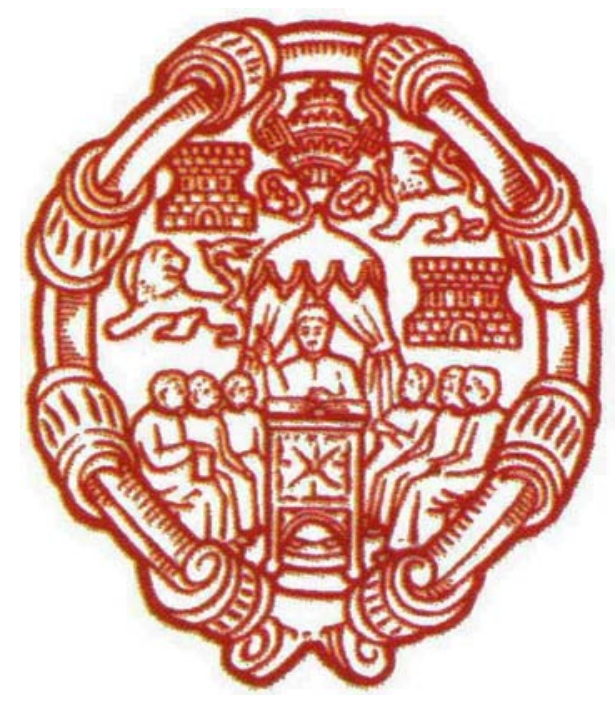

\section{TESIS DOCTORAL}

\section{Los ritos de iniciación en la Universidad de San Carlos de Guatemala: Un estudio de caso de la Facultad de Agronomía}

Licda. Da Ligia Maribel Monterroso López

\author{
Directora \\ Dra. Da Ángela Barrón Ruiz \\ Codirectora \\ Dra. D a Rosa Herrera García
}

Madrid, 2015 
A la memoria de los estudiantes y docentes de USAC que fueron secuestrados y asesinados, vilmente, durante el conflicto armado interno en Guatemala. 


\section{AGRADECIMIENTOS}

A los estudiantes universitarios de la Facultad de Agronomía de la Universidad de San Carlos de Guatemala (de aquí en adelante nos referiremos a ella como USAC) quienes aceptaron, amable y desinteresadamente, colaborar en la presente investigación, respondiendo a los cuestionarios presentados y participando en los diversos grupos focales implementados. Rompiendo de esta manera con el no reconocido, pero implícito, Código del Silencio de los bautizos en USAC. Por ustedes la lucha, por el respeto a la dignidad del estudiante novato, por la lucha contra la impunidad y la búsqueda del respeto a los Derechos Humanos de las futuras generaciones de jóvenes guatemaltecos que ilusionados tocan con alegría las puertas de esta casa de estudios por primera vez.

A mis colegas: amigos, profesores y profesionales egresados de esta Unidad Académica quienes compartieron conmigo su perspectiva de la celebración del bautizo o bienvenida, como se le ha dado en llamar para burlar las normas institucionales que establecen que esta práctica está prohibida.

A las autoridades académicas de la Facultad de Agronomía por permitirme dar seguimiento a la celebración de las novatadas, documentándolo durante el período comprendido entre los años 2013-2015. Quienes me otorgaron tiempo dentro de mi carga docente para culminar los estudios de doctorado. A los profesionales en Medicina, Psicología, Derechos Humanos, Sociología y Antropología que fueron abordados en entrevistas a profundidad.

En especial, agradezco el esmero, paciencia y reconozco la experiencia y capacidad de mi directora de tesis, doctora Ángela Barrón Ruiz quien paciente y sabiamente me asesoró en la ejecución de la investigación en campo y elaboración del informe final.

Finalmente a mi esposo Fredy Rodríguez Morataya y mis pequeños hijos Emanuel y Valeria, quienes pacientemente renunciaron a mi atención durante cientos de horas y me vieron 
embebida en el esfuerzo por recorrer los caminos de esta aventura llamada investigación. Una aventura que me ha llevado a conocer a profundidad una realidad que anualmente nos desborda y genera múltiples y radicales reacciones en la sociedad guatemalteca. Las notas de prensa abundan denunciado agresiones y luego, como por arte de magia, todo queda en el olvido.

Por mi bella Guatemala, por las instituciones que han permitido mi formación académica a lo largo de tantos años. 


\section{ÍNDICE GENERAL}

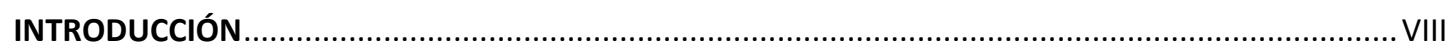

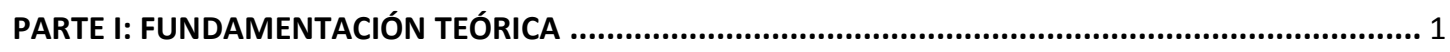

CAPÍTULO 1: MARCO TEÓRICO DE LA VIOLENCIA..................................................................... 1

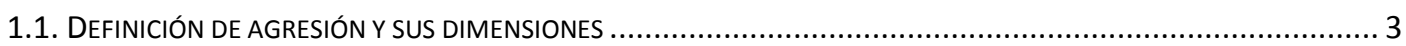

1.1.1. Delimitación conceptual de la violencia................................................................................ 5

1.1.2. Delimitación conceptual de la agresión .......................................................................... 7

1.1.3. Teorías sociológicas relativas a la conducta agresiva y la violencia................................... 13

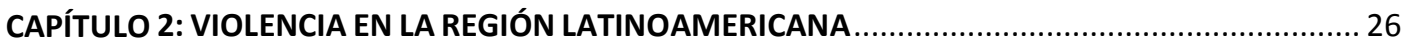

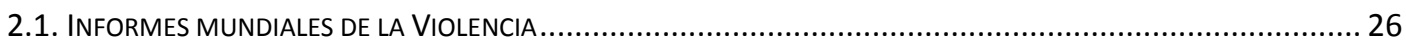

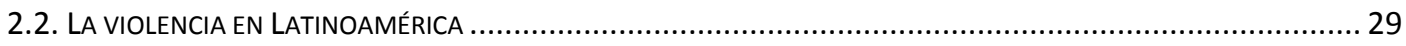

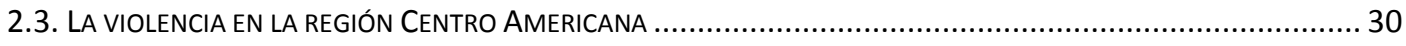

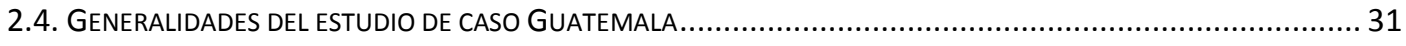

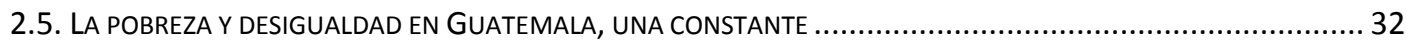

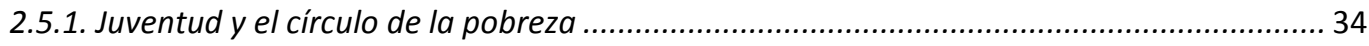

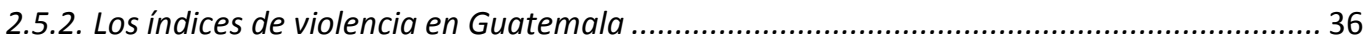

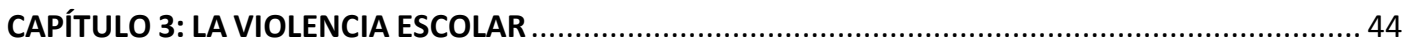

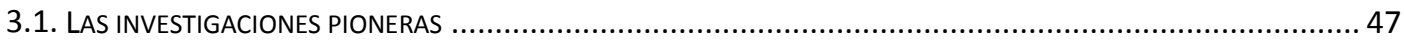

3.1.1. Las novatadas o bautizos desde la perspectiva de los ritos de iniciación ............................ 48

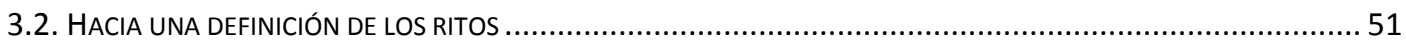

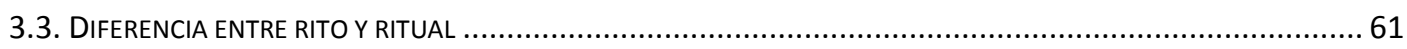

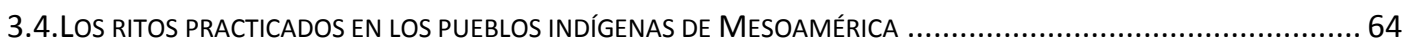

CAPÍTULO 4: LAS NOVATADAS COMO UNA PRÁCTICA ESTUDIANTIL DE CONSUMO CULTURAL O DE

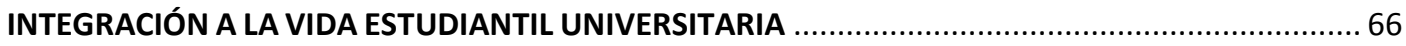

4.1. LA IMPORTANCIA DE LAS NOVATADAS COMO UN MECANISMO DE SOCIALIZACIÓN ENTRE JÓVENES....................67

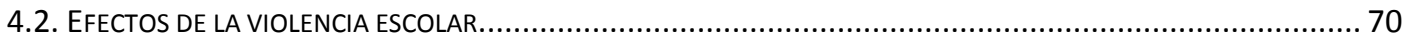

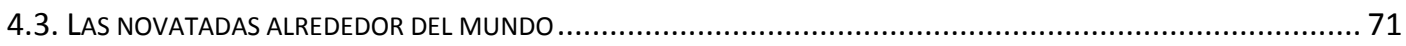

4.4. LAS ACCIONES TOMADAS POR LAS AUTORIDADES DE USAC ANTE LA OLA DE VIOLENCIA DENTRO DEL CAMPUS

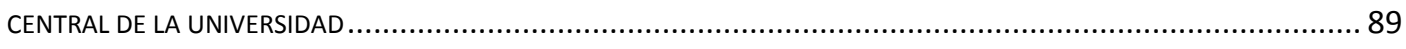

CAPÍTULO 5: ABORDAJE DE LAS NOVATADAS GUATEMALTECAS, DESDE LA PERSPECTIVA LEGAL. 90 


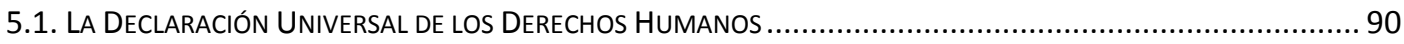

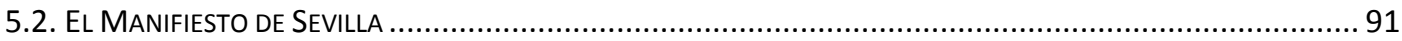

5.3. LAS NOVATADAS DESDE LA PERSPECTIVA DE LAS LEYES GUATEMALTECAS ...................................... 92

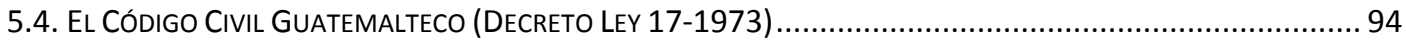

5.5. ANÁLISIS DE LA AGRESIÓN CONTRA ESTUDIANTES NOVATOS CON ARMAS DE FUEGO, ARMAS BLANCAS, FUEGOS

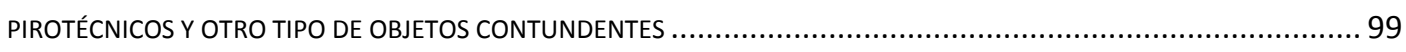

5.5.1. Ley contra la Narcoactividad, Decreto Ley 48-92 del Congreso de la República .............. 101

5.5.2. La obligatoriedad de la denuncia de parte de las autoridades universitarias ................. 102

5.5.3. Los Estatutos de la Universidad de San Carlos de Guatemala.................................... 102

PARTE II: ESTUDIO EMPÍRICO ............................................................................................. 106

CAPÍTULO 6: PLANTEAMIENTO DEL PROBLEMA Y METODOLOGÍA .......................................... 106

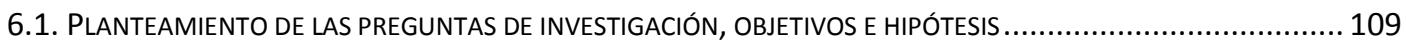

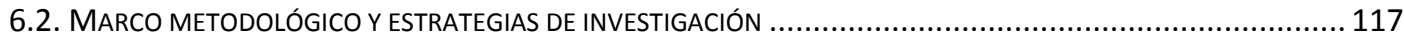

6.3. EL PERFIL DE LOS PARTICIPANTES: POBLACIÓN Y MUESTRA ....................................................... 120

6.3.1. La población objeto de estudio ......................................................................... 121

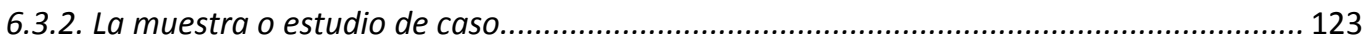

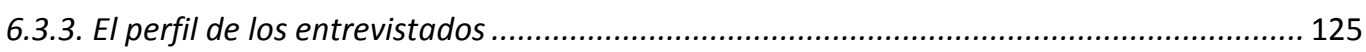

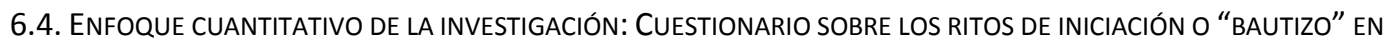

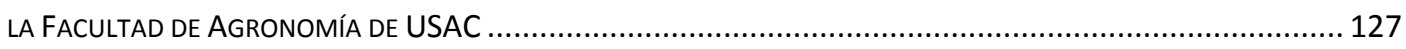

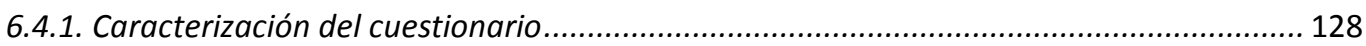

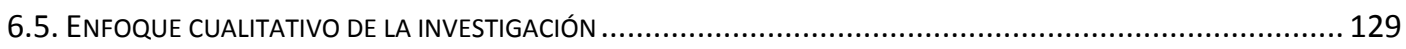

6.5.1. Descripción de las herramientas cualitativas empleadas ........................................ 130

6.5.2. Dimensiones del estudio cualitativo realizado..................................................... 131

CAPÍTULO 7: ESTUDIO DESCRIPTIVO DE LAS NOVATADAS EN LA FACULTAD DE AGRONOMÍA .... 134

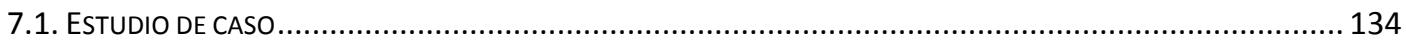

7.1.1. Antecedentes del estudio de caso................................................................. 134

7.2. DESCRIPCIÓN DE LAS NOVATAdAS EN LA FACULTAD DE AGRONOMÍA ............................................ 135

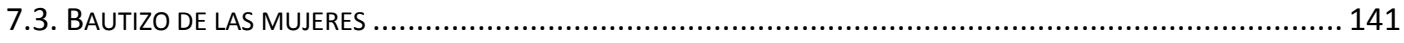

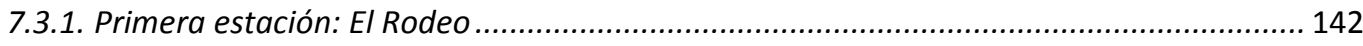

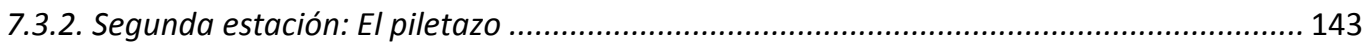




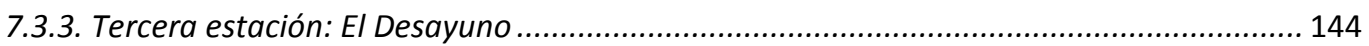

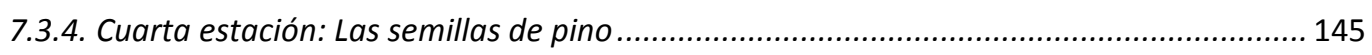

7.3.5. Quinta estación: Refacción con huevo crudo............................................................... 146

7.3.6. Sexta estación: El salón de belleza.......................................................................... 146

7.3.7. Séptima estación: El recorrido por los campos del CEDA........................................... 147

7.3.8. Octava estación: Alfombra de cerdaza .................................................................. 148

7.3.9. Novena y última estación: El recorrido triunfal por el campus central de USAC ............. 149

7.4. DESCRIPCIÓN DEL BAUTIZO DE LOS ESTUDIANTES NOVATOS VARONES........................................... 151

7.4.1. Primera estación: Encerrona en el auditórium ......................................................... 151

7.4.2. Segunda estación: El corte de cabello.................................................................. 152

7.4.3. Tercera estación: El Piletazo, borrachera y recorrido final ......................................... 153

CAPÍTULO 8 : ESTUDIO CUALITATIVO DE LAS NOVATADAS EN LA FACULTAD DE AGRONOMÍA... 158

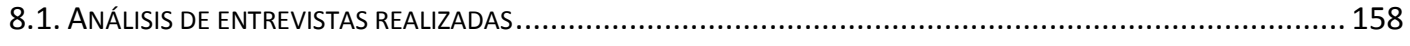

8.1.1. Entrevista a estudiantes novatos.................................................................. 159

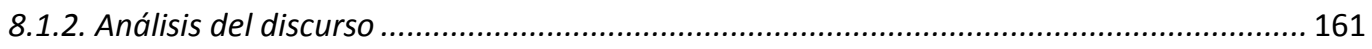

8.2. ENTREVISTA A PROFUNDIDAD DIRIGIDA AL SECTOR DOCENTE DE FAUSAC ....................................... 166

8.3. RESULTADOS DE LA ENTREVISTA DIRIGIDA A UN EGRESADO.................................................. 172

8.4. LA OPINIÓN DE UN PROFESIONAL EN EL CAMPO DE LA PSICOLOGÍA: ENTREVISTA DIRIGIDA AL PSICÓLOGO DE LA

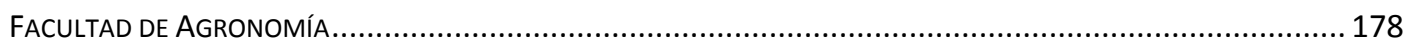

8.5. ENTREVISTA CON UNA PROFESIONAL EN EL CAMPO DE LA SOCIOLOGÍA ............................................ 179

8.6. ENTREVISTA DIRIGIDA A LA JEFA DE LA UNIDAD DE SALUD DEL DEPARTAMENTO DE BIENESTAR ESTUDIANTIL.... 180

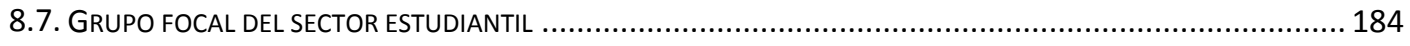

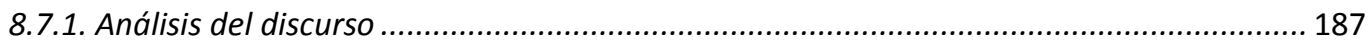

8.7.2. La Relación del poder y la subordinación ................................................................. 191

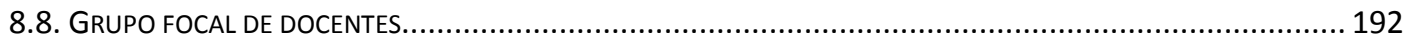

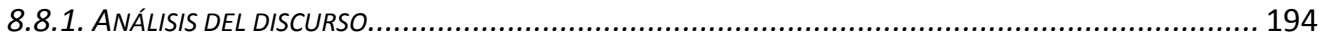

8.9. UN CICLO DIFÍCIL DE ROMPER, OTRAS UNIDADES ACADÉMICAS QUE SE UNEN A LA CELEBRACIÓN DE LA PRÁCTICA DEL

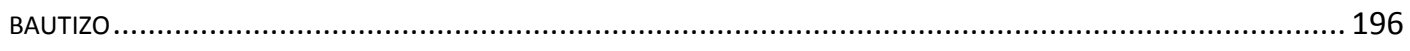

CAPÍTULO 9: RESULTADOS DE LA APLICACIÓN DE HERRAMIENTAS DE INVESTIGACIÓN ............... 198 


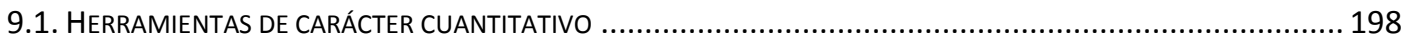

9.1.1. Características generales de los estudiantes encuestados ....................................... 198

9.1.2. Percepción estudiantil relativa a la seguridad dentro del campus universitario .............. 200

9.1.3. Percepción de los estudiantes novatos relativa a su bautizo........................................ 201

9.1.4. Ponderación estudiantil de las prácticas del bautizo................................................. 203

9.1.5. Análisis de los resultados del estudio cuantitativo ...................................................... 207

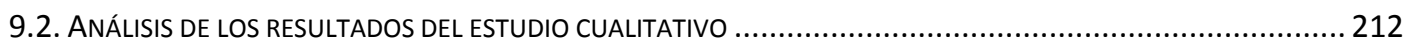

9.2.1. ¿Los bautizos refuerzan la identidad de los estudiantes como sancarlistas? ................. 212

9.2.2. La percepción estudiantil relativa al maltrato físico y psicológico................................... 214

9.2.3. Cuestionamiento acerca de la obligatoriedad del bautizo....................................... 218

9.2.4. Reflexión relativa a la obligatoriedad de la denuncia................................................. 219

9.2.5. El grado de organización del evento.................................................................. 223

9.2.6. El tiempo empleado para el bautizo .................................................................. 223

9.2.7. Reflexiones realizadas por los estudiantes en torno a la práctica del bautizo................. 224

9.2.8. Del drama de la cultura moderna y la deshumanización de los estudiantes................... 227

9.2.9. ¿Pueden las prácticas del bautizo conducir al suicidio?............................................. 229

9.3. La inversión del poder el día del bautizo..................................................................... 231

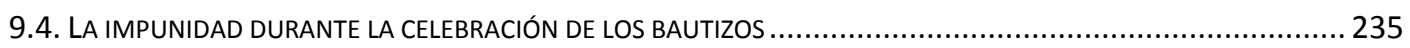

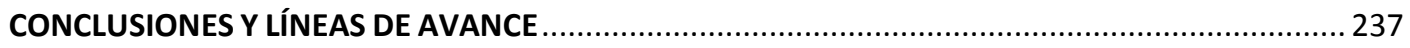

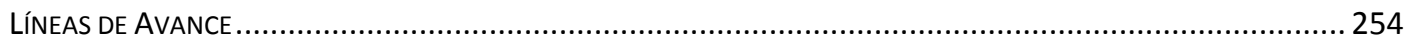

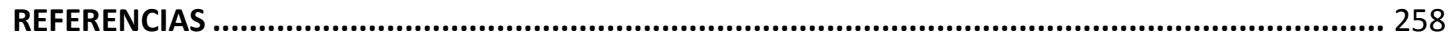

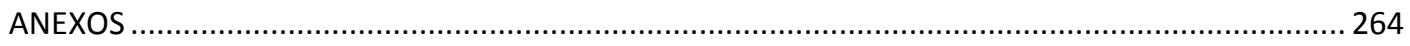

ANEXO I: Acta del Consejo Superior Universitario de USAC ............................................... 264

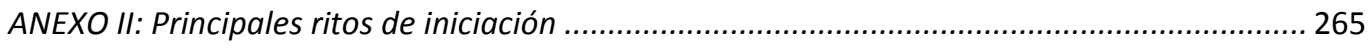

ANEXO III: El acoso entre estudiantes y las redes sociales................................................ 265

ANEXO IV: Estudiantes encapuchados secuestraron a las autoridades de FAUSAC ................. 266 
ANEXO V: Fotografía de estudiantes de Agronomía portando machetes

ANEXO VI : Legislación a nivel mundial relativa a Derechos Humanos

ANEXO VII: Nota de Prensa relativa a abusos cometidos en el año 2015

ANEXO VIII: Nota Periodística acerca de las denuncias realizadas por los bautizos. 268

ANEXO IX : La Procuraduría de los Derechos Humanos investiga acerca de abusos 270

ANEXO X: Comunicado de Consejo Superior Universitario

ANEXO XI: Bitácora de abusos cometidos durante los bautizos

ANEXO XII: Circular 274

ANEXO XIII: Nota anónima escrita como reacción a las jornadas de Bautizo en FAUSAC. . 275 ANEXO XIV: Fotografía de estudiantes encuestados. 276

ANEXO XV: Cuestionario aplicado a los estudiantes novatos de FAUSAC.. 276

ANEXO XVI: Guía práctica para la implementación de grupo focal 281 ANEXO XVII: Guía práctica para la implementación de grupo focal. 
Introducción

\section{INTRODUCCIÓN}

La presente Tesis Doctoral tiene como objeto de estudio los ritos de iniciación en las instituciones educativas. Se ha profundizado en la identificación, análisis y reflexión relativa a la celebración de los bautizos en la única universidad estatal en Guatemala, la Universidad de San Carlos de Guatemala, -USAC-. Esta celebración tiene más de medio siglo de antigüedad. Se ha elegido como estudio de caso la celebración de los bautizos en la Facultad de Agronomía porque ella nos ofreció condiciones ventajosas para darle seguimiento a tales celebraciones durante tres años consecutivos (2013-2015) aunque las entrevistas y grupos focalizados fueron realizados concretamente durante la jornada de bautizos realizados durante el año 2013. En ellas participaron estudiantes novatos (principalmente), estudiantes antiguos, profesores y profesionales en Medicina y Ciencias Sociales.

La celebración de los bautizos es sumamente controversial porque mientras que algunos ven en ellos un simple juego entre jóvenes; motivo de risas y alegría, otros ven una amenaza a la integridad física y salud mental. De acuerdo a un estudio de diagnóstico realizado por la autora principal de la presente Tesis Doctoral existen archivos de la Unidad de Salud de -USAC- que han recopilado información relativa al daño físico y psicológico sobre decenas de estudiantes que han tenido la necesidad de algún tipo de tratamiento posterior a la celebración de los bautizos.

De la misma manera mientras algunos entusiastas lo consideran desencadenante de sentimientos de solidaridad y amistad entre iguales; profesionales en el campo educativo y la Psicología ven un fenómeno que provoca efectos negativos en el estudiante y lo califican como una vil tortura.

Tal es el caso del estudio realizado por Aizpún y García-Mina (2013) denominado: Novatadas: comprender para actuar. Ambas profesionales han aportado interesante información relativa a la práctica de las novatadas en el ámbito superior universitario. Información que ha sido 
Introducción

útil para que la cámara de Diputados tomara decisiones relativas a prohibir tales prácticas en los Colegios Mayores de España. Sin embargo existe un elemento en común en las novatadas alrededor del mundo y es el trato vejatorio y el abuso de poder de los estudiantes antiguos sobre los novatos. Señalan que en tales prácticas impera la “Ley del Silencio”, tanto entre quienes realizan las novatadas (como medida defensiva) como quienes entre las sufren (Aizpún y García-Mina, 2013, p.11) Entre los principales defensores de tales prácticas se encuentran aquellos que no están dispuestos a renunciar al dominio que ejercen a su sabor y antojo sobre los novatos. Los insultos, golpes, y el sometimiento es el común denominador de estas prácticas en diferentes regiones geográficas a nivel mundial.

Las autoridades educativas, padres de familia y principalmente los agredidos en algunos países europeos y Estados Unidos han venido dando la voz de alarma relativa a las prácticas violentas y deshumanizantes. En algunas universidades de los Estados Unidos se encuentran terminantemente prohibidos estos rituales de iniciación, tal es el caso de los Estados de: Alaska, Hawái, Michigan, Montana, Nuevo México, Dakota del Sur y Wyoming. Las penas impuestas a los infractores son múltiples y van desde el resarcimiento económico (pago de multas), cancelación de matrícula e incluso, los padres de las víctimas (si fueren menores de edad) pueden darle seguimiento legal y presentar ante los Tribunales una demanda formal. Estas acciones concretas han sido el detonador que ha permitido dar la voz de alarma a la sociedad en general y en la actualidad ya existen instrumentos legales que buscan prevenir y erradicar tales prácticas ${ }^{1}$, debido a que las consecuencias para muchos estudiantes han sido nefastas. Para el caso europeo existe en la actualidad un movimiento social que denominado “Cero tolerancia a las novatadas”.

Algunos especialistas como Piñuel (2014) lo califican como bullying, señalando que la única diferencia entre este y las novatadas (o bienvenida, como se le llama en la Universidad de San

\footnotetext{
${ }^{1}$ Declaración de Intenciones de los Colegios Mayores de España para prevenir y erradicar las notadas de los Colegios Mayores.
} 
Introducción

Carlos de Guatemala ${ }^{2}$ ) es el hecho que los segundos se realizan en épocas específicas dentro del calendario escolar, generalmente durante los primeros meses del año cuando a los novatos son matriculados formalmente en las instituciones educativas (Piñuel, 2014).

En tiempos pasados las novatadas eran actividades que involucraban únicamente a los estudiantes (novatos y antiguos), sin embargo en la actualidad la "celebración” ha derribado los muros y ha salido a la calle. Esto provoca que haya nuevos actores que podrían definir el futuro de las mismas. Las novatadas están en el ojo del huracán y la opinión pública tiene pleno conocimiento de los excesos y abusos, por lo que la presión de los medios de comunicación sobre las autoridades educativas podría provocar un cambio radical en tales prácticas. De tal manera que mientras algunos buscan los mecanismos legales para frenarlas, otros se movilizan para apoyarlas.

Mientras tanto las novatadas se siguen practicando anual y sistemáticamente en cientos de instituciones educativas de nivel medio y universidades alrededor del mundo entero.

La psicóloga Ana García-Mina³ opina que: “Las novatadas son una lacra social en las que predomina la Ley del Silencio (Aizpún y García-Mina, 2013, p. 11). A pesar que se encuentran fuertemente arraigadas en la sociedad y que estudios empíricos demuestran que las novatadas dejan huellas en todos los que participan en ellas. Es mucho más complicado que pretender que solamente los novatos que son violentados en su dignidad resultan con heridas profundas, pues en su oportunidad cambiarán los papeles y los que ahora son víctimas en un nuevo ciclo académico serán victimarios. He allí la riqueza de la investigación, pero a la vez el principal reto.

La violencia es considerada por la Organización Mundial de la Salud (2003) como un problema de salud pública por lo que también se implementan medidas para prevenirla; de igual manera que adelantarse a recibir el daño es la medida más conveniente en el esquema de las

\footnotetext{
${ }^{2}$ Los estudiantes universitarios que participan en las novatadas han optado por la estrategia de llamarle. bienvenida, en vista a que el Consejo Superior Universitario ha prohibido la celebración de bautizos (novatadas).

${ }^{3}$ Vicerrectora de la Comunidad Universitaria de la Universidad Pontificia Comillas -ICADE-Madrid, en España, autora del libro: Novatas: comprender para actuar.
} 
Introducción

enfermedades físicas. De allí la importancia de realizar estudio como el presente porque permite sacar a luz los detalles de la celebración en mención, rompiendo la cultura del silencio y permisividad.

Algunos profesionales guatemaltecos en el campo de la Psicología, como José María Santos ${ }^{4}$ ha expresado que "los bautizos en la Facultad de Agronomía son una muestra de que la instauración del terror durante el Conflicto Armado Interno en Guatemala, únicamente ha adoptado nuevas expresiones y consecuentemente va cobrando nuevas víctimas. Incorporando la tecnología a la manera de intimidar”. Ello se ve reflejado en el acoso expreso en diferentes medios de comunicación, especialmente en las redes sociales implementadas por medio de teléfonos celulares $^{5}$.

Algunas de las prácticas más populares en la celebración de las novatadas, en el ámbito universitario de Guatemala, son sumamente violentas. De allí la importancia de la presente investigación, porque al abordar el fenómeno de manera seria, podemos contemplarlo desde todas sus aristas. La problemática social que representan las novatadas es superior a la que se cree, por su carácter de "obligatorias”, así mismo porque se practican sistemáticamente cada inicio de ciclo académico; lo que le imprime un carácter de acumulativo. Aunque entre estudiantes se asevera que estas son opcionales, todos son conocedores de la intimidación ejercida sobre aquellos novatos que intenten eludir el bautizo. Por esta razón un escaso porcentaje de estudiantes novatos renuncian al bautizo, ninguno de ellos deja de afrontar las consecuencias de tal decisión.

El fenómeno de las novatadas resulta complejo por sus múltiples manifestaciones (así mismo por las interpretaciones que puedan hacerse de él). Sin embargo por complejo que sea; es imperativo realizar investigaciones que puedan aportar información que permita analizarlo de

\footnotetext{
${ }^{4}$ Psicólogo de la Unidad de Planificación Educativa, Facultad de Agronomía.

${ }^{5}$ Es importante considerar que este mecanismo de acoso a través de las redes sociales en Guatemala es muy efectivo, considerando que es una de las naciones latinoamericanas con promedio de 4 teléfonos celulares per cápita.
} 
Introducción

manera objetiva. Como han expresado investigaciones recientes sobre novatadas, es necesario “conocer para comprender y comprender para actuar” (Aizpún y García-Mina, 2013). Sobre todo, es importante, capturar la apreciación que de él hacen los mismos estudiantes, autoridades académicas y comunidad estudiantil en general. De igual importancia es documentar la interacción entre agredidos y agresores, así mismo las reacciones de los espectadores. La importancia de realizar cualquier tipo de investigación dirigida al sector estudiantil sancarlista se debe a consideraciones tales como: que alberga al 50 \% del total de la población universitaria a nivel nacional. Otro dato importante a considerar es que en las aulas de USAC interactúan más de 170,00 estudiantes de todas las regiones geográficas del país. Así mismo que el 80 \% de los estudiantes matriculados son jóvenes entre las edades de 16 a 25 años.

La USAC ostenta una condición de Autonomía ${ }^{6}$ que le permite tener personalidad jurídica, manejar su propio presupuesto y diseñar sus propias políticas educativas. Estas condiciones representan por sí mismas una ventaja comparativa muy alta, pero también un reto y riesgo de perderse en acciones erráticas que le impidan alcanzar los objetivos estipulados en la Carta Magna. El generar información objetiva relativa a esta expresión cultural de los estudiantes universitarios podría brindar una luz a los tomadores de decisiones respecto a las acciones preventivas. Ello porque según estudios preliminares realizados por la autora de la presente tesis, la frustración, el enojo y tristeza de los agredidos por sí mismos no son motivo suficiente para provocar algún tipo de cambio en tales prácticas (dado el caso que fuera necesario). Las consecuencias de este tipo de agresión son difíciles de medir y cuantificar. Por esta razón es importante determinar el grado de aceptación o rechazo de tales prácticas por la población estudiantil. De esta manera será posible

\footnotetext{
${ }^{6}$ Autonomía, según el Artículo No. 82 de la Constitución Política de la República de Guatemala, la USAC tiene su propio gobierno, maneja su propio presupuesto y puede administrarse económica, académica y legalmente de acuerdo a su Reglamento Interno. Sin embargo para el trabajador universitario representa una conquista realizada en épocas importantes de la historia de Guatemala que permite el ejercicio y práctica que permite el ejercicio y práctica de pensar con libertad, crear y difundir ideas, conocimientos y valores libremente, (Universidad de San Carlos de Guatemala, 2007).
} 
Introducción

diseñar acciones a futuro que permitan a las autoridades universitarias de la USAC promover la convivencia pacífica y el respeto a los Derechos Humanos entre los universitarios. La tendencia que reportan las investigaciones realizadas en ese tema es que el camino que debe recorrerse es la implementación de acciones que permitan transformar tales prácticas en "oportunidades de convivencia pacífica, y desborde de energía a través de actividades deportivas”. En Guatemala también se ha iniciado una voz de alerta que ha provocado que el Ministerio de Educación proponga una Guía para la prevención del acoso escolar.

Para poder profundizar en el fenómeno en cuestión se seleccionó un estudio de caso, y este fue: las novatadas en la Facultad de Agronomía de la Universidad de San Carlos de Guatemala USAC-. La Facultad de Agronomía fue elegida como estudio de caso, en vista que es considerada, en el medio universitario, como una de las unidades académicas con mayores expresiones de violencia. Según estudios preliminares realizados por la autora, los estudiantes de esta unidad académica se destacan por el uso de machetes, bates de béisbol, leños, mazos, hierros y todo tipo de objeto punzante durante la celebración de los bautizos ${ }^{7}$. El objetivo de portar los mismos, es puramente intimidatorio.

La investigación tiene como objetivo principal: Conocer, describir y analizar la experiencia de la celebración del ritual del bautizo en la Facultad de Agronomía. Este evento fue documentado durante tres años (2013-2015). Dentro de los objetivos específicos destacan: Determinar si en las prácticas realizadas durante la celebración del ritual del bautizo pueden identificarse algunas que vayan contra la integridad física y emocional de los estudiantes novatos. Así mismo el determinar si la práctica como tal aporta al fortalecimiento de la identidad universitaria sancarlista. Por esta razón se establecieron herramientas de la investigación cualitativa para determinar la percepción de los diferentes actores.

\footnotetext{
${ }^{7}$ Ver Anexo v: Fotografía en donde se observa a estudiantes de la Facultad de Agronomía portando machetes durante la celebración del bautizo en el año 2014.
} 
Introducción

De acuerdo a los objetivos planteados (conocer y describir y analizar el ritual de la novatada en FAUSAC) puede determinarse que la presente investigación es de carácter cualitativo. La investigación puede ubicarse, concretamente, dentro del tipo de investigación Descriptiva y Explicativa. Además de describir la práctica de la novatada se profundizó en el análisis (desde diversas perspectivas) para tratar de comprender el comportamiento humano manifiesto durante tal práctica.

También es importante señalar que la investigación es de carácter Exploratorio, debido a que a la fecha (Agosto de 2015) no existen investigaciones específicas que exploren acerca de este fenómeno social. Esto se debe a que (según investigaciones preliminares) en el ámbito sancarlista se ha considerado que las novatadas son simplemente: una tradición estudiantil o un juego. En algunos sectores académicos el tema es considerado tabú y se considera preferible no hablar de él. Sin embargo el problema ha salido a luz pública debido a los escándalos provocados por los estudiantes durante las jornadas de bautizo, mismos que han sido publicados por importante medios de comunicación en Guatemala.

La riqueza de la presente Tesis Doctoral es que se documentó ampliamente un fenómeno que anteriormente era sinónimo de tabú y que por lo tanto no había sido abordado con seriedad. Esto porque hablar negativa o positivamente del evento significa, dentro del ámbito estudiantil, sinónimo de cobardía. En el ámbito docente es desestimado como un tema serio de estudio pues (según entrevistas preliminares realizadas por las autoras) son simples juegos, tradiciones, bromas que no merecen mayor atención de la comunidad científica universitaria. Pese a estas aseveraciones y advertencias que aportan al Código de Silencio acerca de este capítulo en la vida universitaria (que para muchos es motivo de vergüenza); las opiniones de estudiantes novatos, estudiantes antiguos, profesores, profesionales, especialistas en diversos temas, egresados y autoridades académicas universitarias han quedado plasmadas en la presente Tesis Doctoral. 
Introducción

Durante la ejecución de la investigación se procuró tener en cuenta la credibilidad (por cuanto es un criterio de rigor de toda investigación cualitativa) en el sentido de que las conclusiones a las que se llegaron reflejaran la realidad observada sin ningún tipo de sesgo ideológico.

Dentro de las herramientas cuantitativas utilizadas se encuentra la implementación de cuestionarios dirigidos a los estudiantes novatos del año 2013. A estos resultados se les complementó con cuestionarios implementados con estudiantes novatos de los años 2014 y 2015. Estos cuestionarios fueron diseñados de acuerdo a información preliminar que fue recopilada en la misma Unidad Académica. Las herramientas fueron previamente aplicadas en el sector estudiantil con el objetivo de realizar los ajustes necesarios. Se presentan los resultados de los cuestionarios aplicados a los novatos del ciclo académico 2013.

Este trabajo es producto de un esfuerzo sistemático realizado durante tres años. Para la mejor comprensión del mismo se ha divido en dos partes. En la primera parte se describe la Fundamentación Teórica distribuida en cinco capítulos. En el capítulo primero se inicia desglosando y analizando el marco teórico de la violencia. En el capítulo dos se describe específicamente las expresiones de violencia en la región latinoamericana, centroamericana y guatemalteca. Posteriormente en el capítulo tres se aborda el tema de la violencia en el ámbito escolar, realizando una reseña histórica de las investigaciones realizadas, hasta llegar a la época moderna en donde es introducido mundialmente el término de bullying. En los capítulos cuatro y cinco se hace un estudio sobre el interesante tema de las novatadas desde la perspectiva de la normativa guatemalteca.

En la Segunda Parte de la Tesis Doctoral se establecen los resultados del Estudio Empírico. En el capítulo seis se describe el planteamiento del problema y la metodología empleada para el estudio de caso. En el capítulo siete se presentan los resultados del estudio cuantitativo para continuar con los resultados del estudio cualitativo en el capítulo siguiente. 
Introducción

En el capítulo nueve se presentan los resultados del a aplicación de las herramientas de investigación. El objetivo de aplicar las herramientas ya mencionadas fue lograr la triangulación de la información recopilada y llegar a conclusiones objetivas carentes de sesgo ideológico.

Finalmente en la última sección de la investigación se presentan las conclusiones generales y se esbozan algunas líneas de avance con el objetivo de promover una Cultura de Paz y Convivencia entre los estudiantes de la Universidad de San Carlos de Guatemala. 


\section{PARTE I: FUNDAMENTACIÓN TEÓRICA}

\section{CAPÍTULO 1: MARCO TEÓRICO DE LA VIOLENCIA}

El siglo XX se recordará como un siglo marcado por la violencia. Nos lastra con su legado de destrucción masiva, de violencia infligida a una escala nunca vista y nunca antes posible en la historia de la humanidad. Menos visible, pero aún más difundido, es el legado del sufrimiento individual y cotidiano: el dolor de los niños maltratados por las personas que deberían protegerlos, de las mujeres heridas o humilladas por parejas violentas, de los ancianos maltratados por sus cuidadores, de los jóvenes intimidados por otros jóvenes y de personas de todas las edades que actúan violentamente contra sí mismas.

Nelson Mandela

El ex presidente de Sudáfrica Nelson Mandela (1994-1999) cuyo activismo permitió erradicar las prácticas de segregación racial en su país, hizo importantes reflexiones en torno a la violencia. Preocupado declaró durante su participación en el informe de la Organización Mundial de la Salud (2002) como el siglo XX sería recordado como uno de los más violentos de la historia de la humanidad cuyo legado sería la violencia (Organización Panamericana de la salud para la Organización Mundial de la Salud, 2002).

Ello gracias a su auto reproducción lograda cuando nuevas generaciones aprenden la violencia de las anteriores y los agredidos de sus agresores. Mientras los ciudadanos se acostumbren a ella existen pocas oportunidades de superarla pues el estado de seguridad y garantías no surgirán espontáneamente; sino solo cuando existan esfuerzos colectivos por conocer sus distintos rostros y hacer profundos análisis relativos a ellas en búsqueda de la paz, la justicia y la prosperidad.

En el mismo informe, la doctora Gro Harlem Brundtland reflexiona que la violencia es parte de la vida cotidiana de miles de personas alrededor del mundo. De una u otra manera esta 


\section{Maco teórico de la violencia}

afecta a todos. Para algunos la solución es cerrar bien puertas y ventanas, pero qué hay de aquellos cuyo principal temor se encuentra dentro de esas puertas y ventajas, lejos de la vista de los demás, para ellos verdaderamente no existe escapatoria.

Según la -O.M.S.- la violencia puede entenderse como “el uso intencional de la fuerza o el poder físico (de hecho o como una amenaza) contra uno mismo, otra persona o un grupo o comunidad, que cause o que tenga muchas probabilidades de causar lesiones, muerte, daños psicológicos, trastornos del desarrollo o privaciones” (Organización Panamericana de la salud para la Organización Mundial de la Salud, 2002, p. 15). De acuerdo a esta definición la violencia puede tener múltiples objetivos, múltiples efectos y sobre todo el alcance de los daños que puede provocar es grave. A nivel individual el daño puede ser profundo y permanente (aunque generalmente se vive en silencio) mientras que en el plano de lo colectivo puede tener efectos multiplicadores y creadores de la aceptación, configuración y recreación de una subcultura de violencia.

Tal como lo asegura Jares (2002) es difícil hacer una distinción entre agresión y violencia, así mismo entre: violencia y conflicto, pero es necesario hacerla porque son diferentes. Nos explica que cuando las personas aceptan la violencia como una condición humana natural lo único que están afirmando es la agresividad. Los especialistas se debaten en la polémica si el ser humano es agresivo o violento por naturaleza y si lo es, ¿¿cuáles son las razones? Si las razones son genéticas como muchos aseguran la violencia a acompañado a la humanidad desde sus orígenes.

Aunque las manifestaciones de violencia cambian (de acuerdo a la tecnología y complejidad del mundo actual) únicamente han mudado convirtiéndose cada vez en mucho más refinadas, pero de la misma manera más brutales. Freud (1921) citado por Jares (2002) mantiene la tesis que los seres humanos tenemos un instinto agresivo que forma parte de nuestros genes. La violencia es parte del sujeto humano, es constitutiva, propia y estructural. Esta representa la conocida como teoría innatista. En sentido contrario los ambientalistas mantienen la teoría que las conductas 
agresivas son aprehendidas. Cuando el ser humano actúa de manera violenta lo hace por las circunstancias a la cuales se encuentra expuesto y simplemente responde a estímulos.

Martín (2003) asegura que uno de los primeros aprietos al intentar definir lo que es violencia es determinar si violencia, agresividad y maltrato son sinónimos, esto porque en cada concepto se encuentran estrechamente arraigados los juicios de valor. Todos los términos anteriormente señalados conllevan una carga emocional muy amplia por lo que es muy fácil caer en conclusiones erróneas. Sin embargo Fernández, citado por Martín (2003) opina que la agresión es un fenómeno que ocupa al pensamiento en general por esa razón se considera una preocupación básica de la Filosofía, Derecho y de la Política. Esto porque la agresión resquebraja y reta el orden social, conmueve los cimientos de las relaciones interpersonales, transforma la sociedad y la naturaleza. Por esa misma razón una de las pocas ideas en las que la mayoría de las sociedades y doctrinas están de acuerdo es que la agresión debería ser evitable en la medida de lo posible porque es necesario defender un orden social específico que tiende a la perpetuación y cuya estabilidad es amenazada por esta.

De esa cuenta que conviene, inicialmente, acercarnos a una precisión terminológica estricta porque de estos términos hablaremos a lo largo de la presente investigación.

\subsection{Definición de agresión y sus dimensiones}

Según el Diccionario de la Real Academia Española la palabra agresión proviene del latín agressio -onis y significa "acto de acometer a alguien para matarlo, herirlo o hacerle daño// Acto contrario al derecho de otra persona”.

Otros autores como: Baridón (2012) hace la observación que como agresión debe entenderse a cualquier tipo de accionar cuyo objetivo sea, directamente, dañar o perjudicar a otro ser vivo que está motivado a evitar tal maltrato. Este y muchos otros autores hacen hincapié en que 
es necesario considerar que existen diversos tipos de violencia, describiendo para nuestros intereses, las siguientes: i) Agresión afectiva: Se refiere a la que se caracteriza porque su objetivo concreto es “causar daño”. En ella se revela un accionar claro y dirigido hacia interferir con el bienestar del otro. Este tipo de accionar es hostil o emocional y se caracteriza por ser impulsiva. ii) Violencia Instrumental: que se refiere a aquella que es un medio para obtener una meta u objetivo específico. Se puede describir como el efecto secundario de la original finalidad. En este caso las acciones catalogadas como producto de este tipo de violencia son más deliberadas y racionales que la anterior. Es tan grande el deseo de obtener el objetivo que no importa provocar algún tipo de daño en su logro.

Ambos tipos de agresiones pueden producirse en cualquier cultura. Sin embargo, es evidente que los procesos de socialización son diferentes entre culturas. Considerando que las actitudes agresivas y violentas se aprenden; entonces puede asegurarse que son fenómenos culturales. De este modo en cada lugar del planeta Tierra este tipo de accionar será castigado o premiado de acuerdo a los valores morales, creencias religiosas, ideología o costumbre de cada país.

Para el caso de los estudiantes de enseñanza media y superior de la Universidad de San Carlos de Guatemala, puede considerarse a la agresión, en términos generales, como las expresiones de conductas hostiles (en manifestaciones físicas, verbales o medios electrónicos) que desvirtúan al otro y sobre todo niegan el trato como igual.

Según González, Ortega, Echeburúa y Paz de Corral (2008) la violencia, en lo relativo a los agresores, es más frecuente cuando existen algunos factores que demuestran que hay manifiesto algún tipo de personalidad anómala. Entre ellos destacan: impulsividad alta, ausencia de autoestima y baja empatía.

Con el objetivo de aportar a la comprensión del fenómeno en cuestión haremos un breve recorrido por algunas de las principales teorías y sus autores. 


\subsubsection{Delimitación conceptual de la violencia}

La amplia variedad de códigos morales imperantes en los distintos países hace sumamente dificultoso el abordar el problema de la violencia a nivel mundial. Según se expresa la Organización Panamericana para la salud en el Informe Mundial de la Violencia (2002) esta es una de las cuestiones más difíciles y delicadas de definir. Sin embargo es necesario y urgente hacerlo pues la protección de la vida y la dignidad humana debe ser una tarea prioritaria para todas las naciones. En el mismo informe define la violencia como: "El uso deliberado de la fuerza física o el poder, ya sea en grado de amenaza o efectivo, contra uno mismo, otra persona o un grupo o comunidad que cause o tenga muchas posibilidades de causar lesiones, muerte, daños psicológicos, trastornos del desarrollo o privaciones” (Organización Panamericana de la Salud para la Organización Mundial de la Salud, 2002, p.15). Esta definición es tan amplia que comprende tanto la violencia interpersonal como el comportamiento suicida y los conflictos armados. Así mismo otro tipo de numerosísimas consecuencias del comportamiento violento como lo son: daños psicológicos, privaciones, y privaciones en el desarrollo que repercutan en el individuo, su familia o su comunidad.

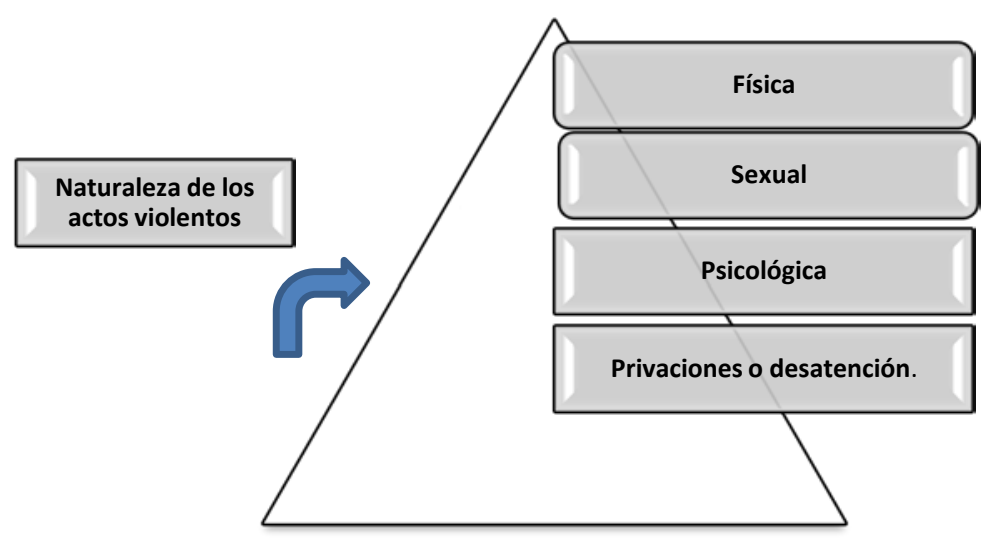

Figura 1. Clasificación de la violencia según su naturaleza.

Fuente: Creación personal con información del Informe Mundial de la Violencia, 2002 de la Organización Panamericana de la salud para la -O.M.S-. 
Algunos autores como Arendt (2005) hace la reflexión que la violencia ha evolucionado al ritmo de la evolución tecnológica y ha desempeñado, históricamente, un papel importante en los asuntos humanos, pues se encuentra presente en todos los ámbitos de la sociedad.

Es así como la violencia física, sexual, psicológica y la violencia de tipo indirecta (privaciones o desatención) ha evolucionado y han incorporado nuevas herramientas técnicas.

La violencia también puede ser clasificada de acuerdo al sujeto u objeto sobre el cual enfoca su energía, tal como observamos en la siguiente figura.

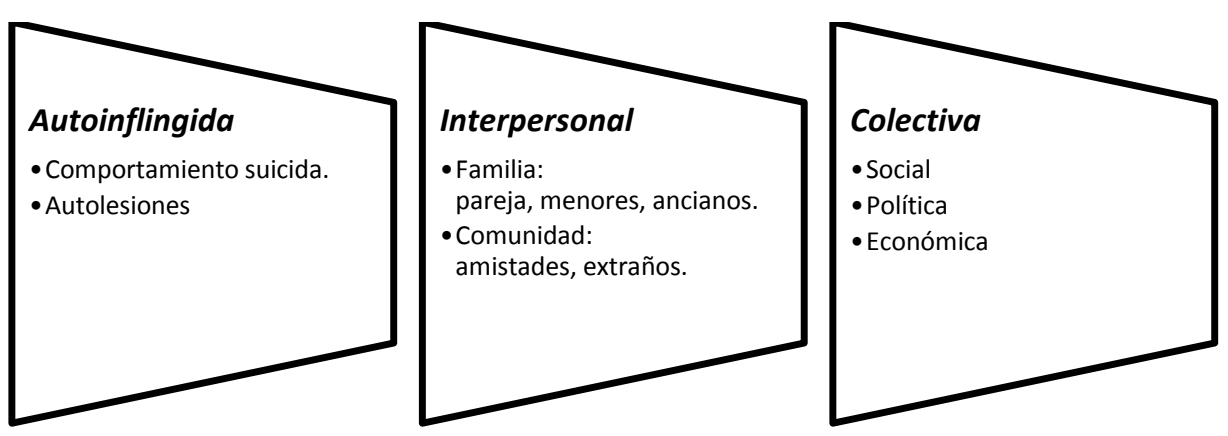

Figura 2. Clasificación de la violencia según el objetivo o agredido.

Fuente: Creación personal con información del Informe Mundial de la Violencia (2002).

En la presente Tesis Doctoral enfocaremos nuestro esfuerzo en la descripción de la violencia de tipo colectiva que esencialmente se distingue de la violencia interpersonal-comunitaria porque tanto los agresores como los agredidos se auto identifican como miembros de un mismo grupo. La violencia es el exceso de fuerza aplicado sobre las personas u objetos para sacarlos de su estado natural, sea intencional o no (Markez et al., 2006).

En este sentido la intencionalidad es la característica o condición que puede hacer la diferencia. Es así como Márquez, Moreno e Izarguzaza (2006) indican que el objetivo de la acción violenta, es la que marca la diferencia .Es así como un adulto puede empujar violentamente a un niño para evitar que sea atropellado por un vehículo en marcha. En este caso la violencia es lícita y claramente, necesaria. Sin embargo los fuertes empellones entre estudiantes de 15 años puede ser tipificado como violencia, en vista que el objetivo es provocarle un daño al agredido. 
Existe una confusión en cuanto al uso de los términos: violencia, agresión y maltrato; por lo que es importante entender que aunque entre ellos existen elementos en común, el concepto de cada uno variará, dependiendo de la perspectiva desde la cual se aborde. Sin embargo con fines de sustentar teóricamente la presente investigación, haremos un breve análisis de algunos enfoques.

La violencia es la expresión de la agresión destructiva cuyo objetivo es provocar daño físico concreto a personas o bien objetos de su propiedad que constituyen el patrimonio, medios de vida y símbolos de bienestar (Gil-Verona, Pastor, de Paz, Barbosa, Macías, Maniega y Rami-González, 2002). Desde un sentido práctico puede considerarse a la violencia como toda acción que vaya en contra de la naturaleza esencial del hombre que le impide realizar el destino para el cuál fue creado. Según los modos de violencia, ésta puede ser: Directa, en cuanto los actores y víctimas (individuales o colectivas) son claramente identificables. Sin embargo también existe la violencia Indirecta, cuando no se puede identificar a agredidos y agresores, sino más bien esta es producto de una estructura ya establecida.

Además de la intencionalidad, las circunstancias y el entorno en que se da el hecho violento son, finalmente quienes permiten identificar la violencia e incluso determinar el grado de violencia (Moreno, 2001; citado por Márquez et al., 2006) nos hacen reflexionar en que especialmente cuando las conductas violencias conducen a la muerte de un ser humano, el sistema legal realiza sus análisis y reflexiones sobre la base del grado de: premeditación, alevosía, defensa propia, acto de servicio, crimen pasional, socialización del sufrimiento, venganza.

\subsubsection{Delimitación conceptual de la agresión}

La mayoría de personas hemos sido, en alguna ocasión, víctimas de agresión. Especialmente en la región latinoamericana en donde los índices de violencia son elevados. La 
agresión puede describirse como una conducta tendiente a provocar daño en el otro. Estas conductas pueden identificarse fácilmente en los ámbitos más importantes de los seres humanos: familiar, escolar, laboral, en las calles. El energúmeno que nos grita groserías porque al conducir su vehículo no vamos tan suficientemente rápido como él quiere. El extraño que pasa cerca de una mujer bien arreglada y maliciosamente lanza un comentario vulgar, ocultándose rápidamente entre la gente. Toda conducta u acción que busca provocar daño, herir, lastimar o simplemente provocar malestar, puede ser considerada un acto de agresión.

Existen ocasiones en que cambian los papeles y nos convertimos en los agresores porque debido a diversas circunstancias somos llevados al límite, tal como nos explica Philip Zimbardo en el estudio denominado: El efecto Lucifer (García, 2010). En otras circunstancias, nos convertimos en simples espectadores; aquellos que pasivamente observan y de alguna manera aceptan el maltrato como algo que no les compete, deshumanizándose tanto como el agresor.

La agresión puede expresarse o materializarse de diferentes maneras, siendo las más frecuentes: agresiones de tipo físico, psíquico o sexual. Incluso en sociedades convulsas y con escasa gobernabilidad puede considerarse otro tipo de violencia, la violencia política. El elemento en común entre estos es que causan daño físico o vulneran la libertad del otro con el fin de provocar y mantener miedo e intimidación, control y poder por el maltratador.

De acuerdo a los actores, la violencia puede tipificarse de la siguiente manera: 


\begin{tabular}{|l|l|l|l|}
\hline No. & Agresor & Agredido & Tipo de violencia de acuerdo a actores \\
\hline 1 & Del individuo & Sí mismo & Suicidio \\
\hline 2 & Del individuo & Otro & Crimen pasional \\
\hline 3 & De un individuo & Un grupo de personas & Delito contra la sociedad \\
\hline 4 & De un grupo & Contra un individuo & Delito de pena de muerte \\
\hline 5 & De un grupo & Contra otro grupo & Guerra, terrorismo \\
\hline
\end{tabular}

Cuadro 1. Tipos de violencia de acuerdo a los actores

Fuente: Creación personal con datos de Gil-Verona, et al. (2002).

Moyer (1976) citado por Gil-Verona et al. (2002) proponen una clasificación relativa al tipo de agresión, desde la perspectiva de la Psicobiología. En ella podemos ver que existen diferentes expresiones de la agresión de acuerdo a sus actores y a algunas circunstancias específicas. Así por ejemplo se habla de un tipo de violencia maternal que es manifiesta por la madre en defensa de las crías.

La perspectiva psicobiológica de las conductas agresivas o violentas otorgan los elementos de análisis necesarios para lograr un entendimiento integral de la evolución de este comportamiento. De la misma manera que su clasificación podría permitir el tratamiento de las manifestaciones patológicas de las conductas violentas.

Por esta razón en el cuadro 2 se presenta una síntesis de la clasificación ya señalada. En el mismo se hace una distinción entre las conductas predatorias propias de los animales que se ven obligados a proteger a sus crías y agenciarles el alimento y aquellas que están motivadas por la necesidad de proteger su territorio. En todas ellas se descubre un elemento en común y es que la agresión es parte de la necesidad de supervivencia. 


\begin{tabular}{|l|l|l|}
\hline No. & Expresión de la violencia & Tipificación según la Psicobiología. \\
\hline 1 & Conductas de ataque motivadas & Agresión predatoria \\
\hline 2 & Agresión inter-machos & $\begin{array}{l}\text { Conducta de sumisión exhibida por los machos } \\
\text { mutuamente). }\end{array}$ \\
\hline 3 & Agresión inducida por el miedo & $\begin{array}{l}\text { Respuestas biológicamente programadas de modo que } \\
\text { se actúa de forma agresiva hacia cualquier clase de } \\
\text { confinamiento forzado. }\end{array}$ \\
\hline 5 & Agresión territorial & $\begin{array}{l}\text { Conducta de amenaza o ataque que se muestra hacia } \\
\text { una invasión del territorio propio, o conducta de } \\
\text { sumisión y retirada tras enfrentarse con el intruso. }\end{array}$ \\
\hline 6 & Agresión irritable & $\begin{array}{l}\text { Conducta agresiva mostrada por las hembras cuando } \\
\text { intrusos se acerca a sus crías. }\end{array}$ \\
\hline 7 & Agresión sexual & $\begin{array}{l}\text { Agresión e ira dirigidas hacia un objeto cuando el } \\
\text { agresor se siente frustrado, herido o estresado. }\end{array}$ \\
\hline 8 & Agresión instrumental & $\begin{array}{l}\text { Provocada por los mismos estímulos que disparan la } \\
\text { respuesta sexual. }\end{array}$ \\
\hline
\end{tabular}

Cuadro 2. Clasificación de los tipos de violencia.

Fuente: Creación personal con la propuesta de Gil Verona et al. (2002).

Aunque el objeto de estudio de la presente Tesis Doctoral es la agresividad transmitida entre estudiantes universitarios sancarlistas; consideramos importante mencionar que las organizaciones delincuenciales juveniles que operan en el país, conocidas comúnmente como maras, son un claro ejemplo del alto grado de violencia en el que convive buen porcentaje de jóvenes guatemaltecos. Estas han instaurado en el país una cultura de violencia por lo que es interesante determinar si en algunas de sus expresiones (humillación, maltrato físico, maltrato verbal) pueda existir similitud con algunas expresiones de las novatadas o bautizos. En ambos casos hay un aprendizaje social y la propia cultura incorpora, facilita y perpetúa (directa o indirectamente) ese tipo de acción social. En ambas existe la posibilidad de incrementar, conforme el paso del tiempo y la especialización en ese tipo de estructura social, esos niveles de expresiones agresivas. Aunque el repaso de estas organizaciones será breve, consideramos que era imperativo realizarlo por lo que lo presentamos a continuación. 
Los especialistas en Psicología Social consideran que los jóvenes que se enrolan en este tipo de organizaciones delincuenciales se encuentran en una situación de exclusión social y tienen un futuro poco o nada halagüeño (Morales et al., 2007). Entre ellos pesa sobremanera la idea de defender el honor, por lo que la violencia entre pandillas es un común denominador. Las diferentes manifestaciones de agresión son únicamente una manera de romper la monotonía. Desde el Sur de México hasta Nicaragua, existen innumerables bandas juveniles que delinquen bajo el auspicio de actividades ilegales como la extorsión, trata de blancas y participación activa en el narcotráfico que de Sur se impulsa hacia el Norte del continente americano.

En los últimos diez años se ha incrementado el número de niños, jóvenes y adultos que se han incorporado a estas bandas delincuenciales. Con ojos atónitos hemos contemplado como las tácticas y estrategias empleadas en la operación de estos grupos se han ido perfeccionando. Los hechos violentos protagonizados por los miembros de estar organizaciones delincuenciales tienen una marca indeleble y es la violencia inter y exo-grupal. Según Javaloy, Rodríguez y Espelt (2001) citados por Morales et al. (2007) los conflictos y muestras de agresión de este tipo se deben frecuentemente a: i) Pugnas por adquirir el liderazgo o estatus dentro del grupo. ii) Al sentirse amenazados o bien, iii) Agentes externos que les perjudican o bien por la posición de sus líderes.

Es importante mencionar que para el caso guatemalteco las pandillas juveniles o "maras" son las que se han encargado de instaurar el "terror" en los habitantes. Siendo este uno de los fenómenos sociales que más preocupan al guatemalteco promedio. Según una encuesta realizada en el año 2007 por VOX LATINA (Seijo, 2007) la violencia es el problema más grave del país. Tan intensa es la problemática que los entrevistados han expresado apoyar la pena de muerte como mecanismo para que disminuya la delincuencia común y crimen organizado.

Winton (2011) sostiene que uno de los factores más distintivos de la violencia en esta región es la amplia gama de instituciones y grupos violentos. Destacando entre ellos privados, civiles, formales y criminales que, sorpresivamente, están inter-conectados de múltiples maneras. 


\section{Maco teórico de la violencia}

Estas mismas conexiones o nexos son el elemento que le da el carácter de arraigo y por lógica de difícil erradicación de los mismos. Lógicamente si el Estado tiene gananciales en las actividades ilícitas, difícilmente saldrán a luz los verdaderos desestabilizadores de la paz y seguridad en los países centroamericanos y Sur de México.

Las acciones de estos son terribles: Asesinado y desmembramiento de personas, abuso sexuales y deshonestos, robos a mano armada, extorsiones, cobro de impuesto de pandillas, etc.

Muchos son los males de los tiempos modernos, las sociedades se mueven aceleradamente hacia el futuro. La sociedad moderna está embebida en el consumismo y la meta anhelada (independiente del ámbito geográfico) es tener más, poseer mayor cantidad de bienes, ser una persona más famosa, más importante, más atractiva físicamente o en el mejor de los casos más saludable. En esa eterna búsqueda de la satisfacción de las propias necesidades en muchas ocasiones nos olvidamos del otro, nos deshumanizamos. Peor aún, en algunas ocasiones pasamos sobre él, escalamos a través de él, intencionalmente. El negar las cualidades y condiciones humanas en el otro, es lo que especialistas de diversos ámbitos consideran la expresión más evidente de la deshumanización. Una de las expresiones de esta grave condición son precisamente las conductas agresivas.

Es elemental considerar que en la mayor parte de definiciones de violencia y agresión aparecen dos ideas que debemos considerar como básicas: la conducta o acción concreta que ocasiona el daño en el sujeto u objeto y en segundo lugar, los componentes subjetivos de la agresión, especialmente la intención del agresor y la interpretación (Markez et al., 2006). 


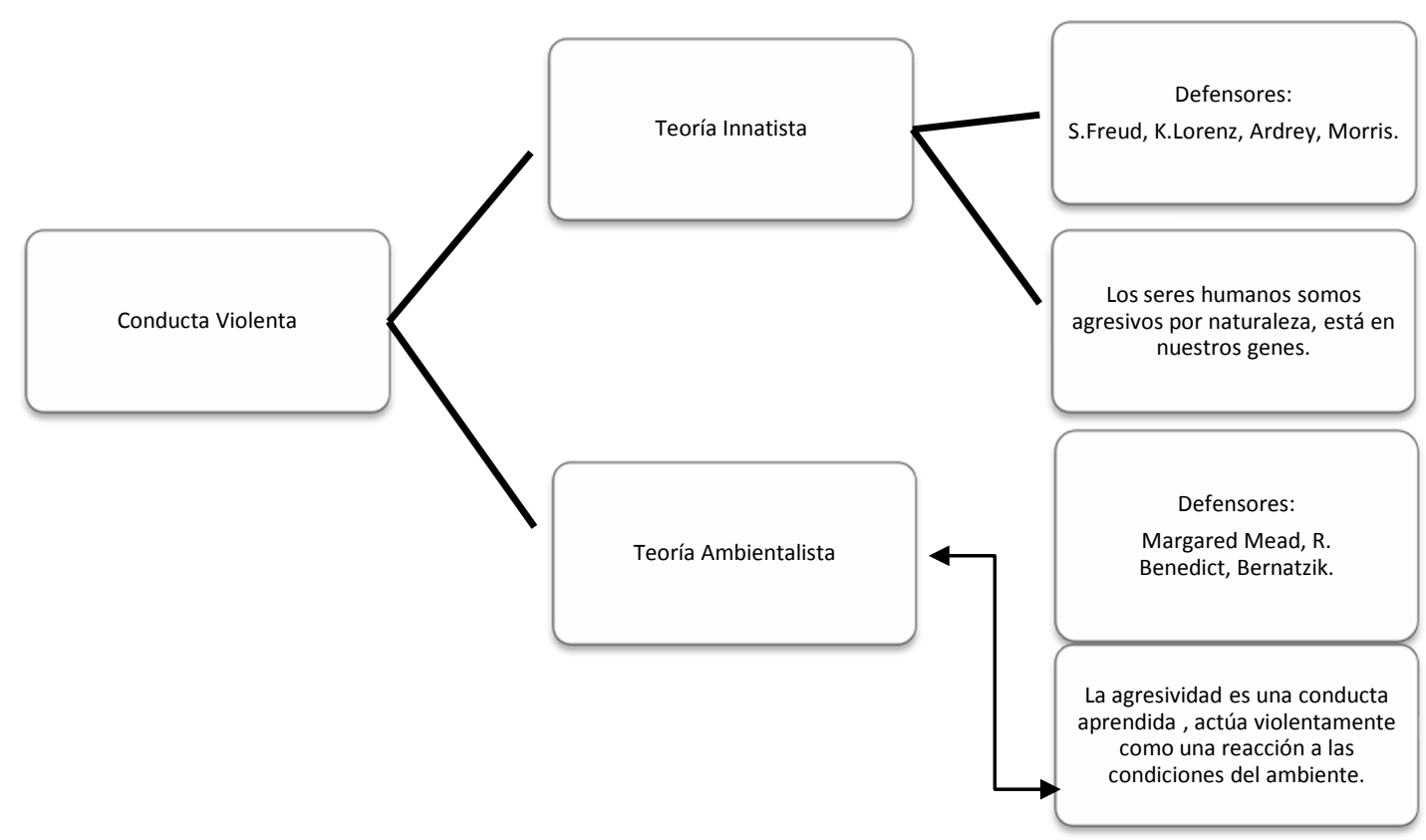

Figura 3. Principales teorías relativas al origen de la conducta violenta o agresiva. Fuente: Creación personal con datos de Jares (2002).

La Teoría Innatista es una de las que ha sido más aceptada por décadas pues resulta mucho más cómodo pensar que la maldad y agresividad del ser humano le viene por naturaleza. De esta manera se evade la responsabilidad y sobre todo se encuentra un espacio de comodidad en el cual no está la exigencia de provocar cambios porque “está en nuestra naturaleza”. Otra corriente del pensamiento que ha sido muy difundida en época moderna es la ambientalista en donde se asegura que la maldad y conductas agresivas son aprendidas de los demás.

\subsubsection{Teorías sociológicas relativas a la conducta agresiva y la violencia}

Muchas son los abordajes que se han realizado, según lo demuestra la historia, para comprender las complejidades de la conducta violenta en los seres humanos. Para ello se han realizado infinidad de experimentos con niños, jóvenes, excombatientes y sobrevivientes de campos 
de guerra y de concentración. Aún los animales han sido sometidos a los laboratorios, buscando en el comportamiento animal analogías con el comportamiento humano. El objetivo es comprender ¿Cuál es el origen de la maldad en el ser humano? ¿Es natural o aprehendida? ¿Existen mecanismos para erradicarla o por lo menos atenuarla? Si existen, ¿cuáles son?

Autores como Dómenech e Iñiguez (2002) opinan que gracias al análisis que se ha realizado de las conductas agresivas y violencia desde la Psicología Social se pueden identificar dos momentos importantes. En primer lugar están las teorías clásicas (llamadas: Instintivitas) porque explican el comportamiento agresivo desde el interior de la persona. En este caso atribuyen al instinto la manera de accionar. Los principales representantes de esta corriente del pensamiento son: Eibel-Eibesfeldt (1973), Lorenz (1963) y Freud (1930). Por el contrario las teorías contemporáneas encuentran las explicaciones a las conductas agresivas en factores externos a la persona.

Palomero y Fernández (2001) opinan que para poder comprender la violencia es necesario reconocer su pluricausalidad y su pluridimensionalidad. Así mismo que es necesario darle seguimiento y analizar sus diferentes expresiones. En especial el fenómeno de la violencia escolar exige una explicación: global, dialéctica, ecológica y sistemática que puedan prevenir su prevención y tratamiento. 


\begin{tabular}{|c|c|c|c|}
\hline No. & Enfoque & Autores & Explicación \\
\hline 1 & & Rousseau & $\begin{array}{l}\text { La agresividad es el resultado de la } \\
\text { sociedad represiva }\end{array}$ \\
\hline 2 & $\begin{array}{ll}\text { Biología } & \text { y } \\
\text { Neurología } & \end{array}$ & $\begin{array}{l}\text { Mikczek, Raine, } \\
\text { Cocarro, Ferris }\end{array}$ & $\begin{array}{l}\text { La semilla del mal anida en nuestros } \\
\text { genes }\end{array}$ \\
\hline 3 & Psicología & Freud & $\begin{array}{l}\text { No puede ser controlada por la razón, } \\
\text { pero si es susceptible de sublimación y } \\
\text { canalización }\end{array}$ \\
\hline 4 & & Lorenz & $\begin{array}{l}\text { Es instinto de nuestra supervivencia y } \\
\text { elemento crucial para nuestra propia } \\
\text { evolución }\end{array}$ \\
\hline \multirow[t]{3}{*}{5} & & Bowlby & $\begin{array}{l}\text { Un impulso que se refuerza a través de } \\
\text { una historia de necesidades y } \\
\text { frustraciones insatisfechas desde } \\
\text { edades tempranas. }\end{array}$ \\
\hline & & Berkowitz & $\begin{array}{l}\text { Reaccionamos con agresividad } \\
\text { solamente cuando estamos frustrados e } \\
\text { iracundos. }\end{array}$ \\
\hline & & Bandura & $\begin{array}{l}\text { La agresividad es fruto de un proceso } \\
\text { de aprendizaje social por imitación de } \\
\text { modelos. }\end{array}$ \\
\hline
\end{tabular}

Cuadro 3. El origen del comportamiento agresivo, a lo largo de la historia.

Fuente: Creación personal con datos de Fernández (2001).

Ahora bien es interesante hacer la reflexión de que un individuo puede ser violento en su individualidad de acuerdo a características de su propia personalidad, pero ¿qué sucede cuando es parte de una multitud? ¿Tiene la multitud influencia sobre ese individuo y viceversa? El médico, etnólogo, sociólogo y Psicólogo francés Gustave Le Bon (1895) dedicó muchos de sus más famosos estudios al tema de la Psicología de las masas. Opina que al perderse los límites de la propia identidad individual se presenta una nueva posibilidad: la ilusión de una nueva identidad colectiva, cabe subrayar que lo homogéneo se hunde en lo heterogéneo. Explica que más que identidad parecen tener una sola alma. En esencia esta le parece mucho más atractiva al individuo en vista sustituye al yo tímido y asustadizo por una nueva y mejor identidad (sentimiento de poder). La identidad colectiva significa que en conjunto se puede ser más fuerte y poderoso. Dentro de la masa 
es fácil entregarse a los instintos, que al estar solo, habrían tenido que ser reprimidos (Le Bon, 1895).

La masa es mucho más que una multitud o aglomeración (desde el punto de vista psicológico) porque la masa está sometida a consideraciones de las que, generalmente, no tiene conciencia. Por esa misma razón la masa puede ser fácilmente tan heroica como criminal porque los procesos intelectuales se ven disminuidos y los sentimientos anulados (Le Bon, 1895). Al final de cuentas el pertenecer a un colectivo puede generar dependencia, pero también otorga un sentimiento de seguridad y protección. . Los sentimientos, pensamientos y acciones, en grupo, pueden llegar a ser totalmente diferentes a los que se puedan tener individualmente.

Según (Morales et al., 2007) la desindividuación se da cuando las personas se encuentran en un estado de anonimato, en el que, debido a la difusión de la responsabilidad y la presión del grupo, apenas controlan su conducta. Por esta razón esa desinhibición provocará condiciones para que surjan conductas impulsivas como violencia y vandalismo.

Aún las acciones que puedan ser reprobadas irreprensiblemente en lo individual, en lo colectivo adoptan la característica de ser altamente contagiosas. Según Le Bon (1895) otra de las nuevas fuerzas que actúan sobre el individuo como parte de una masa o grupo es la sugestionabilidad. Esta puede considerarse como un efecto de donde el contagio es la causa. En este sentido puede mencionarse que estudios recientes desde la Fisiología ha revelado que por diversos procedimientos (desde muchas disciplinas) el ser humano puede perder por entero su personalidad consciente y obedecer a las sugestiones de aquel que haya logrado despojarlo de ella. Este estado emocional puede tipificarse como un estado de “fascinación” que en casos extremos puede convertir al individuo en un autómata carente de voluntad.

La conducta agresiva también fue objeto de profundas reflexiones por Freud (1921) quien determina que es válido atribuir a la dotación pulsional una importante cuota de la agresividad manifiesta en el ser humano. En este caso el prójimo es una excelente oportunidad para explorar su 
fuerza del trabajo, para usarlo sexualmente (sin su consentimiento), arrebatarle su patrimonio, humillarle y provocarle múltiples dolores de todo tipo, incluso, asesinarlo. En resumen es la posibilidad de ser el Homo homini lupus; sin embargo aún en el reino animal no se arremete contra los otros por el simple placer de destruir, sino para satisfacer las necesidades apremiantes. Aunque la frustración puede ser también una de las razones de la agresión, no es la única pues el ser humano puede tener acciones violentas que van mucho más allá de toda necesidad de defensa o conservación.

Según Carlisky (2000) una de las conclusiones más valiosas de Freud, relativas a la agresión, es que la cultura tiene un gran reto y responsabilidad como reguladora de las pulsiones agresivas de los seres humanos. La cultura plantea severas exigencias ideales cuyo cumplimiento es castigado mediante una angustia de la conciencia moral. Estas exigencias culturales se materializan a través de la ética y la justicia.

Otra cuestión interesante por analizar es el vínculo existente entre el poder y la agresión. Carlisky (2000) determina que el poder debe tener como característica estar al servicio de la vida, en este caso estamos hablando de una agresión reactiva. Sin embargo no siempre se manifiesta de esa manera, pues en los seres humanos utilizan ese poder para lograr sus particulares deseos, en muchas ocasiones estos pueden ser extremadamente egoístas. El individuo se encuentra ensimismado y carente de muestras de empatía por el prójimo. Según Freud es posible que aislado fuera quizás un individuo culto, pero dentro de la masa puede descender varios escalones en la escala de la civilización y actuar bárbaramente en acciones de puro salvajismo. En sentido opuesto con entusiasmo desbordante y heroísmo que también son muestras de seres primitivos. Aquella persona que quiera o necesite influirla tiene un trabajo sencillo: únicamente debe presentarle imágenes más vivas, exagerar y repetir siempre lo mismo. En este sentido nos explica que la masa es sumamente vulnerable en vista que en su estado de excitación no abriga ninguna duda sobre lo 
verdadero o falso. Otra característica que le distingue es que tiene conciencia de su gran fuerza. Puede adoptar actitudes radicalmente opuestas de obediencia o intolerancia ante la autoridad.

Dentro de la masa los héroes son los más violentos, considerando las buenas maneras como un signo de debilidad. Este permite identificar a aquellos que no "honran" ser parte de la masa. Reflexionando acerca del aspecto moral de la masa encontramos que Reguera (2001) considera que al reunirse los individuos de la masa desaparecen todas las inhibiciones pues las acciones que se realizan tienen como elemento en común el llamado a la libre satisfacción pulsional de los instintos crueles, brutales y hasta destructivos.

Esto nos hace reflexionar en el fenómeno de los “linchamientos en Guatemala” en donde los principales medios de comunicación nos dan cuenta de la gravedad de los actos violentos cometidos por personas comunes y corrientes en barrios, aldeas, mercados cantonales; en donde frustrados por los hechos delictivos cometidos en su contra y desencantados del poco accionar policíaco se precipitan a tomar la justicia en sus manos.

Freud (1921) señala que: por el mero hecho de pertenecer a una masa, el ser humano desciende varios escalones en la escala de la civilización. Aislado era quizás un individuo culto; en masa puede llegar a ser un bárbaro que con gran espontaneidad demuestra violencia y salvajismo.

Otra teoría que vale la pena explorar es la denominada Innatista. Según Reguera (2007) estas explican el origen de la agresión en los impulsos internos, siendo, por tanto, innata porque viene con el individuo en el momento del nacimiento y es consustancial con la especie humana. Otro elemento importante de estas teorías es la hipótesis de que la violencia va en aumento simplemente porque paulatinamente se han ido debilitando los controles sociales que impedían que se manifestara esta carga de violencia.

En esta teoría descansan los modelos relativos a mecanismo internos (genéticos, biológicos o pulsiones instintivas). Las dos corrientes de pensamiento más conocida en esta línea son la Etología y el Psicoanálisis Freudiano. La Psicoanalítica, postula que la agresión se produce como 
resultado del instinto de muerte que es dirigido hacia los demás (en vez de a uno mismo) como una forma de violencia.

Eibel-Eibesfeldt citado por Reguera (2007) define los comportamientos agresivos como aquellos que conllevan a la huida, a la evitación, a la subordinación y a veces también al daño físico de un congénere. Por esta razón el concepto etológico puede sintetizarse en los siguientes puntos: i) El impulso agresivo es una conducta filogenéticamente adaptativa, al servicio de la supervivencia, con unas funciones territoriales, sexuales y de dominación de los más fuertes. ii) La respuesta agresiva depende de la energía acumulada en el organismo y el umbral del estímulo desencadenante. iii) Existen en el ser humano, como en el animal, impulsos innatos inhibidores de la agresión.

Existe otra teoría bastante aceptada, en el medio de la Psicología Social, siendo la denominada: Teoría de la Frustración-Agresión como una búsqueda del equilibrio entre lo interno y lo ambiental.

Aunque para muchos autores las hipótesis planteadas por esta teoría han sido ya superadas, conviene citarlas en el presente estudio; pues solamente teniendo a la vista la mayor cantidad de teorías relativas a las conductas violentas y agresividad; podremos llegar a identificar aquella que permitirá abordar de mejor manera el objeto de investigación en la presente Tesis Doctoral.

De acuerdo a Reguera (2007) para muchos psicólogos el término frustración hace referencia a una barrera externa para alcanza una meta, mientras que otros piensan que la frustración es una reacción emocional interna que surge ante una contrariedad.

Según el Diccionario de la Real Academia Española, la palabra frustrar proviene del latín frustrāre que significa: privar a alguien de lo que esperaba o dejar sin efecto un propósito contra la intención de quien procura realizarlo. Para muchos psicólogos el término frustración hace referencia a una barrera externa que impide a alguien alcance una meta, mientras que otros piensan que la frustración es una reacción emocional interna que surge ante una contrariedad. 
Hoy en día se reconoce que la existencia de frustración no conduce siempre a cierta forma de agresión. Así mismo que una conducta agresiva no presupone necesariamente la existencia de frustración. En general a estas teorías se les conoce con el nombre de Teorías Reactivas. En esencia, según explica Dómenech e Iñiguez (2002) este modelo prevé que efectivamente la agresión es un comportamiento resultante de la pulsión interna, pero que esta pulsión depende de un elemento externo: la generación de la frustración. La riqueza de este enfoque es que representa a una de las pocas que han intentado aunar los elementos de naturaleza externa e interna para explicar la conducta violenta.

Otra teoría interesante para su análisis es la del Aprendizaje Social propuesto por Bandura (1986) es una de las más importantes, pues ha realizado un aporte extraordinariamente fecundo en la comprensión del comportamiento agresivo y la percepción de la violencia. Albert Bandura asegura que la agresión es: una conducta aprendida más que, otras conductas sociales, que se rige por los principios de control del estímulo, refuerzo y control cognitivo. Determina que toda conducta se adquiere y está mantenida por uno o más de los siguientes sistemas regulatorios. i) El control estimular externo: estímulos ambientales que felicitan y evocan respuestas. ii) Procesos de “feedback”: (refuerzo y castigo). iii) Procesos simbólicos, especialmente de aprendizaje observacional.

Tal como hemos analizado, la violencia puede interpretarse de diferentes maneras. Ello dependerá inicialmente del momento histórico, político y de aspectos culturales y regionales. Otros factores a considerar es ¿quién y para qué hace el análisis e interpretación de las acciones violentas o agresivas? Habiendo aportado ya, en la presente revisión teórica, elementos indispensables en la comprensión del tema, consideramos imperativo hablar ahora de las víctimas.

Según Iñaky y Moreno (2009) las víctimas pueden ser: i) Víctimas directas o afectados primarios. En este caso se refiere al individuo que ha sido objeto de una acción directa que le ha dañado física o emocionalmente. ii) Víctimas secundarias o indirectas. Se refiere a aquellos 
individuos que han sido traumatizados por el hecho de haber sido testigos del daño directo sobre otro individuo. iii) Víctimas secundarias o indirectas de ingreso. Hace referencia a las personas que voluntariamente acceden a estar presentes en el lugar en donde han acontecido hechos violentos, bomberos, policías, enfermeras, médicos, representantes de Derechos Humanos, etc. (Markez et al., 2009).

Las explicaciones fundamentales sobre agresión y violencia se han centrado en los tres siguientes aspectos: i) aspecto genético de la violencia. ii) Violencia o agresión como respuesta a la frustración y iii) Agresión o violencia en función de los patrones de aprendizaje.

Uno de los supuestos básicos de la Psicología Social es considerar que la agresión es un elemento normal ser humano y no necesariamente una manifestación de algún tipo de anomalía. Se asegura que las conductas agresivas son susceptibles de adquirirse y mantenerse a través del aprendizaje social.

Estudios clásicos realizados en este campo por Bandura\& Ross y Ross (1963) demostraron como un grupo de niños aprendieron y replicaron fácilmente una conducta agresiva cuando observaron como un adulto golpeaba (a propósito) un muñeco inflable. Otro tipo de estudios han demostrado como los adultos son más imitados que los niños, los hombres, más que las mujeres y los grupos mayoritarios más que los minoritarios. El observar que un modelo influyente es reforzado como consecuencia de una agresión promoverá el aprendizaje de dicha conducta y su imitación al enfrentarse a situaciones similares observadas y con personas que fueron agredidos por el modelo (Garrido, Herrero y Masip 2001).

A grandes líneas esta teoría afirma que los seres humanos adquieren el comportamiento agresivo a través de la experiencia pasada u observando las acciones de los demás. En otras palabras que la agresión es eminentemente cultural. La cultura marca lo que debe aprenderse ofreciendo normas estándares, y modelos a imitar. También la cultura ofrece refuerzos y motiva algunas conductas mientras desanima otras. Debido a la condescendencia con algunas de las 
manifestaciones de violencia en la sociedad la situación se agrava y la violencia es un fenómeno cotidiano, en el ámbito de muchos países latinoamericanos. Sobre todo marca el inicio de un proceso deshumanizante. El acostumbrarse a la conducta violenta de la población y aceptarla, es peligrosamente muy fácil. De esta cuenta no hay reacción alguna cuando el asiduo lector del periódico encuentra la nota roja relativa a robos, extorsiones, abusos sexuales, asesinatos y no tiene ningún tipo de reacción. Hasta que un buen o mal día, alguno de sus amigos, conocidos o parientes se convierte en parte de las estadísticas de robos, homicidios u otro tipo de abusos.

En este apartado se hace un esfuerzo por compilar y analizar las principales teorías de la violencia desde la perspectiva de la Psicología Social con el objetivo de comprenderlas y acercarnos al entendimiento de la violencia social. En vista que la práctica del bautizo de la Universidad de San Carlos es una muestra de ella. Inicialmente definiremos lo que es grupo social para luego analizar las dinámicas sociales que acontecen dentro de los grupos sociales.

Finalmente, pero no menos importante traemos a la memoria el experimento en la prisión de Stanford, Estados Unidos, realizado por Philip Zimbardo en el año de 1971. Zimbardo es profesor de Psicología Social en la Universidad de Stanford en los Estados Unidos de Norteamérica. Ha dedicado gran parte de su carrera al estudio de la Psicología del Mal (la violencia, el anonimato, la agresividad, el vandalismo, la tortura y el terrorismo). Este interés es sumamente legítimo, tal como explica el mismo autor, debido a que creció en un gueto del Bronx en la ciudad de Nueva York, Estados Unidos (García, 2010). Allí tuvo que presenciar un sinnúmero de actos violentos y aun siendo un niño tuvo que aprender a identificar situaciones de peligro, agresores; pero sobre todo, tuvo que aprender a sobrevivir. Actualmente dirige el denominado Proyecto Imaginación Heroica -HIP-que es una organización sin fines de lucro que enseña a las personas a tomar medidas eficaces en diversas situaciones difíciles.

El experimento en la prisión de Stanford -E.P.S- arrojó resultados abrumadores relativos a la conducta humana por lo que se hizo mundialmente famoso. El experimento consistía en reclutar a 
estudiantes universitarios para un supuesto experimento de Psicología, Los estudiantes debían recrear el ambiente propio de una prisión. Algunos estudiantes debían cumplir el rol de prisioneros y otros de carceleros. Se decidió acerca del papel que jugaría cada estudiante al azar, lanzando una moneda.

Aunque el experimento estaba programado para que tuviera una duración de dos semanas, fue necesario abortarlo en el día número seis. Ello porque los estudiantes que jugaron el papel de carceleros iniciaron a perder su identidad olvidando que aquel en el que participaban era simplemente un experimento. Explicaron posteriormente que el portar un uniforme (el de carceleros) les hizo olvidar por algunos breves momentos quienes eran en realidad y se convirtieron en lo que el uniforme representaba. Pronto empezaron a ver los estudiantes que participaron desempeñando el papel de prisioneros; como verdaderos maleantes, capaces de cualquier desorden e iniciaron a agredirlos, porque era justo lo que merecían. Consideraban que había que mantenerlos en control. Aunque la orden fuera orientada hacia el abuso de los supuestos prisioneros, era implementada ciegamente, a esto Bandura le llamó Obediencia Ciega, de tal forma que el individuo inicia a hacer cosas que no encajen probablemente con su moral, pero que son aceptadas por el colectivo Bandura citado por (García 2010).

El reto que este autor nos plantea en tan interesante trabajo es cuestionarnos ¿qué tanto nos conocemos a nosotros mismos?, ¿'somos capaces de cometer actos realmente inhumanos?, ¿si somos capaces de cometer atrocidades, qué elementos son los que entran en juego? Finalmente demostró que personas que pueden considerarse normales y gente que comúnmente es considerada como buena es capaz de ser sumamente cruel. Explica que todo dependerá de la situación que toque vivir. Una de las preguntas más interesantes que nos plantea es ¿Descubrir cuál es el catalizador de la maldad? Entre los principales elementos menciona la pérdida de identidad individual, la obediencia a la autoridad, la pasividad ante las amenazas, la auto justificación y la racionalización. Sin embargo la más importante es la deshumanización que es como una catarata en el cerebro que nubla 
el pensamiento y que niega a otros su condición de seres humanos. Ello los hace merecedores de todo tipo de vejámenes, tortura y castigo. Para Zimbardo las conductas sádicas o de maldad son aprehendidas, siendo su definición de maldad: Obrar deliberadamente de una forma que dañe, maltrate, humille, deshumanice o destruya a personas inocentes, o en hacer uso de la propia identidad y del poder sistémico para alentar o permitir que otros obren así en nuestro nombre (García, 2010). Sin embargo además de la disposición y condiciones existe un tercer elemento que crucial y este es los sistemas de poder.

Otra idea que es interesante explorar es la llamada: Teoría del Contagio. Burillo citado por Muñoz y Vásquez (2002) señala que en la práctica las teorías del contagio no son en realidad teorías puesto que cuando hablamos de contagio, estamos refiriéndonos simplemente a un mecanismo explicativo presente en la obra de diferentes autores, siendo el más representativo Le Bon, para quien el contagio es uno de los tres procesos implicados en la conducta colectiva.

Blumer explica que la teoría del contagio es una "reacción circular" en la que el contagio, tiene, además un efecto reforzador, puesto que el hecho de que una persona reaccione de la misma forma que otra ante un determinado acontecimiento, lleva a que la conducta de la primera persona se vea a su vez reforzada. Es un contagio de ida y vuelta (Muñoz y Vásquez, 2002).

Finalmente Scandroglio et al. (2008) publican un artículo en el que se describe lo que en lo sucesivo será conocido como: Experimento del Paradigma Mínimo. Los resultados obtenidos por los autores permiten conocer como en una situación en la que se reparte una cantidad de dinero entre una persona perteneciente al propio grupo y otra perteneciente a otro, existe una tendencia a favorecer al miembro del mismo grupo. Sin embargo lo interesante en este experimento es que la tendencia a favorecer no se da en términos absolutos, sino más bien relativos. El favoritismo puede implicar, por ejemplo, dar una cantidad baja de dinero a la persona del propio grupo, siempre y cuando eso implique que la persona del otro grupo obtenga una cantidad todavía inferior. 
Según Martín (2003), la violencia aparece como una constante en la existencia humana, en todos los momentos históricos la humanidad ha utilizado la violencia con el fin de ejercer el poder, el control o el dominio sobre los otros imponiendo su voluntad a través del uso de la fuerza. Concluye que la violencia como fenómeno humano se encuentra presente en todas las esferas donde se desarrolla la actividad humana: ya sea en la esfera social o en la esfera familiar.

En Psicología Social este tipo de conducta dio pie a una de las teorías más importantes denominada: Teoría de la Categorización, Comparación e Identidad Social. Esta se resume en la necesidad de obtener una identidad social positiva la que conduce a que procuremos diferenciar positivamente a nuestro grupo respecto a otros grupos. 


\section{CAPÍTULO 2: VIOLENCIA EN LA REGIÓN LATINOAMERICANA}

\subsection{Informes mundiales de la violencia}

El Informe Mundial de la Violencia (2002) es un primer esfuerzo a nivel mundial que reveló como esta cobra 1.6 millones de vidas humanas anualmente, además de millones más dañadas de maneras no siempre evidentes. De esta manera se demostró que donde hay violencia, la salud siempre estará en riesgo. Según la doctora Brundtland uno de los más importantes retos que lanza este informe es cuestionar la idea que los actos violentos son cuestión de intimidad familiar, elección individual o bien aspectos inevitables en la vida, instándonos a trabajar con colaboradores diversos y adoptar una estrategia preventiva, científica e integral.

La violencia es una de las principales causas de muerte en la población comprendida entre los 15 y 44 años de edad y la responsable del 14\% de la muerte de hombres y el 7\% de las mujeres. Está presente en cada rincón del mundo por lo que en muchas ocasiones se le ha llegado a considerar, erróneamente, como parte de la condición humana. Convirtiéndose por esa razón en un pionero en el enfrentamiento de las raíces de la violencia, (Organización Panamericana de la salud para la Organización Mundial de la Salud, 2002). De esta importante reunión de especialistas en el tema, emanaron las recomendaciones presentadas en el siguiente cuadro. 


\begin{tabular}{|l|l|l|}
\hline No. & Recomendación: \\
\hline 1 & $\begin{array}{l}\text { Evaluar los tipos y la eficacia de las medidas y programas destinados a prevenir la } \\
\text { violencia y mitigar sus efectos, prestando especial atención a las iniciativas de } \\
\text { orientación comunitaria. }\end{array}$ \\
\hline 2 & $\begin{array}{l}\text { Promover actividades para } \\
\text { resolver este problema a } \\
\text { nivel tanto internacional } \\
\text { como } \\
\text { de país, inclusive medidas } \\
\text { tendentes a: }\end{array}$ & $\begin{array}{l}\text { a) } \\
\text { gestión de las consecuencias de la violencia. } \\
\text { b) Promover una mayor participación intersectorial en la } \\
\text { prevención y la gestión de la violencia. } \\
\text { c) Promover investigaciones sobre la violencia dándoles } \\
\text { prioridad entre las investigaciones de salud pública. } \\
\text { d) Preparar y difundir recomendaciones para programas } \\
\text { de prevención de la violencia a nivel de nación, Estado } \\
\text { y comunidad en todo el mundo. }\end{array}$ \\
\hline 3 & $\begin{array}{l}\text { Asegurar la participación coordinada y activa de los programas técnicos apropiados de la } \\
\text { OMS. }\end{array}$ \\
\hline 4 & $\begin{array}{l}\text { Reforzar la colaboración de la Organización con gobiernos, autoridades locales y otras } \\
\text { organizaciones del } \\
\text { Sistema de las Naciones Unidas en la planificación, la aplicación y el seguimiento de } \\
\text { programas sobre la prevención y la mitigación de la violencia. }\end{array}$ \\
\hline
\end{tabular}

Cuadro 4. Recomendaciones de la Asamblea Mundial de la Salud para erradicar la violencia. Fuente: Elaboración personal relativa a la Resolución WHA49.25 de la Asamblea Mundial de la Salud.

A menudo suele considerarse a la violencia un problema inevitable y se busca reaccionar a ella en vez de prevenirla. Un requisito básico para abordarla, de manera integral, es que todas las personas trabajen juntas en asociaciones de todo tipo y a todos niveles. Dentro de las recomendaciones ya mencionadas, deseamos destacar la que concluye que para prevenirla es necesario estimular y fortalecer investigaciones serias sobre la violencia, privilegiándolas entre las investigaciones de salud pública (Organización Panamericana de la salud para la Organización Mundial de la Salud, 2002). Esta ha sido una de las principales motivaciones de la presente Tesis Doctoral, como se expone a continuación. 


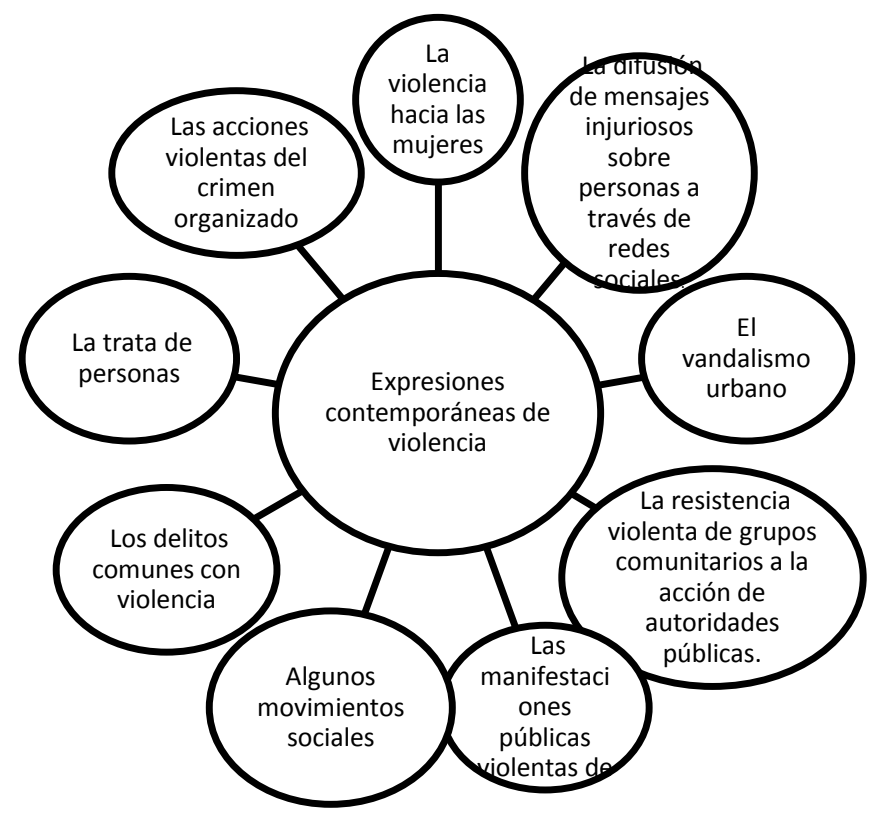

Figura 4. Diferentes manifestaciones de la violencia en la sociedad moderna Fuente: Creación personal con información de O.M.S (2002).

En figura cuatro podemos apreciar otro tipo de conductas violentas que van más allá que la que nos sugiere la clasificación desde la perspectiva psicosocial que están justificadas por la supervivencia misma. En casos como: i) las acciones violentas del crimen organizado, ii) la trata de personas y iii) los delitos comunes de violencia, vemos que no existe manera de argumentar que la conducta agresiva es debido a la necesidad de supervivencia. En estos casos podemos identificar que el elemento en común es el deseo incontrolable de poder y bienes materiales. En estos casos es necesario deshumanizar al a víctima para creer, que los bienes arrebatados (materiales o emocionales y espirituales) son mercancías que pueden aportar a satisfacer las necesidades del agresor. 


\subsection{La violencia en Latinoamérica}

Los estudios sobre violencia en la región han sido más que necesarios, en la última década, pues el Estudio Global de Homicidios de la Organización de Naciones Unidas (2013) revela que América ha superado a África como la región más violenta del mundo. A nivel regional es necesario hacer mención que Centro América tiene a tres de los países que ocupan las primeras posiciones como los más violentos a nivel mundial, siendo en orden de importancia: Honduras, El Salvador y Guatemala.

Mesoamérica ha sido considerada desde hace décadas como países cuyos niveles de violencia los hacen altamente peligrosos. Se argumenta que puede ocurrir todo tipo de hecho violento Tal como vemos en el cuadro que exponemos a continuación, Mesoamérica es una de las regiones más peligrosas de Latinoamérica.

\begin{tabular}{|c|c|c|c|c|c|}
\hline Posición & Ciudad & País & Homicidios & Habitantes & Tasa \\
\hline 1 & San Pedro Sula & Honduras & 1,411 & 753,990 & 187.14 \\
\hline 2 & Caracas & Venezuela & 4,364 & $3,247,971$ & 134.36 \\
\hline 3 & Acapulco & México & 940 & 833,294 & 112.80 \\
\hline 4 & Cali & Colombia & 1,930 & $2,319,684$ & 83.20 \\
\hline 5 & Maceió & Brasil & 795 & 996,733 & 79.76 \\
\hline 6 & Distrito Central & Honduras & 946 & $1,191,111$ & 79.42 \\
\hline 7 & Fortaleza & Brasil & 2,754 & $3,782,634$ & 72.81 \\
\hline 8 & Guatemala & Guatemala & 2,123 & $3,103,685$ & 68.40 \\
\hline 9 & João Pessoa & Brasil & 515 & 769,607 & 66.92 \\
\hline 10 & Barquisimeto & Venezuela & $1,242,351$ & 804 & 64.72 \\
& & & & $1,242,351$ & \\
\hline
\end{tabular}

Cuadro 5.Ranking de las ciudades más violentas del mundo.

Fuente: Elaboración personal de acuerdo a los datos otorgados por el Consejo Ciudadano para la Seguridad Pública y Justicia Penal A.C. México relativo al ranking de las 50 ciudades más violentas del mundo en el año 2013.

En la mayoría de barrios pobres y comunidades rurales son frecuentes los hechos violentos provocados por la violencia común. Sin embargo en las ciudades más urbanizadas el narcotráfico y 
la corrupción de las mismas instituciones de gobierno (tal es el caso de la Policía Nacional Civil) las han convertido en sitios poco seguros para propios y ajenos.

Los criterios de selección de la información para generar el ranking de las 50 ciudades más violentas del mundo fueron que debían corresponder a urbes bien delimitadas geográfica y políticamente y que fueran fácilmente diferenciables de las áreas caracterizadas como rurales. Al respecto de la diferenciación entre ambos tipos de ciudades podemos mencionar elementos como: densidad poblacional, infraestructura, principales actividades económicas y sobre todo las carencias y problemas que identifican a las urbes son diferentes a las de las áreas rurales (Ortega, 2013). Para demostrar la objetividad de la información presentada se hace la observación que los datos de homicidio fueron otorgados por instituciones oficiales y por el Instituto Nacional de Estadística, Geografía e Informática de México.

\subsection{La violencia en la región Centro Americana}

Centroamérica es una región sumamente violenta, en el año 2013 la Organización de Naciones Unidas declaró que en estos países se registran las tasas más altas se homicidios ${ }^{8}$ a nivel mundial. Guatemala es el quinto país que presenta índices más elevados a nivel internacional al reportar una tasa de 39.9 \% (Centro de Investigaciones Económicas Nacionales, 2010). Aunque la mayor cantidad de personas muertas son hombres, el estudio revela que mujeres y niños fallecen en contextos familiares en donde justicia tarda mucho más tiempo en llegar.

En el año 2010 se registró una de las tasas más altas de homicidios (116.6) según los datos de la Oficina de la Organización de Naciones Unidas contra la Droga y el Delito. La capacidad de las instituciones estatales que investigan, enjuician y castigan crímenes carece de la logística necesaria para hacerlo. Así mismo el tema de la corrupción se ha infiltrado aún en estos aparatos de

\footnotetext{
${ }^{8}$ El estudio define al homicidio como el hecho de matar intencionalmente a alguien.
} 
Estado. Guatemala, El Salvador y Nicaragua comparten historias recientes de conflictos armados internos. Según especialistas en criminología las ciudades post-conflicto presentan tendencias a la violencia por la disponibilidad de armas de fuego. Así mismo el alcoholismo, la desintegración familiar y la escasez de programas de prevención de la violencia intra-familiar son factores que inciden directamente en la proliferación de pandillas juveniles y participación de niños y jóvenes en el crimen organizado.

Es preocupante determinar, de acuerdo a este tipo de estudios, que 46 de las ciudades más peligrosas del mundo se encuentran en América y en particular (41 de ellas) en América Latina. Esto confirma que la violencia homicida en América Latina presenta una incidencia muy por encima de la media mundial.

\subsection{Generalidades del estudio de caso Guatemala}

Guatemala es un país ubicado estratégicamente dentro del Istmo Centroamericano. Limita al Norte y Oeste con México mientras que al Oeste con Belice, Mar Caribe, Honduras y el Salvador. Finalmente en dirección sur colinda con el Océano Pacífico. Posee una extensión geográfica de $108.889 \mathrm{Km}^{2}$.

Según el último censo poblacional del Instituto Nacional de Estadística (año 2002) para este año Guatemala tenía una población de 12 millones de habitantes y según las proyecciones realizadas por la misma institución para el año 2014 la población es de 15,806,675 habitantes que se encuentran distribuidos en 22 departamentos y 334 municipios.

La población de Guatemala es eminentemente rural ${ }^{9}$ estimándose que por cada 100 personas que viven en el área rural 94 viven en el área urbana (Instituto Nacional de Estadística, 2014).

\footnotetext{
${ }^{9}$ La relación de urbanidad corresponde a la razón entre la población que vive en las áreas urbanas con respecto a la que vive en las áreas rurales.
} 
A diecisiete años de la firma de los Acuerdos de Paz Guatemala aún se encuentra lejos de ser una Nación incluyente, plural y equitativa. Muchas fueron las esperanzas de reconstruir el país y de avanzar de una manera sustancial hacia el desarrollo. A pesar de los esfuerzos realizados, aún prevalecen muchos de los problemas que provocaron el conflicto armado interno: inequidad en la distribución de la tierra, pobreza extrema, conflictividad agraria y política; entre las más importantes.

En los últimos veinte años, el Gobierno de Guatemala se mantuvo firme en la convicción de que la mancuerna democracia y mercado traería prosperidad, desarrollo y bienestar para la mayoría de la población. Sin embargo la reflexión acumulada de diez años de Informes Nacionales de Desarrollo Humano en Guatemala dan cuenta que la realidad nacional dista mucho de esa visión de prosperidad y desarrollo humano (Programa de Naciones Unidas para el Desarrollo, 2008).

Uno de los problemas estructurales del país es la centralización de la inversión pública y por añadidura de los servicios y oportunidades en la región metropolitana. Por esa razón la ciudad de Guatemala se ha convertido en la ciudad más densamente poblada de la región Centroamericana. Sin embargo aunque hay algunos sectores que logran el crecimiento económico se desencadena todo tipo de problemas sociales y económicos en la región como producto de la sobrepoblación. Entre ellos puede mencionarse la escasez de vivienda y manipulación del mercado de tierras, congestionamiento vial, mendicidad, colapso de servicios públicos (transporte, servicio de drenajes, agua potable).

\subsection{La pobreza y desigualdad en Guatemala, una constante}

Cuando se habla de Guatemala a nivel mundial, en el imaginario colectivo surge la imagen de un país lacerado por la pobreza, marcado por la discriminación y la desigualdad en el acceso a los bienes materiales. El grupo cultural de ascendencia maya ha sido históricamente despojado y en 


\section{Violencia en la región latinoamericana}

la actualidad representa al grueso de la población que se encuentra en condición de vulnerabilidad extrema.

Los especialistas del Programa de Naciones Unidas para el Desarrollo -PNUDrecomiendan que al realizar el análisis de las condiciones de pobreza del país, se considere que ésta es de carácter multicausal. Así mismo que se considere que existen indicadores cuantitativos (monetarios) y cualitativos (desnutrición, nivel educativo, acceso a los servicios básicos) que en su interacción conforman el mosaico de lo que comúnmente se conoce como pobreza(Programa de Naciones Unidas para el Desarrollo, 2008). Sin embargo debe tenerse en cuenta que el término pobreza es un término aún no consensuado. Existen algunas directrices para poder dimensionar correctamente el problema, de esta manera es importante considerar que según el concepto de desarrollo humano se entiende pobreza como la privación de las capacidades humanas para alcanzar el bienestar. Para el caso guatemalteco los especialistas han señalado algunos indicadores multidimensionales, quienes en conjunto representan el Índice de Pobreza Multicausal, siendo los siguientes: i) Ingreso; ii) cobertura en salud; iii) saneamiento; iv) esperanza educativa v) acceso al agua; vii) acceso a la escolaridad; viii) hacinamiento y ix) acceso a vivienda.

Según datos del informe de Programa de Naciones Unidas para el año 2012 la pobreza en Guatemala es severa y prueba de ello es que el 70 \% de la población no cuenta con algún tipo de cobertura de servicios de salud y este mismo porcentaje no tiene acceso a la canasta básica (Programa de Naciones Unidas para el Desarrollo, 2012). Por otro lado un 30 \% de los adultos de la población guatemalteca no alcanzó ningún grado de escolaridad y el mismo porcentaje de niños es muy probable que no alcancen a terminar la escuela primaria. Casi cada una de cinco personas no posee ningún tipo de red de agua potable instalada en su vivienda y uno de cada diez habitantes no tiene servicio de sanitario.

El panorama luce mucho más sombrío en cuanto a educación se refiere y es así como se determina que el 9 \% de la población infantil ha quedado fuera del sistema educativo y es muy 
posible que nunca tenga ningún grado de escolaridad. Guatemala es uno de los países de la región que menos invierte en salud y educación.

Es imperativo mencionar que estas condiciones son más recurrentes en la población rural e indígena. Es innegable el hecho que siglos de marginación de este sector han llevado a un buen sector de la población indígena a condiciones de pobreza extrema que en la actualidad son difíciles de superar.

\subsubsection{Juventud y el círculo de la pobreza}

A pesar que en América Latina se ha experimentado una desaceleración en el crecimiento poblacional, Guatemala tiene uno de los índices de crecimiento poblacional más altos de la región. Se ha determinado que para el año 2085 la población superará los 30 millones de habitantes (Programa de Naciones Unidas para el Desarrollo, 2012). Es lógico pensar que la presión sobre los recursos naturales existentes en los 108,889 kilómetros ${ }^{2}$ que corresponden a su extensión territorial, tendrá mucha mayor demanda. La tierra, bosque, agua y otros recursos tendrán que ser suficientes para la sobrevivencia de la población. Ello sugiere que desde ya deberían estarse realizando programas que permitan condiciones de sostenibilidad a futuro. Sin embargo la realidad es muy distinta y los recursos naturales son aprovechados en gran medida por programas agresivos de agricultura de extensión (caña de azúcar, café, palma africana) y por empresas transnacionales en la minería.

Guatemala es una sociedad joven y para el año 2012 más del 60 \% de la población tiene menos de 25 años. Este importante sector de la población está marcado por la exclusión y aunque buen porcentaje de él está en edad de trabajar, se carece de oportunidades de empleo digno. Para poder llegar a la juventud es necesario sobrevivir la niñez y esto es bastante difícil en un país en 
donde la mitad de niños y niñas padecen de desnutrición crónica. Según encuestas realizadas recientemente se determina que al guatemalteco promedio le preocupan sobremanera tres problemas estructurales, siendo ellos: el desempleo, la corrupción y la violencia. Guatemala ha sido catalogado como uno de los países más violentos de la región. Así por ejemplo los jóvenes guatemaltecos se encuentran sin empleo y además inmersos en un ambiente en donde el narcotráfico y la delincuencia común y organizada parecieran ser las únicas vías de escape de las míseras condiciones de vida. Es así según los especialistas en el tema han determinado que el 9 \% de la población joven guatemalteca no sobrevivirá a los 30 años de edad.

Según los especialistas existen dos corrientes dominantes para abordar el fenómeno de la violencia. En el primer caso se plantea una asociación inevitable entre la conducta delictiva y violencia y los factores estructurales y sociales (pobreza, inequidad social) del contexto donde acontecen los hechos violentos. En este caso se determina que en una sociedad donde prevalecen las condiciones de pobreza extrema, inequidad social será una sociedad inevitablemente violenta.

Sin embargo existe otro tipo de explicación acerca del fenómeno de la violencia. Esta es abordada desde una perspectiva de las Ciencias Psicológicas y reza de la siguiente manera: Existen aspectos de orden, subjetivos y psicológicos (por ejemplo las formas de interrelación personal, formas asociativas y disociativas y aspectos culturales) que son los que determinan y condicional la manera de actuar de los individuos. De acuerdo a esta corriente del pensamiento, las condiciones económicas, sociales y políticas, poco o nada tiene que ver con la generación de hechos violentos; más bien este tipo de proceder depende de aspectos psicológicos del individuo. 


\subsubsection{Los índices de violencia en Guatemala}

Disminuir paulatinamente hasta erradicar la violencia constituye uno de los principales retos para la convivencia entre guatemaltecos. En el año de 1997 (Primer año de la Firma de la $\mathrm{Paz}^{10}$ ) murieron diariamente 13 guatemaltecos y para el año 2,010 la cifra se incrementó a 16 personas (Programa de Naciones Unidas para el Desarrollo de Guatemala, 2007). A pesar de ello el país carece de una Política clara acerca de los mecanismos y estrategias para erradicar y/o disminuir los hechos violentos en el país. Esta política debería estar coordinada con el resto de países del Istmo Centroamericano, en vista a que gracias a su posición estratégica se ha constituido en un puente para el tráfico de drogas, armas y aún de seres humanos.

Las instituciones que están encargadas de coordinar los mecanismos de seguridad a nivel nacional reciben un presupuesto impresionantemente alto, en comparación a otros sectores como Educación y Alimentación y a pesar de ello existe gran debilidad en el accionar institucional. Peor aún poseen poca credibilidad porque según los especialistas algunas organizaciones delictivas (que se conformaron durante la época del Conflicto Armado Interno) se han infiltrado en las instituciones. Así por ejemplo el Ministerio de Gobernación que es la organización estatal de quien dependen las instituciones obligadas a otorgar seguridad recibe un presupuesto equiparable al del Ministerio de Salud.

Las dependencias del Ministerio de Gobernación son las siguientes: i) Direcciones generales de Inteligencia Civil y Policía Nacional Civil; ii) Dirección General de Migración y iii) Departamento de Tránsito y Sistema Penitenciario.

\footnotetext{
${ }^{10}$ Entiéndase por Firma de la Paz el acuerdo firmado entre el gobierno de Álvaro Arzú y la comandancia de la Unidad Revolucionaria Guatemalteca en el mes de diciembre del año de 1996.
} 


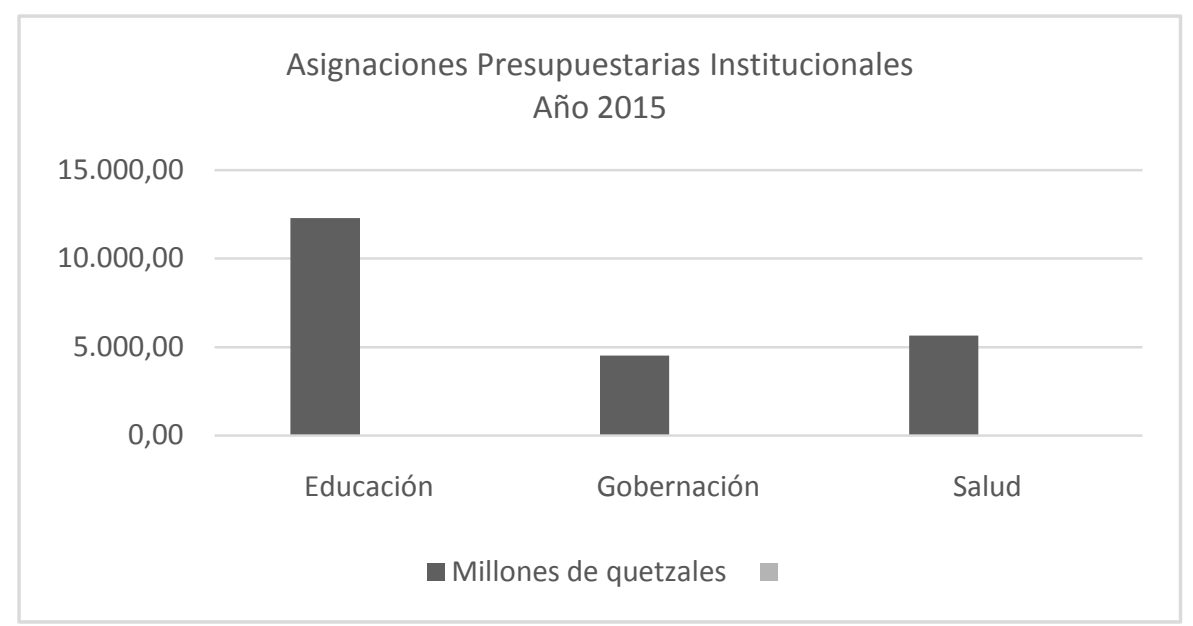

Figura 5. Inversión que el Estado guatemalteco hace. (Millones de quetzales) Fuente: Elaboración propia con datos del Ministerio de Finanzas (2015).

A pesar de la fuerte inversión que se hace en tales instituciones la violencia en el país se ha incrementado, desbordando a la población en general en olas de miedo e histeria. En la figura número 6 se demuestra como los homicidios en el país han ido incrementándose; muy a pesar que vivimos en condiciones políticas de Paz, declarada oficialmente como tal.

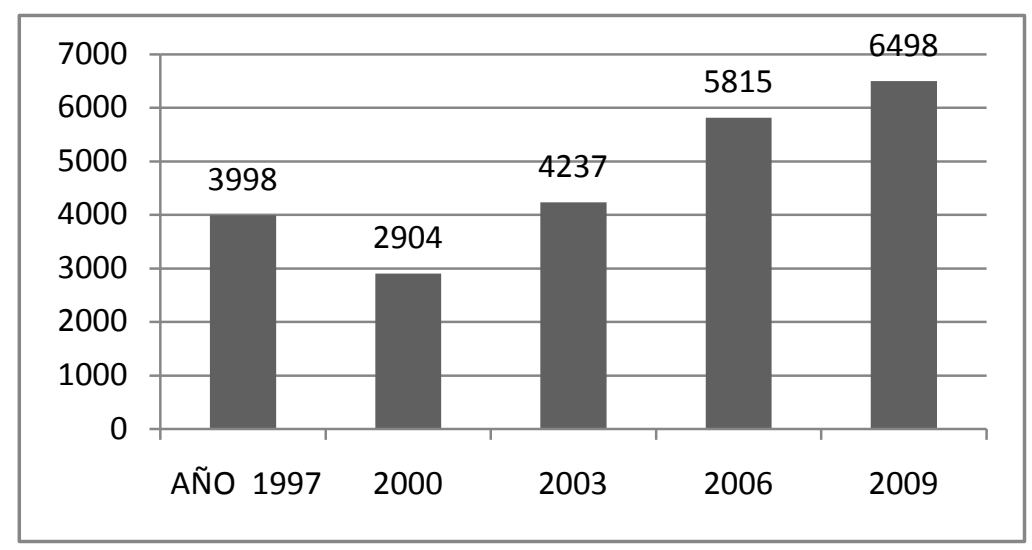

Figura 6. Número de homicidios cometidos en Guatemala durante el período de 1997-1999 Fuente: Elaboración personal con datos del informe del Arzobispado de Guatemala ODHAG (2011).

Estas estadísticas posicionan al país (de los declarados oficialmente en paz) como uno de los más violentos a nivel mundial (Matute, 2010). 
Es importante realizar un monitoreo de la violencia, a continuación se presentan algunos datos: Para el caso guatemalteco la tendencia en el tema de la violencia es el incremento, especialmente en épocas cercanas a las elecciones presidenciales. Sin embargo el grupo político, denominado Grupo de Apoyo Mutuo -GAM- ha dirigido investigaciones cuyo objetivo es monitorear los índices de violencia y nos revelan datos interesantes como los que a continuación se presentan: Durante los primeros siete meses del año 2014 se han reportado 3,345 víctimas de las cuales el 86 \% son hombres y el 14 \% restantes corresponden a crímenes cometidos contra mujeres (Grupo de Apoyo Mutuo, 2014).

Dentro de las causas estructurales de la violencia en Guatemala está el Conflicto Armado Interno (1960-1996). En Guatemala la violencia ha alcanzado límites inimaginables y parece que el horror que fue materializado por las miles muertes y desapariciones forzosas provocadas durante los 36 años que duró el conflicto armado interno (1960-1996) no era la última tragedia que los guatemaltecos tendrían que vivir. En diferentes capítulos de la historia del país se revelan hechos violentos que han marcado a cada generación de guatemaltecos. Por ahora mencionaremos que la violencia está presente tanto en las carreteras urbanas de la ciudad de Guatemala como en las calles empedradas de las aldeas de área rural del país. Hechos violentos y agresiones en contra de la población acontecen en las plazas y mercados de barrio como en los centros comerciales más exclusivos. Los medios de comunicación dan cuenta que aún en los jardines infantiles y todo tipo de centros educativos acontecen todo tipo de agresiones en contra de los infantes y jóvenes. Lo cierto es que la violencia es ya una marca sobre la sociedad guatemalteca y el riesgo de acostumbrarse a ella es cada vez más grave.

Otro tema cuya reflexión es indispensable es: los efectos de la violencia en Guatemala. Nos pareció importante contextualizar el fenómeno objeto de estudio en el ámbito de la realidad guatemalteca relativa a la violencia. El análisis de este fenómeno se puede realizar a través de la línea del tiempo. La historia de Guatemala como la de muchas otras naciones es la historia de 


\section{Violencia en la región latinoamericana}

despojo, terror y sometimiento. Ya en la época Precolombina los pueblos mantenían el respeto a sus dominios territoriales a través de crueles castigos a sus enemigos de pueblos cercanos. Los prisioneros de guerra eran sometidos a crueles castigos y en muchas ocasiones eran objeto de ceremonias ofrecidas a los dioses. En ellos se practicaban desmembraciones, perforaciones de diferentes partes del cuerpo y en algunas ocasiones extracción del corazón, aunque una de las prácticas más comunes era la decapitación.

En el Siglo XIV poco o nada varió la situación relativa a la violencia. Fueron ahora los conquistadores y colonizadores quienes impusieron en la América india una cultura de despojo y violencia. Deshumanizados al extremo de asegurar que los nativos no tenían alma, perpetuaron su dominio durante más de tres siglos.

La Guatemala independiente, no varió mucho porque ahora aparecía en la práctica un nuevo tipo de violencia; esa que conocemos como violencia estructural. Sin embargo existe una época en la historia guatemalteca que está fuertemente marcada por un tipo de violencia integral: siendo esta el Conflicto Armado Interno, que inició abiertamente desde el año de 1932 hasta 1996 con la firma de los Acuerdos de Paz. En esta época la violencia fue de todo tipo: material, física, simbólica. Sobre todo dirigida a un grupo humano concreto: la población indígena y pobre. Llegando muchos especialistas a denominarla como Genocidio.

Durante los 36 años de guerra interna que sufrió Guatemala las condiciones fueron propicias para un despliegue sistemático de violencia en contra de las fuerzas rebeldes y la población civil que los apoyaba. Esta dinámica de guerra provocó la muerte de más de 200000 personas entre población civil y militares. El campesinado guatemalteco y el sector estudiantil (en el primer caso por ser los más vulnerables y el segundo por ser los más beligerantes) fueron severamente afectados. Aún hoy en día el país se convulsiona ante juicios contra militares que tuvieron el poder político del país durante la década de 1980. Uno de los casos que acapara la atención de los medios de comunicación guatemalteco es el juicio por genocidio contra tres 


\section{Violencia en la región latinoamericana}

militares, entre ellos el ex-presidente de la República General José Efraín Ríos Mont. Sin embargo no es nuestro interés entrar en esta profunda discusión que requiere un esfuerzo metodológico individual y específico. Más bien nos dedicaremos a desmenuzar el fenómeno de la violencia como tal, tratando de revelar algunas acciones concretas que en épocas contemporáneas superviven. El objetivo de esto es identificar algunos aspectos que pueden encontrarse dentro del comportamiento de los estudiantes.

Otros datos interesantes son los que reporta el Consejo Ciudadano para Seguridad Pública y la Justicia Penal A.C de México (2014) quien determina que la ciudad de Guatemala es la octava más violenta del mundo de acuerdo a información sistematizada para el año 2013. Esto con una tasa de 2123 homicidios por cada 3103685 habitantes (Ortega, 2014).

En la actualidad las causas de la violencia son múltiples y difíciles de identificar. Sin embargo los expertos del Programa de Naciones Unidas para Guatemala afirman que las dos causas principales son la exclusión social y consecuente pobreza y la falta de aplicación de la ley. De cada una de ellas puede hablarse exhaustivamente, sin embargo con fines de no distraer la atención sobre el tema principal de la investigación hablaré brevemente de ellas.

Con respecto a la exclusión social y pobreza como causa de la violencia reflexionamos que Guatemala es uno de los países más desiguales del mundo con respecto a la distribución de la riqueza (según Programa de Naciones Unidas 0.57 para el año 2003) y esta constituye la principal razón por la cual prevalece una condición de tensión social a nivel nacional.

En el mismo sentido, según la Encuesta Nacional de Condiciones de Vida -ENCOVI(2006) el 51 \% de la población se encuentra en condiciones de pobreza y el 15 \% en condiciones de pobreza extrema. Las oportunidades de empleo son escasas y aunque cada año cientos de jóvenes egresan del nivel medio; en muchas ocasiones tienen que conformarse con un sub-empleo mal remunerado y totalmente ajeno al tipo de formación académica que han recibido (Instituto Nacional de Estadística de Guatemala 2013). Por esta razón es que jóvenes que se han graduado de peritos 
contadores, secretarias, bachilleres, maestros trabajan en empleos como dependientes de una tienda de conveniencia, expendios de gasolina, pilotos, etc.

El tema de la niñez y juventud en Guatemala se encuentra estrechamente ligado con el tema de la vulnerabilidad y pobreza porque ambos actores son protagonistas en un círculo perverso de pobreza.

El sociólogo contemporáneo Roberto Brenneman, en su libro Homies and hermanos, God and Gangs in Central América (2012) [Hermanos y Pandilleros en Centro América] señala que una de las razones primordiales por las cuales los jóvenes se identifican con la violencia de las pandillas es porque comparten (además de pertenecer a familias disfuncionales) atributos como enojo, baja autoestima y vergüenza promoviendo la violencia colectiva. Sin embargo una de las pocas posibilidades que tienen de alejarse de tales organizaciones es a través de las iglesias evangélicas pentecostales. Al consultar a los entrevistados acerca de cómo esa hazaña era posible, respondían: Ya sabes ni con la pandilla ni con Dios se juega (Breneman, 2014).

Las consecuencias, costos humanos y materiales de la violencia son altísimos; la más grave son los cientos de vidas humanas que ha cobrado anualmente. Los medios de comunicación han hecho partícipe a la población de los cientos de niños secuestrados que ha perdido la vida en las manos de sus secuestradores. Mujeres violentadas sexualmente; sobrevivientes que procuran recuperar su humanidad, el deseo de vivir y de sentirse cómodos en una sociedad que los abandonó a su suerte entre las manos de los delincuentes.

En el ámbito económico debe señalarse que el país pierde anualmente millones de quetzales por el pago de servicio de seguridad privada (que otrora fuera innecesaria en diferentes condiciones).

Así mismo a pesar que Guatemala fue declarada en el año 2010 como centro de Biodiversidad, ofreciendo una variedad de sitios turísticos el país no logra posicionarse 
regionalmente como en el rubro del turismo debido a que los turistas tienen miedo de visitar Guatemala.

Según reportan los periódicos de mayor circulación en el país (Prensa Libre, Nuestro Diario y Al Día) diariamente decenas de comerciantes son asesinados por extorsionadores al no ceder a las pretensiones del pago de extorsiones. El sector comercial se ve amenazado y deprimido por las condiciones de inseguridad que imperan. Vale la pena mencionar que este fenómeno ya no es una condición exclusiva de las áreas urbanas, pues este tipo de problemas se ha extendido al área rural. Algunos datos recopilados por la Policía Nacional Civil durante el período 2006-2009 en el sector metropolitano se registran el $35 \%$ de los hechos delictivos.

En este ambiente violento conviven actualmente 16 millones de guatemaltecos, que de una forma u otra han sido víctimas de la violencia. En este ámbito grotesco acontece el fenómeno que es objeto de investigación en la presente Tesis Doctoral. Con respecto a la educación superior, debemos mencionar que la cobertura de educación superior en Guatemala es una de las más bajas en América Latina. Esta condición es bastante acorde con los altos porcentajes de analfabetismo del país. Existe una relación inversamente proporcional pues mientras más se asciende en el nivel educativo menor es el porcentaje de estudiantes matriculados. Se calcula que la cobertura bruta de la educación superior en Guatemala es de 12 por ciento. Significa que solo 12 de cada 100 guatemaltecos entre 18 y 24 años está matriculado (Hurtado 2011).

La Universidad de San Carlos de Guatemala es la única universidad estatal. Para el año 2012 tenía matriculados 165,000 estudiantes y se han hecho proyecciones que para el año de publicación de la presente Tesis Doctoral (2015) tiene 200,000 estudiantes matriculados (Montenegro, 2013). Estos corresponden aproximadamente al 50 \% de la población universitaria guatemalteca (Hurtado, 2011).

Ello se debe a que a pesar que existen doce universidades privadas, las condiciones económicas de los estudiantes hacen que tengan como única alternativa matricularse en la única 


\section{Violencia en la región latinoamericana}

universidad estatal. Ello conlleva a serios problemas por los efectos de la masificación estudiantil. Entre ellos pueden mencionarse: i) El abarrotamiento de algunos salones de clases (especialmente en las carreras de Ciencias Jurídicas y Sociales y Ciencias Económicas, jornadas nocturnas). ii) La carencia de suficientes sitios de parqueo. Esto porque, según explica el encargado general de parqueos, existe capacidad física para 2500 parqueos, pero actualmente ingresan un aproximado de 6000 vehículos. iii) El incremento de violencia dentro del campus. iv) Los asaltos a mano armada y robo de vehículos. v) La contaminación auditiva y vi) La generación de desechos sólidos a gran escala (García, 2009).

La oferta académica de la Universidad de San Carlos de Guatemala es alta pues ofrece carreras en Ciencias Humanísticas, Naturales, Ciencias Exactas, Jurídicas y Sociales. Así mismo se cuenta con Sistemas de Estudios de Postgrado en donde se ofrecen Especializaciones y Maestrías en diversas ramas.

En algunas unidades académicas como Ingeniería y Agronomía se ofrecen los primeros programas doctorales cada uno en su especialidad. Sin embargo aunque existe diversidad de alternativas para los estudiantes, la demanda supera tal oferta. A cuenta de ello y también con el objetivo de mejorar el sistema educativo se implementó, hace seis años, un Sistema de exámenes de admisión. Son miles los estudiantes de nivel medio que no logran superar las pruebas para ingresar a la universidad. Al consultar con los personeros del Sistema de Nivelación de -USAC- , acerca de las causas, manifiestan que el nivel de formación educativa de cientos de estudiantes, especialmente del área rural, es excesivamente bajo. Por esa razón no tienen los conocimientos necesarios para poder ingresar a la universidad. 
La violencia escolar

\section{CAPÍTULO 3: LA VIOLENCIA ESCOLAR}

Según Reguera (2001) cuando hablamos de violencia escolar nos referimos a una situación de acoso, intimidación o victimización en la que el alumno o alumna es agredido o se convierte en víctima cuando está expuesto, de forma repetida y durante un tiempo, a acciones negativas que lleva a cabo otro alumno o grupo de ellos. Por acciones negativas se entiende tanto las cometidas verbalmente o mediante contacto físico y las psicológicas relativas a las acciones directas para excluir a un individuo de su grupo natural de trabajo.

La violencia es "el uso intencional de la fuerza o el poder físico de hechos o con amenaza contra uno mismo o un grupo o comunidad, que cause o tenga muchas probabilidades de causar lesiones o muerte, daños psicológicos, trastornos o privaciones” (Organización Mundial de la Salud, 2003, p.4). Es preciso desmenuzar esta definición porque en ella pueden detectarse varios factores. Uno de ellos es la víctima, que puede ser individual, colectiva o bien hacia uno mismo. Llevándolo al campo de estudio que en esta ocasión nos interesa podemos concluir entonces que puede ser el acoso sistemático de un grupo de estudiantes hacia otro; que aisladamente se ve obligado a soportar burlas o agresiones físicas. $\mathrm{O}$ al contrario un estudiante tipo matón, el típico estudiante de gran talla y agresivo, que disfruta de amedrentar a sus compañeros. Sin embargo también nos hace la aclaración que la violencia también puede ser de un tipo menos visible, una de tipo psicológico (una de difícil detección), la que solamente sale a luz cuando la víctima decide hablar. De allí la importancia de este tipo de estudios que generan las condiciones necesarias para escuchar la voz de los que hasta ahora no la han tenido.

Otro tipo de violencia, de acuerdo al objeto de la misma, es cuando es auto-infringida. En este caso el análisis es más conveniente desde las ciencias que hacen un estudio exhaustivo y profundo de los seres humanos. 
La definición de la -O.M.S- hace hincapié en la intencionalidad del agresor; entendiendo que éste puede ser un individuo o varios. Tal es el caso del acoso de un profesor hacia un grupo de estudiantes.

Otros autores como Ortega et al. (2001) describen a la intimidación o violencia entre iguales (refiriéndose al ámbito educativo) al proceso en el cual uno o más alumnos intimidan a otros por medio de mecanismos como: insultos, motes (apodos), vejaciones o bien aislando y señalando a otro. Aunque reconocen que también pueden haber agresión física. Todo esto provoca daños tanto a los agredidos (quienes pueden cargar con efectos devastadores el resto de la vida) y a los agredidos y espectadores quienes también podrían experimentar sentimientos de culpa.

Aunque los hechos violentos en el ámbito educativo ha existido desde hace mucho, es hasta la década de 1990 en donde inician a surgir las primeras investigaciones serias, tal como se ha mencionado en el apartado anterior. Ha surgido entonces una serie de maneras de llamar al fenómeno para denominar al mismo problema. Según Jiménez (2007) se han escrito diversas nomenclaturas como: violencia o acoso escolar, victimización, hostigamiento, maltrato entre pares, matonaje, agresión entre pares, interacciones agresivas, etc. Conforme ha ido avanzando la investigación en el ámbito educativo en este aspecto en especial se han ido estandarizando y aceptando maneras de llamarle al mismo fenómeno, tal como refleja el cuadro posterior.

\begin{tabular}{|l|l|}
\hline Región o país & Término \\
\hline Noruega, Dinamarca, Suecia, Finlandia & $\begin{array}{l}\text { Mobbing: El término derivado de su raíz inglesa } \\
\text { y dentro del campo de la Zoología: Aquellas } \\
\text { acciones de animales pequeños para defenderse } \\
\text { de usurpadores. }\end{array}$ \\
\hline Japón & Ijime: refiriéndose al mismo término. \\
\hline Francia e Italia & Racket \\
\hline Países mesoamericano & $\begin{array}{l}\text { Violencia entre iguales, acoso escolar; aunque a } \\
\text { partir en las últimas décadas se ha adoptado el } \\
\text { término anglosajón, Bullying. }\end{array}$ \\
\hline
\end{tabular}

Cuadro 6. Denominación de la violencia entre iguales.

Fuente: Creación personal con información de Jiménez (2007). 
Afortunadamente en las dos últimas décadas se ha aportado mucha información gracias a investigaciones realizadas en diferentes regiones del mundo. Investigaciones en donde se ha tenido como población de estudio infantes que cursan la educación primaria trasladando la investigación hasta el ámbito universitario. Uno de los aportes sustanciales, independientemente del enfoque, es que han logrado visibilizar el fenómeno y han aportado elementos de análisis para procurar comprenderlo. Por esta razón el término bullying se ha generalizado globalmente. Según Avilés (2006) palabra bullying proviene del inglés bully que significa matón o bravucón y se relaciona con conductas que están ligadas a la intimidación, la tiranización, el aislamiento, la amenaza y los insultos entre otros. Así mismo lo considera como: “el ejercicio del poder de forma abusiva sobre alguno de los miembros del grupo (de tal manera) que se hace habitual y reiterada” (Avilés, 2006, p. 21). El autor hace hincapié en que para abordar el fenómeno de manera responsable es necesario visualizarlo desde una perspectiva ecológica; desde dentro y desde afuera. Haciendo referencia a que es necesario analizar el contexto dentro de la escuela y fuera de ella. Otro aporte interesantísimo del autor ya referido es la posibilidad de diferenciar entre los conceptos de agresión y agresividad. Explica que mientras la agresividad es una condición natural de los seres humanos, y más aún, necesaria para la superación y progreso, la conducta agresiva es artificial y está dirigida a provocar daño.

Según el Diccionario Oxford, bullying, se refiere a meterse con alguien, intimidar a alguien con amenazas; en la versión 2006 se establece como: persona o animal que se convierte en un terror para el débil e indefenso. Aunque en el Diccionario de la Real Academia Española aún no aparece su definición, a la fecha (junio, 2015), en los países de habla hispana se reconoce ampliamente su significado.

Considerando lo difícil que es el abordaje del fenómeno de la violencia, por las múltiples connotaciones que pueden dársele, en el presente apartado se desarrollará la fundamentación teórica de la violencia en el ámbito escolar. Inicialmente se presentarán aportes esenciales, desde diversas 
disciplinas, para definir el significado de violencia en el ámbito escolar, conocido desde la década de 1990 por estudios realizados en Inglaterra, como bullying.

Baridón (2010) menciona que las investigaciones pioneras en el ámbito educativo fueron realizadas por Dan Olweus en Suecia y Noruega en la década de 1970. Al respecto describe que el trabajo de Olweus (1983) se centró en lo que hoy se conoce como una de las formas de violencia escolar.

\subsection{Las investigaciones pioneras}

Los rituales de iniciación han existido desde las sociedades primitivas sobreviviendo en la actualidad en prácticas modernas dentro de las instituciones religiosas, laicas, militares, deportivas y todo tipo de instituciones civiles. Las investigaciones realizadas en España, Francia, Suecia, Inglaterra y Holanda son las pioneras a nivel mundial. En el caso de la región latinoamericana es hasta el Siglo XX cuando la comunidad científica ha iniciado a dar la voz de alerta y han iniciado a aportar información que demuestra objetivamente que este fenómeno social no es un juego simplemente, sino un tema que debe abordarse desde la perspectiva de los Derechos Humanos.

Se ha concluido que las novatadas son un fenómeno mucho más integral y que sus consecuencias son en muchos casos de carácter permanente. En la presente Tesis Doctoral hemos de profundizar en su análisis y conocimiento con un estudio de caso implementado en el campus central de la Universidad de San Carlos de Guatemala, ubicado en la ciudad capital de Guatemala.

La comunidad de científicos sociales han iniciado a plantearse preguntas que es necesario responder. Entre ellas destacan: ¿Cuáles son las características de las novatadas universitarias en Guatemala?, ¿Qué funciones cumplen?, ¿Qué es lo que verdaderamente ocurre durante los bautizos universitarios?, ¿Existe algún contenido dentro de las novatadas que puedan decirnos sobre el sistema de enseñanza? 
Es necesario implementar mecanismos que permitan romper el Código de Silencio y lograr que el tema de las novatadas sea considerado con objetividad y responsabilidad. Sistematizando las experiencias en diferentes ámbitos educativos y seculares.

\subsubsection{Las novatadas o bautizos desde la perspectiva de los ritos de iniciación}

Las novatadas pueden ser consideradas como ritos de pasaje, en vista que contienen los elementos esenciales para ser catalogadas de esta manera. Existe en ellas una condición inicial, menospreciable, impura, natural y una final: pura, deseable y que permite una imagen completa. Sin embargo para llegar a obtenerla es necesario superar ciertas pruebas o bien demostrar ciertas cualidades o capacidades. Por esa razón constituyen una buena oportunidad para generar nuevas reflexiones acerca del comportamiento humano en comunidades educativas y promover reflexión acerca de las reacciones de los estudiantes y de la colectividad que los observa.

A diferencia de otros ritos de iniciación en la vida secular o religiosa, los ritos de iniciación en las instituciones educativas tienen el carácter de obligatoriedad. De tal suerte que aunque el neófito no esté de acuerdo con las prácticas de ese evento específico se ve obligado a participar en él y a sufrir las prácticas humillantes que le expondrán a una condición de vulnerabilidad en donde no es nadie y por lo tanto no vale nada. Inclusive algunos estudiantes veteranos, que aunque puedan tener rendimiento académico muy inferior, tienen derecho a realizar crueles bromas. El único requisito para poder participar en el bautizo y cometer abusos es ser veterano.

Los rituales y las creencias pueden crear ansiedad y sensación de peligro e inseguridad tanto en el que cambia de estado como para la propia comunidad implicada. La participación en un rito puede dar lugar a tensión común que, generalmente, se reduce al culminar el rito. Las novatadas o bautizos como se les conoce en el ámbito sancarlista representan un fenómeno social que se expresa 
concretamente como una tradición. Nada tiene que ver con los ritos de carácter religioso, ni dentro de la categoría de los rituales que antropólogos ubican dentro de las sociedades identificadas como primitivas. Por el contrario se trata de un fenómeno bastante moderno, laico, de la vida secular. Sin embargo las perspectivas religiosa, antropológica e histórica nos ayudan a comprender más profundamente el fenómeno ante el cual nos encontramos. Por esa razón se hace un breve recorrido por las obras de los autores más importantes en este tema.

Es indiscutible que al estudiar acerca de los ritos de pasaje es imperativo reflexionar acerca de los hallazgos realizados por Émile Durkheim en su obra: Las formas elementales de la vida religiosa (1912). Así mismo algunas obras de otros autores Arnold, Van Gennep (1909) con la obra denominada Los ritos de pasaje.

Entre los autores de épocas contemporáneas destaca el enfoque del sociólogo francés Pierre Bourdieu quien ha escrito acerca de los ritos no religiosos en ámbitos educativos europeos. Antes de iniciar a hacer este recorrido por las teorías propuestas por diversos autores, hemos considerado importante profundizar en algunos de los principales conceptos que en esta investigación deben quedar clara y objetivamente señalados.

Es necesario destacar es que los ritos de paso son las prácticas que acompañan los cambios de posición estructural o estatus que son de interés público. Esto porque el reconocimiento colectivo del nuevo estado del individuo es el fin último de tales prácticas, por esa razón suelen ser repetitivos. Para Edmund Leach citado por Leflaive (2003) los ritos son todas aquellas acciones no instintivas ni predecibles que no pueden encontrar explicación racional como medio para el logro de un objetivo concreto.

El mundo de lo mágico e intangible es muy diverso y profundo por lo que acercarse a él requiere de gran sensibilidad y sobre todo de mucha creatividad e imaginación. Para poder comprenderlo hay que contemplarlo desde diversas experiencias espirituales como una expresión 
cultural de cada pueblo, es necesaria una mente abierta que previamente se haya despojado de la propia cosmovisión.

Existe otro tipo de categorizaciones como la realizada por Vann Gennep (1969) quien propone hacer una separación concreta tal como se describe a continuación: i) Ritos de separación: marcan el abandono de una categoría social previa. Generalmente en este momento el individuo que será iniciado es separado, bruscamente, del resto de la comunidad y apartado para poder iniciar un proceso simbólico en donde será sometido a todo tipo de pruebas en la cuales será promovido a una condición muy superior. Ello ocurrirá solamente si tiene todo tipo de cualidades y virtudes que son bien ponderadas por el resto del grupo. ii) Ritos de margen: destinados a representar transición. Se caracterizan porque son un estado intermedio entre la condición profana y la deseable, finalmente describiremos brevemente los iii) Ritos de agregación: aseguran la incorporación a una nueva categoría social. Generalmente estos ritos son practicados de manera sistemática y cíclica.

Este tipo de fenómenos humanos tiene un elemento en común, según este autor es asegurar un cambio de estado o de paso de una sociedad mágico-religiosa o profana a otra. El autor nos hace ver que entre estos ritos no existe una equivalencia puesto que corresponden a diferentes naturalezas: preliminares, liminares y post-liminares, según su orden.

Cualquier persona que pase de una situación a otra transita durante cierto espacio de tiempo entre dos mundos. Se ve motivada (generalmente por otros miembros del grupo) a cruzar el umbral y transformase en un ser mucho más noble e ideal, abandonar el hombre viejo para nacer investido de autoridad. Según el autor lo verdaderamente interesante no es el detalle del rito, sino más bien su significación esencial. 


\subsection{Hacia una definición de los Ritos}

Según la Real Academia de la Lengua Española la palabra rito proviene del latín ritus que significa costumbre o ceremonia (en su primera acepción) o bien: conjunto de reglas establecidas por el culto y ceremonias religiosas. Es valioso considerar que el ser humano está íntimamente relacionado con la práctica de ritos porque a través de ellos se logra conservar una relación con el pasado y todo lo que en él nos fortalece. Así mismo con símbolos y significados que de otra manera quedarían en el olvido. Es la manera de vincularnos, incluso, con los aquellos que ya no habitan en el mundo material, pero que de alguna manera son referentes positivos que nos inyectan de energía para proyectarse al futuro. Gracias a ellos se da un acercamiento entre los individuos y se despiertan los sentimientos colectivos, fortaleciendo lazos, aún con aquellos, que naturalmente no serían considerados como tal. Mircea Eliade opina que los ritos o rituales representan uno de los eventos más importantes en la historia de la humanidad porque constituyen actos que no solo implican la vida religiosa del individuo, sino toda su vida(Eliade, 2000).

Para Émile Durkheim los ritos son maneras de actuar que no surgen más que en el seno de grupos reunidos que están destinados a suscitar, a mantener o rehacer ciertos estados mentales de determinados grupos. Según este autor existen dos tipos de ritos: Positivos y Negativos. Ambos dan respuesta a la necesidad de conservar la relación entre actor y receptor (Durkheim, 1976). Así por ejemplo en algunas sociedades primitivas existe una pulsión que mueve a los miembros de una comunidad a entregar ofrendas de todo tipo (florales, alimento, sacrificios animales) para mantener vigente esa relación. Según algunos miembros de las sociedades primitivas estos ritos son practicados porque los dioses así lo desean. El cumplir con los mismos les otorga a los miembros de esas sociedades un estado de bienestar moral, éstos son los ritos positivos.

De la misma manera los ritos llamados Negativos se refieren a las prohibiciones y distanciamientos empleados como castigos. Los ritos son tan dinámicos como tan compleja es la 
sociedad donde se practican. Durkheim afirma que a pesar que los ritos son sumamente diversos todos poseen un punto de encuentro y es que los seres humanos tenemos necesidad de afirmarnos, constantemente, como parte de un colectivo.

A los ritos se les confiere todo tipo de virtudes: expiatorias, sagradas, purificadoras, etc. Un solo rito puede servir para muchos fines y entre las principales actitudes rituales pueden mencionarse los siguientes: ritos Conmemorativos, de Oblación (ofrenda y sacrificio que se hace a Dios), Comunión, Imitativos y muchos otros tipos.

Para Leflaive (2003) los ritos de iniciación deben tener sus tres partes bien definidas, siendo éstas:

i) Ritos Preliminares o de Separación: Estos son considerados los que marcan el inicio de cualquier ritual; en ellos se realiza la separación de la condición normal. Por ello son considerados los que marcan el inicio de cualquier ritual; en ellos se realiza la separación de la condición normal. Para poder lograrlo es necesario invertir energía y se creativo para poder atravesar la barrera social y espacial del mundo de origen. Leflaive explica que en el tema del bizutage en Francia, estos ritos Preliminares se dan inicialmente con el paso de mando del poder de las autoridades académicas (director, profesores) a los estudiantes antiguos. Así mismo cuando se despoja a los novatos de sus pertenencias y documentos de identificación. En este sentido se sobreentiende que ya no soy las personas que creían ser (hijos de buena familia); sino simplemente un novato más atraviesa una barrera social y espacial del mundo de origen.

ii) Ritos Liminares o de Margen: Estos corresponden a la etapa intermedia entre los ritos Preliminares o Separación y los de Agregación. Para Leach, citado por Leflaive (2003) esta fase es concretamente la transición; consiste en convertir a la persona anormal en un tipo normal. Se logra de manera sencilla, separando al iniciado del resto de la sociedad y estableciendo restricciones, prohibiciones y prescripciones. 
Los novatos se encuentran literalmente en manos de los antiguos; inmersos en un tiempo y espacio diseñado arbitrariamente por los autores de su separación. Así pues por ridículo, grotesco o extraño que sea lo que los iniciados hacen (no por voluntad propia) estas acciones marcan su inmersión total a la condición de bizutage (según el término francés) de la que pronto saldrán si cooperan con lo que ha sido diseñado. Según los antropólogos existe una relación paralela entre los ritos de paso y el morir y renacer en una condición de supuesta superioridad. Sin embargo lo interesante en el bizutage es que existen símbolos de pérdida de identidad y aniquilación. Al despojarlos de lo que los hace diferentes (identidad personal) pues al momento del bizutage, todos son iguales y representan un estado de no persona y no existencia. Esto se concreta con la serie de burlas y humillaciones a las cuales se les somete. El objetivo concreto del ritual es convertirlo simbólica (y a veces materialmente) en un ser sucio, contaminado, anormal, intocable, que inspire asco. Para ello existe todo tipo de sustancias como: pintura, champú de huevos, harina, etc.

iii) Ritos de Agregación: Estos representan el momento cumbre de los rituales de paso. Es la meta deseada, para poder llegar a ser “uno más” fue necesario pasar por una serie de pruebas, de morir para renacer en nuevas y mejores condiciones. Según Leach citado por (Leflaive, 2003) las representaciones de lo colectivo, la solidaridad de grupo, la pertenencia a un solo cuerpo, son aspectos subrayados a lo largo de ritual.

Posterior a haber superado las pruebas, a haber entonado canciones, procesiones, lenguaje en común, se encuentran al final de la cumbre y pueden “agregarse, ser uno más” a las tan deseadas condiciones. En ese momento se rompe la barrera clasista entre iniciados y antiguos. Existen otro tipo de ritos un tanto más identificados con prácticas religiosas como los siguientes:

iv) Ritos para ser miembro de una sociedad secreta o Bund: Una de las características principales de este tipo de rito es que están limitadas a un sexo (masculino) y son sumamente celosas de la información que manejan. En las culturas primitivas existen muy escasos ejemplos de grupos o cofradías conformados por ambos sexos y cuando existen representan generalmente un festín de 
excesos de todo tipo. La francmasonería es una de las organizaciones secretas que aún existen. Son escasas las publicaciones de estudios relativos a las mismas.

Van Helsig (1998) publicó un interesante estudio relativo a estas sociedades secretas. Entre ellas: Los Sabios de Sión, Francmasones en Inglaterra y Los Iluminados de Baviera. Aunque sus reflexiones son en muchos sentidos relativas a política mundial, hace un interesante aporte al conocimiento de los ritos de iniciación en tales sociedades secretas. Los rituales, la magia y el secreto gozan de gran importancia en este tipo de sociedades. "El conocimiento espiritual de los francmasones fue traducido por símbolos, alegorías y rituales, que servían también para la comunicación” (Van Helsig, 1998, p.28).

El fin último de los masones es develar las mejores virtudes y cualidades en los seres humanos. Para ello es necesario realizar ritos de iniciación masónica. El objetivo es enseñarle al iniciado a conquistarse a sí mismo y pasar de ser un "ignorante y grosero a un pensador y sabio" (Wirth, 1894, p.66). El ritual es muy complejo, pero claramente está dividido en tres fases.

1) Pulimiento intelectual y moral. En ese caso se busca la purificación del iniciado, despojarlo de todo lo mundo que pueda haber en él.

2) El Gabinete de Reflexión. Se le llama así a un lugar de retiro. Este es necesario porque "para aprender a pensar, es necesario ejercitarse en aislarse y abstraerse” (Wirth, 1894, p.67), finalmente el denominado:

3) Cáliz de la Amargura. Todo progreso intelectual, como el que se supone que ha sido alcanzado, exige que haya mayor responsabilidad oral. El pensador contrae deberes mucho más superiores porque ya posee conocimiento del bien y del mal. Muchos son los rituales de iniciación en diferentes culturas, pero para ilustrar uno interesante en la región mesoamericana exponemos un breve resumen del rito de iniciación dedicado a los chamanes o hechiceros mayas.

v) Ritos para dar respuesta a una vocación mística de chamán o hechicero: En este caso se responde voluntaria o involuntariamente (porque hay un llamado de los dioses) a la vocación de 
convertirse en un miembro con poderes especiales dentro de la comunidad. Los curanderos en especial tienen un llamado muy específico y es a calmar la ira de los dioses. En general esta es provocada por aquellos que cometen faltas morales o incumplimiento de las exigencias de los dioses. La enfermedad es considerada, en la cultura mayence, como la materialización del castigo dirigido a los infractores.

Existe gran diversidad de curanderos o chamanes, dentro de la cultura azteca existían incluso especializaciones, como las siguientes: i) Tepationi: hombre de medicina y experto conocedor de las propiedades medicinales de las plantas. ii) Tlamatqui: Sabio que usaba la palpación y el masaje como método de curación de diversas dolencias. iii) Tetlacuicuiliani: aquel médico que extraía las enfermedades chupándolas directamente del cuerpo del enfermo. iv) Tetonalmacani: Aquel sabio de la medicina que podía hacer volver el alma a quien la había perdido.vi) Teixpatinai: El que curaba las enfermedades de los ojos y finalmente, vii) Temixihutiani: la sabia que atendía los partos (Aguirre, 1947).

Las pruebas a las que se somete a los iniciados en las artes de la salud serán especialmente duras por lo que no cualquiera es llamado a enfrentarlas, solamente aquel en el que se han encontrado especiales cualidades. Una de las características de las que debe hacerse distinción en este sentido es el éxtasis que experimenta del iniciado durante el proceso porque éste es prueba de su legítima transformación de un ser inferior a uno que ostenta poderes mágicos. Para lograrlo en muchas ocasiones los antiguos mayas utilizaban pócimas que contenían extractos de plantas con propiedades alucinógenas.

La iconografía de las ciudades mayas que sobrevivieron al paso del tiempo revelan figuras humanas con algún tipo de padecimiento físico (encorvamiento, enfermedades en los ojos, entre muchos otros) y también la actividad curandera de los médicos antiguos. Existen tres maneras de convertirse en chamán. La primera es la llamada de los dioses (o vocación). Esta puede darse mediante sueños, visiones o transes espirituales. La segunda es por medio de la herencia y la tercera 
por la búsqueda voluntaria de la incorporación a esa estirpe social con el apoyo de los miembros del clan.

También existen ritos que se encuentran enmarcados dentro del ámbito religioso, como lo expone Mirceae Eliade a continuación:

vi) Los ritos de iniciación según Mirceae Eliade: Esta corresponde a una perspectiva desde la historia de la religión. Aunque existen argumentos fuertes acerca que la práctica de los ritos de iniciación son ya obsoletas, autores como Eliade (1958) nos muestran que están más vigentes que nunca.

Es así como lo vemos en el seno de numerosas religiones, en prácticas mucho más modernas y comunes; como puede ser el ingreso de un individuo a un equipo de futbol. El matrimonio por ejemplo y el bautismo mismo en ciertas religiones no son más que las expresiones de esa necesidad del ser humano de someterse a actividades que le llevarán a alcanzar una nueva condición, una que se considera más leal y noble.

“El término iniciación, en el sentido más amplio, denota un cuerpo de ritos y enseñanzas orales cuyo propósito es producir una alteración decisiva de la situación religiosa o social de la persona iniciada” (Eliade, 1958, p.4). Desde la perspectiva filosófica también puede considerarse como el equivalente a un cambio básico en la condición existencial. Se pasa por una serie de duras pruebas (y deliberadamente brutales) con el objetivo de convertirlo en otro; de evolucionar. La nueva condición humana le permitirá tener acceso a una comunidad humana que posee valores espirituales y culturales superiores.

Un elemento importante mencionado por Eliade es que estas prácticas son de carácter obligatorio. Así por ejemplo ningún adolescente (de una tribu primitiva) podrá ni deberá (por su propio prestigio y bienestar) liberarse de las prácticas duras del rito de iniciación porque ello constituirá una condición necesaria para su incorporación a la vida adulta. Esta es una manera de 
demostrar que es lo suficientemente responsable para poder cumplir con las responsabilidades que como hombre adulto puedan asignársele (Eliade, 1958).

Finalmente, presentamos un enfoque de los ritos de iniciación desde la perspectiva de las emociones. Para ello hemos incluido las reflexiones del siguiente autor:

vii) Los ritos de iniciación desde la perspectiva de las emociones: Randall Collins en su obra Interaction Ritual Chains [Cadenas de Rituales de Interacción] donde explica acerca de la importancia de los rituales porque nos proveen de energía emocional que nos permite sentirnos seguros de sí mismos y a emprender acciones de coraje que de otra manera no seríamos capaces. Para Collins, según señala Soto (2011, p.23) los rituales son: “mecanismos que enfocan a una emoción y a una atención conjuntas, generando una realidad temporalmente compartida”. La vergüenza crónica es un componente violento del comportamiento y la búsqueda de ganar y preservar el respeto de otros y la posibilidad de pasar de la invisibilidad y anonimato social a la notoriedad pública (Collins, 2005).

A través de ciertas prácticas (que en muchas ocasiones son duras) el novicio es introducido a un mundo que antes le era desconocido, pero para ser digno de ese proceso antes debe ser preparado espiritualmente. La única manera es probar su valía a través de soportar mucho dolor. Esas prácticas, ocasiones detestables, permitirán la muerte iniciática, condición impura o profana y le permitirán la transformación a una condición muy superior, la deseada la de mejor estima. Únicamente desde esta perspectiva puede comprenderse el dolor que pasan las niñas (pertenecientes a culturas musulmanas) que son víctimas de ablación o los jóvenes de culturas primitivas australianas que son privados durante semanas de cobijo, agua y comida para renacer y pasar a formar parte de un grupo humano con mejores condiciones, el mundo de los adultos.

Para Collins los rituales tienen un efecto de estratificación entre los miembros del grupo participante pues así una clara diferenciación entre incluidos y excluidos y entre líderes y 
seguidores. Para Collins, según Soto (2011) las experiencias rituales expresan el sentido de la necesidad de la persona de servirse de los demás para poder completar la imagen de sí mismo.

En esencia los rituales de interacción tienen cuatro efectos principales: i) Solidaridad grupal, ii) Energía emocional individual iii) Generación de símbolos que representan al grupo y iv) Sentimientos de moralidad. La solidaridad grupal es un tema discutible, pues en el caso de las novatadas entre universitarios hay solidaridad hacia el estrato al que se pertenece. Así pues hay solidaridad entre antiguos, pero contradictoriamente, hay un completo abuso dirigido hacia los novatos. En el mismo sentido, los novatos expresan solidaridad entre ellos porque eso les permite un sentimiento de protección.

Collins cuestiona las teorías que aseguran que el individuo se convierte en un irracional cuando está entre la multitud. Considera que los tiempos actuales exigen otra perspectiva de los fenómenos colectivos. Introduce nuevos elementos en el análisis de los rituales. Entre ello nos habla de: Rituales Naturales y Rituales Forzados. Estimando que los rituales forzados en especial, no provocan sentimientos de solidaridad porque no ha legitimidad en la participación. Por el contrario cuando los rituales son naturales son rituales eficaces y pueden generar símbolos compartidos, sentimientos de solidaridad y promover que el individuo complete su propia identidad auxiliándose de los demás.

No todos los ritos o rituales constituyen un ejemplo de prácticas que cohesionen a la sociedad y que expresen aspectos positivos entre la acción humana. Muchos de ellos buscan, exclusivamente, la deshumanización, tal es el caso de los ritos de iniciación realizados en los campos de concentración de Auschwitz-Birkenau, ubicados a 59 Km. Al Oeste de Cracovia, cerca de la frontera germano-polaca durante la Segunda Guerra Mundial. Estos reflejan la crueldad vivida por 2.5 millones de personas (judíos, gitanos, entre otros) durante el holocausto nazi.

Este está magistralmente descrito en la obra denominada: El Corazón de la Zona Gris, una lectura etnográfica de los campos de Auschwitz de Feliu Paz Moreno. En esta obra se relata 
magistralmente acerca del plan de exterminio implementado en los campos de Auschwitz, Polonia. Se reconstruyen los hechos inhumanos acontecidos en tal lugar a partir de los relatos de diversos actores (Baridón, 2012) especialmente de los prisioneros. Sin embargo el aspecto relevante, que para fines prácticos del presente estudio, interesan son los rituales de iniciación practicados en los campos por los -S.S.- o trabajadores y guardias alemanes. Fueron tan efectivos tales rituales que los sobrevivientes al ser liberados y devueltos a la sociedad sentían avergonzados y culpables por haber sobrevivido a las jornadas de horror. Culpables de volver a ser seres humanos después de haber adquirido el "conocimiento venenoso” de una vida infrahumana, como le llama la autora, al habitar en la zona gris o campos de concentración (Paz, 2010). Esto se debe a que objetivo del ritual puesto en práctica en los campos de concentración fue: suprimir la moralidad, humanidad y dignidad de los prisioneros. El ciclo de la iniciación principia con la detención y transporte en donde viajan apiñados de pie uno al lado del otro, tratando de tener cercanía con los miembros de la familia; sin oxígeno suficiente, sin comida ni bebida, pero aún juntos.

La naturaleza del ritual es una verdadera marcha hacia la muerte. Sin embargo aún en esas condiciones conservaban el sentimiento de estar acompañados por su familia. Algo diferente ocurrió al llegar a los campos de concentración pues los varones fueron violentamente separados de sus mujeres e hijos. Hasta ese momento desconocían el destino que le aguardaba a cada uno, en primera instancia porque las órdenes eran dadas en un idioma que les era desconocido. Ya esa separación era suficientemente desgarradora, pero fue más devastador aún al enterarse del destino fatal de sus familiares. Algunas mujeres sobrevivieron, pero eran sometidas a tan crueles tratos que vieron desaparecido su período femenino. Relatan algunas sobrevivientes que había alguna sustancia química que aplicaban a las minúsculas raciones de sopa y pan que recibían porque notaron como pronto empezó a crecer bello en su cuerpo y lucían cada vez más masculinas. Algunas llegaron a tener barba y bigote (Paz, 2010). 
En el caso de los hombres fueron obligados a desvestirse y descalzarse, teniendo que vestir harapos que otros prisioneros habían dejado. Peor aún marcaron sobre su brazo izquierdo la palabra Häftling (que en español significa: preso) y un número. Nunca más serían llamados por su verdadero nombre; nunca más lo recordarían serían únicamente un número. Desde el momento en que llegaban a los campos de concentración su vida se resumía en entrar y salir de las barracas, trabajar, dormir, comer (aunque escasamente), ponerse enfermo, sanar o morir. El tiempo perdió total importancia, les fue vedado el uso de reloj y calendario y lógicamente todos los días eran iguales, no existía ningún tipo de situación especial que esperar(Paz, 2010).

La actitud de las víctimas su resistencia y fortaleza mental eran decisivas para sobrevivir, pues la violencia física y psicológica era la orden de los -S.S.- alemanes. Al llegar al campo de concentración se consideraba a los prisioneros como mercancía porque solamente de esta manera era posible llegar a los extremos inhumanos a los que llegaron. En este rito se vislumbran nuevos elementos y un proceso diferente en donde se pasa de un estado humano, de dignidad a un estado inhumano, de desvalorización total.

La vida de los seres humanos está llena de estos ritos de paso o mecanismos en los que se pasa de un estado a otro: de niño a adolescente, de soltero a casado, de vivo a muerto. Durkheim profundizó acerca de los ritos religiosos, pero también aporta la reflexión acerca que a veces los ritos pueden ser simplemente corrobbori vulgar, simplemente diversión pública que nada tiene que ver con lo religioso y en la cual todo el mundo puede tomar partida indiferentemente (Durkheim, 1976). En este caso responden simplemente a la necesidad de actuar, de moverse, de gesticular que sienten los fieles. Son únicamente saltos, giros, danzas, gritos, pero no es posible darle un sentido a este estado de agitación.

Desde una perspectiva filosófica los ritos de iniciación representan a un cambio básico en la realidad existencial. El novicio emerge de su dura experiencia de iniciación como un ser dotado de cualidades que antes le eran totalmente ajenas. La iniciación introduce al novato en una comunidad 
humana y un mundo de valores espirituales y culturales. Los ritos de iniciación se distinguen por una característica particular llamada: fenómeno del margen. Este se refiere a la energía física en los ritmos cósmicos porque es necesario que dos movimientos en sentidos contrarios estén separados por un punto muerto.

Existirá un momento en que este se reducirá al mínimo en la fuerza mecánica y no existirá que la potencia en el movimiento circular. Pero si el cuerpo puede moverse circularmente en el espacio con una velocidad constante, no ocurre ya lo mismo cuando se trata de actividades biológicas o culturales, pues estas se desgastan y deben regenerarse a intervalos más o menos próximos. A esa necesidad fundamental es a la que responden en definitiva los ritos de paso, hasta el punto de adoptar a veces ritos de muerte y renacimiento.

Ardoino, citado por Zamanillo (2002), señala que es de vital importancia considerar el carácter iniciático que tienen los grupos en su dimensión educativa. Resalta la necesidad de aproximar iniciación (paso, entrada en algo nuevo) y educación (conducción, alimentación).De esta manera estos grupos cumplen de cierta manera un requisito de iniciación a la vida en sociedad y la construcción de una visión del mundo apropiada. En este sentido el rito iniciático va acompañado de dos dimensiones fundamentales del ser fraternal (de sus compañeros de grupo) y parental (por las figuras de los monitores).

\subsection{Diferencia entre rito y ritual}

Aunque algunos autores utilizan indistintamente ambos términos, con fines de tener claridad en manejo de los conceptos teóricos en la presente investigación, conviene detenerse un momento y cuestionarse acerca de la diferencia o complementariedad de los mismos. Al leer los textos publicados por Eliade, Durkheim y Bourdieu entre otros autores, pude llegar a algunas conclusiones que refiero a continuación: Cuando hablamos de rito nos referimos a un acto de 
carácter individual o colectivo que procura mantenerse dentro de su práctica fiel a ciertas reglas, que son precisamente las que constituyen lo que en él hay de ritual.

En cuanto al término ritual puede determinarse que son puramente aquellos elementos dentro del rito destinados a la repetición. De esta cuenta que son conceptos que mantienen una relación de interdependencia. Sin repetición (ritual) el rito no puede mantener su esencia, el poder simbólico que desea transmitir. De esa cuenta que los ritos se distinguen de las demás costumbres porque su papel más importante es la repetición. También es importante mencionar que ambos conceptos juntos emanan un poder al cual se le teme, se le repele, pero también fascina y se le quiere utilizar. Estos no necesitan ser obedecidos ni ejercer dominio, sino más bien ser reconocidos por su carácter enigmático y simbólico (Durkheim, 1976).

La manera en que cada individuo vive el rito es diferente, porque tal como explica Durkheim cada hombre considera y recrea su propia actividad religiosa de acuerdo a su individualidad. Bourdieu y Passeron, hicieron un aporte importantísimo porque contribuyeron a renovar la discusión sobre la Teoría de la Acción Social. Inclusive algunos intelectuales han concluido que sus estudios apuntan a ser una Sociología de la Sociología. Cuestiona todo, pero también hace aportes valiosos que obliga a los círculos intelectuales a cuestionarse aquellas teorías que se suponían completamente aceptadas.

Una de las primeras obras que contiene tan interesantes reflexiones es la denominada: el poder de lo simbólico: señalando que éste se refiere a un poder de construcción de la realidad que tiende a establecer un orden gnoseológico: el sentido inmediato del mundo (y en particular del mundo social). Nos hablan también de los símbolos, señalándolos como los instrumentos por excelencia de la integración social: en cuanto instrumento de comunicación y conocimiento (Bordieu y Passeron, 2003). También aclara otro importante concepto, como lo es el mito definiéndolo como el producto colectivo y colectivamente apropiado, indica que las ideologías 
sirven a los intereses particulares que ellas tienden a presentar como intereses universales, comunes al conjunto del grupo.

El aporte que Bourdieu realiza acerca de los ritos es muy amplio señalando que éste genera actitudes para dominar el comportamiento de la persona (esta es la magia social o simbólica). En sencillos gestos, entonaciones, saltos, giros puede ser legitimada la "autoridad tradicional” que expresa los fundamentos de la comunidad. Para que un acto ritual (independientemente de cuál sea el campo donde se practica) sea eficaz las palabras utilizadas deben ser pronunciadas con claridad y autoridad, ese es el poder del lenguaje. Tal parece que aunque las sociedades están sometidas a dinámicas exponencialmente veloces, existen determinados patrones de conducta de las sociedades primitivas que sobreviven el paso del tiempo.

Así por ejemplo los inicios de las novatadas en la Universidad de San Carlos de Guatemala, datan desde hace más de medio Siglo, cuando iniciaron las protestas estudiantiles y la Huelga de Todos los Dolores $^{11}$. En estos espacios geográficos luchan y hasta compiten entre ellos. Por esa razón explica el autor que un campo es a la vez un espacio de significación y un espacio de luchas. Estas luchas se darán en diferentes campos: social, económico, político. En todo caso destaca la lucha entre el poder dominante (quien trata de mantener su monopolio) y el recién llegado (quien trata de acceder a él lo más pronto posible).

La sociedad contemporánea avanza a pasos agigantados hacia la modernidad. Algunos de los efectos positivos de la globabilización son: el avance de las ciencias a través de aplicaciones tecnológicas-electrónicas y de comunicación. Sin embargo esos mismos aportes promueven efectos negativos en las relaciones humanas. Por esas razones muchas de las tradiciones, mística y creencias que distinguen e identifican a los pueblos van desapareciendo.

\footnotetext{
${ }^{11}$ Huelga de Dolores: Desfile bufo que caracteriza a los estudiantes de la Universidad de San Carlos de Guatemala. Se realiza anualmente y en ellas se satiriza a personas de la clase política y oligárquica del país. Es un desfile típicamente de protesta y sátira.
} 
Entre esas expresiones culturales que van perdiendo vigencia, existen algunas que sobreviven entrelazándose en prácticas religiosas e institucionales, estos son los ritos y rituales.

Exiten procesos biológicos (nacimiento, adolescencia, vejez, senectud, muerte) y otros de tipo social (matrimonio, paternidad, incorporación a sociedades económicas, políticas, educativas, religiosas) que son inevitables y dentro de ellos se recrean y reafirman los ritos de paso.

La interacción social es de hecho quien permite que ellos subsistan y según muchos autores es el deseo humano de trascender. Es a través de ellos que lo mágico y simbólico de los antepasados puede sobrevivir y proyectarse al futuro porque ellos constituyen la representación de sentimientos colectivos de un grupo de individuos inclinados a aproximarse e identificarse.

\subsection{Los ritos practicados en los pueblos indígenas de Mesoamérica}

A inicios del siglo $\mathrm{XX}$, los ritos practicados por los indígenas latinoamericanos eran considerados como símbolo de atraso y para muchos, como lo es el caso del estudio realizado por Enríquez (1909) en México denominado: Los grandes problemas nacionales, expone la preocupación de los intelectuales del país por las prácticas religiosas antiguas que practican los indígenas en México. Incluso llegó a considerarlos como el principal obstáculo para la integración nacional y el desarrollo (Oseguera, 2008). Conforme las nuevas teorías antropológicas y etnográficas iban llegan a Latinoamérica de Estados Unidos y Europa fue cambiando la perspectiva de las prácticas rituales indígenas y el campo de investigación fue mucho más profundo y fructífero.

Para el caso guatemalteco es importante mencionar que se han identificado 23 grupos culturales en los cuales el $90 \%$ son de ascendencia del grupo cultural maya. Éstos comparten espacios geográficos y elementos históricos que les permiten cierta cercanía. A cuenta de ello surge una amalgama de costumbres, tradiciones y una considerable variedad de ritos que son practicados 
en comunidades ubicadas en los 334 municipios del país. Dentro de los principales atractivos turísticos pueden contabilizarse la variedad ecológica y cultural.

Estos rituales son practicados en diferentes épocas y ocasiones a lo largo de año. Sin embargo existe un rito en el que la mayoría de ellas coincide y éste es el rito practicado para dar la bienvenida a la época de invierno. A pesar de la heterogeneidad de las prácticas dentro de cada grupo cultural, el evento de la entrada del invierno es esperado con similar devoción por los campesinos guatemaltecos. Esto porque el día 15 de Mayo, día de San Isidro Labrador se marca el inicio de la época de siembra, no solo de la semilla del producto agrícola que permitirá la supervivencia familiar; sino de la vida misma, de la esperanza y la fe de un futuro. 
Las novatadas como una práctica estudiantil

\section{CAPÍTULO 4: LAS NOVATADAS COMO UNA PRÁCTICA ESTUDIANTIL DE CONSUMO CULTURAL O DE INTEGRACIÓN A LA VIDA ESTUDIANTIL UNIVERSITARIA}

Los jóvenes se integran a la universidad por medio de diversas prácticas, entre ellas destacan las institucionales (procedimientos y trámites escolares) las disciplinares y por su puesto las prácticas de socialización (Ramos, 2011).

Si se analiza a profundidad puede concluirse que la universidad es mucho más que una casa de estudios y que más bien representa una comunidad académico-humana encargada de la formación integral del hombre. Es importante no restringir su accionar exclusivamente a la formación intelectual y profesional porque debe ocuparse de un fin mucho más espléndido e integral en donde su ideal debe ser integrar todos los elementos propios de la actividad humana (Alonzo, 2012). El papel de la Universidad de San Carlos en Guatemala es importante desde la perspectiva que de sus aulas egresan profesionales que han de estar fielmente comprometidos con las necesidades de la población, por cuanto ella ha financiado sus estudios.

Corresponde a los universitarios desarrollar el pensamiento creativo, innovador en un ambiente de respeto y sobre todo tolerancia a las diferentes corrientes del pensamiento y manifestaciones culturales; considerando las características pluriculturales de la nación. Dentro de los valores que deben promoverse entre los universitarios destacan, según Alonzo (2012) los cinco siguientes: libertad, justicia, tolerancia, autonomía y creatividad expresándolos en todas las ramas del saber y del arte. En Guatemala el sector universitario es privilegiado desde muchas perspectivas. El estudiante es privilegiado porque sus estudios son financiados (en alto porcentaje) por el estado; el profesor porque puede expresarse libremente pues su accionar no está comprometido con ninguna corriente del pensamiento en particular. 
El reto de los profesionales universitarios en Guatemala es fuerte porque la dinámica social en este país es convulsa. La Historia denuncia gobiernos de corte militar, treinta y seis años de conflicto armado interno e intentos de Revolución, entre algunos de los eventos catastróficos para el país. Así mismo el crecimiento de la densidad poblacional coloca al país en una situación problemática en cuanto al manejo y conservación de los recursos naturales renovables y no renovables. Los grupos sociales se organizan alrededor de tales recursos. Los profesionales universitarios no sólo deben cambiar para adaptarse, sino que deben asumir el reto de una formación integral para tener control sobre el progreso tecnológico y hacer reducir la violencia en un país que tiene la cuarta ciudad más violenta del mundo. Por esta razón hemos considerado que los hechos violentos y agresiones físicas de estudiantes contra estudiantes durante las diversas celebraciones universitarias deberían ser visualizados desde diversas perspectivas.

Las acciones violentas de las cuales dan cuenta los medios de comunicación y las expresiones de repudio de diversos sectores de la sociedad son una voz de alerta que debe motivar a diversos sectores de la sociedad sancarlista a abrir los ojos ante la realidad. No porque se niegue un hecho, este dejará de existir, así que es mejor abrir los ojos e iniciar a abrir brecha en este tipo de investigación. De estos hechos se hace un recuento histórico en el marco referencial de la presente Tesis Doctoral. Esto porque según nos muestran diversos autores como lo es el caso de Baridón (2010) es muy difícil establecer las causas de la violencia escolar sin tomar en cuenta el contexto de la propia institución educativa.

\subsection{La importancia de las novatadas como un mecanismo de socialización entre jóvenes}

En la actualidad la vida moderna ofrece una complejidad en la que muchos jóvenes no logran encajar ni encontrar momentos de encuentro con sus padres o maestros. Cada adulto está muy 
ocupado, viviendo su propia vida y afrontando diversos retos. Naturalmente los padres, maestros y tutores son quienes tienen mayores posibilidades de encontrar esa cercanía con los jóvenes estudiantes. Sin embargo esa posibilidad disminuye cuando socialmente se acepta que la comunicación con los adultos ya que no es relevante.

Hoy en día muchos jóvenes encuentran más respuestas a sus preguntas en Internet o en las redes sociales que de los adultos que deberían orientarlos. Probablemente sean respuestas que no den una solución viable e inteligente a sus problemas, pero esa es la realidad. Los jóvenes se han convertido en el agente de mayor socialización para sus semejantes. He allí la importancia de prestar mayor atención a los mecanismos empleados por la comunidad universitaria para socializar. Las prácticas (por aberrantes que sean) se convierten en cíclicas, de carácter permanente y sobre todo la misma práctica aporta a legitimarlos.

García (2002) opina que en la actualidad se han multiplicado los nuevos espacios de socialización donde se cultivan la integración e identidad, completando - y en ocasiones, desplazando- los lugares tradicionales de la familia, la escuela y las iglesias. Los jóvenes coinciden en que los amigos constituyen el entorno más cercano y válido. Principalmente porque proporciona las mayores satisfacciones vitales y, tal vez, las convicciones más firmes. Se viene anunciado que la modernidad exalta los derechos y eclipsa los deberes. Hay quien piensa que de este atolladero sólo nos podrá sacar una pedagogía autoritaria, que haga mayor hincapié en los compromisos a cumplir; y no falta quien propone una Declaración Universal de los Deberes Humanos para salir del naufragio colectivo. ¿Qué mayor solidaridad cabe que la vigencia de los Derechos Humanos? Según Domínguez (2012) cualquier debilitamiento de los derechos humanos es, simultáneamente un atentado a la solidaridad.

En la actualidad entre los jóvenes hay un hiatus, una falla entre los valores finalistas y los valores instrumentales, los actuales jóvenes invierten afectiva y racionalmente en los valores finalistas (pacifismo, tolerancia, ecología, exigencia de lealtad, etc.), a la par que presentan, sin 
embargo, grandes fallos en los valores instrumentales, sin los cuales lo anterior corre el gran riesgo de quedarse en un discurso bonito: sin esfuerzo, sin auto-responsabilidad, sin compromiso o abnegación, las metas son capítulos de la retórica.

Según estudio realizado por Roldán (2010) en escuelas normales de educación media en Guatemala, las agresiones entre estudiantes son frecuentes y de diferente índole: física, robo de tareas, lanzamiento de objetos, prácticas de racismo y discriminación, uso de sobrenombres, insultos, menosprecios, exclusión de grupo, ignorar, violación a la intimidad de las personas, escupir, empujar, etc. Todas estas acciones llevan a los agredidos a experimentar cuadros de angustia, dolor, que en casos extremos les han llevado al suicidio.

En Latinoamérica la investigación es mucho más reciente y se apoya en importantes estudios realizados en Inglaterra, Irlanda, Suecia y España, así mismo en algunos realizados en Estados Unidos de América. Sin embargo se han realizado investigaciones en países como: Chile, Brasil y Argentina (Abramovay, 2005; Berger, 2009; Cabrera Murcia, 2005; García y Madriaza, 2005 y Di Leo, 2009).

Ortega et al. (2001; citado por Baridón, 2009) considera que es importante hacer una diferenciación entre las manifestaciones esporádicas de comportamiento antisocial y violencia interpersonal aunque reconoce que ambos representan un componente agresivo. Puede considerarse que existe violencia en el ámbito educativo cuando hay un problema de violencia interpersonal, injustificada. Así mismo cuando una persona o grupo de personas se ve insultada, físicamente agredida, socialmente excluida o aislada, acosada, amenazada o atemorizada por otros que realizan impunemente sobre la víctima estos comportamientos. 


\subsection{Efectos de la violencia escolar}

Los efectos de la violencia en este ámbito son múltiples y profundos; así mismo escurridizos al análisis considerando que aún el mismo término de violencia, en general, es de difícil conceptualización debido a sus múltiples expresiones concretas, cultura, tradición y aún la misma época histórica y más recientemente la era tecnológica donde se dan esas manifestaciones. Por esa razón una de las lecciones aprehendidas de los diversos estudios realizados en la última década es que tales estudios deben abordarse de una manera integral.

Los estudios de Abramovay (2005) demuestran que sin duda alguna la violencia es uno de los elementos que tienen incidencia directa en la baja calidad del proceso enseñanza-aprendizaje señalando que desde ese punto de vista, todos somos víctimas, porque nuestras vidas cotidianas se ven alteradas por instituciones educativas que se han convertido en verdaderos campos de batalla. Otros autores como Ortega y Mora-Merchán (1997) citados por Barragán (2010) señala que como respuesta a la violencia escolar las víctimas pueden padecer: daño físico (lesiones) e incluso la muerte (a través del suicidio).

Así mismo otro tipo de afecciones de salud como enfermedades psicosomáticas (depresión, baja autoestima o secuelas postraumáticas). En general este tipo de consecuencias les impide a los agredidos y agresores tener buenas relaciones con sus iguales y se ha determinado que con frecuencia éstas pueden ser: uso de sustancias adictivas, ausentismo escolar, autolesión y relaciones sexuales prematuras o violentas. La intimidación entre iguales en la escuela secundaria es una manifestación de la búsqueda de identidad. En estas edades la son prioritarias la autoestima y la filiación grupal.

Ramos (2008) opina que los estudiantes que han sido víctimas de acoso sufren de episodios de nerviosismo, estrés, insatisfacción con la vida, depresión e insatisfacción con la vida en general y 
aunque frecuentemente, tratan de ocultarse, tarde o temprano surgen y deben ser atendidas por especialistas en el campo de la Psicología.

\subsection{Las novatadas alrededor del mundo}

De manera general las novatadas o bautizos son todas aquellas actividades que son diseñadas y practicadas por un grupo de estudiantes antiguos para recibir a los estudiantes novatos para su admisión o afiliación a cualquier organización estudiantil. La característica esencial de estas actividades es que no hay ningún tipo de contribución al desarrollo positivo de la persona. Por el contrario pueden tener la intencionalidad explicita o no de provocar daño de tipo físico, mental. Ello porque puede degradar y deshonrar a la persona, sin su consentimiento ${ }^{12}$.

En este capítulo es oportuno mencionar el interesante trabajo que fuera realizado por Leflaive (2003) acerca del bizutage un ritual de bienvenida o novatada, practicado en las escuelas superiores más prestigiosas en el ámbito francés. Leflaive nos hace reflexionar relativo a que las novatadas provocan diferentes reacciones sociales y crean controversia. Analiza el fenómeno en sí, interpretando los elementos simbólicos y sociales del bizutage. Presta especial atención al espacio, tiempo, actores, lenguaje y sistema de pruebas y castigos. Este análisis lo realiza muy oportunamente debido a que recientemente se había prohibido el bizutage en Francia.

Considerando que este ritual es practicado en las instituciones de enseñanza superior más prestigiosas de Francia, representa un contraste con el imaginario colectivo que de tales instituciones tiene la opinión pública. Se supone que son los estudiantes con mejores actitudes y aptitudes del país, de tal forma que es difícil imaginárselos inmersos en actividades que provocan desórdenes, escándalo e irracionalidades. Es organizado por los estudiantes veteranos en los cuales

\footnotetext{
${ }^{12}$ Definición de acuerdo a las campañas denominadas: Stophazing, implementadas en los estados de Alaska, Hawaii, Migchigan, Montana, Nuevo México, Dakota y Wyoming de los Estados Unidos de América.
} 
durante tres o cuatro meses someten a los estudiantes de primer ingreso -bizuts- a duras y hasta crueles pruebas. En algunos casos las pruebas son de carácter individual y en otras de carácter colectivo. Así mismo en algunas ocasiones las pruebas son realizadas dentro de las instalaciones de los centros educativos y en algunos otros invaden los espacios públicos. Agregando de esta manera el elemento de humillación pública.

Muchos han escrito acerca de los ritos de paso, pero existe un trabajo en particular que ha resistido el paso del tiempo y que se ha convertido en un clásico al demostrar que tiene aplicabilidad en diferentes momentos históricos y geográficos, este es el caso del trabajo de Arnold Van Gennep y su brillante trabajo publicado en el año 1960, denominado: Los Ritos de Paso (Hendry, 1999).

En esta obra clásica queda muy claro que los ritos de paso tienen un elemento en común y es el movimiento, lo que muchos autores han denominado: la promoción. Gennep y algunos otros hace hincapié en la transición de un estado primitivo a un estado superior, uno deseable.

Generalmente este movimiento va de una condición inferior a una superior o deseable. Gennep establece cuatro tipos de movimientos o pasos, siendo los siguientes:

\begin{tabular}{|l|l|l|l|}
\hline No. & Condición Inicial & Condición Final & $\begin{array}{l}\text { Evento/ Tipo de } \\
\text { movimiento }\end{array}$ \\
\hline 1 & Soltería & Casado & $\begin{array}{l}\text { Matrimonio/Movimiento de } \\
\text { un estado a otro }\end{array}$ \\
\hline 2 & Punto geográfico original & $\begin{array}{l}\text { Punto geográfico de } \\
\text { destino }\end{array}$ & $\begin{array}{l}\text { Viaje/ Movimiento de un } \\
\text { lugar a otro }\end{array}$ \\
\hline 3 & Desempleado & Empleado & $\begin{array}{l}\text { Trabajo/Movimiento de una } \\
\text { condición a otra }\end{array}$ \\
\hline 4 & Año viejo & Año Nuevo & $\begin{array}{l}\text { Celebración de fin de } \\
\text { año/Movimiento o cambio } \\
\text { en el tiempo }\end{array}$ \\
\hline
\end{tabular}

Cuadro 7. Ritos de paso en los cuales se da una transformación simbólica.

Fuente: Creación personal con datos de Hendry (1999).

En el tema de las novatadas o bautizos este autor concluye que el ritual tiene como objetivo recordar a los presentes qué posición ocupan exactamente cada uno de ellos en relación con los 
demás y en relación con un sistema amplio. Es evidente quien tiene el poder y las consecuencias que pueden llegar a sufrir aquellos que se revelen contra lo que tradicionalmente se ha establecido y practicado. Sin embargo dentro de estas prácticas existen actores que tienen un papel intermedio con respecto al poder. Por esa razón describiremos el papel de los intermediarios o padrinos. Arnold Van-Gennep (1986) opina que el papel que juegan los intermediarios es indispensable para la culminación exitosa del rito de pasaje porque ellos son los responsables de guiar a los iniciados por la senda que hay que transitar para lograr el fin último de transformación.

Estos personajes pueden ser considerados como la cadena o vínculo esencial para dar el paso importante dentro de la transformación. El término padrino adquiere, según el contexto, muchos otros significados. Uno que nos interesa especialmente es el de valedor, garante y protector del iniciado dentro del nuevo grupo. Sin embargo no siempre son únicamente los responsables de hacer que todo salga bien, sino que además son el puente, la cadena o el vínculo que facilita a los que cambian de estado el paso sin sacudidas sociales violentas.

En las culturas primitivas y según la cosmogonía; la repetición simbólica de esas prácticas es de gran importancia porque se recupera toda la magia y el poder (de los dioses) del hecho primigenio de los tiempos antiguos. Esta es una de las razones por las cuales los ritos deben ser preservados porque ellos contienen toda la magia, todo lo sagrado de los primeros tiempos, de los creadores (generalmente seres muy superiores). Constituyen la esencia, el sentir y los elementos que cohesionan a los miembros de un grupo social.

Si se anulan tales prácticas y se olvida lo que colectivamente tiene sentido (la razón de ser) se avanza un paso más hacia la despersonalización y deshumanización de la sociedad. Será entonces vivir por vivir, el tiempo transcurrirá tras la simple satisfacción de las necesidades elementales (el trabajar para comer, para acumular) y se perderá la creatividad que distingue a los seres humanos de las bestias del campo. 
La muerte iniciática es indispensable para el inicio de una vida espiritual. El hombre no nace debe ser hecho y en ese fin acuden a su auxilio los ancianos de la comunidad aquellos que ya se encuentran investidos de ese poder espiritual. En este tipo de ritual la muerte simbólica se encuentra representada por la oscuridad (estado embrionario) que permitirá germinar como una nueva criatura investida de autoridad espiritual(Leflaive, 2003). Realiza un análisis antropológico y pone de relieve la naturaleza política del ritual, concluye que es un verdadero rito de iniciación esencial para la reproducción de un sistema de estratificación social de los Grandes E-coles de Francia.

Gracias a la práctica se permite fabricar internamente la adhesión a valores y representaciones para fomentar la solidaridad entre sus miembros, necesaria y fundamental para el funcionamiento del sistema y para su cohesión. De esta manera se reafirma y fomenta la competición entre especialidades e instituciones. En otro sentido también se reafirma una jerarquía de poder fuerte, útil para que el sistema funcione. A pesar de ello el bizutage fue terminantemente prohibido y se ignora la contradicción esencial del sistema de educación superior en Francia. Para el autor la prohibición del ritual podría provocar consecuencias importantes para el funcionamiento de la enseñanza superior en Francia, aunque sea difícil prever la naturaleza de los cambios que se producirán.

En otro ámbito geográfico, Echague y Conquero (2014) realizaron una investigación en donde reportaron que el Senado español aprobó por unanimidad una moción presentada por el Parlamento Popular cuyo objetivo es prevenir y erradicar las novatadas de la sociedad y ámbito estudiantil. Esto por considerarlas peligrosas prácticas universitarias, aunque éstas también son comunes en los llamados Colegios Mayores. Presentaron un documento denominado: Manifiesto de Colegios Mayores que tiene como fin último promover la tolerancia cero con las novatadas. Las acciones concretas implementadas por el Senado español son las siguientes: i) Apoyar el Manifiesto de Colegios Mayores de España que tiene como objetivo erradicar las novatadas del ámbito social y 
universitario. ii) Colaboración con las Comunidades Autónomas para promover campañas de divulgación y sensibilización de la normativa que regula las novatadas. iii) Apoyar, defender y proteger a las familias y víctimas de novatadas.

Los Colegios Mayores han considerado que es necesaria la ejemplaridad en el castigo a los infractores de la noción ya señalada, porque aunque anterior a ella existían algunos mecanismos para detectar a los agresores y castigarlos, éstos eran blandos. El señor Luis Aznar portavoz de Interior, declaró que la promoción de aprobación de una Ley que prohiba las novatadas en España deberá estar a cargo de los Ministerios de Educación e Interior, Echague y Conquero (2014). En el cuadro 5 presentamos las prácticas más comunes en las novatadas celebradas en los colegios mayores de España.

Como podemos observar en el cuadro 8hemos clasificado las prácticas más comunes en las novatadas españolas de acuerdo al tipo de daño que provocan. Así por ejemplo algunas prácticas atentan en contra de la integridad física de los estudiantes, aunque eso no excluye que puedan provocar daño el aspecto de la imagen que el individuo pueda tener de sí mismo. En el caso de la ingesta de bebidas alcohólicas el daño físico está claramente identificado, pero dependiendo del carácter, género y circunstancias en las cuales el alumno fue obligado a beber (en el caso que efectivamente haya sido obligado) dependerá el grado de malestar provocado a nivel psicológico.

El Consejo Nacional de Colegios Mayores de España y la Universidad de Comillas, financiaron una importante investigación realizada magistralmente por las profesionales en el campo de Psicología Ana Aizpún y Ana García, titulada: “Novatadas, comprender para actuar”. Se consideró que un estudio serio sobre las novatadas en España era indispensable. Ello porque es evidente que antes de perseguir legalmente los delitos cometidos durante la celebración de las novatadas es necesario comprenderlas y comprobar que no son simples bromas y que sus efectos perniciosos son de carácter permanente. 


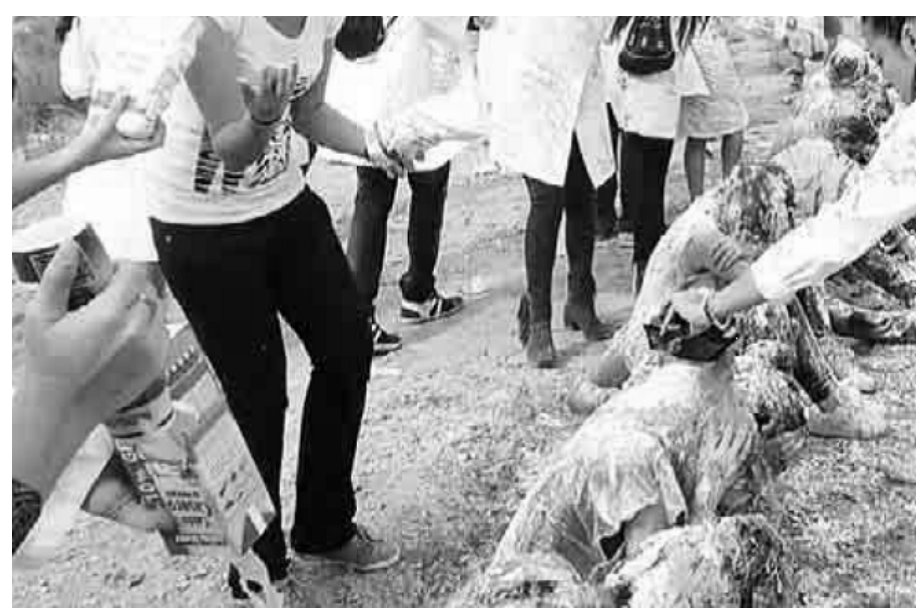

Figura 7. Las novatadas en España.

Fuente: Artículo publicado en el diario español, La Razón, de fecha 02 de Octubre de 2014.

La investigación realizada por ambas profesionales no fue fácil pues fue necesario romper las barreras existentes para la captura de información objetiva y superar la denominada Ley del Silencio, en donde se establece que si "vas a hablar de novatadas, que sea para defenderlas", como expresaron algunos estudiantes españoles que fueron entrevistados. 


\begin{tabular}{|c|c|c|c|c|}
\hline No. & Práctica & $\begin{array}{l}\text { Daño } \\
\text { emocional }\end{array}$ & $\begin{array}{l}\text { Contenido } \\
\text { sexual }\end{array}$ & $\begin{array}{l}\text { Daño } \\
\text { físico }\end{array}$ \\
\hline 01 & $\begin{array}{l}\text { De rodillas, les meten un embudo en la boca y les echan sangría o vodka a } \\
\text { chorros hasta que caen mareados. }\end{array}$ & $\mathrm{X}$ & & $\mathrm{X}$ \\
\hline 02 & $\begin{array}{l}\text { Usan a los novatos de ceniceros en las habitaciones de los «veteranos» que } \\
\text { fuman. Están toda la noche con la mano extendida para recoger la ceniza. A } \\
\text { veces, la ceniza se les echa en la boca. }\end{array}$ & $\mathrm{X}$ & & $\mathrm{X}$ \\
\hline 03 & Beber vinagre, vino mezclado con posos de café y/o gel de baño. & & & $\mathrm{X}$ \\
\hline 04 & Duchas de agua fría, juntos o separados (los novatos), desnudos o vestidos. & & $\mathrm{X}$ & $\mathrm{X}$ \\
\hline 05 & Tienen que lavarse los dientes con la escobilla del WC. & $\mathrm{X}$ & & $\mathrm{X}$ \\
\hline 06 & Los desnudan y les depilan las piernas. También les rapan el pelo. & $\mathrm{X}$ & $\mathrm{X}$ & $\mathrm{X}$ \\
\hline 07 & $\begin{array}{l}\text { Les ponen grapas de papelería en la piel si es que se han producido lesiones } \\
\text { por otras novatadas. }\end{array}$ & & & $\mathrm{X}$ \\
\hline 08 & $\begin{array}{l}\text { Les pintan un testículo de verde y el otro de rojo. Tienen que hacer de } \\
\text { semáforo. }\end{array}$ & $\mathrm{X}$ & $\mathrm{X}$ & $\mathrm{X}$ \\
\hline 09 & $\begin{array}{l}\text { Son llevados a la Puerta del Sol o a otros sitios céntricos para practicar el } \\
\text { «tartazo al novato». A } 1 \text { euros el tiro. Hubo una señora que pagó } 10 \text { euros }\end{array}$ & $\mathrm{X}$ & & $\mathrm{x}$ \\
\hline 10 & $\begin{array}{l}\text { El pringue. Les hacen pasar por un pasillo humano donde se les azuza y, entre } \\
\text { gritos, se les arrojan huevos y harina. Otras veces, se arrojan sustancias } \\
\text { altamente peligrosas, como disolventes o sosa cáustica }\end{array}$ & $\mathrm{X}$ & & $\mathrm{X}$ \\
\hline 11 & $\begin{array}{l}\text { Tumbados los novatos, les ponen una cereza o una manzana en la entrepierna } \\
\text { o el ombligo. Los novatos del otro sexo, arrodillados y sin usar las manos, } \\
\text { tienen que comer la fruta en cuestión. Por lo visto, a esto se apuntan muchos } \\
\text { veteranos. }\end{array}$ & $\mathrm{X}$ & $\mathrm{X}$ & \\
\hline 12 & Desplazarse con las nalgas desnudas por el suelo. & $\mathrm{X}$ & $\mathrm{X}$ & $\mathrm{X}$ \\
\hline 13 & $\begin{array}{l}\text { Servir comidas a los veteranos. Las novatas tienen que sentarse en el regazo } \\
\text { de los veteranos y darles la sopa con la cuchara. }\end{array}$ & $\mathrm{X}$ & $\mathrm{X}$ & \\
\hline 14 & $\begin{array}{l}\text { Tirarse por un terraplén o encima de unos setos. Acaban heridos y } \\
\text { ensangrentados. }\end{array}$ & $\mathrm{X}$ & $\mathrm{X}$ & \\
\hline 15 & $\begin{array}{l}\text { Los novatos son obligados a tragarse una cucharada de vómito de otra } \\
\text { persona. }\end{array}$ & $\mathrm{X}$ & $\mathrm{X}$ & \\
\hline 16 & Les hacen cantar el «Cara al sol» y gritar «Franco es mi Dios». & $\mathrm{X}$ & & \\
\hline 17 & $\begin{array}{l}\text { Las novatas tienen que desnudarse, en mayor o menor medida, y «seducir» a } \\
\text { los novatos, a quienes, a menudo, meten un plátano en la bragueta para que } \\
\text { lo apriete contra la chica. }\end{array}$ & $\mathrm{X}$ & $\mathrm{X}$ & \\
\hline 18 & $\begin{array}{l}\text { Se le coloca un plátano en la bragueta al novato. Una novata, de rodillas, tiene } \\
\text { que similar una felación. }\end{array}$ & $\mathrm{X}$ & $\mathrm{X}$ & \\
\hline 19 & Los veteranos les gritan: «iEsclavos!», «negros»... & $\mathrm{X}$ & & \\
\hline 20 & Se echan monedas al WC para que los novatos las «pesquen» con la boca. & $\mathrm{X}$ & & $\mathrm{X}$ \\
\hline
\end{tabular}

Cuadro 8. Las novatadas más frecuentes en España, de acuerdo al daño que provocan.

Fuente: Creación personal con datos del sitio Web https://www.google.com.gt/webhp?ei=dDGaVPbsLoexggSvIKgBg\&ved=0CAYQqS4oBA\#q=DIARIO+LA+RAZON+MAYOR+PRESENCIA+POLICIAL+EN+NOVATAD AS+ESPA\%C

Existía gran interés por mantenerlas en la clandestinidad; a los agresores les convenía porque de esa manera se liberaban de la posibilidad de ser juzgados y castigados por los abusos y los segundos porque tenían miedo de recibir castigos mayores de parte de sus agresores. Esto es comprensible si tomamos en cuenta que muchas de estas prácticas se realizaban en los Colegios 
Mayores españoles en donde el sistema educativo ofrece condiciones para el estudiante viva en un complejo habitacional que es parte del mismo establecimiento educativo.

La búsqueda de información objetiva para poder documentar el fenómeno de las novatadas fue el principal objetivo de esta valiosa investigación. Principalmente porque "el maltrato, el acoso, el abuso, sometimiento gratuito, humillación y vejación; nunca pueden ser justificados y menos aún bajo los argumentos que son diversión o bien en aras de una malentendida integración” (Aizpún y García-Mina, 2013, p. 10).

Se entiende que el que el novato que se queja con las autoridades o tan solo que osaba comentar acerca de ellas fuera del círculo educativo, era un cobarde y sobre todo una persona que no era digna de confianza y mucho menos de respeto. Por esta manera fue tan difícil actuar legalmente para prohibir las novatadas. Gracias al estudio mencionado en los párrafos anteriores fue revelada importante información relativa a: los principales actores y actitudes de los mismos, los perfiles de los agresores, las causas, los efectos y mucha información que fue la base para la toma de decisiones importantes. Las decisiones que se tomaron fueron drásticas pues fueron terminantemente prohibidas.

Aizpún y García-Mina (2013) definen las novatadas como: “cualquier situación que se da en un grupo en el que se considera que hay miembros que tienen poder (los antiguos) y otros miembros que no lo tienen (los recién llegados) que fuerza a estos últimos a cometer actos (normalmente degradantes) para ganarse el acceso a la organización o para ser “estimados” dentro de la misma”. Para las autoras de la investigación citada en este párrafo las novatadas son realidades estructurales cuya principal característica es que son injustas y violentas. En ellas se establece una relación de poder-sumisión, independientemente de su nivel de violencia, consecuencias o intencionalidad de la misma. Finalmente consideran que es un error considerar que son hechos inofensivos. 
El siguiente cuadro contiene uno de los aportes, que a nuestro parecer, son de mayor importancia en el contexto de la comprensión de las novatadas.

\begin{tabular}{|l|l|l|}
\hline Tipo de agresión. & Descripción & Algunos ejemplos \\
\hline Física & $\begin{array}{l}\text { Aquellas que implican el uso intencional } \\
\text { de la fuerza contra otra persona o la } \\
\text { coacción hacia la víctima para que ponga } \\
\text { en riesgo su integridad física. }\end{array}$ & $\begin{array}{l}\text { Golpear, empujar, arrojar objetos os } \\
\text { sustancias peligrosas (huevos, harina, } \\
\text { detergente). } \\
\text { Obligar a la ingesta de alimento u otras } \\
\text { sustancias en descomposición (mezclas con } \\
\text { vinagre, orina, heces, vómito de otra } \\
\text { persona), bebidas alcohólicas, etc. } \\
\text { Obligarlos a desnudarse y mantenerse así } \\
\text { expuestos a temperaturas extremas. } \\
\text { Utilizarlos de cenicero. }\end{array}$ \\
& $\begin{array}{l}\text { Acción intencionada que tiene el objetivo } \\
\text { de humillar, controlar, asustar } \\
\text { manipular. }\end{array}$ & $\begin{array}{l}\text { Insultos } \\
\text { Amenazas implícitas o explícitas. } \\
\text { Vejación de la integridad moral. } \\
\text { Obligar al novato a realizar actividades } \\
\text { vergonzosas o referirse a sí mismo como una } \\
\text { "mierda". }\end{array}$ \\
\hline Sexual & $\begin{array}{l}\text { Conllevan a forzar cualquier conducta en } \\
\text { un individuo que implique un acto de } \\
\text { naturaleza sexual. }\end{array}$ & $\begin{array}{l}\text { Obligar a la desnudez total o parcial, privada } \\
\text { o pública. } \\
\text { Coaccionar al nuevo para que simule actos } \\
\text { sexuales con objetos u otras personas. }\end{array}$ \\
& & \\
\hline
\end{tabular}

Cuadro 9.Tipos de agresión que se ejercen durante la práctica de las novatadas.

Fuente: Creación personal con datos de Aizpún y García-Mina (2013).

La Secretaría de Educación del Distrito Federal de México realizó en el año 2011 un trabajo que consistió en formular y ejecutar un programa de intervención, protección y protección de los derechos de los niños/niñas y jóvenes en edad escolar como parte del Observatorio Mexicano sobre convivencia escolar. Es importante destacar el hecho que según Olweus (1978) citado por (Avilés y Monjas, 1999) expresan que para poder identificar objetivamente el bullying entre estudiantes es necesario comprender que las acciones intimidatorias deben ser sostenidas en el tiempo. Así mismo que debe identificarse claramente una relación de poder víctima-agresor.

En este caso las novatadas presentan estas características siendo, institucionalizadas, de cierta manera cuando las autoridades administrativas autorizan una suspensión de las actividades docentes y administrativas para dar paso a la celebración de la bienvenida, como se le ha llamado. 
Consideramos importante incluir dentro de la presente Tesis Doctoral experiencias en ámbitos geográficos de América Latina, por lo que a continuación presentamos los resultados del estudio realizado por Ramos y Vásquez (2011) en el Centro Universitario de los Altos de Guadalajara, México.

El objetivo del mismo fue conocer la percepción que los estudiantes tienen de la violencia en el ámbito universitario y determinar si tienen disposición a participar en un programa para mejorar la interacción estudiantil. Los investigadores realizaron los estudios convencidos que los múltiples problemas que el psicólogo de la universidad debía atender, se relacionaban con: agresiones entre estudiantes, insultos, gritos y conductas amenazadoras. La investigación fue muy amplia pues también exploró expresiones de violencia de parte de los profesores, autoridades y personal administrativo en contra de los estudiantes. Llegando a la conclusión que dentro de las maneras más preocupantes de violencia entre estudiantes se encuentra el reconocido como bullying y agresiones de los profesores a los estudiantes.

Entre las agresiones más frecuentes entre estudiantes se pueden enumerar: hacer la carretilla (burlas constantes) insultos, apodos, gritos y discusiones; algunos autores como Spitzer (2004) reconocen en ellas únicamente manifestaciones lúdicas. Señala que los estudiantes están acostumbrados a hablar con groserías por lo que puede considerarse únicamente como una muestra de masculinidad; sin embargo en este caso la población estudiantil es mayoritariamente femenina. A pesar de ello las mujeres muestran igual facilidad para hablar de la misma manera por lo que los expertos señalan que esto puede ser una muestra de empoderamiento. Sin embargo el estudio permitió detectar actos que implican violencia física, entre ellos: golpes y acoso sexual.

Abramovay (2011) citado por (Ramos y Vásquez, 2011) señala que el bullying genera una atmósfera negativa que tiene efectos del mismo tipo que inciden directamente sobre la calidad de la enseñanza y el desarrollo académico porque afecta el desempeño del equipo técnico-pedagógico. 
Otras de las consecuencias señaladas es que modifica la idea y confianza que los estudiantes tienen de la administración escolar y modifica las impresiones relativas a sus propios colegas.

En el caso de Estados Unidos de Norteamérica las novatadas (denominadas: Hazing en idioma inglés) tienen un antecedente histórico importante en las escuelas militares del país. Las pruebas físicas están a la orden del día y los novatos deben demostrar al colectivo que están capacitados para soportar las más terribles afrentas a su dignidad y sobre todo fortaleza física.

Durante la Segunda Guerra Mundial, la situación se recrudece y las novatadas se hacen mucho más populares en diversas instituciones civiles y se extienden a las fraternidades en universidades estatales y equipos deportivos. Existen documentos importantes en donde el propio novato, cansado del guardar silencio, decide romper con el mismo y escribir su autobiografía al respecto. Estos documentos son de suma importancia porque recrean la vivencia del novato y sobre todo otorgan al espectador, al estudiante antiguo y a la sociedad en general, conocer lo que el novato vive durante esos eventos.

\begin{tabular}{|l|}
\hline Prácticas sexuales \\
\hline Consumo de alcohol \\
\hline Privación del sueño \\
\hline Humillación \\
\hline Comportamientos abusivos, peligrosos e ilegales \\
\hline $\begin{array}{l}\text { En el } 50 \% \text { de los casos de novatadas en donde se reportan incidentes, al menos uno de los } \\
\text { agresores publica fotografías en las redes sociales, de tal manera que la humillación es } \\
\text { reproducida por este medio de comunicación. }\end{array}$ \\
\hline Los estudiantes reconocen las novatadas como parte de la cultura del campus. \\
\hline Menos del 10\% de los estudiantes reconocen a las novatadas como agresivas. \\
\hline
\end{tabular}

Cuadro 10. Características de las novatadas o Hazing en Estados Unidos de Norteamérica. Fuente: Creación personal de acuerdo a resultados de la investigación de Madden (2008).

Algunas recomendaciones de los investigadores: i) Diseño de esfuerzos de prevención de las novatadas involucrando a las organizaciones del campus y equipos deportivos. ii) Hacer un compromiso serio para educar a la comunidad universitaria sobre el peligro de las novatadas. iii) Los agresores tendrán que rendir cuentas. iv) Ampliar la gama de las personas que participan en los 
equipos para prevenir las novatadas. Entre ellos deben contarse profesores, estudiantes, personal administrativo y miembros de familia. v) Evaluar sistemáticamente la eficacia de los programas de prevención. vi) Hacer públicos los datos recopilados de las investigaciones relativas a las novatadas dentro de las instituciones educativas.

Finalmente para el caso guatemalteco ofrecemos un breve resumen, preliminar. El escenario que ofrece la celebración de las novatadas en la Universidad de San Carlos representa una oportunidad única de revelar la identidad colectiva y autónoma de los estudiantes; del conocimiento de sus derechos y defensa, de los valores compartidos y la manera en que se estructura y funciona este grupo social tan particular e importante.En el caso guatemalteco, se han realizado investigaciones de diversa índole que han aportado valiosa información relativa a la violencia en sus diversas expresiones como las siguientes: conflicto armado interno (acontecido entre 1960-1996) y las secuelas de éste: crimen organizado, delincuencia común y pandillas juveniles. Así mismo existen múltiples aportes en el campo investigativo de la discriminación racial, violencia de género, violencia estructural y pobreza extrema entre muchas otras. Sin embargo existen solamente algunas investigaciones que indagan acerca de la violencia entre iguales. Entre ellas destacan las de los guatemaltecos Roldán y Pérez (2010). Es así como se han aportado algunos datos concretos (denuncias, estadísticas) del daño provocado durante el acoso escolar.

Ramos y Vásquez (2011) señalan en sus investigaciones que la violencia en los centros educativos tienen una característica muy especial y es que son muy cambiantes y sofisticadas, pues se transforman al ritmo del avance de la era tecnológica por lo que tienden a tornarse paulatinamente en situaciones graves y peligrosas.

Según Allport citado por (Morales et al., 2007) es de vital importancia hacer múltiples esfuerzos por comprender y explicar la manera en que los pensamientos, sentimientos y conducta de los individuos se ve influido por el colectivo. 
Algunos defienden la celebración argumentando que es parte de la identidad sancarlista como una importante tradición estudiantil. Sin embargo diversos sectores la condenan porque consideran los vejámenes y daño material causado. Cada año ingresan a USAC miles de estudiantes que deberán transitar (obligadamente) por un difícil ritual que les investirá (simbólicamente) de nuevas características que les permitirá incorporarse a la comunidad sancarlista. Generalmente existe un estudiantes o grupo de estudiantes investidos de una real o imaginaria cuota de poder muy superior a la condición de vulnerabilidad a la que se encuentra sometida el novato quien, le guste o no, quiera o no (para el caso de algunas unidades académicas de USAC la novatada o bautizo es de carácter obligatorio) deberá pasar por tal evento.

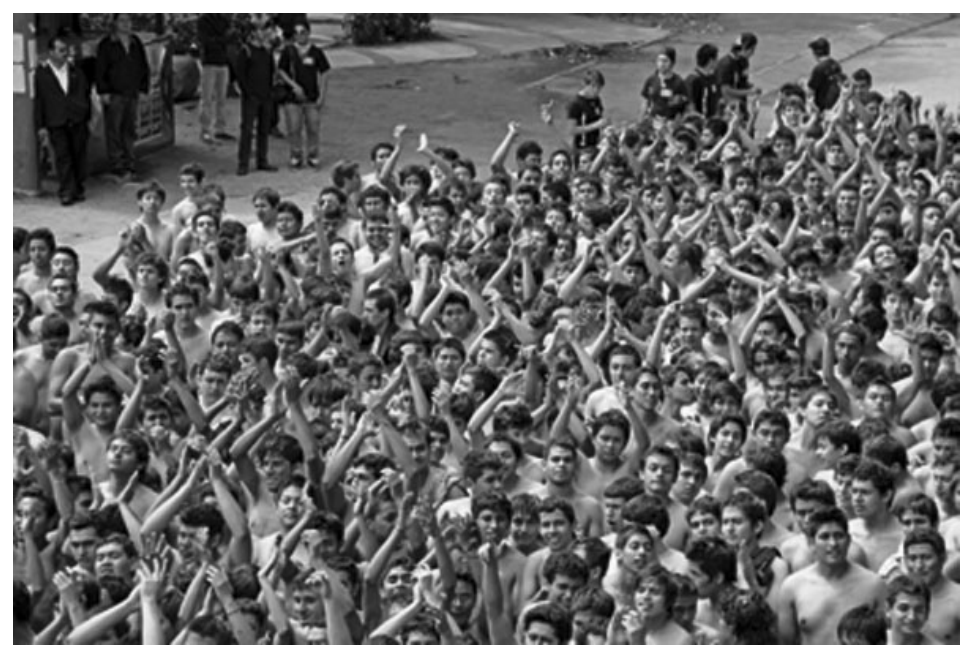

Figura 8. Estudiantes de Ingeniería de USAC, el día de su bautizo Febrero de 2014. Fuente: Creación personal, fotografía tomada el día del evento.

El sector estudiantil se ha pronunciado en reiteradas ocasiones en favor de la aplicación de medidas de control necesarias para garantizar la seguridad de los estudiantes, pero se han opuesto abiertamente al ingreso de la Policía Nacional Civil al campus universitario, argumentando que es una violación a la Autonomía Universitaria ${ }^{13}$. Estos hechos cobran especial relevancia si se considera que existe una relación estrecha entre los valores y capacidad de los universitarios de un

\footnotetext{
${ }^{13}$ Acta No. 05-2012 de fecha 14 de Marzo del año 2012.
} 
país y el abordaje científico y comprometido de los problemas sociales, económicos y políticos de la nación a la cual pertenecen y de alguna manea representan.

Los bautizos a estudiantes novatos se realizan anualmente a principios del primer semestre (de enero-febrero) de la jornada académica. Durante esta época artículos noticiosos relativos al tema hacen su aparición en los principales medios de comunicación. Algunos expresando con efusiva vehemencia su desacuerdo ante tales atropellos considerándolos muestra del grado de deshumanización en el que vertiginosamente está cayendo la población universitaria; mientras que otros aplauden las prácticas como una manifestación clara de las tradiciones de la tricentenaria universidad $^{14}$.

Lo objetivamente cierto es que en este campus universitario, ubicado en la zona central de Guatemala, se congregan miles de jóvenes universitarios de todas las regiones del país sobre quienes recae una responsabilidad histórica como la descrita a continuación. Según lo establecido en el Artículo 82 de la Constitución Política de la República "la Universidad de San Carlos de Guatemala es la única universidad estatal y le corresponde con exclusividad, dirigir, organizar y desarrollar la educación superior del Estado” (Congreso de la República de Guatemala, 1993). Señala en otra sección del mismo artículo que por la misma razón le compete la solución de problemas nacionales.

Naturalmente es lógico pensar que en cualquier lugar en donde cohabitan individuos en edades juveniles probablemente haya situaciones que promuevan el desborde de emociones y que entre ellas algunas sean muestra de la violencia colectiva. Las fiestas inter-semestrales, las actividades deportivas y los desfiles bufos ${ }^{15}$ son solamente algunas de las que en esta ocasión mencionaremos. Sin embargo por información preliminar recabada (que es presentada en el capítulo

\footnotetext{
${ }^{14}$ La Universidad de San Carlos de Guatemala fue fundada en el año de 1776.

${ }^{15}$ Tipo de desfile organizado y representado por estudiantes universitarios. En el mismo se hacen representaciones jocosas de diversos personajes de la vida pública guatemalteca con sátira, morbo y mofa. Como una expresión de las inconformidades estudiantiles.
} 
de resultados) relativa al daño físico y emocional provocado a muchos estudiantes consideramos necesario aceptar el reto de incursionar en este campo de la investigación.

Muchos son los hechos violentos que se han escrito en las páginas de la historia de la Universidad de San Carlos de Guatemala. Esto es natural en una sociedad convulsa en donde han prevalecido gobiernos de corte militar y los índices de inequidad más altos en Latinoamérica ${ }^{16}$. De hecho la Autonomía Universitaria fue concedida durante el gobierno de Jacobo Árbenz Guzmán (quien fue el promotor de la truncada Reforma Agraria de Guatemala 1952-1954). Durante las jornadas de la Revolución de Octubre (1944) la USAC obtuvo su Autonomía institucional superando la Reforma de Córdova en territorio argentino. De esta manera surgió una década de transformaciones sociales y reforma educativa.

El balance de la década entre 1944-1954 fue positivo para la universidad pues alcanzó la Autonomía y la creación de tres carreras nuevas, Humanidades, Arquitectura y Agronomía (Universidad de San Carlos de Guatemala, 2007, p. 13).

En el año de 1960 surgió en Guatemala un Movimiento insurgente denominado Movimiento Revolucionario 13 de Noviembre (MR13) así mismo las Fuerzas Armadas Rebeldes. Los estudiantes de la universidad de San Carlos de Guatemala muchos estudiantes sancarlistas fueron simpatizantes y partícipes en ambas fuerzas insurgentes. Durante el Gobierno de Méndez Montenegro se inicia a perseguir a todo aquel que tenga la menor relación con la izquierda. La casa del rector Edmundo Vásquez fue cateada en diversas oportunidades y desconocidos dispararon en repetidas ocasiones rompiendo los vidrios de los ventanales de las oficinas de Rectoría. “Otros estudiantes fueron muertos, sujetos a prisión o secuestrados, los locales universitarios allanados, dando lugar a excesos de las autoridades militares y policiales que con pretexto de la lucha contra la insurgencia se ensañaron contra estudiantes y profesionales” (Universidad de San Carlos de

\footnotetext{
${ }^{16}$ Guatemala tiene unos de los Coeficientes de Gini, más altos a nivel latinoamericano, siendo éste el equivalente a 0.82 .
} 
Guatemala, 2007, p. 11). Las páginas de los diarios se llenaron de notas que relataban tales hechos violentos y en el colectivo imaginario del pueblo guatemalteco quedó grabada la imagen de un estudiante sancarlista que lucha por las demandas populares, “que se constituye en la voz de los que no tienen voz”.

Sin embargo en la USAC contemporánea muchas cosas han cambiado. Los estudiantes que otrora fueron quienes sistemáticamente se opusieron y protestaron contra los hechos violentos que cobraron miles de vida en el país, son muchos de los que hoy en día protagonizan el derramamiento de sangre dentro de las instalaciones del campus central y sus sedes regionales. Así por ejemplo puede mencionarse como dos grupos de Asociaciones estudiantiles en la unidad académica de Ciencias Económicas protagonizaron el 12 de Febrero del año 2012 un sangriento enfrentamiento por el manejo de los fondos recaudados por la misma asociación estudiantil. En esa oportunidad un grupo de supuestos estudiantes encapuchados y armados de bates y palos golpearon violentamente a otros estudiantes dentro de las instalaciones del edificio denominado S-10 en donde actualmente se alberga a la población estudiantil de Ciencias Económicas.

En esa oportunidad los estudiantes fueron gravemente heridos y trasladados al hospital Roosevelt (hospital nacional ubicado en la zona 12 de la ciudad capital de Guatemala). En esa oportunidad se dio a conocer a los principales medios de comunicación que el hecho violento fue debido a una pugna por el poder económico de los dirigentes estudiantiles que cobran el uso de los parqueos y manejan los fondos de las asociaciones. La opinión pública no se hizo esperar y los hechos fueron descalificados sistemáticamente ${ }^{17}$.

Las pugnas por el poder estudiantil en las unidas académicas es un hecho bastante común, especialmente durante la época de la celebración de la Huelga de Dolores (durante los meses de Febrero y Marzo de cada año). El fenómeno de masificación estudiantil ha llevado a estos extremos,

17 Es posible ver el video de tal evento en la siguiente dirección electrónica: www.prensalibre.com./noticias/justicia/videos-10 USAC. 
considerando que el incremento de la población estudiantil es directamente proporcional al incremento del número de vehículos que ingresa diariamente al campus central. Cada automóvil que ingresa a los parqueos debe pagar Q3.00 (\$0.37). Según estudios realizados por estudiantes de la facultad de Arquitectura a los campus de la USAC ingresan diariamente un aproximado de 6000 vehículos, a pesar que la capacidad de los parqueos en el lugar es de 2500 automotores. Según García (2009) ello provoca que las ganancias obtenidas por el cobro de parqueos sea motivo de pugnas entre las asociaciones estudiantiles. En el campus central de USAC, son usuales las protestas por inconformidad estudiantil. Las acciones generalmente son: i) Toma de edificios. ii) Bloqueo de las dos principales puertas de acceso al campus central.

En el año 2010 el campus central fue tomado durante cincuenta y cuatro días consecutivos; paralizándose todo tipo de actividad, académica, administrativa y comercial. Ello representó pérdidas millonarias para la universidad considerando que existen unidades académicas que manejan reactivos, material perecedero, campus de cultivos (caso de Agronomía) o bien que tienen animales bajo su cuidado (tal es el caso del Centro de Estudios del Mar y Medicina Veterinaria y Zootecnia).

La serie de enfrentamientos entre asociaciones estudiantiles, el robo a mano armada, los abusos sexuales en contra de estudiantes han provocado que el Consejo Superior Universitario se pronuncie y reaccione con la puesta en Marcha de un Plan de Seguridad. Ello está fielmente documentado en el Acta No. 06-2012 de fecha 14 de Marzo del año 2012 (Ver ANEXO I). 


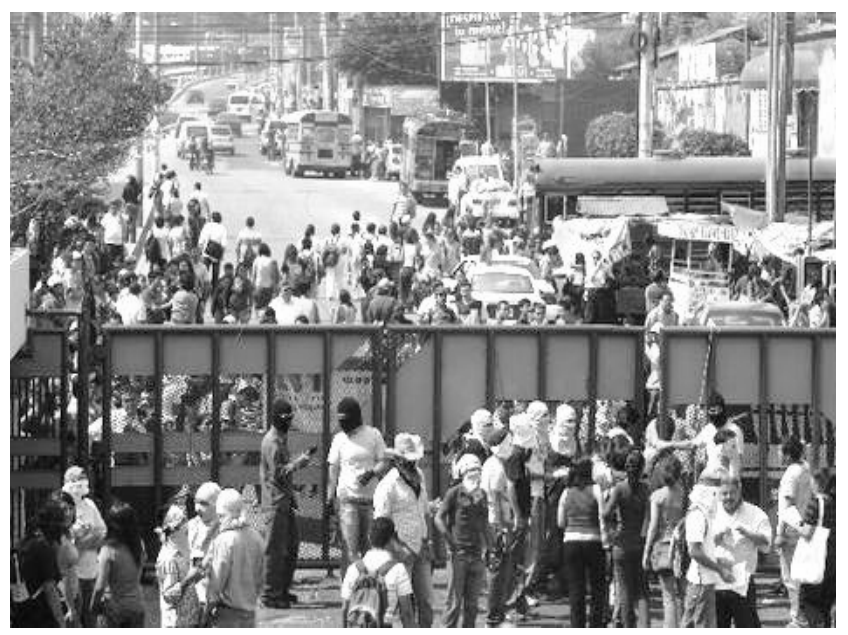

Figura 9. Toma del campus central Universidad de San Carlos de Guatemala. Fuente: Página electrónica del diario Prensa Libre.

En ella se establece un comité de Seguridad conformado por catedráticos, estudiantes y administrativos de esa casa de estudios. Una de las peticiones reiterativas de EPA (Estudiantes por la Autonomía de la Universidad de San Carlos de Guatemala) es evitar a toda costa el ingreso de la Policía Nacional Civil a las instalaciones del campus, argumentando que ello es una violación a la Autonomía Universitaria.

El secuestro de las instalaciones universitarias ha sido un problema recurrente. Recientemente, en el año 2010 el grupo estudiantil autodenominado como Estudiantes por la Autonomía -EPA-, secuestraron el campus central por un total de 54 días. 


\subsection{Las acciones tomadas por las autoridades de USAC ante la ola de violencia dentro del campus central de la universidad}

Aunque los hechos violentos siguen ocurriendo dentro del campus universitario, las autoridades administrativas y académicas se han iniciado a reaccionar en favor de la seguridad del estudiantado. Inicialmente se organizó un grupo élite encargado de sistematizar información acerca de todo tipo de hechos violentos y agresiones directas entre estudiantes. Así mismo es el encargado de diseñar e implementar un Plan de Seguridad.

En este grupo participan varios miembros del Consejo Superior Universitario (máximo órgano de dirección universitaria). El Decano de la Facultad de Agronomía es partícipe de tal grupo. Entre las acciones concretas que han venido desarrollando desde el año 2012, destacan las siguientes: i) Han ordenado a la Unidad de Asuntos Jurídicos investigar y determinar detalles acerca de los hechos violentos ocurridos entre el sector estudiantil en las Unidades Académicas de Ciencias Jurídicas y Económicas. ii)Se ha solicitado a la Dirección General de Administración que determine y presente una propuesta para el control de la portación de armas de fuego dentro del campus central de USAC. iii) Se ha contratado como asesores a especialistas en diversos temas de seguridad. 


\section{CAPÍTULO5: ABORDAJE DE LAS NOVATADAS GUATEMALTECAS, DESDE LA PERSPECTIVA LEGAL}

\subsection{La Declaración Universal de los Derechos Humanos}

Para la construcción del Marco Legal que permita realizar un análisis serio de las novatadas en Guatemala es necesario iniciar analizando lo establecido en la Declaración Universal de los Derechos Humanos del 10 de diciembre de 1948. En ella instan a los pueblos y naciones a esforzarse por promover mediante la enseñanza y educación el respeto a los derechos y libertades expresados en ellos para lograr la libertad, la justicia y la paz. En el Apéndice 6 se hace un recorrido por la normativa establecida a nivel mundial acerca de la defensa de los Derechos Humanos.

Los artículos que están se relacionan directamente con los abusos cometidos durante la celebración de las novatadas pueden ser observados en el siguiente cuadro.

\section{Artículo 1. \\ Todos los seres humanos nacen libres e iguales en dignidad y derechos y dotados como están de razón y conciencia, deben comportarse fraternalmente los unos con los otros.}

\section{Artículo 3.}

Todo individuo tiene derecho a la vida, a la libertad y a la seguridad de su persona.

\section{Artículo 4.}

Nadie será sometido a torturas ni a penas o tratos crueles, inhumanos o degradantes.

Cuadro 11. Artículos de la Declaración de los Derechos Humanos que son violentados Fuente: Programa de Naciones Unidas (2007).

En los artículos citados anteriormente se hace hincapié en que es imperativo que la condición de seres humanos y dignidad debe ser respetada. La libertad, la seguridad y sobre todo la 
dignidad como seres humanos es en cualquier punto geográfico del planeta y en cualquier condición la prioridad.

Ninguna persona (sin hacer distinción de ningún tipo) deberá ser sometido a torturas, penas ni tratos crueles inhumanos y degradantes. En la presente Tesis Doctoral consideramos necesario sistematizar las principales prácticas implementadas durante el bautizo en la Facultad de Agronomía. Para poder analizarlas a la luz de las reacciones que provocan en los diferentes actores (novatos, estudiantes antiguos, profesores, autoridades, especialistas en el tema). De esta manera se aportarán elementos claves para determinar la conveniencia o inconveniencia de las mismas, a la luz de los fines de la Cultura de Paz, que según la misión y visión de -USAC- está llamada a promover.

Existen otros documentos que han sido promulgados a nivel internacional. En esta ocasión hablaremos del Manifiesto de Sevilla que data del año de 1986.

\subsection{El Manifiesto de Sevilla}

Este importante documento fue redactado en el año de 1986 por un grupo multidisciplinario de científicos interesados en realizar reflexiones profundas y planteamientos concretos relativos a búsqueda de la paz en el mundo. El objetivo es difundir y fomentar su utilización en los programas de educación para la paz y la comprensión internacional. Este fue organizado en ocasión del Año Internacional de la Paz. Sobre todo se hizo hincapié en que en todos los tiempos de la historia de la humanidad han existido autores que afirman que "el hombre es fundamentalmente violento y egoísta” (Organización de las Naciones Unidas, 1992). Se han apoyado en la teoría de la Evolución de Charles Darwin. Estos argumentos han sido analizados y refutados por tan importante grupo de científicos, afirmando que si “el hombre puede mostrarse violento y egoísta, también es capaz de actuar de modo no-violento y cooperar con sus semejantes”. Posterior a realizar experimentos con 
Abordaje de las novatadas guatemaltecas, desde la perspectiva legal

animales (ratas, perros y lobos) llegaron a la conclusión que "la personalidad no es sólo la resultante de los genes, sino que está determinada por las condiciones de la educación y, por lo tanto del entorno social y ecológico”. Dentro de las proposiciones más importantes se encuentran las siguientes:

Es científicamente incorrecto: i) Decir que hemos heredado de nuestros antepasados una propensión a hacer la guerra. ii) Decir que la guerra o cualquier otra forma de comportamiento violento está genéticamente programado por la naturaleza humana. iii) Decir que a lo largo de la evolución humana se haya operado una selección a favor del comportamiento agresivo sobre otros tipos. iv) Decir que los hombres tienen un "cerebro violento”; aunque nuestro aparato neurológico nos permite actuar con violencia, no se activa de manera automática. v) Decir que la guerra es un fenómeno instintivo o que responde a un único móvil. En conclusión establecieron que la humanidad no está condenada a la guerra y que al contrario puede emprender actividades colectivas para construir la paz. Si las guerras empiezan en el alma, de la misma manera allí puede empezar la paz por lo que los seres humanos somos capaces de inventar la paz, así como hemos inventado la guerra(Organización de las Naciones Unidas, 1992).

\subsection{Las novatadas desde la perspectiva de las leyes guatemaltecas}

En el Art.3 de la Constitución Política de la República de Guatemala se establece claramente que el Estado "Se organiza para garantizar y proteger la vida humana; así como la integridad y seguridad de la persona” (Congreso de la República de Guatemala, 1993). Sin embargo durante las novatadas los estudiantes de Agronomía son obligados a ingerir licor, alimentos en descomposición y según información otorgada por la Unidad de Salud de la misma universidad muchos estudiantes novatos resultan seriamente lesionados el día de la celebración de las novatadas. 
En el Art. 4 se menciona claramente que ninguna persona debe ser sometida a condiciones que menoscaben su dignidad y mantener una conducta fraternal entre sí. A pesar de ello, muchos varones son desnudados completamente y sobre sus cuerpos desnudos son escritos frases que menoscaban su dignidad como hombres y como seres humanos. Al respecto hacemos la observación que los novatos no ponen en práctica lo establecido por el Art. 5 en donde se establece que no están obligados a hacer lo que la ley no prohíbe y a acatar órdenes (en este caso de los estudiantes antiguos y encapuchados).

Algunos estudiantes novatos han tenido la valentía de preguntarse ¿¿son éstas prácticas vergonzosas, necesarias para ser un sancarlista más? En el capítulo relativo a la investigación cualitativa presentaremos algunas reflexiones al respecto. Por ahora presentaremos en el Cuadro 2 una síntesis de los artículos de la Carta Magna que son violentados durante las prácticas del bautizo en USAC.

\section{Artículo 3. Derecho a la vida:}

El Estado garantiza y protege la vida humana desde su concepción, así como la integridad y la seguridad de la persona.

Artículo 4. Libertad e igualdad: En Guatemala todos los seres humanos son libres e iguales en dignidad y derechos. (...) Ninguna persona puede ser sometida a servidumbre ni a otra condición que menoscabe su dignidad. Los seres humanos deben guardar conducta fraternal entre sí.

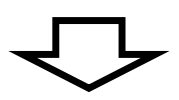

Cuadro 11. Artículos de la Carta Magna que son violentados durante el bautizo.

Fuente: Creación personal con datos de la Constitución Política de la República de Guatemala (1993).
Artículo 5. Libertad de acción:
Toda persona tiene derecho a hacer lo que la ley no prohíbe; no está obligada a acatar órdenes que no estén basadas en ley y emitidas conforme a ella. 


\subsection{El Código Civil Guatemalteco (Decreto Ley 17-1973)}

En Guatemala existe un Decreto Ley mucho más específico que permite analizar las prácticas estudiantiles durante la celebración del bautizo desde una perspectiva mucho más severa. Este es el Decreto Ley 17-1973. Promulgado en el año de 1973, conocido como Código Civil. En él se tipifican los delitos y faltas que pueden cometerse en contra de los seres humanos y las penas a las que se hacen acreedoras como se expone a continuación.

Artículo 36 son autores de delitos quienes:

i) Tomen parte directa en la ejecución de actos propios del delito.

ii) Fuercen o induzcan directamente a otro a ejecutarlo.

iii) Cooperen en la realización del delito, ya sea en su preparación o en su ejecución, con un acto sin el cual no se hubiere podido cometer.

iv) Quiénes habiéndose concertado con otro u otros para la ejecución de un delito, están presentes en el momento de su consumación (Congreso de la República de Guatemala, 1993). Desde esta perspectiva puede determinarse que durante las novatadas en la Facultad de Agronomía, se cometen una serie de delitos. Los estudiantes antiguos que toman en liderazgo en este tipo de eventos, quienes los planifican, organizan, proporcionan los materiales (animales muertos, heces de animales de granja, etc.) y dirigen a otros podrían considerarse como los autores intelectuales.

Sin embargo muchos son los que participan, por lo que consideramos necesario aportar mayor información con lo que establece el Artículo 37 del Código Civil con respecto a las personas que participan de manera directa e indirecta. Se establece que son cómplices de delitos quienes:

i) Animaren o alentaren a otro en su resolución de cometer un delito.

ii) Prometieren su ayuda o cooperación para después de cometido el delito.

iii) Proporcionaren informes o suministraren medios adecuados para realizar el delito. Finalmente, quienes: 
iv) Sirvieren de enlace o actuaren como intermediarios entre los partícipes para obtener la concurrencia de éstos en el delito (Congreso de la República de Guatemala, 1993).

Aunque pueda parecer extremista, es importante tener claridad en que la muerte accidental de alguno de los participantes en las jornadas de bautizo en FAUSAC, es posible. Esto porque existen estudiantes que padecen problemas de salud serios. Entre ellos se señalan los más usuales: problemas respiratorios, cardíacos, estomacales. Se ha documentado el caso de muchachos que posterior a la celebración del bautizo inician a padecer problemas estomacales crónicos.

No se ha realizado ningún estudio formal al respecto, pero la convivencia con los estudiantes permite conocer estos detalles. Por esa razón es necesario realizar una revisión profunda de lo que las leyes guatemaltecas comprendiendo que en este despliegue de emociones puede ocurrir el infortunio de un homicidio simple. Según entrevistas preliminares se determinó que en la década de 1980 un estudiante novato de la carrera de Odontología y Estomatología, se suicidó un día después de haber sido bautizado. Aunque no se realizó un estudio relativo a las razones que tuvo aquel joven para tomar tan drástica decisión, existen algunas hipótesis. Estas fueron reveladas por el médico responsable de la Unidad de Salud de la Universidad de San Carlos de Guatemala, con quien puede conversar.

Según ha relatado la profesional ya señalada (en aquella ocasión) el estudiante libremente manifestó su preferencia sexual de carácter homosexual. Por esa razón la turba de estudiantes se ensañó con él y le propinaron tal bautizo que no tuvo ganas de seguir viviendo. Al respecto se presenta el contenido de los siguientes artículos del Código Civil guatemalteco.

El homicidio simple, según establece el Artículo 123; comete homicidio quien “diere muerte a alguna persona”. Al homicida se le impone prisión de 15 a 40 años, sin embargo si el homicidio se comete en estado de emoción violenta la pena se reduce a 8 años de prisión (Congreso de la República de Guatemala, 1993). 
Abordaje de las novatadas guatemaltecas, desde la perspectiva legal

Tal como hemos veremos en el capítulo siguiente Guatemala es un país sumamente violento por el número de homicidios que se cometen diariamente. Las riñas callejeras, disputa de territorio por narcotraficantes y linchamientos son eventos comunes en Guatemala. Sin embargo existen riñas tumultuarias, conocidas en el medio como linchamientos. En el campus central de la USAC también se han protagonizado este tipo de fenómenos sociales. Esto se da en especial durante la celebración de las fiestas de bienvenida y bautizos. Al respecto el Artículo 125 del mismo Decreto Ley, tipifica el Homicidio en riña tumultuaria: Se considera riña tumultuaria "cuando varias personas participan, acometiéndose entre sí, confusa y tumultuariamente. Resultado muerta una o más personas y no conste su autor, pero sí los que hubieren causado lesiones graves.” En esta ocasión se les impondrá prisión, a todos los participantes, de seis a doce años, según sea el análisis de los especialistas (Congreso de la República de Guatemala, 1993).

Durante las jornadas de novatadas algunos estudiantes novatos resultan con lesiones considerables, y los casos de homicidio son poco comunes, aunque como veremos en la sección del estudio empírico se han dado casos de suicidio posterior a la celebración del ritual de bienvenida. Aunque el homicidio pueda ser un caso extremo dentro de la celebración del bautizo en la FAUSAC, la agresión si es una realidad. Por esta razón incorporamos al presente estudio lo normado relativo a la agresión: Artículo 141 del Código Civil guatemalteco: “Quien agrediere a otro excepto en los casos de riña o pelea entre los dos, ya embistiéndolo con armas o lanzándole cualquier objeto capaz de causar lesión, será sancionado con multa de diez a doscientos quetzales. Si a consecuencia del acontecimiento se causare lesión, sólo será sancionado por ésta”(Congreso de la República de Guatemala, 1973). Al respecto podemos mencionar que no existe ningún caso documentando en el cual se haya perseguido legalmente a ninguno de los estudiantes que cometen abusos en contra de sus compañeros novatos.

Los disparos con arma de fuego también son frecuentes durante la fiesta nocturna realizada el día del bautizo en FAUSAC, al respecto el Artículo 142 de la misma ley establece: “Quien, de 
propósito, dispare arma de fuego contra otro, aunque causare una lesión leve, será sancionado con prisión de uno o dos años. En este punto si existe mucho que comentar porque la portación de armas de fuego está prohibida dentro del campus, sin embargo estudios preliminares realizados por la autora, determinan que uno de cada diez estudiantes porta arma de fuego por lo menos durante las fiestas estudiantiles.

De acuerdo a los artículos ya referidos se concluye que existen penas para los infractores que cometieren lesiones en contra de otros. Sin embargo es indispensable definir el término lesión. Al respecto el Artículo 144 establece que: "Comete delito de lesiones quien, sin intención de matar, causare a otro daño en el cuerpo o en la mente”. También se ha tipificado las lesiones graves para las cuales existe una pena de dos a ocho años de cárcel. Lesiones consideradas como graves: Dentro de la celebración de las novatadas existen algunas que han sido capaces de provocar lesiones graves, tal como se presenta en el capítulo relativo a resultados. Como lesiones graves pueden ser consideradas las siguientes: i) Debilitación permanente de la función de un órgano, de un miembro principal o de un sentido. ii) Anormalidad permanente en el uso de la palabra. iii) Incapacidad para el trabajo por más de un mes y iv) Deformación permanente en el rostro.

Algunas lesiones pueden ser consideradas como leves, siendo éstas las siguientes: i) Enfermedad o incapacidad para el trabajo por más de diez días, sin exceder de treinta. ii) Pérdida o inutilización de un miembro no principal y finalmente, iii) Cicatriz visible y permanente en el rostro. Es importante observar que dentro de las prácticas más populares en la celebración de las novatadas se encuentran algunas que pueden clasificarse como tipos de agresión de carácter sexual. Entre estas prácticas podemos mencionar: obligar a los novatos a tomarse de la mano, besarse, insinuar relaciones sexuales, desnudarlos y vestirlos con ropa interior femenina (en el caso de los novatos). En Febrero del año 2015 la Procuraduría de Derechos Humanos recibió denuncias relativas a abusos sexuales cometidos contra estudiantes novatos el día del bautizo. Este hecho salió a luz pública gracias a la nota de prensa publicada por Prensa Libre (Ver ANEXO IX). 
Abordaje de las novatadas guatemaltecas, desde la perspectiva legal

A continuación presentamos lo establecido en el Código Civil al respecto de tales prácticas: Artículo 17. Violación: Quien con violencia física o psicológica, tenga acceso carnal vía vaginal, anal o bucal con otra persona o le introduzca cualquier parte del cuerpo u objetos, por cualquiera de las vías señaladas, u obligue a otra persona a introducírselos a sí misa, será sancionado con pena de prisión de ocho a doce años. Siempre se comete este delito cuando la víctima sea una persona menor de catorce años de edad, o cuando sea una persona con incapacidad volitiva o cognitiva, aun cuando no media violencia física o psicológica ${ }^{18}$. En este mismo artículo se describe lo relacionado a la Agresión de carácter sexual: Quien con violencia física o psicológica realice actos con fines sexuales o eróticos a otra persona, al agresor o a sí misma, siempre que no constituye delito de violación, será sancionado con prisión de cinco a ocho años.

Según el Artículo 174 la pena se aumenta en dos terceras partes cuando la conducta se cometa por acción conjunta de dos o más personas. Este dato es de suma importancia porque las agresiones sexuales en contra de los novatos son ordenadas o cometidas por estudiantes antiguos, en muchas ocasiones, aun cuando estos portan capuchas. Otro elemento importante para agravar la pena es cuando el agresor actuare con uso de armas o sustancias alcohólicas, narcóticas o estupefacientes. Así mismo cuando utilizare otros instrumentos o sustancias que lesionen gravemente la salud de la persona ofendida ${ }^{19}$ (Congreso de la República de Guatemala, 1973).

\footnotetext{
${ }^{18}$ Adicionado por el artículo 29, del Decreto número 9-2009 del 3 de abril de 2009.

${ }^{19}$ Reformado por al artículo 30, del Decreto número 9-2009 de fecha 3 de abril de 2009.
} 


\subsection{Análisis de la agresión contra estudiantes novatos con armas de fuego, armas blancas, fuegos pirotécnicos y otro tipo de objetos contundentes}

Según lo establecido en el Artículo 141: Quien agrediere a otro ya embistiéndolo con armas o lanzándole cualquier objeto capaz de causarle lesión, será sancionado con multa de diez a doscientos quetzales. Si a consecuencia del acontecimiento causare lesión, solo será sancionado por ésta.

Según resultados de investigaciones preliminares realizados por la autora; dentro de la Facultad de Agronomía uno de cada diez alumnos porta (ilegalmente) arma de fuego. En especial gustan de llevarlas durante las fiestas vaqueras y celebraciones dentro de la USAC. Las novatadas no son la excepción, esto convierte el evento en algo más que un juego y hace vulnerables a los participantes, incluso a los observadores. En Guatemala existe una ley específica para regular la portación y uso de armas de fuego. Esta se denomina: Ley de armas y municiones según el Decreto 15-2009 del Congreso de la República: De la misma manera el Código Civil guatemalteco establece en el Artículo número 142 lo siguiente: Disparo de arma de fuego, Artículo 494: Quien de propósito, disparare arma de fuego contra otro, aunque causare lesión leve, será sancionado con prisión de uno a dos años. Si a consecuencia del disparo causare lesiones graves o gravísimas o se ocasionare muerte, sólo se le impondrá la pena que por estos delitos corresponda. Si el individuo disparare en sitio público o frecuentado será sancionado con arresto de diez a sesenta días (Congreso de la República, 2000).

Además de las armas de fuego es común observar estudiantes que portan navajas, cuchillos y otro tipo de objetos corto- punzantes. También se emplean otros objetos como: bates de béisbol, machetes, palos, hierros, martillos, cadenas. Este es, generalmente, privilegio de los estudiantes encapuchados, estudiantes antiguos o el grupo de estudiantes del denominado Comité de Orden. Al 
respecto lo establecido en el Decreto Ley de Armas y Municiones) dice lo siguiente: Pueden ser consideradas como armas blancas las siguientes: i) Las de uso personal o trabajo. Por ejemplo cuchillos, instrumentos de labranza o de cualquier oficio, arte o profesión. Navajas de bolsillo, cuya hoja no exceda de diez centímetros de longitud. ii) Las armas blancas deportivas son: ballestas, arcos, flechas, florete, sable y espada (Congreso de la República de Guatemala, 2009).

Es natural que con el uso de armas de fuego, armas blancas y otro tipo de herramientas de trabajo (martillos, machetes) los novatos se sientan coaccionados (como lo expresaron en entrevistas preliminares). Debido a esta consideración también presentamos información relativa a lo normado en este tema. Ello a pesar que algunos de los estudiantes entrevistados previamente manifestaron que el bautizo "no es obligatorio” aunque es obvio que sí lo es.

Cuando los estudiantes novatos deciden dejar de participar en su propio bautizo son posteriormente bautizados de manera individual y exclusiva. Esta condición los hace mucho más vulnerables a todo tipo de burla y trato vejatorio. Ahora no están con otros iguales, ahora deben soportar todo el dolor y humillación, solos. Desde la perspectiva legal con relación a la coacción, presentamos lo establecido en el artículo 214 del Código Civil: “Quien sin estar legítimamente autorizado mediante procedimiento violento, intimidatorio o que en cualquier forma compela a otro, obligue a éste para que haga o deje de hacer lo que la ley no le prohíbe, efectúe o consienta lo que no quiere o que no tolere que otra persona haga, sea justo o no, será sancionado con prisión de seis meses a dos años”20.

\footnotetext{
${ }^{20}$ Reformado por el artículo 2 del Decreto 38-2000 del Congreso de la República.
} 
Abordaje de las novatadas guatemaltecas, desde la perspectiva legal

\subsubsection{Ley contra la Narcoactividad, Decreto Ley 48-92 del Congreso de la República}

En el primer considerando de la Constitución Política de la República de Guatemala se hace énfasis en que garantizar la vida, integridad y desarrollo de la persona humana es una prioridad en el Estado guatemalteco. La salud de los guatemaltecos es prioritaria por lo que se ratificaron los tratados internacionales relativos a la lucha contra el narcotráfico y toda actividad relacionada con la fabricación, uso, tenencia, tráfico y comercialización de estupefacientes psicotrópicos y drogas. Dentro de las más comunes en el medio guatemalteco son: cocaína, crack y otras drogas sintéticas. Sin embargo el alcohol no es considerado una droga (Congreso de la República, 1992). Según varios analistas guatemaltecos esto se debe a que es conveniente tener al alcohol y tabaco como drogas lícitas en vista que generan muchos impuestos. Según el Patronato Antialcohólico de Guatemala solo en el año 2008 el Estado de Guatemala recaudó por concepto de bebidas alcohólicas y fermentadas la cantidad de doscientos millones de quetzales.

Según Barreda (2010) el hecho que el Decreto Ley considere al alcohol como una droga lícita es un error pues es evidente que provoca los mismos efectos narcóticos adictivos que otras drogas. Pues los obliga a consumirlas y padecer perturbaciones físicas y/o corporales en caso de no hacerlo periódica y continuamente.

Finalmente se hace la observación que aunque existe una ley específica para el tema del alcohol en Guatemala; esta hace referencia únicamente a aspectos relativos a la producción, distribución y pago de impuestos. Es contradictorio que no exista algún apartado de la misma ley se regule el consumo (lugar, hora, edad mínima para consumir). Esta condición pone en mucho riesgo a la niñez y juventud guatemalteca. Afortunadamente la Normativa de la Universidad de San Carlos

de Guatemala si considera este aspecto y tiene una prohibición para el tema del expendio y establece la prohibición de distribuir bebidas alcohólicas dentro del campus universitario. 


\subsubsection{La obligatoriedad de la denuncia de parte de las autoridades universitarias}

Considerando la gravedad de algunas prácticas durante la celebración de las novatadas dentro de las instituciones educativas, las autoridades académicas y administrativas están obligadas a denunciar las faltas o delitos, de acuerdo a lo establecido en el Código Procesal Penal de la República de Guatemala. Esto queda establecido en los siguientes artículos de la ley señalada. Artículo 297. Denuncia: “Cualquier persona deberá comunicar, por escrito u oralmente, a la policía, al Ministerio Público o al tribunal el conocimiento que tuviere acerca de la comisión de un delito o acción pública”.

En este caso el denunciante deberá ser plena y legalmente identificado. Según el Art. 298, están obligados a denunciar el conocimiento que tienen sobre un delito las siguientes personas: i) Los funcionarios y empleados públicos que conozcan el hecho en el ejercicio de sus funciones, salvo el caso que pese sobre ellos guardar el secreto. ii) Quienes por disposición de la ley, de la autoridad o por acto jurídico tuvieren a su cargo el manejo, administración, el cuidado o control de bienes o intereses de la institución, entidad o persona, respecto a los delitos cometidos en su perjuicio, o en perjuicio de la masa o patrimonio puesto bajo su cargo o control siempre que conozcan el hecho con motivo del ejercicio de sus funciones (Congreso de la República de Guatemala, 1992).

\subsubsection{Los Estatutos de la Universidad de San Carlos de Guatemala}

Considerando que la actividad del bautizo o novatada que ha sido objeto de investigación es considerada una actividad pública se presenta lo estipulado al respecto de acuerdo a marco legal de la Universidad. En este caso la ley vigente son los Estatutos de la Universidad de San Carlos de Guatemala, cuyos artículos analizamos a continuación. 
Abordaje de las novatadas guatemaltecas, desde la perspectiva legal

De acuerdo a lo establecido en el Artículo 1: puede considerarse como actividad pública todos los eventos o actividades de carácter político, académico, cultural, deportivo, comercial y laboral que realicen personas de los diversos sectores (docente, administrativo o estudiantil), dentro de las instalaciones de la Universidad. Uno de los principales objetivos del reglamento es: promover una serie de actitudes y conductas que contribuyan al bienestar físico, mental y social de la comunidad universitaria, durante el desarrollo de las actividades (Universidad de San Carlos de Guatemala, 2000).

También se establece en el Artículo 6 que para que las actividades públicas se desarrollen de conformidad a los términos o condiciones que fueron autorizadas, serán objeto de supervisión por las unidades de vigilancia de la Universidad. Esta autorización tendrá que ser solicitada por personas que deben presentar documento de identificación y poder establecer quiénes son los responsables de la actividad.

Es importante recalcar que dentro de las prohibiciones está el interrumpir el proceso de enseñanza aprendizaje y demás actividades académico-administrativas propias de la Universidad. Así mismo el poner en peligro la integridad física del personal académico, administrativo, técnico y especialmente de los estudiantes regulares de la Universidad.

Uno de los fines elementales de la Universidad es "elevar el nivel espiritual de los habitantes de la República, promoviendo, conservando, difundiendo y transmitiendo la cultura en todas sus manifestaciones”, según los normado en Art.5 del instrumento legal señalado al inicio. 


\section{Artículo 93. Disciplina estudiantil}

Los alumnos regulares de las Unidades Académicas están obligados a conservar el orden, mantener la disciplina en la Universidad y procurar el enaltecimiento.

conial dal oramin actudiantil

\section{Artículo 94}

La violación por parte de los estudiantes universitarios de las normas legales, estatutarias y reglamentarias que correspondan a la Universidad o de los deberes éticos que deben observar, lleva consigo la imposición de las sanciones disciplinarias que estos Estatutos determinan

Artículo 95. Sanciones disciplinarias

Retiro durante una hora de clase

Amonestación privada

Amonestación pública

Suspensión temporal

Expulsión de la Unidad Académica

Cuadro 12. Lo establecido en los Estatutos de USAC, relativo a la disciplina estudiantil.

Fuente: Creación personal con información de Universidad de San Carlos de Guatemala (2000).

Este fin supone una exigencia natural a nivel interno y es que los emisarios de ese nivel espiritual y cultural tan deseable y conveniente deberían tener como mínimo condiciones de convivencia pacífica, respetuosa que promueva un ambiente en donde la ciencia, el arte, tecnología y cultura puedan desarrollarse sin ningún tipo de inconveniente(Universidad de San Carlos de Guatemala, 2000). Por el contrario existen diversas actividades estudiantiles que(según las evidencias presentadas en este capítulo) han provocado algún tipo de daño o malestar físico o psicológico contra estudiantes.

Las autoridades universitarias han prohibido la comercialización, expendio y consumo de bebidas alcohólicas o fermentadas, drogas y estupefacientes. El portar armas de fuego, la utilización de explosivos y materiales inflamables, así como incurrir en conductas y actitudes que riñan con la moral y la ley. Si se incurre en faltas a lo ya establecido existen sanciones específicas para el personal académico y administrativo. Lo relativo a las sanciones estudiantiles está referido en el Título VIII del Capítulo I de los Estatutos de la Universidad de San Carlos de Guatemala. 
Abordaje de las novatadas guatemaltecas, desde la perspectiva legal

Como podemos observar, la norma disciplinaria es clara. Las sanciones impuestas a los infractores van desde el retiro de una hora de clase hasta la expulsión definitiva de la universidad. A pesar de ello prevalece la indisciplina y los estudiantes (organizados en Asociaciones Estudiantiles) se han empoderado; quebrantando todo tipo de norma sin recibir ningún tipo de castigo.

En vista de la conducta reincidente las autoridades se ven forzadas a publicar comunicados como el que podemos observar en el Apéndice 10 en la sección correspondiente. 
Planteamiento del problema y metodología

\section{PARTE II: ESTUDIO EMPÍRICO}

\section{CAPÍTULO 6: PLANTEAMIENTO DEL PROBLEMA Y METODOLOGÍA}

Los ritos de iniciación son conocidos desde épocas muy antiguas de la humanidad. Alrededor del mundo primitivo existen innumerables ejemplos que asombran y a la vez intrigan por su simbolismo, la magia y fuerza con la que se arraigaron en el seno de las comunidades que las han practicado.

Ya Ortega y Gasset describe el origen de las fratías, en la antigua Grecia, que antecedieron a las antiguas polis como asociaciones juveniles en donde se combinaban prácticas desbordantes de rituales y simbolismo, concretamente dentro de las actividades de danza y guerra (Ortega y Gasset, 1966). Éstas prácticas, según los historiadores, permitían la construcción colectiva de identidad fortaleciendo los lazos de solidaridad y cohesión. Fernández (2007) hace la reflexión que los ritos de iniciación representan mucho más que un mecanismo de cohesión pues también constituyen un banco de pruebas físicas en donde los jóvenes de las tribus deben demostrar su valía individual. En este caso el superar una serie de obstáculos demuestra su excelencia personal.

Hoy en día los ritos de iniciación siguen vigentes, poseen vital importancia como una expresión de la cultura transmitida de generación en generación. Por esta razón se han mantenido vigentes a lo largo de siglos, especialmente en el caso de las escuelas militares y centros educativos en donde los jóvenes son sometidos a duras pruebas físicas porque se cree que ello permite ponderar el valor y resistencia de los novatos. En muchos casos se considera que el superar las pruebas a las cuales son sometidos garantiza su futuro buen desempeño en el campo de batalla. Así mismo plantea otro elemento indispensable para asegurar el éxito durante los enfrentamientos con líneas 
enemigas y es que cuando el novato emerge triunfante de las pruebas a las que es sometido lleva consigo un sello que garantiza la identidad y cohesión al grupo al que pertenece.

Si bien es cierto en época antigua los ritos de iniciación tuvieron un objetivo muy claro y por la misma razón se afianzaron dentro de la comunidad, en la actualidad existen nuevos elementos a considerar. Algunas de las prácticas antiguas se transformaron y sobrevivieron, pero los objetivos perseguidos ya no están muy claros. Algunos de ellos son criticados fuertemente porque al hacer el balance, provocan mucho más daño físico, psicológico, colectiva e individualmente; que las pruebas de fuerza física, gallardía, solidaridad, identidad que puedan promover.

Es necesario mencionar casos extremos como el ritual de la ablación femenina ${ }^{21}$ practicada por algunas tribus somalí-africanas como la midgaan. Sin embargo estás prácticas son consideradas tabú y prevalece un sentimiento colectivo que aboga por que prevalezca el código del silencio. El daño provocado a las mujeres que pasan por este tipo de ritual es profundo y de carácter permanente y provoca daño físico y psicológico irreversible. Cuando alguna víctima decide hablar hay un cambio sustancial en la manera de ver las cosas. La somalí Warries Dirie ${ }^{22}$, declaró relativo a su propia ablación que cuando tomó consciencia de la mutilación que había sido objeto no podía hablar libremente de ella porque sentía angustia y miedo de que algo malo pudiera pasarle por hablar públicamente de algo que debía ser conservado como secreto exclusivo de los miembros de su comunidad.

Los ritos de iniciación siguen dándose especialmente en el seno de las instituciones deportivas, militares y educativas, entre muchas otras. La energía propia de la juventud, la creatividad y otros elementos como la violencia que ha sido aceptada en algunos sectores de la

\footnotetext{
${ }^{21}$ La ablación femenina es la mutilación genital femenina consiste en la eliminación total o parcial de los genitales femeninos externos u otras lesiones en los mismos órganos por razones culturales o religiosas o por otros motivos no terapéuticos, como lo es según el ritual de esta tribu africana el hacer a las mujeres "limpias y puras”.

${ }_{22}$ Warries Dirie se convirtió en la primera mujer somalí víctima de ablación que habló públicamente del ritual que le fuera practicado cuando era aún una niña, obteniendo el reconocimiento mundial y convirtiéndose en una embajadora en la lucha contra la ablación femenina en el continente africano y el mundo entero.
} 


\section{Planteamiento del problema y metodología}

sociedad han sido los ingredientes de un cardo bordelés que ha rendido como fruto un ambiente lleno de agresión en el ámbito escolar.

Según Abramovay (2005) la violencia en el ámbito escolar es uno de los factores que mayor peso tiene en la baja calidad de la enseñanza, llegando a extremos en donde las aulas se han convertido en verdaderos campos de batalla. En el mismo sentido Varela (2012) expresa que las prácticas de novatadas dentro de las instituciones educativas se han convertido en tema de preocupación para la comunidad científica por los efectos negativos que tienen sobre las comunidades educativas. Por esta razón diferentes sectores intelectuales han dirigido e implementado investigaciones como las siguientes: Buelga, Musitu y Murgui (2009), Defensor del Pueblo (2007), Smith y Brain (2000), Akiba (2004), Gofin, Palti y Gordon (2002), Liang, Flicher y Lombard (2007) y Smith (2003). En estas investigaciones se hace énfasis en el daño provocado a los estudiantes novatos con las prácticas del bautizo, sin embargo a pesar de que existe rechazo sistemático por muchos sectores de la sociedad, éstas se siguen dando. Guatemala no ha sido la excepción y ésta es la razón por la cual se ha realizado la presente Tesis Doctoral. A continuación presentaos las principales preguntas de investigación. 


\subsection{Planteamiento de las preguntas de investigación, objetivos e hipótesis}

Las principales preguntas de investigación que permitieron el planteamiento y diseño del presente trabajo de investigación fueron las siguientes:

i) ¿Las actividades implementadas durante la celebración de las novatadas de FAUSAC pueden considerarse como actos violentos o son simplemente un juego entre jóvenes?

ii) ¿Cuál es la motivación que hay detrás de esta práctica estudiantil?

iii) ¿Cuál es la intencionalidad de los estudiantes antiguos en la implementación de las prácticas más comunes dentro de las novatadas?

iv) ¿Es posible considerar las acciones violentas durante la celebración del ritual del bautizo de los estudiantes de primer ingreso a FAUSAC como reflejo de la violencia que caracteriza a la sociedad guatemalteca moderna? o bien ¿̇representa únicamente una expresión de una tradición de carácter lúdico?

v) ¿Cuál es el nivel de aceptación de la celebración del bautizo por los estudiantes novatos, antiguos, personal docente y egresados?

vi) ¿Puede ser considerado el bautizo de los estudiantes novatos como una expresión de acoso escolar?

vii) ¿Qué tanto influye el entorno en la conducta de los estudiantes?

viii) ¿Existe algún grado de intimidación durante la celebración del bautizo?

ix) Posterior a su participación en el bautizo, ¿siente el estudiante antiguo algún tipo de culpa?

x) Consideran los principales actores que existen mecanismos prácticos para transformar la celebración de las novatadas en prácticas más amigables?

xi) ¿Si existen, cuáles son?

xii) ¿Existe predisposición de los alumnos y profesores para implementar tales mecanismos? 
xiii) ¿Desde la perspectiva legal y en cuestión de Derechos Humanos, pueden considerarse las prácticas dentro del bautizo como un delito o son simplemente inocentes juegos?

Este rito de iniciación originalmente fue denominado bautizo, sin embargo debido a las denuncias presentadas ante la Procuraduría de los Derechos Humanos a causa de los excesos cometidos en contra de los novatos; las autoridades educativas han optado por la prohibición institucional de tal práctica. A pesar de ello las Asociaciones Estudiantiles siguen promoviendo su celebración y como estrategia para no ser censurados ha sido cambiar el nombre del evento en mención al de Bienvenida aunque las prácticas siguen siendo las mismas.

El carácter de esta actividad es anual, permanente y de participación obligatoria (en el caso de los novatos). La importancia de la presente Tesis Doctoral radica en el sentido que gracias a la información sistematizada ha sido posible la reflexión de dinámicas contemporáneas en el ámbito universitario guatemalteco. Así mismo inferir acerca del comportamiento en nuevas generaciones de estudiantes de primer ingreso en USAC al evaluar las tendencias en el comportamiento colectivo. Es importante considerar que la universidad tiene más de tres siglos de ofrecer sus servicios al pueblo guatemalteco y en cuanto no haya cambios estructurales en la Carta Magna, seguirá siendo la única universidad estatal en el país. Por esta razón, principalmente, es valioso todo tipo de esfuerzo encaminado a estudiar las dinámicas entre un sector estudiantil tan importante.

La celebración de bautizo genera polémica porque durante un día al año el poder cambia, completamente, de manos y la autoridad administrativa se ve completamente anulada para dar paso al poder estudiantil. Aunque la celebración se realiza en un solo día los desórdenes provocados por la celebración inician con la misma jornada académica durante los meses de enero y Febrero de cada año ${ }^{23}$.

\footnotetext{
${ }^{23}$ Este hecho queda demostrado con la toma o secuestro de los edificios de la Facultad de Agronomía y en algunas ocasiones también del personal académico y administrativo. Ver en ANEXOS las fotografías de la toma de edificios y afiches estudiantiles que incitan a tomar medidas de hecho.
} 
Un aspecto que es necesario mencionar es que esta actividad es pública, pero de carácter exclusivamente estudiantil pues no tolera la supervisión ni participación directa o indirecta de ningún tipo de autoridad. Tantos decanos como profesores se ven desplazados y considerando los riesgos que se corren la mayoría opta por quedarse en casa; pues las mismas autoridades suspenden actividades académicas y administrativas.

Un par de días antes de la celebración del bautizo es enviada una nota firmada por el Secretario Académico en donde se suspenden las actividades académicas y administrativas, debido a las actividades de bienvenida, programadas por la Asociación de Estudiantes de Agronomía $\mathrm{AEA}^{-24}$.

Esta situación es contraproducente porque oficialmente, las novatadas están prohibidas por las autoridades universitarias, pero al momento de implementar las medidas pertinentes en cada Unidad Académica, algunas optan por abalarlas, indirectamente, al momento de suspender actividades.

Estudios preliminares realizados por la autora, permitieron conocer la opinión de algunos exsecretarios académicos (quienes pidieron mantenerse en el anonimato), explicando a sabiendas que en las jornadas de los bautizos hay total descontrol, que es mejor no participar regulándolas. Esto porque al suspender las actividades académicas los únicos responsables, legalmente, son los estudiantes que organizan y dirigen. Si un grupo de profesores decidiera presentarse ese día, es cómplice de los abusos allí cometidos.

Sin embargo es importante considerar que estas condiciones permiten un ambiente en el que se ha llegado a cometer algunos excesos en condiciones de estados etílicos y eufóricos. Personeros de la Unidad de Salud de la universidad han reportado a decenas de estudiantes novatos que han

\footnotetext{
${ }^{24}$ Ver ANEXO XII la nota en donde el Secretario Académico, suspende las actividades para permitir la celebración de la bienvenida.
} 
sufrido quemaduras de tercer grado, indigestión por ingesta de brebajes de todo tipo, problemas respiratorios, cardiacos y fracturas en brazos piernas.

Desde la perspectiva psicológica también existen algunas reacciones porque en el caso de la Facultad de Agronomía, nuestro caso de estudio, los novatos varones son despojados de su ropa quedando únicamente vestidos con ropa interior. Aún esas prendas son rasgadas a sabor y antojo de los estudiantes antiguos llamados “padrinos”. Algunos de estos estudiantes actúan impunemente con la oportunidad que les otorga el anonimato por el uso de una sotana y una capucha. Esto ocurre especialmente con los miembros de la Asociación Estudiantil que durante esas jornadas son quienes asumen el rol de organizadores y auditores de las actividades programadas por sus compañeros de clase.

En contraposición a la desaprobación de algunos actores sociales un buen porcentaje del sector estudiantil considera que esta práctica es una de las tradiciones sancarlistas que mejor permiten identificarlos como tales. Así mismo consideran que el mantener viva esta tradición es obligación de todo buen sancarlista que se precie de serlo. Por esta razón en la presente investigación se aborda este fenómeno social desde diversas perspectivas y a la luz de la opinión de diferentes actores. Ello porque cada uno (novatos, estudiantes antiguos, profesores, egresados) cuenta la misma historia según su personal apreciación.

El escenario que ofrece la celebración de las novatadas en la Universidad de San Carlos representa una oportunidad única de revelar la identidad colectiva y autónoma de los estudiantes; del conocimiento de sus derechos y defensa, de los valores compartidos y la manera en que se estructura y funciona este grupo social tan particular e importante.

Para el caso específico de Guatemala, se han realizado investigaciones de diversa índole que han aportado información de importante relativa a la violencia en sus diversas expresiones como las siguientes: conflicto armado interno (acontecido entre 1962-1996) y las secuelas de éste: crimen organizado, delincuencia común y pandillas juveniles. Así mismo existen múltiples aportes 
en el campo investigativo de la discriminación racial, violencia de género, violencia estructural y pobreza extrema entre muchas otras. Sin embargo existen solamente algunas investigaciones que indagan acerca de la violencia entre iguales o bullying como es reconocida ya mundialmente la violencia en el ámbito escolar entre ellas destacan las de los guatemaltecos Roldán y Pérez (2010). Es así como se han aportado algunos datos concretos (denuncias, estadísticas) del daño provocado durante el acoso escolar. Las investigaciones relativas al acoso entre universitarias son más escasas, por lo que abordar la problemática de violencia entre universitarios, de manera objetiva, representa una excelente oportunidad y desafío a la vez. Desafío por que la cultura de violencia, pasividad y permisividad exige que implementar diferentes herramientas de investigación que permitan recopilar la información de manera objetiva.

Aunque no existen datos concretos de las consecuencias físicas, económicas y psicológicas que provocan las novatadas en San Carlos, las autoridades universitarias están conscientes que dentro del campus existen problemas serios de agresión, violencia e inseguridad. Por esa razón en el año 2002 se reunieron y nombraron a un grupo élite para que trabaje en el planteamiento de un Plan de Seguridad institucional. Dentro de esta organización figuran los actuales decanos de las Facultades de Agronomía, Arquitectura y Dirección de Asuntos Jurídicos. Otra acción concreta importante fue pedir auxilio al Ministerio de Gobernación y Ministerio Público para investigar las acciones y presentar cargos formales contra los que fueran hallados culpables de acuerdo a las leyes vigentes en el país (Ver Acta contenida en el ANEXO I).

Aunque esta acción es acertada; el buscar culpables y aún el resarcir a las víctimas (que se cuentan por decenas) no es la solución. El problema de las novatadas está profundamente arraigado por cuanto es una tradición aceptada y avalada por muchos, pero más preocupante aún es que sus consecuencias sean desconocidas para muchos. A pesar de ello aún el sector estudiantil también se ha pronunciado en reiteradas ocasiones en favor de la aplicación de medidas de control necesarias para garantizar la seguridad de los estudiantes, pero se han opuesto abiertamente a la prohibición de 
las novatadas y especialmente a la intervención e ingreso de la Policía Nacional Civil al campus universitario. Argumentando que es una violación a la Autonomía Universitaria. En este punto es interesante plantearse el pulso entre el gobierno estudiantil- versus el gobierno académico.

Estos hechos cobran especial relevancia si se considera que el sector estudiantil sancarlista se convertirá en uno de los grupos élite de profesionales que, por su naturaleza, deben estar comprometido en el análisis y búsqueda de solución a los problemas sociales, económicos y políticos de la nación a la cual pertenecen y de alguna manea representan ${ }^{25}$. En este sentido vale la pena preguntarse ¿qué tipo de esfuerzos se realizan en la actualidad para comprender y resolver los problemas de expresión de violencia en el seno de la misma institución?

Por las razones antes expuestas el sistematizar información, describir, analizar e interpretar las prácticas de las novatadas o "bautizos" a estudiantes de primer ingreso a la Universidad de San Carlos de Guatemala es el Objetivo General de la presente Tesis Doctoral. De este objetivo se desprenden los objetivos específicos que son: i) Realizar observación antropológica de la práctica del bautizo durante los ciclos académicos 2013, 2014 y 2015, documentándolas fotográficamente. ii) Describir y analizar (individualmente) la celebración del ritual del bautizo en la Facultad de Agronomía para novatos y novatas. Esta situación permitirá identificar algunas diferencias en el comportamiento entre hombres y mujeres bajo la perspectiva de los niveles de agresividad. iii) Determinar si en las prácticas realizadas durante la celebración del ritual del bautizo existen algunas que vayan contra la integridad física de los estudiantes novatos.

La Universidad de San Carlos de Guatemala tiene, por mandato Constitucional, un presupuesto anual no menor del cinco por ciento del Presupuesto General de Ingresos Ordinarios del Estado, debiéndose procurar un incremento presupuestal adecuado al aumento de su población

\footnotetext{
${ }^{25}$ Según lo establecido en el Artículo 82 de la Constitución Política de la República "la Universidad de San Carlos de Guatemala es la única universidad estatal y le corresponde con exclusividad, dirigir, organizar y desarrollar la educación superior del Estado". Señala en otra sección del mismo artículo que por la misma razón le compete la solución de problemas nacionales.
} 
estudiantil o al mejoramiento del nivel académico”26. En sentido práctico puede determinarse que un porcentaje de los impuestos que pagan los guatemaltecos es invertido en su funcionamiento y de ella se espera una retribución recíproca de carácter real y sustancial. Por esa razón todo lo que acontece dentro del campus universitario y lo relacionado con la vida estudiantil es de particular importancia y tema recurrente en la opinión pública. La comunidad guatemalteca permanece atenta al accionar colectivo de esta comunidad universitaria.

En el año de 1999 se realizó en la escuela de Postgrado de Ciencias Económicas un encuentro de profesionales en donde se determinó que debido a la gran demanda de educación a USAC-, se derivan problemas típicos del fenómeno de masificación. Entre ellos destacan algunos de carácter primario: hacinamiento estudiantil, carencia de parqueos, congestionamiento vehicular, inseguridad en el campus central y proliferación de ventas informales dentro del campus. Algunos otros son efectos secundarios de los ya mencionados anteriormente, entre ellos destacan: desórdenes estudiantiles, tráfico de drogas y armas de fuego, asaltos a mano armada, delincuencia organizada (extorsiones) entre otros. Las autoridades han reaccionado promoviendo un Plan de Seguridad Universitaria dirigido a individuos ajenos a San Carlos que ingresan al campus central para delinquir. Sin embargo vale la pena preguntarse ¿qué ocurre cuando los protagonistas de esos delitos son los mismos estudiantes? ¿De qué manera reaccionan las autoridades y cuáles son las sanciones impuestas? Así por ejemplo en el año de 2010 aconteció un hecho violento entre supuestos estudiantes de la Escuela de Ciencias Económicas (considerando que escondían sus rostros con capuchas fue imposible establecer su identidad). En esa ocasión dos estudiantes, plenamente identificados como tal, fueron vapuleados por encapuchados, hecho que fue repudiado

\footnotetext{
${ }^{26}$ Recurso económico otorgado por el Organismo Ejecutivo, establecido en Leyes y Reglamentos de la Universidad de San Carlos de Guatemala, Guatemala.
} 
públicamente por las autoridades y sector estudiantil y docente. Ello provocó el desprestigio de la institución.

Estos atentados en contra de la seguridad de los estudiantes universitarios proliferan especialmente durante épocas claves. Entre ellas pueden señalarse la celebración de la Huelga de Dolores, recaudación de la Talacha, elección de Rey Feo estudiantil ${ }^{27}$ y principalmente durante la celebración del rito del bautizo en diferentes unidades académicas. Considerando que esta práctica se realiza de manera sistemática, obligatoria y pública, ofrece la oportunidad de ser observado y analizado en todo su simbolismo y esplendor.

Desde la perspectiva económica puede considerarse que el costo de la celebración del bautizo es alto porque a pesar que los insumos utilizados en tal práctica son relativamente económicos: huevos, harina, estiércol de vaca, cerdo o gallinaza; licor, pinturas, tintas; a nivel institucional existe una pérdida considerable. Ello porque los días que se realizan las celebraciones se paraliza completamente la actividad académica y administrativa y esto tiene costos elevados considerando que se han perdido jornales de trabajo importantes.

Esta celebración tiene una antigüedad de más de 80 años y a pesar que ha sido prohibida por las autoridades universitarias, se sigue realizando y generando polémica. Tampoco ha sido formalmente documentada por lo que la principal motivación de la ejecución de la presente Tesis Doctoral es la oportunidad de reflexionar acerca de las dinámicas sociales contemporáneas dentro la

${ }^{27}$ Huelga de Dolores: Celebración estudiantil característica de USAC en donde en un desfile bufo se satiriza a las autoridades universitarias y estatales en general. En ella participan miles de estudiantes que utilizan todo tipo de disfraces y hacen parodia de los principales problemas de la sociedad guatemalteca.

Cobro de la Talacha: Hace referencia a la recaudación de fondos económicos para financiar la elaboración de carrozas, disfraces y licor que es ingerido libremente durante el desfile bufo o Huelga de Dolores.

Elección de Rey Feo Estudiantil: Se refiere a una velada estudiantil en donde cada Unidad Académica presenta a un personaje que compite con sus homólogos por ser coronado como Rey Feo general de USAC. Durante la jornada debe presentar un discurso mordaz en donde debe mostrar ingenio, creatividad, sátira, burla y sobe todo mucha tolerancia a los insultos que le profiere el público que constantemente le atacará durante la presentación con el objetivo de hacer la elección del personaje con más agallas y temple para manejar la situación. 
institución, generando nuevas herramientas metodológicas para el abordaje del fenómeno social, facilitando el trabajo para nuevos investigadores.

Finalmente es importante considerar que las novatadas en el ámbito universitario de Guatemala son perniciosas en gran medida, a pesar que algunos siguen considerándolas como un simple juego. El primer paso para la solución de cualquier problema es la toma de conciencia de parte de los principales actores. Para ello es necesario conocer las diferentes aristas del fenómeno.

La Hipótesis planteada en la investigación fue la siguiente: La violencia física, psicológica y sexual está presente en la práctica del bautizo de la Facultad de Agronomía de la Universidad de San Carlos de Guatemala. Esto provoca el rechazo de la actividad de parte de los novatos quienes la toleran por miedo al rechazo y la humillación.

Para poder alcanzar los objetivos y comprobar la hipótesis planteada, diseñamos el siguiente marco metodológico y en la misma sección describimos las estrategias de investigación implementada.

\subsection{Marco Metodológico y estrategias de investigación}

De acuerdo a la recomendación de algunos autores como Manuel Valles (2000) los pasos que se siguieron en la presente Tesis Doctoral fueron los siguientes: i) Definición del Problema; ii) Diseño del Trabajo; iii) Recopilación de datos; iv) Estructura y sistematización y validación de datos y finalmente: v) Estructura y presentación del informe final.

Considerando los objetivos planteados (conocer y describir y analizar el ritual de la novatada en FAUSAC) puede determinarse que la presente Tesis Doctoral es de carácter cualitativo. Habiéndose enmarcado específicamente dentro del tipo de investigación Descriptiva y Explicativa. Esto porque además de describir la práctica de la novatada se profundizó en el análisis para tratar de comprender el comportamiento humano manifiesto durante tal práctica. 
En el trabajo de campo se recopiló información acerca de las interacciones entre los distintos actores dentro de la práctica del bautizo. Ocupó especialmente la atención las reacciones i) Estudiantes novatos de las jornadas de 2013,2014 y 2015; ii) Estudiantes antiguos de las mismas jornadas; iii) profesores titulares de la Facultad de Agronomía; iv) el psicólogo de la unidad académica en cuestión; v) un médico representante de la Unidad de Salud de la -USAC-, vi) una trabajadora social conocedora del tema y finalmente vi) un exalumno que vive en Bélgica desde hace más de una década.

Especialmente son interesantes las entrevistas realizadas a profesores (quienes en algún momento también fueron estudiantes de la Facultad de Agronomía) y quienes ponderan el fenómeno desde una perspectiva muy integral, en primera ocasión como ex - estudiantes y en tiempos modernos, como profesores.

En el capítulo de resultados se presentan algunas gráficas obtenidas con los cuestionarios aplicados durante el año 2013, pero las entrevistas fueron realizadas de manera sistemática durante las jornadas 2013,2014 y 2015. Se empleó la herramienta de la observación antropológica durante tres semanas del período ya mencionado. La razón se debe a que las jornadas de intimidación y acoso a los novatos inician muy prematuramente a la celebración como tal y continúan semanas después cuando los novatos son fácilmente identificables porque les han rasurado la cabeza y se presentan a clases luciendo las cabezas calvas. Aunque se documenta y sistematiza las jornadas de bautizo del año 2013, más formalmente, también se evaluó las jornadas de bautizos de los años 2014 y 2015. No se reportan las experiencias individualmente, porque no hubo mayor variación a excepción de las que se relatan en el capítulo de resultados y conclusiones.

En la ejecución de la investigación se procuró tener en cuenta la credibilidad (por cuanto es un criterio de rigor de toda investigación cualitativa) en el sentido de que las conclusiones a las que se llegaron reflejaran la realidad observada sin ningún tipo de sesgo ideológico. 
El método empleado fue el Etnográfico en donde se han implementado las herramientas de la entrevista a profundidad a diferentes actores, como ya se ha señalado. El objetivo fue contar con suficiente información que pudiera ser triangulada y minimizar el sesgo del investigador. Así mismo el recuperar la opinión de los principales actores (quienes desde hace más de cuatro décadas han estado presenciando este tipo de actividades) es importante porque se puede realizar un análisis en la línea del tiempo y realizar algunas reflexiones relativas a las tendencias.

Así mismo el evento denominado bautizo, conocido en el ámbito europeo como novatadas, fue observado sistemáticamente durante tres años (2013-2015) durante el día de la celebración (generalmente el mes de Febrero) y la semana que antecede y precede el evento porque en ellos también hay muestras de intimidación y acoso. En el año 2012 se realizaron estudios preliminares que aportaron información útil en el diseño de la presente Tesis Doctoral.

La muestra fue intencional y no representativa pues se seleccionó a la Facultad de Agronomía por ser considerada, de acuerdo a las publicaciones de prensa y denuncias estudiantiles presentadas ante las autoridades, como una de las más violentas en la Universidad de San Carlos de Guatemala. En esta investigación se privilegia el análisis, exploración y descripción del fenómeno de las novatadas en Guatemala mediante un estudio de caso. El objetivo de los estudios de caso es explicar eventos y tratar de comprenderlos (Miles et al., 1994).

Con respecto a la recopilación de la información, implementamos los siguientes pasos: i) Hemos recopilado información general acerca de los rituales de paso; revisando las investigaciones de los autores más destacados en el tema. ii) Hemos complementado esta información con una revisión bibliográfica acerca de los índices de violencia en Guatemala. iii) También hemos recopilado notas de prensa y videos publicados en YouTube en donde se señalan actos violentos dentro del campo de USAC, éstos se presentan en un disco compacto adjunto a la presente investigación. Fueron útiles para aportar ideas en la estructuración de la presente investigación. En el mismo archivo electrónico se ofrece la grabación de una entrevista realizada por estudiantes 
antiguos, quienes ofrecieron apoyar el proyecto de sensibilización acerca de "No a los bautizos en USAC”. iv) Se gestionó la obtención de las bases de datos de los estudiantes de primer ingreso de la Facultad de Agronomía. Estas se presentan en el capítulo que contiene los resultados de carácter cuantitativo. v) Se aplicó la herramienta de Observación Participante, durante la celebración del ritual de bienvenida en las jornadas 2013, 2014 y 2015. Se reporta la información recopilada en el bautizo realizado el día viernes 15 de febrero del año 2013.

Aunque la fiesta organizada por los estudiantes antiguos (supuesta bienvenida para los novatos) dura hasta la media noche, la observación del evento se redujo a las doce del mediodía. Ello debido a que los novatos tienen una mínima participación en la fiesta que supuestamente es organizada para darles la bienvenida. La explicación es sencilla; terminan agotados, semidesnudos, cubiertos de estiércol de animales de granja que su prioridad es encontrar una ducha donde poder asearse. De esto hablaremos en el capítulo de los resultados obtenidos. Una semana después y mientras permanecían en clase se aplicó un cuestionario dirigido a los estudiantes novatos. vi) Finalmente, se complementó esta información con la realización de dos grupos focales. El primero de estudiantes (novatos y antiguos indistintamente) y el segundo de profesores.

\subsection{El perfil de los participantes: Población y muestra}

Las novatadas son un fenómeno popular en Guatemala. Instituciones educativas, organizaciones deportivas, militares y otros sectores organizados ponen en práctica este tipo de celebraciones. Cada una implementa el ritual de bienvenida de acuerdo a la tradición establecida. Las prácticas son muy variadas y violentas en la mayoría de casos, pero existe una condición que las caracteriza y es que son dinámicas. En Guatemala las novatadas eran consideradas como simples bromas, juegos entre jóvenes; ocurren desde hace muchas décadas, hasta que en el año 2013 la madre de Mario Humberto Rodas llegó a instancias judiciales. El joven adolescente aprobó las 
pruebas para ser miembro de un equipo juvenil de balompié denominado Xelajú Mario Campo Seco. Los futbolistas antiguos lo bautizaron y cometieron serios abusos en contra de su integridad física y emocional por lo que fueron juzgados, ver la nota de prensa del diario Siglo 21 en ANEXO XVIII.

\subsubsection{La población objeto de estudio}

En la presente Tesis Doctoral se eligió como población meta los universitarios que interactúan en el campus central de la Universidad de San Carlos de Guatemala, durante los años 2013-2015. Ello porque a través de estudios preliminares se ha determinado que durante la celebración de las novatadas en esta institución de educación superior se han cometido una serie de abusos que van en contra de los Derechos Humanos de los estudiantes novatos. Aunque los principales medios de comunicación difunden algunas noticias al respecto, el tema aún es tratado con gran recelo en el medio sancarlista. Los motivos son muy variados, entre ellos destacan: a) A los infractores les interesa continuar el ciclo de abusos porque ello también les representa fuentes de ingreso por el recurso económico que se exige a los estudiantes que son bautizados. b) A las autoridades no les conviene sacar a luz un problema que es difícil erradicar. c) Entre algunos sectores estudiantiles es vergonzoso que los universitarios se comporten de esa manera. d) Algunos novatos tienen miedo de hablar porque generalmente son acusados de ser cobardes.

Según (Hurtado, 2011), en el campus central de la USAC interactúan cerca de 155000 estudiantes universitarios, que representan al 49.5 por ciento de la población estudiantil universitaria a nivel nacional y cerca de 70000 trabajadores docentes y administrativos ello representa un amplio laboratorio social. Es importante mencionar que la población estudiantil de USAC es sumamente heterogénea considerando que a sus aulas son convocadas personas de 
diversas condiciones económicas, procedencias, grupos culturales, edades e ideologías políticas. Así mismo que su crecimiento poblacional es acelerado, estimándose para el año 2015 una población estudiantil de 200000 estudiantes. Estas condiciones son suficiente razón para prever, que naturalmente siendo la USAC una institución educativa a nivel superior en donde prevalece la diversidad cultural y de pensamiento surgirán dinámicas sociales cuyo estudio es conveniente e interesante a la vez.

Según el sociólogo francés (Bordieu, 2003) citado por (Velasco, 2011)el considerar que las condiciones de los estudiantes son homogéneas es un grave error puesto que la cultura expresada en las comunidades educativas no es simplemente una cultura escolar sino más bien la expresión de una cultura de clase. A pesar de ello los bautizos son eventos que motivan la participación de cientos de estudiantes, independientemente de esas condiciones particulares pues al momento de la celebración del bautizo las condiciones de los estudiantes se homogenizan.

Por las razones antes expuestas es imperativo explicar que el presente estudio es de carácter exploratorio, por todas las condiciones ya referidas, sin embargo pretende aperturar una nueva línea de investigación denominada: “Las Dinámicas estudiantiles en la población sancarlista”, misma que pretende ser uno de los ejes del programa de Investigación-Acción de la Facultad de Agronomía de -USAC-. Hemos considerado que esta línea es de gran importancia porque en la Universidad de San Carlos se organiza para responder a las principales problemáticas del país, generando investigaciones y propuestas de solución. Sin embargo en muy pocas ocasiones acostumbra ver hacia adentro de la propia institución y reflexionar acerca de los problemas que surgen entre la población estudiantil.

A la fecha (Agosto 2015) no existen investigaciones específicas que exploren acerca de este fenómeno social. Esto se debe a que (según investigaciones preliminares) en el ámbito sancarlista se ha considerado que las novatadas son simplemente: una tradición estudiantil o un juego. En algunos sectores académicos el tema es considerado tabú y se considera preferible no hablar de él. Sin 


\section{Planteamiento del problema y metodología}

embargo el problema ha salido a luz pública debido a los escándalos provocados por los estudiantes durante las jornadas de bautizo, mismos que han sido publicados por importante medios de comunicación en Guatemala.

La riqueza de la presente Tesis Doctoral reside en que se documentó ampliamente un fenómeno que anteriormente era sinónimo de tabú y que por lo tanto no había sido abordado con seriedad. Esto porque hablar negativa o positivamente del evento significa, dentro del ámbito estudiantil, cobardía.

\subsubsection{La muestra o estudio de caso}

Como se ha explicado en el inicio del presente capítulo la muestra fue intencional y no representativa pues se seleccionó a la Facultad de Agronomía -FAUSAC- dentro de muchas otras unidades académicas de la -USAC-. Esta decisión se tomó por ser considerada (de acuerdo a las publicaciones de prensa y denuncias estudiantiles presentadas ante las autoridades) como una de las más violentas. A continuación se presentan los cuadros que contienen la información de la matrícula estudiantil de los estudiantes novatos de la Facultad de Agronomía para el año 2013. Ello con el objetivo de apreciar el número de estudiantes novatos involucrados en la actividad ya señalada. 


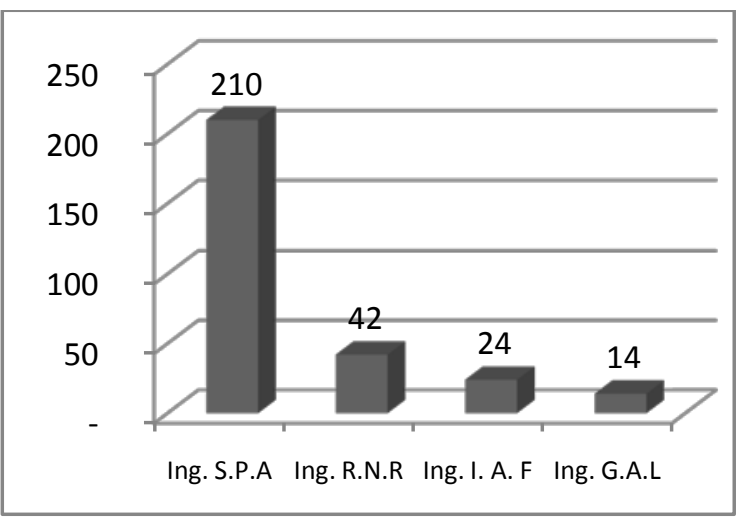

S.P.A $=$ Sistemas de producción agrícola R.N.R $=$ Recursos Naturales Renovables

A.F $=$ Agroindustrias Forestales

G.A.L = Gestión Ambiental Local

Figura 10. Estudiantes de Primer Ingreso Facultad de Agronomía/USAC, año 2013.

Fuente: Elaboración personal con datos otorgados por el Departamento de Registro y Estadística/USAC.

En el cuadro 1 puede observarse que el número de estudiantes de primer ingreso a la Facultad de Agronomía (ciclo académico 2013) fue relativamente bajo (290 estudiantes en total). Sin embargo el número de estudiantes antiguos es de 1286. El bautizo es una actividad sumamente popular en la cual participaron aproximadamente mil estudiantes. Al momento de la celebración del bautizo existían aproximadamente 23 estudiantes antiguos por cada estudiante novato. Es importante reconocer que no todos los estudiantes antiguos participan de esta celebración. Mientras que el bautizo es obligatorio para los novatos, los estudiantes antiguos pueden decidir si participan o no.

El grupo de alumnos ya mencionado fue considerado como el universo total de la población sobre la cual se realizó la investigación. El 100 \% de los estudiantes participantes en la novatada del año 2013, 2014 y 2015 fueron objeto de estudio mediante la técnica de la Observación Participante o Antropológica. Sin embargo los cuestionarios y grupos focales fueron aplicados a grupos más reducidos, pues mientras el bautizo era de carácter obligatorio para los novatos, el responder los cuestionarios nunca lo fue. De tal manera que aunque todos los novatos 2013 (290 estudiantes) fueron invitados a responder el cuestionario diseñado, únicamente 63 accedieron a hacerlo. 


\subsubsection{El perfil de los entrevistados}

A quiénes y cuántos entrevistar es un detalle importante por considerar. Según los expertos no existen recetas ni fórmulas universales, pero sí existen algunas claves que pueden ser útiles. Holstein y Gubrium (1995) citados por Valles (2002) recomiendan hacerse en cada circunstancia de investigación una pregunta clave. Esta es: ¿Qué voces serán oídas y cuáles silenciadas según nuestra particular concepción de la gente?

Los principales actores de la presente tesis doctoral son tres: i) Estudiantes novatos, ii) estudiantes antiguos y iii) profesores. Por esa razón haremos una breve descripción de algunos de los aspectos relevantes de cada uno de estos grupos que consideramos son de utilidad en la presente investigación.

i). Los estudiantes novatos: Las edades de los novatos de los años 2013 oscilaron entre los 17 y 20 años. El grupo es sumamente heterogéneo desde la perspectiva social, económica y de formación académica. En un 50 \% los jóvenes de primer ingreso son peritos agrónomos egresados de las diferentes escuelas técnico-agrícolas del país, en especial de la Escuela Nacional Central de Agricultura ubicada en el municipio de Bárcena, Villa Nueva. El resto son bachilleres en distintas especialidades y maestros de educación primaria, secretarias y peritos contadores. El 55 \% de los estudiantes son hombres y el restante $45 \%$ mujeres. ii) Los estudiantes antiguos:

El grupo estudiantil de los antiguos es también heterogéneo. Las edades oscilan entre los 18 y 65 años. El extremo superior en las edades se debe a que existen estudiantes que se han retirado por décadas de la unidad académica y han retomado estudios al ser mayores. Se ha determinado que estas personas no participan en la celebración del bautizo por diversas razones. Una de ellas es que la consideran sumamente perjudicial para la unidad académica (según entrevistas preliminares realizadas por la autora de la presente investigación). 
Con respecto al tema de género, Control Académico de la Facultad de Agronomía ha determinado que el 45 \% de la población estudiantil son mujeres. Respecto a las condiciones económicas de los estudiantes podemos mencionar que son también sumamente heterogéneas. Mientras que algunos estudiantes tienen una doble jornada en la cual deben trabajar para generar recursos económicos que les permitan estudiar; algunos otros se dedican exclusivamente a estudiar.

Entre los estudiantes que estudian algunos cuentan con condiciones económicas muy convenientes (son propietarios de vehículos particulares por ejemplo) algunos otros son procedentes de las áreas urbanas de la periferia y utilizan el transporte colectivo. Con respecto al grupo cultural, también existen diferentes condiciones. Algunos estudiantes se auto identifican como indígenas (vistiendo incluso sus trajes tradicionales) muchos otros se consideran mestizos. Como ya se ha hecho mención en otro apartado de la presente Tesis Doctoral durante la celebración del bautizo todas estas condiciones de los estudiantes se homogenizan y es un día en que no existen diferencias o categorías sociales. Únicamente existe un tipo de diferenciación vigente; antiguos versus novatos. iii) Los profesores de la Facultad de Agronomía: La edad de los profesores de la Facultad de Agronomía oscila entre los 40 a 65 años (que es la edad de retiro obligatorio, de acuerdo a la normativa establecida en la universidad).

Entre las características relevantes e importantes para la presente Tesis Doctoral mencionaremos que el 90\% de los profesores son ingenieros agrónomos de profesión y en su mayoría son egresados de la misma unidad académica en donde se realiza el estudio. El total de profesores es de 75 y la distribución por género es sumamente desigual; existiendo 4 profesoras y 71 profesores.

Es importante mencionar en esta sección que en el ámbito docente, el tema de las novatadas, es desestimado como un tema serio de estudio. Según entrevistas preliminares (realizadas por la autora) algunos profesores consideran que las novatadas son simples juegos, tradiciones, bromas 
que no merecen mayor atención de la comunidad científica universitaria. Prueba de ello es que muy pocos profesores aceptaron participar en el grupo focal organizado por las autoras.

Los profesores entrevistados, cuyos resultados se presentan en el siguiente capítulo, fueron aquellos que accedieron a otorgar tiempo para conversar relativo a un tema tan controversial. De la misma manera la invitación a la participación en grupos focales fue extensa al Claustro de la Facultad de Agronomía, habiendo participado únicamente 07 profesores. Esto a pesar que fueron invitados en reiteradas ocasiones, ello demuestra el desinterés o bien la poca importancia que le dan a la problemática.

\subsection{Enfoque cuantitativo de la investigación: Cuestionario sobre los ritos de iniciación o "bautizo” en la Facultad de Agronomía de USAC}

Por las características del fenómeno social que se ha abordado en la presente Tesis Doctoral puede determinarse que las herramientas empleadas en su mayoría corresponden a la investigación cualitativa, sin embargo tuvimos la oportunidad de implementar un cuestionario que fue diseñado para recopilar información de carácter cuantitativo. Consideramos que esta información vendría a complementar la obtenida mediante las entrevistas a profundidad y grupos focales. Los cuestionarios fueron aplicados durante los años 2013, 2014 y 2015 a grupos de estudiantes novatos de la Facultad de Agronomía de USAC. Éstas corresponden al período en el que se dio seguimiento al fenómeno en cuestión. Con los resultados obtenidos en el año 2013 se generaron gráficas que se presentan en el capítulo de resultados del estudio cuantitativo. Los resultados de las encuestas realizadas durante los años 2014 y 2015 fueron coincidentes con los obtenidos durante la jornada 2013 por lo que no fueron incluidos, sin embargo algún tipo de información relevante fue útil para complementar la información de carácter cualitativo obtenida en las entrevistas a profundidad y grupo focal. 


\subsubsection{Caracterización del cuestionario}

Fue dirigido a estudiantes de primer curso de la Facultad de Agronomía de USAC, una semana después de que los estudiantes novatos fueran bautizados por sus compañeros antiguos. Para poder diseñar los cuestionarios se realizó en 2012 una investigación preliminar denominada: “Los Ritos de Iniciación en la Universidad de San Carlos de Guatemala”, que fue presentada a la UPSA como Investigación Tutelada. La información generada en esta investigación permitió modelar y ajustar algunas preguntas de investigación, tal como se determina en el siguiente cuadro.

\begin{tabular}{|c|c|c|}
\hline Objetivos específicos & Variables evaluadas & Preguntas planteadas \\
\hline \multirow[t]{3}{*}{ 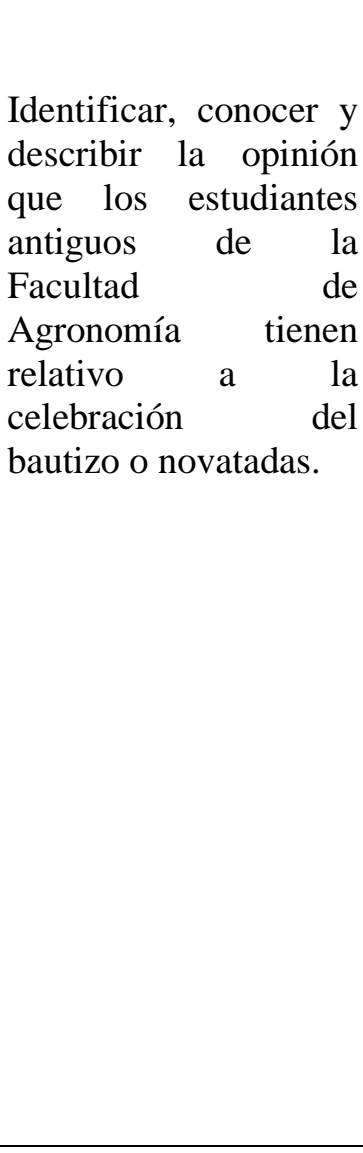 } & $\begin{array}{l}\text { Grado de aceptación del bautizo. } \\
\text { Grado de percepción del daño } \\
\text { mental y emocional que provocan } \\
\text { las novatadas en los estudiantes } \\
\text { novatos. }\end{array}$ & $\begin{array}{l}\text { 1.Si fuiste bautizado puedes catalogar la } \\
\text { práctica como: } \\
\text { Es un juego alegre y divertido } \\
\text { Una actividad necesaria } \\
\text { Es denigrante } \\
\text { Me es indiferente } \\
\text { 2. Cómo te sientes cuando culmina el } \\
\text { bautizo de los novatos y los observas } \\
\text { semidesnudos, enlodados y a veces } \\
\text { alcoholizados. } \\
\text { Me causa gracia. } \\
\text { Me da pena, pero todos debemos pasar } \\
\text { por eso. } \\
\text { Me es indiferente. }\end{array}$ \\
\hline & $\begin{array}{l}\text { Tendencia a futuro de la } \\
\text { celebración de las novatadas. }\end{array}$ & $\begin{array}{l}\text { Si en tus manos estuviera la decisión } \\
\text { acerca de los bautizos, ¿qué harías? } \\
\text { Que se sigan celebrando } \\
\text { Que se prohíban } \\
\text { Que se regulen }\end{array}$ \\
\hline & $\begin{array}{l}\text { Percepción estudiantil } \\
\text { novatos tienen relativo al } \\
\text { físico que les es provocado. }\end{array}$ & $\begin{array}{l}\text { Consideras que los estudiantes } \\
\text { bautizados } \\
\text { Pasan un buen momento y se divierten } \\
\text { Algunos resultan con lesiones leves } \\
\text { Algunos resultan con lesiones severas }\end{array}$ \\
\hline & $\begin{array}{l}\text { Percepción estudiantil relativa al } \\
\text { tema de la seguridad dentro del } \\
\text { campus central de USAC. }\end{array}$ & $\begin{array}{l}\text { Te sientes seguro al caminar por el } \\
\text { campus central de USAC? }\end{array}$ \\
\hline
\end{tabular}

Cuadro 13.Preguntas planteadas en cuestionario aplicado a estudiantes novatos.

Fuente: Creación personal con datos elementos obtenidos en investigaciones preliminares realizadas por la autora 2012. 
Las preguntas son de carácter cerrado (por cuanto había necesidad de sistematizar posteriormente los resultados) y fueron planteadas para conocer la percepción que los estudiantes novatos tenían de la celebración del bautizo, una semana después de haber sido bautizados. Las herramientas fueron previamente aplicadas en el sector estudiantil con el objetivo de realizar los ajustes necesarios. Se presentan los resultados de los cuestionarios aplicados a los novatos del ciclo académico 2013. Durante los años 2014 y 2015 también fueron entrevistados algunos novatos y se aplicó el mismo cuestionario empleado en el año 2013 obteniendo resultados que confirmaban los obtenidos durante el año 2013. Similar situación ocurrió con los cuestionarios aplicados durante el año 2014, por tal razón, algunos pequeños hallazgos se incorporaron a los resultados obtenidos en el año 2013. En otro sentido, hacemos la observación que la validez del cuestionario se basa en la observación de que los resultados obtenidos se ajustan a la realidad, dado que se trata de explorar hechos probados.

\subsection{Enfoque cualitativo de la investigación}

En la presente Tesis Doctoral hemos privilegiado el carácter reflexivo de la investigación social haciendo uso de herramientas de carácter cualitativo para acercarnos objetivamente a un

fenómeno real y contemporáneo, las novatadas en la USAC. Entre estas herramientas sobresale la observación antropológica u observación participante. Nos hemos acercado paulatinamente al fenómeno de la celebración de la novatada o bautizo en la FAUSAC a través de jornadas de observación sistemática de la actividad realizada durante los años 2013, 2014 y 2015.

Las preguntas de investigación planteadas en el inicio del capítulo dieron origen a los objetivos generales y específicos planteados en la presente investigación. A su vez éstas dieron origen a los cuadros 15 y 16 en los cuales se sintetizan los objetivos, variables y preguntas utilizadas como guía en la implementación de grupos focales y cuestionarios aplicados. 


\subsubsection{Descripción de las herramientas cualitativas empleadas}

La información obtenida en los cuestionarios fue complementada con la aplicación de otras herramientas de la investigación cualitativa como las i) Entrevistas a profundidad, según determina Valles (2002) en este tipo de entrevista se busca un conocimiento más a fondo (asuntos muy personales) experiencias vividas, valores y decisiones, etc. Según Atkinson y Silverman (1997) retomados por Gubrium (2002) las propiedades confesionales de la entrevista no solo construyen la subjetividad individual, sino que profundizan y amplían las verdades experienciales de los sujetos. Ya no recurrimos al cosmos, a los dioses, a la palabra escrita, al sumo sacerdote o a las autoridades locales en busca de conocimiento auténtico, más bien buscamos habitualmente la autenticidad a través de la entrevista a profundidad. Durante la entrevista se cumplió con las siguientes condiciones: a) la participación del entrevistado y del entrevistador contaba con expectativas explícitas: el uno de hablar y el otro de escuchar. b) Se animó al entrevistado a hablar libremente sin contradecirle nunca. Para poder realizar las entrevistas a profundidad se contaba con un guión estructurado previamente. Este se planteó de la misma manera que el guión empleado para los grupos focales y cuestionario; es decir orientados a dar respuesta a las preguntas de investigación planteadas en el inicio del presente capítulo.

Uno de los factores determinantes del éxito en este tipo de actividad fue haber propiciado un ambiente de confianza y reciprocidad. Hubo necesidad de ofrecerles a los estudiantes la confidencialidad de sus declaraciones conservándolas en el anonimato, por esa razón los nombres empleados son ficticios. Sin embargo, la edad y el género del participante son reales.

Los grupos focales fueron implementados en uno de los salones donde los estudiantes reciben clases. Este elemento fue positivo porque es su ambiente natural, las mismas condiciones se otorgaron a los profesores que participaron en el respectivo grupo focal. 


\subsubsection{Dimensiones del estudio cualitativo realizado}

En el presente estudio de caso hay muchos actores implicados: profesores, estudiantes novatos, antiguos, personal administrativo, autoridades, medios de comunicación, etc. Sin embargo hemos privilegiado las voces de aquellos que interactúan directamente en la celebración de las novatadas. En este caso nos referimos a los profesores y estudiantes. Por esa razón los grupos focales se han reducido a estos dos actores.

Al grupo focal estudiantil fueron invitados muchos estudiantes, pero solamente algunos decidieron participar. Esto se debe a que las novatadas son consideradas por muchos, un tema prohibido de conversación. Prevalece la idea que los bautizos, "son lo que son y seguirán siendo lo mismo ${ }^{28,}$. La manera en que se lleva a cabo la celebración. El procedimiento para invitar al grupo focal estudiantil fue caminar por los pasillos (un día antes del evento) y explicar el objetivo de la actividad, asegurando que era únicamente con fines de investigación. La actividad se realizó en un horario en el cual no existiera interrupción al horario normal de clases.

Posterior a esta invitación personalizada, veintiséis estudiantes aceptaron participar en el grupo focal. Los requisitos para poder ser parte de este grupo fueron a) haber sido bautizados, b) ser estudiantes regulares de FAUSAC y c) Desear participar.

En el cuadro 16 se presentan los nombres de los estudiantes que finalmente desearon hablar del tema. Es importante mencionar que participaron 03 jóvenes y 06 señoritas.

\footnotetext{
${ }^{28}$ Este es el argumento más común empleados por los estudiantes antiguos que rechazaron la invitación a participar en los grupos focales.
} 


\begin{tabular}{|c|l|c|}
\hline No. & Nombre & Año de ingreso a la Facultad de Agronomía \\
\hline 01 & Miguel Ángel De León & 2013 \\
\hline 02 & Sara Rebeca Puzul & 2007 \\
\hline 03 & Ariel Girón & 2012 \\
\hline 04 & Ana Montejo & 2006 \\
\hline 05 & André Pedroza & 2012 \\
\hline 06 & Paola Pastor & 2012 \\
\hline 07 & Maggy Monroy & 2012 \\
\hline 08 & Jackeline Marroquín & 2012 \\
\hline 09 & Rosana Pérez & 2012 \\
\hline
\end{tabular}

Cuadro 14. Estudiantes participantes en grupo focal.

Fuente: Creación personal con datos del evento.

Tampoco se hizo ninguna distinción de género ni pertenencia al grupo organizado dentro de la unidad académica.

Para considerar todos los puntos de vista posibles también se organizó un Grupo focal de profesores: La invitación a participar en el grupo focal de docentes fue realizada a todos los profesores titulares de la Facultad de Agronomía (75 profesores), respondiendo positivamente 15 de ellos. Sin embargo el día del evento participaron únicamente 7 personas. A pesar de ello, la experiencia fue muy enriquecedora porque la formación de cada uno de los profesores es muy diversa. Ello es comprensible porque aunque el 95\% de los profesores son egresados de la Facultad de Agronomía y fueron bautizados en su oportunidad, ello ocurrió en distintos momentos históricos (décadas 1980-1990-2000-2010). Esto permitió tener una perspectiva en la línea del tiempo.

En el presente cuadro se presentan los nombres se los profesionales que accedieron a participar en la actividad, quienes estuvieron de acuerdo en que sus nombres y comentarios fueran divulgados en la presente investigación. 


\begin{tabular}{|c|c|c|c|}
\hline No. & Nombre completo & $\begin{array}{l}\text { Año en que ingresó a la Facultad de } \\
\text { Agronomía como docentel Área a la que } \\
\text { pertenece }\end{array}$ & $\begin{array}{l}\text { Año en que ingresó a la } \\
\text { Facultad de Agronomía } \\
\text { como estudiante. }\end{array}$ \\
\hline 01 & Hugo Antonio Tobías & 1980/ Subárea de Manejo de Suelo y Agua. & 1972 \\
\hline 02 & José Pablo Prado Córdova & 2001/Ciencias Sociales y Desarrollo Rural. & 1992 \\
\hline 03 & Sandra Castañeda Paiz & $\begin{array}{l}\text { 2005/Subárea de Ciencias Sociales y } \\
\text { Desarrollo Rural }\end{array}$ & $\begin{array}{l}\text { Egresada de la Facultad de } \\
\text { Ciencias Jurídicas }\end{array}$ \\
\hline 04 & Pedro Celestino Cabrera & $\begin{array}{l}\text { 2001/Subárea de Ciencias Sociales y } \\
\text { Desarrollo Rural }\end{array}$ & $\begin{array}{l}\text { Egresado de la Escuela de } \\
\text { Historia de USAC }\end{array}$ \\
\hline 05 & José Mario Saravia Morales & 1995/Subárea de Ciencias Forestales & Ingeniero Forestal \\
\hline 06 & Eddy Vanegas Chacón & 1991/Área Tecnológica & 1984 \\
\hline 07 & Fredy Hernández Ola & 1980/Área Integrada & 1970 \\
\hline
\end{tabular}

Cuadro 15. Profesores que participaron en el grupo focal.

Fuente: Creación personal con datos obtenidos el día del evento.

Los profesores participantes pertenecen a diferentes subáreas y tiene diferentes especialidades. Algunos ingresaron a la Facultad de Agronomía como estudiantes desde la década de 1970 por lo que pueden revelar algunas características del bautizo en la unidad académica desde sus inicios. De la misma manera los profesores más jóvenes pueden otorgar una perspectiva objetiva de la manera en que se celebran los bautizos en épocas modernas. En el capítulo 7 se presentarán los resultados de estos grupos focales. 


\section{CAPÍTULO 7: ESTUDIO DESCRIPTIVO DE LAS NOVATADAS EN LA FACULTAD DE AGRONOMÍA}

"El buen pensador procura ver en todos los objetos todo lo que hay Pero, no más de lo que hay”. Jaime Balmes

\subsection{Estudio de caso}

Los bautizos en la Universidad estatal de Guatemala constituyen una tradición profundamente arraigada desde hace décadas. Aunque las autoridades han realizado una serie de esfuerzos para erradicar las prácticas violentas dentro de los mismos, la práctica permanece más vigente que nunca. Con el objetivo de comprender mejor este fenómeno cuya evolución revela la tendencia a la agudización de la violencia se presenta un estudio de caso en la Facultad de Agronomía.

\subsubsection{Antecedentes del estudio de caso}

La celebración del rito de iniciación del bautizo en la USAC es de carácter obligatorio en las unidades académicas en las cuales ha sobrevivido tal práctica. En estas condiciones se convierte en una actividad de carácter masivo, naturalmente este hecho tiene serias implicaciones relativas al desborde y excesos cometidos considerando que la edad de los estudiantes oscila entre 17 y 25 años.

La Facultad de Agronomía fue fundada en el año 1963. Originalmente la carrera de Agrónomo fue de carácter generalista en cuatro vertientes principales: Fitotecnia, Fitopatología, Suelos y Riegos y Drenajes. El número de estudiantes que ingresaban a la Facultad de Agronomía 
era muy limitado por lo que la celebración de los bautizos fue adoptada, en la década de los ochenta) de otras unidades académicas (originalmente fue promovida por la Facultad de Ciencias Médicas y Derecho).

Fue hasta la década de 1980 cuando los estudiantes antiguos iniciaron a organizarse para darle la bienvenida a los novatos. Originalmente la práctica comúnmente aceptada era el corte de cabello y rasgado de la ropa (en el caso de los varones). Posteriormente en la década de los 2000 la actividad se fue transformando y se incorporaron nuevas prácticas, como la ingesta de alimentos en descomposición, licor y recorrido por el campus universitario. Del año 2010 a la fecha, la celebración del bautizo se ha convertido en un desborde de prácticas que atentan en contra de la integridad física y psicológica de los novatos. Otro elemento interesante es que en el período comprendido entre 2000-2010 se incrementó, vertiginosamente, la población femenina. Ello como una consecuencia natural que en la Escuela Nacional Central de Agricultura -ENCA ${ }^{29}$ - se aceptaron estudiantes mujeres a partir del año de 1991. Ello ha incorporado nuevos elementos a las prácticas del bautizo de las novatadas. Actividad que siempre ha estado en manos de las estudiantes antiguas, quienes hacen gala de su creatividad y en cierta manera de la malicia.

\subsection{Descripción de las novatadas en la Facultad de Agronomía}

Aunque el bautizo de los novatos se realiza en un solo día, el acoso hacia los recién llegados a la facultad es desde el primer día en que se presentan a la universidad. Pronto se les inicia a etiquetar como “nuevos”. Se les grita cuando van por los pasillos, se les intimida aun cuando están dentro de los salones interactuando con sus profesores. Esta situación es parte de la cotidianeidad de

\footnotetext{
${ }^{29}$ En la actualidad la Escuela Nacional Central de Agronomía es una de las más importantes instituciones educativas en el campo de la Agronomía. Es importante aclarar que en esta institución las novatadas son populares y según revelan entrevistas a egresados, son sumamente deshumanizantes, ver anexo.
} 
los primeros días de clases, a inicios del ciclo académico en el mes de enero hasta la segunda semana del mes de febrero cuando se realiza el esperado y temido evento.

Durante estas jornadas los estudiantes antiguos hacen valer su antigüedad, llevando entre los bolsillos juegos artificiales, lanzando cohetillos por los pasillos, inclusive dentro de los salones, irrespetando de esta manera las actividades académicas. Desde ese momento los estudiantes novatos saben que la intimidación será constante hasta el día del bautizo.

Los estudiantes antiguos han marcado ya su territorio y establecen una relación de poder en la que se sienten sumamente cómodos, a juzgar por su proceder. Entre risas y burlas, eligen a quienes serán sus “nuevos”, inician a buscar características sobresalientes en los novatos (reales o imaginarias) para acuñar sobrenombre que les acompañarán toda la vida estudiantil y a veces aún en el ámbito profesional. Algunos estudiantes novatos aprovechan el hecho de tener algún amigo, familiar o conocido dentro de los estudiantes antiguos para pedirle que sea su "padrino", como veremos en el transcurso de la investigación, estos también cumplen con una función importante.

A pesar que existe una prohibición expresa de la celebración de las novatadas (llamadas en el medio sancarlista, bautizos) los estudiantes siguen practicándolas sin que las autoridades tomen medidas disciplinarias. Debido a las faltas cometidas diariamente por los estudiantes en los pasillos se han instalado (desde el año 2012) cámaras en los pasillos, sin embargo cuando cometen tales faltas buscan estrategias como aglutinarse frente a las cámaras con el objetivo que las faltas queden en la impunidad.

Otro aspecto importante que evita que los estudiantes tengan que rendir cuentas es el uso de la capucha verde (ver figura 10). Es justamente en el inicio de semestre cuando surge el uso de las capuchas, muchos estudiantes esperan este momento porque ello les permite adquirir una identidad diferente. Anulan su propia identidad y se convierten automáticamente en un encapuchado como suelen llamarse. Es importante señalar que los estudiantes también usan sotana del mismo color de la capucha y en algunas ocasiones cubren sus manos usando guantes de cualquier material. 
Todo este atuendo se hace necesario pues desde la impunidad es posible ser violento con sus compañeros, gritar groserías y faltar al respeto a las mujeres, inclusive retar (colectivamente) a sus profesores.

Este hecho reviste gran importancia pues tal como afirma Zimbardo (2008) el carácter de una persona puede transformarse por las condiciones. De esta manera un estudiante promedio con un comportamiento que demuestra respeto y en algunos casos empatía hacia sus compañeros, puede transformarse durante estas jornadas en un energúmeno que es parte de la manada, parte de los que insultan y desprecian a todos los novatos. En las entrevistas a profundidad realizada a algunos estudiantes reconocieron que muchos llegan a la universidad creyendo que este es un lugar donde todo les será permitido, en donde pueden hacerse cosas que antes no se hacía. Es así como fumar, beber licor y conductas inapropiadas, son permitidas; mejor aún son símbolo de estatus y demuestran que el estudiante es popular.

La comunidad estudiantil tolera tales desórdenes y los considera hasta normales. En algunas ocasiones cuando la situación desborda los ánimos de los estudiantes, algunos profesores optan por cancelar la clase, retirándose a su oficina. En este momento los estudiantes antiguos se anotan una victoria que les hace reafirmar el poder y control que tienen del medio durante estas celebraciones. El uso de la capucha verde puede considerarse también un ritual y simboliza que el estudiante que la porta está investido de cierto poder que le autoriza a cometer ciertos desórdenes y faltas que sin ella no se atrevería a hacer.

A continuación, se describe la jornada vivida el día 08 de febrero del año 2013, una semana previa a la celebración del bautizo de los estudiantes novatos para aportar mejores elementos que permitan describir el fenómeno social que estamos presentando.

El viernes 08 de febrero a las 9:00 de la mañana en la Facultad de Agronomía se vivió un ambiente de incertidumbre y tensión pues iniciaron las actividades estudiantiles que anunciaban la celebración del ritual del bautizo. Ello aún en desacato a la prohibición expresa por las autoridades 
académicas y administrativas de FAUSAC. Pareciera que mientras más prohibiciones hay, mejor es la recompensa al realizar la celebración porque entonces queda claro quienes "mandan en la universidad”.

Muy de mañana, los estudiantes que son miembros de la Asociación de Estudiantes de Agronomía -AEA- vistieron las tradicionales sotanas y capuchas de color verde y haciendo gala de su fuerza entraron violentamente a los salones en donde los novatos recibían clases. Les indicaron que debían salir y congregarse en el auditórium de la Facultad. En esta oportunidad la autoridad de los profesores se vio completamente anulada pues nada se pudo hacer por evitar el desorden y optaron por abandonar las aulas y regresar a sus oficinas.

Una de las justificaciones más frecuentes expresadas por los profesores, al consultarles el ¿por qué de su comportamiento? es que: los “supuestos” estudiantes miembros de la asociación escondían sus rostros en capuchas y llevaban consigo morteros ${ }^{30}$, bates de madera y cadenas constituyéndose en individuos sumamente violentos. De alguna manera (según experiencia de la autora quien también es profesora en tal unidad académica), la presencia de cincuenta estudiantes que cubren su identidad con capuchas y portan bates y cadenas, es en verdad intimidante.

Es importante hacer mención que para poder secuestrar a los novatos, sacándolos de sus aulas, los organizadores de la actividad, previamente habían encerrado al Señor Decano, Secretarios Académicos y Administrativos en sus oficinas. Esto ocurrió a las 8:50 horas. Para ello hicieron uso de cadenas y candados. Ante esta situación a las autoridades no les quedó otra alternativa que esperar que los estudiantes terminaran su actividad y retiraran los candados de los portones de metal.

\footnotetext{
${ }^{30}$ Mortero: Tipo de fuego artificial de gran potencia capaz de provocar serios daños a la integridad física humana.
} 


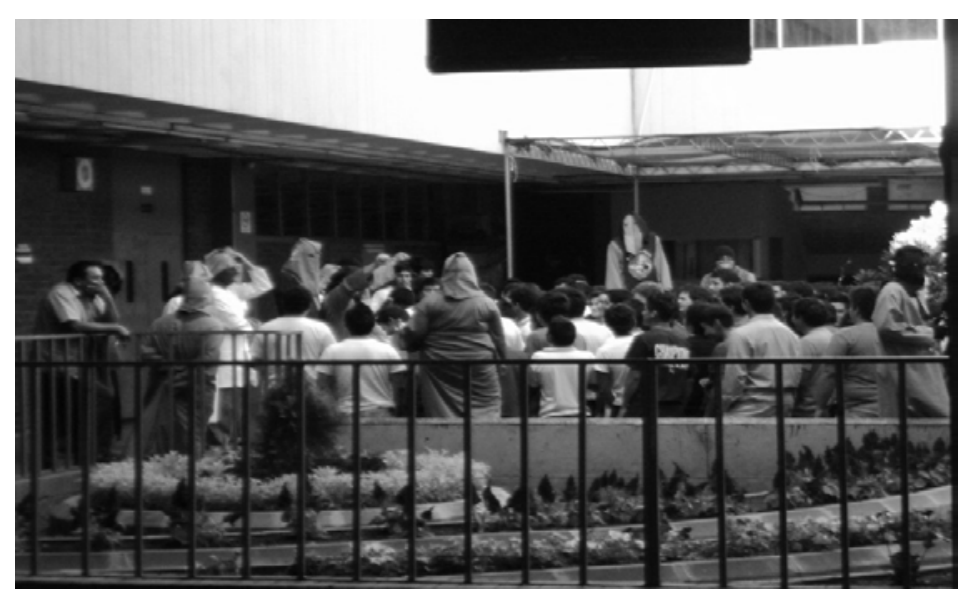

Figura 11.Estudiantes de Agronomía vistiendo las tradicionales capuchas y sotanas Fuente: Fotografía tomada por la autora el día 15 de Febrero de 2013.

En esa ocasión los miembros del Honorable Comité de Huelga, conocidos también como “Los Verdes” (encapuchados) introdujeron a los novatos al auditórium y apagaron completamente las luces y lanzaron cohetillos sobre los novatos. Posteriormente, otro grupo ingresó al salón portando cirios encendidos. Al tomar la palabra instruyeron a los novatos acerca de lo que debían hacer el viernes 15 de febrero durante la celebración de su bautizo.

La primera recomendación fue que el bautizo era de carácter obligatorio y por lo tanto aquellos que pretendieran burlar lo establecido serían castigados y tendrían un bautizo "privado" con lo que aumentarían los riesgos que habrían de correr. Así mismo, sin excepción, deberían entregar a partir de la fecha una botella de aguardiente y Q100.00 (aproximadamente \$12.00) para el financiamiento de la fiesta de bienvenida y la compra de la playera conmemorativa. Así mismo que deberían llevar ropa limpia para poder retirar la utilizada durante la celebración.

Posterior a las recomendaciones dadas a los estudiantes antiguos derramaron sobre el piso una mezcla de agua y jabón en polvo posteriormente lanzaron nuevamente cohetillos sobre los estudiantes. Algunos de los novatos cayeron al piso al intentar evitar ser quemados por los cohetillos. 
En los rostros de los estudiantes antiguos se reflejaban sonrisas picarescas mientras que los estudiantes de primer ingreso, como es natural, reflejaban en sus rostros incertidumbre, asombro y temor.

Se Observó a una chica, de aproximadamente 18 años, que estaba sola en el pasillo y se le pudo formular la siguiente pregunta:

¿Por qué lloras, es debido a las actividades del bautizo?

"Son muchas emociones juntas, en cierta manera estoy contenta porque pronto llegará el día del bautizo, tendré que sobrevivir a él y dejaré de preocuparme tanto. A decir verdad terminará la pesadilla, estoy definitivamente nerviosa”. Evelyn, estudiante de primer ingreso.

Algunas otras muchachas reían nerviosamente en los pasillos y algunas otras no salían de su asombro al ver lo que sucedía. María (19 años) indicó: “Mis padres me advirtieron que no debía matricularme en la Facultad de Agronomía, todo mundo sabe que aquí hay puros machos y que son bien brutos y malcriados, pero a mí en verdad me gusta la agricultura. Pienso que seré una buena profesional porque cuando me pongo las pilas ${ }^{31}$ las cosas salen bien. Sé que eso del bautizo es bien feo, pero tengo que soportarlo, después de la otra semana ya no seré nueva y nadie tendrá porqué estarme humillando”.

Muchas de las preocupaciones de los estudiantes novatos relativos a su bautizo son fundadas en las historias, anécdotas y hasta amenazas proferidas por estudiantes antiguos, familiares y amigos. También en los periódicos, radio y televisión se da cobertura a la noticia y se hace público el desorden y excesos. Durante una semana completa los estudiantes antiguos estuvieron interrumpiendo las clases e intimidando a los estudiantes de primer ingreso, asegurándoles que la experiencia del bautizo programado para el viernes 15 de febrero seria inolvidable. El lenguaje empleado era totalmente fuera de tono, la conducta agresiva e irrespetuosa fue el denominador

\footnotetext{
31 “Ponerse las pilas”: En Guatemala y en especial en el ámbito juvenil esta expresión significa esforzarse al máximo y trabajar duro para alcanzar los objetivos deseados.
} 
común. Al respecto de ello también se pudo comprobar que muchos de los profesores rechazan las acciones de los estudiantes antiguos, indicando que es necesario que las autoridades pongan un hasta aquí a la barbarie, otorgando castigos ejemplares a los infractores. Sin embargo la situación es sumamente compleja porque no hay a quien castigar, si las principales faltas han sido cometidas por estudiantes que portan sotanas y capucha. De esto hablaremos posteriormente.

Ahora bien, el tan esperado día (para los veteranos dispuestos a participar en el evento) y temido por los novatos (quienes solo quieren que la jornada de bautizo termine) llegó a continuación se describe lo acontecido.

La Facultad de Agronomía es mixta, pero el bautizo es realizado por género. El bautizo de las mujeres inició a practicarse en la década del 2000 cuando inició a incrementarse el ingreso de la población femenina. Esta coincidió con el egreso de agrónomas de la Escuela Nacional Central de Agricultura (estudios a nivel medio) y otras importantes escuelas agrícolas del país. Esto debido a que buen porcentaje de las egresadas de esas escuelas tienen como es natural, interés en estudiar la carrera de Agronomía a nivel universitario. Años anteriores las novatas no eran bautizadas, tal como la suerte que corrió la autora de la presente investigación, pues habiendo ingresado en el año de 1994 (junto a tres chicas más) no sufrimos ningún tipo de novatada o evento de este tipo. Parece que para ese tipo de eventos es necesario contar con una multitud que "anime y se anime a cometer acciones que en lo individual nunca se harían”. El efecto de masa es aquí primordial, como ha quedado demostrado.

\subsection{Bautizo de las mujeres}

Durante los tres años que fue documentada la novatada en la Facultad de Agronomía (20132015), guardó el mismo esquema de desarrollo que se describe a continuación: 
El estudiantado en general de la FAUSAC fue citado a las 6:30 de la mañana al parqueo de uno de los edificios de la Facultad de Agronomía. En el caso de las novatas fueron invitadas a enfrentarse en un encuentro futbolístico contra las estudiantes antiguas. Considerando que existía un ambiente de mucho nerviosismo pudo observarse fuertes choques y un estado de excitación que hacía que las muchachas iniciaran a agredirse verbalmente. En este momento las novatadas aún se defienden y tratar de hacerse respetar, situación que sería completamente suprimida durante la celebración del bautizo como veremos a continuación. El encuentro deportivo terminó rápidamente y las novatas fueron conducidas, por estudiantes encapuchados (armados con bates, cadenas y palos) a los campos de Experimentación Agrícola de la Facultad. Un día previo a la celebración del bautizo el lugar había sido acomodado para dar lugar a nueve estaciones por cada una de las cuales tenían que pasar cada una de las novatadas. Cada una de ellas representaba un reto con especial complicación. A continuación veremos en qué consistía cada una de ellas.

\subsubsection{Primera estación: El Rodeo}

La Facultad de Agronomía cuenta con un rodeo que es utilizado durante las celebraciones estudiantiles de principio o medio año para realizar jaripeos en que participan estudiantes e invitados. Este posee grandes dimensiones y fue suficiente para que las novatas pudieran hacer todo tipo de ejercicios físicos. Desde correr, hacer sentadillas, saltar, brincar como sapitos, hacer despechadas, etc. Esta era apenas la primera fase y considerando que el piso es de tierra, al cabo de quince minutos se había elevado una polvareda difícil de tolerar. Muchas de las novatas tosían y daban muestra de cansancio, sin embargo la actividad no se detuvo sino hasta dos horas después cuando los encapuchados y estudiante que portaban la camiseta de “orden” dieron la señal que era momento de detenerse. 
Durante toda la jornada les lanzaban cohetillos y todo tipo de fuegos pirotécnicos. La dirección de la actividad estuvo a cargo de estudiantes encapuchados (quienes supuestamente cumplían el papel de guardar el orden) y estudiantes mujeres antiguas, identificadas con playeras de color verde. Estas playeras tenían un tipo de serigrafía especial en donde se leía la palabra “orden”, así como una caricatura en donde se ridiculizaba a autoridades administrativas y sector docente. Estas fueron adquiridas previamente, con motivo especial de la celebración. Considerando que muchas de las alumnas se hicieron presentes a la cita del bautizo sin haber ingerido ningún tipo de alimentos, algunas flaquearon y se desmayaron, habiendo sido sacadas físicamente del rodeo. Algunas de ellas pudieron retirarse del evento.

Aunque el esfuerzo físico fue grande y la inhalación de polvo también, aún hacía falta camino por recorrer. La relación de poder establecida por los veteranos, encapuchados y estudiantes de orden sobre los novatos apenas iniciaba a marcarse. La jornada aún era joven y había que proseguir a la segunda estación, como lo veremos a continuación.

\subsubsection{Segunda estación: El piletazo}

Dentro de los campos agrícolas en donde se realizó el evento (denominados campos del CEDA) existe desde hace décadas una pileta de cemento de dimensiones aproximadas de 7 metros de ancho por 15 de largo. Ella es empleada usualmente para la crianza de peces de especies comerciales. Sin embargo algunos días antes del bautizo los trabajadores tuvieron la necesidad de sacar todos los peces porque fueron informados que los estudiantes veteranos emplearían la pileta para el bautizo en agua de los novatos. Con esta motivación vertieron en sus aguas: ajo picado,

cebolla, gallinaza, cerdaza, estiércol de vaca, y algunos cadáveres de ratas, sapos y todo tipo de material fétido que encontraron a su paso. La pileta estaba a un $70 \%$ de su capacidad y las alumnas 
fueron obligadas a sumergirse hasta el pecho. Allí les hicieron entonar algunos cantos (que previamente les recitaban) utilizando un lenguaje sumamente vulgar. También fueron obligadas a entonar el Himno Nacional de Guatemala. Cuando olvidaban entonar alguna estrofa eran castigadas exigiendo que iniciaran de nuevo. Al culminar les hicieron sumergirse completamente en aguas negras.

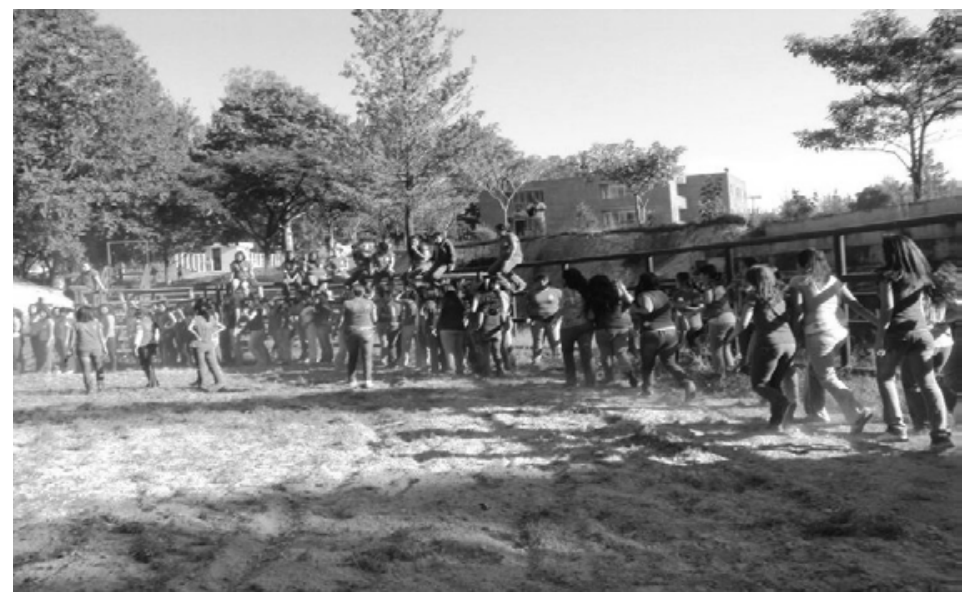

Figura 12.Estudiantes novatas (Año 2013).

Fuente: Fotografía tomada el día el evento.

\subsubsection{Tercera estación: El Desayuno}

Posteriormente obligaron a las alumnas a comer pan untado con una mezcla de ajo y cebolla. El detalle era que nada de lo ofrecido era fresco. Todo había sido preparado con tres días de anterioridad. De esa cuenta que ya había iniciado un proceso de fermentación y el olor de aquellos brebajes y alimentos era tan intensos que podían percibirse a decenas de metros de distancia. Posteriormente les obligaron a beber un brebaje de color blanco y consistencia espesa. Los ingredientes de este eran ignorados, sin embargo no existía la menor posibilidad de evadir el control ejercido por las estudiantes de orden y encapuchados, de tal manera que había que beberlo. Considerando que algunas chicas se negaban a hacerlo, les abrían la boca a la fuerza. Las 
estudiantes antiguas llevaban en las manos bolsas plásticas, a manera de guantes, esa acción demostraba que lo que estaban sirviendo a las novatas eran sustancias sumamente peligrosas capaces de provocar desde indigestión estomacal hasta intoxicaciones. Algunas muchachas no pudieron deglutir lo ofrecido y vomitaban; en cuanto lo hacían, las obligaban a comer y beber una nueva ración hasta que lograran retenerla en el estómago. De no hacerlo, tenían que intentarlo cuantas veces fuera necesario, solamente de esa manera podían pasar a la próxima estación. Aunque en este momento la situación era ya insoportable para las novatadas, aún no había terminado. Todavía estaban preparadas otras seis estaciones y por si fuera poco, las veteranas seguían en todo momento a las novatas, intimidándolas con maltrato verbal, empujones, sobrenombres y burlas. Es importante recalcar que ninguno de los hombres tenía derecho a presenciar el evento, únicamente aquellos que poseían el privilegio de pertenecer a los verdes y portar capuchas.

\subsubsection{Cuarta estación: Las semillas de pino}

En esta estación se encontraban diez recipientes plásticos. Cinco de ellos estaban llenos de agua mezclada con vinagre y flotando en esa mezcla había semillas de pino (recolectadas en días anteriores). En el resto de recipientes había la mezcla de agua y vinagre sin las semillas de pino. El reto consistió en que las novatas debían pasar de un recipiente a otro las semillas de pino. Las cubetas eran gigantes de tal manera que las novatas pudieran meter la cabeza, a lo cual fueron obligadas (en caso que llegaran a negarse). Ninguna de las novatas presentó resistencia ante tal prueba y más bien se alentaban unas con otras a continuar, diciendo que eran capaces de hacerlo. Algunas reían nerviosamente, otras mostraban miedo, pero no por ello se detuvieron o pidieron salir del evento. 
Cada alumna que terminaba pasando las semillas de pino podía pasar a la siguiente estación, que describiremos a continuación.

\subsubsection{Quinta estación: Refacción con huevo crudo}

En esta estación las novatas fueron obligadas a tragar un huevo de gallina crudo. De nuevo si alguna muchacha vomitaba, era obligada a tragar nuevamente otro huevo. Hasta que la prueba fue superada pudieron pasar a la siguiente estación. Esta es una de las estaciones, que a juicio de las novatas, representaba uno de los retos más fáciles de superar. Es importante hacer la observación que en todo momento se referían a las acciones dentro del bautizo como retos. Esto es de suma importancia porque desde la perspectiva del novato, más que un castigo, es un reto y se asume que habrá una recompensa al final. En este caso sería el ser aceptado como uno más y transitar de ser novato a un miembro más de la Facultad de Agronomía. Por el contrario para las veteranas es un castigo que merecen por ser nuevas.

\subsubsection{Sexta estación: El salón de belleza}

A juicio de las investigadoras esta es una de las estaciones con mayor grado de violencia y que permite considerar el grado de deshumanización de la práctica. Así mismo es una de las estaciones más cuestionadas y rechazadas por las novatas de las jornadas estudiantiles 2013, 2014 y 2015. En esta las estudiantes antiguas tenían preparadas previamente recipientes plásticos que contenían heces fecales de cerdo. En vista que de las estaciones anteriores se obtuvo residuos de la mezcla de ajo, huevo y cebolla, también fueron agregadas a la cerdaza, formando una pasta de considerable consistencia. 
Las estudiantes veteranas utilizando guantes o bolsas plásticas colocaron la mezcla en el cabello de las estudiantes novatas. Algunas de las estudiantes novatas tenían cabello largo y se habían presentado con el mismo trenzado, de tal manera que fueron obligadas a deshacer las trenzas y tener el cabello suelto. Ello permitió untar la mezcla en todo el cabello, haciendo diferentes peinados que luego fueron sometidos a competencia. De esta manera se lograba ridiculizarlas aún más.

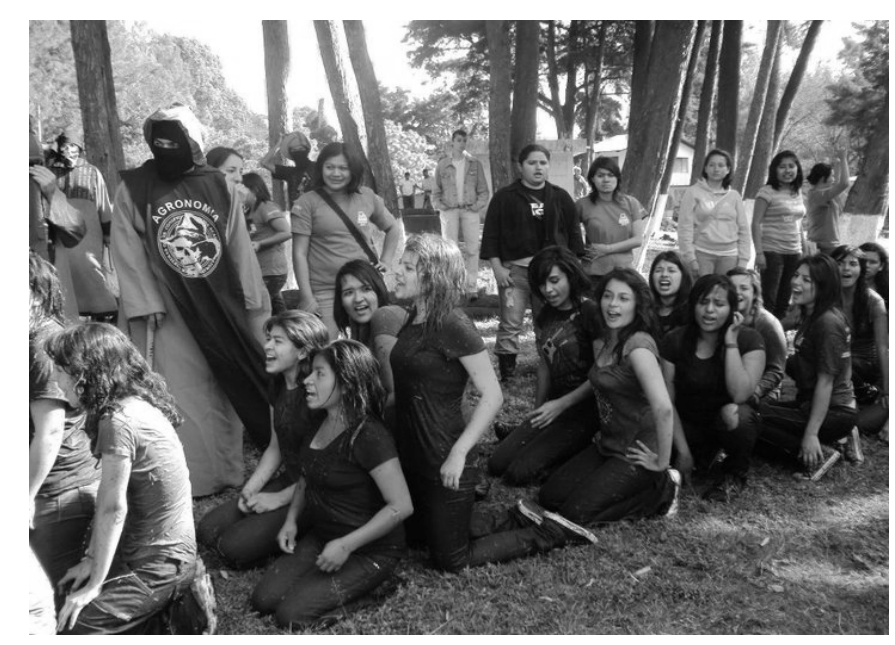

Figura 13. Estudiantes novatas en los campos el Ceda en la estación del Rodeo. Fuente: Fotografía tomada el día del evento.

\subsubsection{Séptima estación: El recorrido por los campos del CEDA}

Las novatas fueron obligadas a hacer un recorrido por los campos agrícolas del CEDA. Al correr debían gritar consignas que fueron previamente creadas por las estudiantes antiguas. El contenido de esas consignas eran: "Somos estudiantes nuevas de la Facultad de Agronomía, somos prostitutas y nos gusta el sexo”. Es importante mencionar que las palabras utilizadas originalmente para este mensaje fueron censuradas en vista que correspondían a palabras utilizadas en los medios más bajos y vulgares del país, totalmente inapropiadas para ser presentadas en el presente documento de investigación. 


\subsubsection{Octava estación: Alfombra de cerdaza}

La pesadilla aún no había terminado y aún había que sortear dos estaciones más. Las estudiantes novatas tenían ya tres horas de sometimiento, pero aún pesaba sobre ellas la carga de dos estaciones llenas de nuevas bromas y sorpresas. En el caso de la estación octava se colocaron sobre el suelo alfombras de plástico de grandes dimensiones. Sobre ellas había estiércol (de todo tipo de animales); el objetivo de la estación fue obligar a las novatas a rodar diez veces, de un extremo a otro sobre la misma. Aunque las estudiantes novatas trataban de resguardar la boca, en algunas ocasiones pequeñas porciones de estiércol entraban por la boca y la nariz. A cada vuelta que daban era agregada agua, para crear una mezcla que se adhiriera más fácilmente al cuerpo de las novatas. Al culminar fueron obligadas a beber un vaso que contenía algún tipo de licor. Al dialogar posteriormente con una de las novatas, comentó que el sabor de la bebida era más a alcohol utilizado en medicina, que a licor. La mezcla tenía un color rosado. Es importante considerar que las estudiantes veteranas entregaban el licor a todas las novatas sin excepción, sin considerar que algunas de ellas nunca habían ingerido licor por razones personales o religiosas.

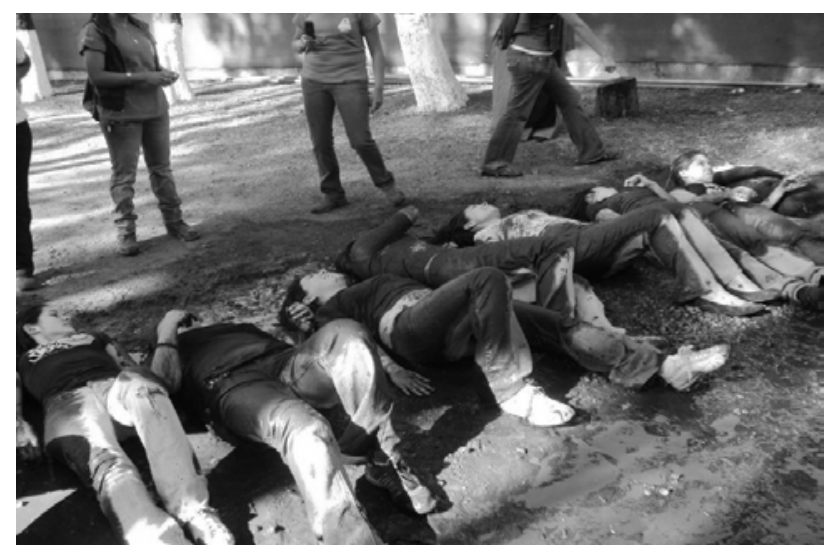

Figura 14. Estudiantes novatas en los campos el CEDA en la estación. Fuente: Fotografía tomada el día del evento. 


\subsubsection{Novena y última estación: El recorrido triunfal por el campus central de USAC}

Eran ya las once y media de la mañana y las novatas estaban cansadas, indigestas, mareadas, enlodadas y sobre todo desorientadas. A pesar de ello hacía falta un momento muy esperado, el recorrido triunfal por el campus universitario. En este momento fueron sacadas de los campos del CEDA y llevadas a recorrer corriendo y gritando consignas estudiantiles de todo tipo. Las lideresas de la actividad y encapuchados les incitaban a gritar todo tipo de insultos a las autoridades universitarias (en especial al rector) y estudiantes de otras unidades académicas. En este caso es importante mencionar que el paso por la Facultad de Ingeniería reviste especial importancia y genera expectativa porque desde hace algunas décadas existe gran rivalidad entre ambas unidades académicas. Siendo la celebración del bautizo la oportunidad para hacerla pública.

Al haber hecho el recorrido completo, finalmente fueron dejadas en "libertad”. Las novatas intentaban realizar el último esfuerzo físico de resistencia y terminar el recorrido. Sin embargo algunas cayeron desmayadas durante el último tramo. Cuando esto ocurría eran apoyadas por sus compañeras novatas o bien por estudiantes (varones) antiguos. Este hecho pude comprobarlo gracias a que estuve siguiendo desde relativa distancia la actividad. No me fue posible tomar fotografías de todas las estaciones porque ningún profesor (como lo es el caso de la autora) o autoridad académica puede observar el evento.

Es conveniente señalar que fue muy frustrante no poder auxiliar, de manera directa, a algunas novatas que parecían necesitar ayuda especial, mostrando muestra de intoxicación, mareo, cansancio o problemas al caminar. Esto se debe a que durante estas actividades está prohibida la participación de personas que no sean estudiantes. De hecho estar a algunos metros de distancia era ya una provocación. 
A pesar de ello fue posible observar la celebración a una distancia prudente, no sin antes, haber sido insultada por estudiantes que portaban capuchas de color verde. La amenaza era retirarse o sufrir las consecuencias.

La mañana del año 2013 una de las novatas, recién bautizada, se acercó con muestras de estar ebria. Saludó efusivamente y sin mostrar ningún tipo de respeto. Recriminó la ausencia de los profesores porque nadie estuvo presente cuando fue golpeada, agredida, enlodada, obligada a beber licor. La estudiante estaba realmente molesta y aprovechó a hacer serias recriminaciones en contra del sector docente. De la misma manera otras muchachas deambulaban por el lugar tratando de quitarse el lodo, cerdaza, vinagre el cuerpo y buscaban agua en los jardines cercanos.

Es importante considerar que un día anterior las autoridades académicas, suspendieron formalmente todas las actividades administrativas y docentes, autorizando al personal a no asistir a sus labores. Por esa razón los edificios que corresponden a la Facultad de Agronomía permanecían cerrados herméticamente y las posibles fuentes de agua para bañarse o por lo menos retirar del cuerpo todas aquellas mezclas eran sumamente escasas. Menos posible era encontrar a algún adulto que auxiliara a las estudiantes, sin embargo fue posible observar a dos padres de familia que esperaban por sus hijas en el parqueo. No todos corrían con la misma suerte de tener vehículo personal y muchos estudiantes buscaban con sus "padrinos o madrinas" las mochilas en donde llevaban la muda de ropa limpia para poder abordar un medio de transporte público y retirarse a casa, parecía que la pesadilla, por fin, había terminado. A pesar de ello algunas novatas lucía alegres y algunas de ellas aún posaban para la cámara como podemos ver en la fotografía que se muestra a continuación. 


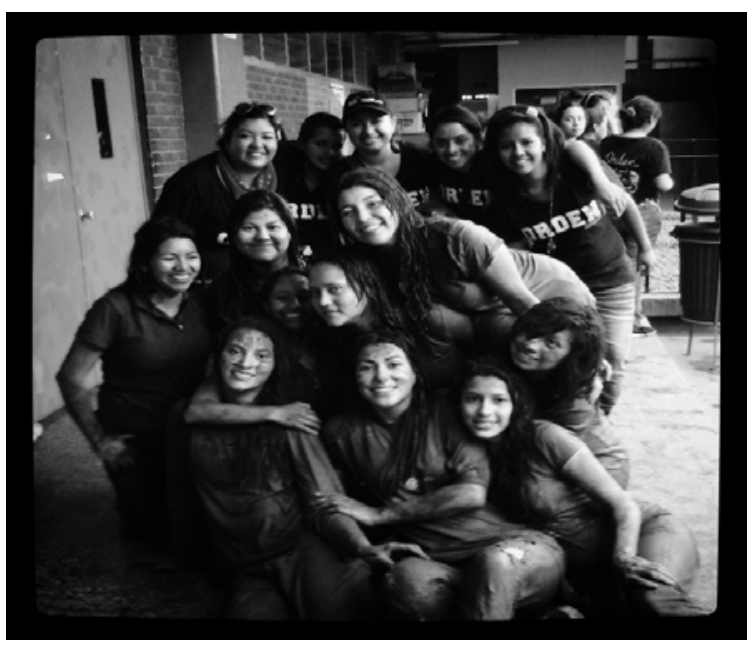

Figura 15. Estudiantes novatas 2013, cuando recién han sido bautizadas Fuente: Tomada el día del evento por estudiante antigua.

\subsection{Descripción del bautizo de los estudiantes novatos varones}

El bautizo de los estudiantes varones fue diseñado, de igual manera por los estudiantes veteranos y estudiantes encapuchados. A las seis de la mañana fueron encerrados en el Auditórium de la Facultad de Agronomía en donde recibieron las instrucciones para el evento. Esta actividad es puramente estudiantil. Por esa razón la información presentada ha sido otorgada a la investigadora por los mismos participantes.

\subsubsection{Primera estación: Encerrona en el auditórium}

Los estudiantes fueron encerrados en el auditórium de la Facultad de Agronomía. Desde los pasillos del edificio) gritos de algarabía, vulgaridades y explosiones de cohetillos, durante el espacio de una hora. Posterior a ello fueron sacados al patio central del edificio T-9 (en el que se ubica el auditórium) y fueron obligados a hacer todo tipo de ejercicios de carácter militar. La situación se salía de control a cada momento y cada nueva ocurrencia de los estudiantes antiguos 
tenía que ser obedecida por los novatos sin ningún tipo de recriminación. En muchos de los ejercicios los estudiantes fueron obligados a tomarse de la mano. La jornada fue extenuante y cuando algún novato caía o daba muestras de algún tipo de debilidad, inmediatamente era humillado con el griterío de la muchachada. Los estudiantes antiguos golpeaban a sus compañeros novatos, dándoles patadas o golpes con codos y puños. Todo tipo de vulgaridades y vituperios eran prodigados, pero las de más empleadas eran aquellas relacionadas a su condición de hombres, por respeto al lector he suprimido tales expresiones.

A diferencia del bautizo de las jovencitas el bautizo de los varones careció de algún tipo de orden y programación. El denominador común fue el caos y la violencia. Sin embargo fue posible identificar tres momentos esenciales. El primero corresponde a la encerrona en el auditórium en donde se lanzaron cohetillos y aún morteros (fuego pirotécnico de gran potencia, cuyo uso está prohibido en el país) al cuerpo de los estudiantes.

\subsubsection{Segunda estación: El corte de cabello}

A pesar del desorden y caos se pudo distinguir una segunda estación esta se desarrolló de la siguiente manera: |Los estudiantes antiguos condujeron a los novatos al parqueo de estacionamiento ubicado frente al edificio T-9. Allí les obligaron a arrodillarse o sentarse en el suelo y haciendo uso de tijeras rompieron la ropa de los novatos, dejándolos únicamente en ropa interior. En muchas ocasiones (como puede observarse en las fotografías posteriores) fueron ridiculizados obligándolos a vestir ropa de mujer que algunas de las veteranas habían llevado. Entre muchos de los atuendos podía distinguirse camisones de mujer, lencería, trajes de baño, trajes de porrista, etc. En este punto es importante mencionar que al contrario del bautizo de los novatos en el bautizo de los hombres 
algunas mujeres pudieron participar libremente, con el consentimiento de los Verdes y estudiantes de la organización denominada de Orden.

Posterior a despojarlos de la ropa se inició el corte de cabello. Cada uno de los veteranos había elegido previamente un novato y se disponía a cortar (a su sabor y antojo) el cabello. El objetivo es realizar cortes que ridiculicen a los novatos. En algunos casos se les coloca listones, flores de plástico.

También fue posible observar como algunos estudiantes novatos llevaban condones amarrados en algunas partes del cabello que no fue cortado. Una de las actividades que más disfrutan los veteranos es maquillar a los novatos. Muy gustosos sacan labiales, coloretes y todo tipo de maquillaje de colores intensos y llamativos.

Se improvisó una competencia, ofreciendo a la pareja (novato y veterano) que presente el mejor modelo de corte de cabello y maquillaje una botella de aguardiente, en este momento ambos son equipo.

\subsubsection{Tercera estación: El Piletazo, borrachera y recorrido final}

Los novatos fueron conducidos a los campos del CEDA y al igual que ocurrió con las novatas fueron obligados a sumergirse en la pileta (que ya contenía los desechos vertidos sobre el cuerpo de las novatas). Allí fueron obligados a cantar el Himno Nacional de Guatemala, gritar todo tipo de insultos dirigidos a otros y a sí mismos. Cuando los veteranos consideraron que ya era suficiente tiempo en la pileta, los llevaron a otro lugar en donde previamente había preparado alfombras de tierra mezclada con heces de animales de granja, orines y cadáveres de todo tipo de animales. La prueba de la estación consistía en tirarse pecho a tierra y arrastrarse a todo lo largo de la alfombra. Durante el recorrido eran escupidos, pateados, rociados con orines por los veteranos. 
La jornada de bautizo del año 2014 tuvo dos elementos nuevos. Siendo el primero que sobre el cuerpo enlodado de los novatos se lanzaron plumas de aves (que fueron llevadas con anticipación para cumplir con ese propósito). Con esta medida se logró un nuevo grado de ridiculización, pues se les llamaba gallinas. El segundo nuevo elemento lo constituyeron los cadáveres de tres lechones. Los novatos del año 2014 tenían que besar en el hocico el cadáver de estos animalitos.

Posterior a estos eventos se les entregaron botellas que contenían bebidas alcohólicas. Es importante mencionar que no existió necesidad de obligar a los novatos a beber porque al parecer tenían muy buena disposición para beber. Esto es natural considerando que un buen de porcentaje de estudiantes universitarios consumen bebidas alcohólicas o bien inician a consumirlas al iniciar estudios superiores. Aunque la venta dentro del campus está terminantemente prohibida por el Consejo Superior Universitario, el consumo es un fenómeno común. Es muy fácil observar durante las jornadas de fiestas de bienvenida inmensas casas de campaña de la Cervecería Centroamericana, quienes distribuyen cientos de botellas de cerveza.

Durante las jornadas de bautizos las botellas de aguardiente sobreabundan, considerando que (como se señaló en párrafos anteriores) cada novato estaba obligado a entregar una botella de licor a los miembros de la Asociación de Estudiantes de Agronomía. Muchos de los novatos se embriagaron, pero aún muestran un buen nivel de coordinación de movimientos. Eso es conveniente pues aún tienen que realizar el último recorrido triunfal por campus. Inicialmente se dirigieron a los edificios en donde se encontraban los estudiantes de veterinaria y farmacia. Gritando insultos relativos a las carreras y agrediendo a todo aquel que se encontrara a su paso, siendo incitados en todo momento por los estudiantes encapuchados y estudiantes de orden.

Algunos estudiantes antiguos portaban armas de fuego y en el recorrido hacían tiros al aire, por lo que muchos de los estudiantes que transitaban por las avenidas internas dentro del campus, optaban por esconderse dentro de los edificios y resguardarse de cualquier tipo de daño. Esto porque también los estudiantes novatos eran obligados a ir y pedirle a cualquier muchacha que fuera 
su novia, si la muchacha se negaba a aceptarlo era duramente castigado por los veteranos. Por esa razón, algunas estudiantes antiguas, movidas seguramente por solidaridad, fingieron aceptar la declaración del novato y permitir que les den un beso en la mejilla para liberarles de sufrir más castigos.

Otro momento importante fue nuevamente cuando se pasó frente a los edificios en donde se ubican los estudiantes de Ingeniería. Esta vez no hubo manera de agredirlos en vista que las autoridades académicas (conocedoras de la rivalidad entre estudiantes de ambas unidades académicas) han acordado suspender actividades docentes y administrativas el día en que se realice el bautizo de cada unidad académica. Esta medida se puso en práctica a partir del año 2011. El objetivo fue que no existiera contacto físico de los estudiantes de ambas unidades académicas el día del evento. De esta manera se han evitado serios enfrentamientos.

El recorrido culminó cuando los novatos se presentaron ante el edificio en donde se encuentran las oficinas del Rector y otras personalidades que son autoridad dentro de la universidad. En esta ocasión lanzaron todo tipo de vituperios, siempre incitados por los organizadores del evento. Esta acción no es exclusiva de los estudiantes de Agronomía, siendo ya una tradición de los novatos de todas las unidades académicas que ponen en práctica el bautizo.

En este punto culminó el evento para los novatos y finalmente fueron dejados en libertad. La mayoría de los estudiantes regresaron a los edificios de la facultad de Agronomía en busca de agua para poder lavarse el cuerpo y retirar el lodo, las plumas y todo tipo de sustancias que fueron vertidas en su cuerpo. En este momento los estudiantes novatos son las víctimas directas de la agresión de los estudiantes antiguos. Sin embargo existen otro tipo de víctimas que no son tan evidentes, pero que reciben algún tipo de daño, como se expone a continuación. 


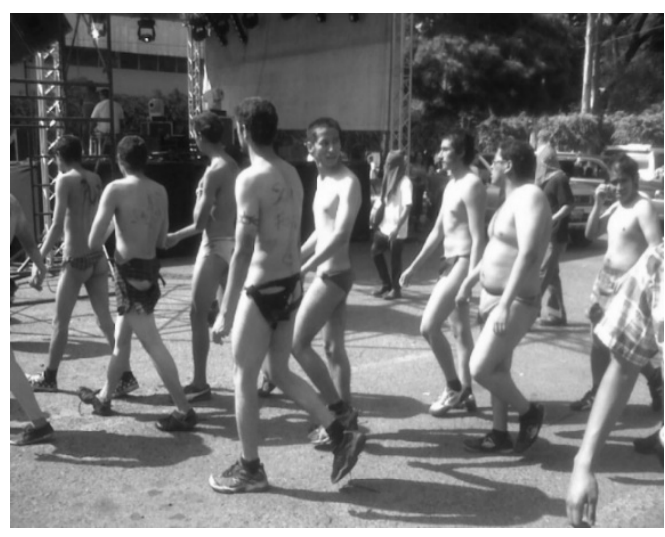

Figura 16. Estudiantes novatos año 2013, durante la jornada de ejercicios. Fuente: Creación personal, fotografía tomada el día del evento.

Según Iñaky y Moreno (2009), las víctimas pueden ser: i) Víctimas directas o afectados primarios. En este caso se refiere al individuo que ha sido objeto de una acción directa que le ha dañado física o emocionalmente. ii) Víctimas secundarias o indirectas. Se refiere a aquellos individuos que han sido traumatizados por el hecho de haber sido testigos del daño directo sobre otro individuo. iii) Víctimas secundarias o indirectas de ingreso. Hace referencia a las personas que voluntariamente acceden a estar presentes en el lugar en donde han acontecido hechos violentos, bomberos, policías, enfermeras, médicos, representantes de Derechos Humanos, etc. (Markez et al., 2009). 


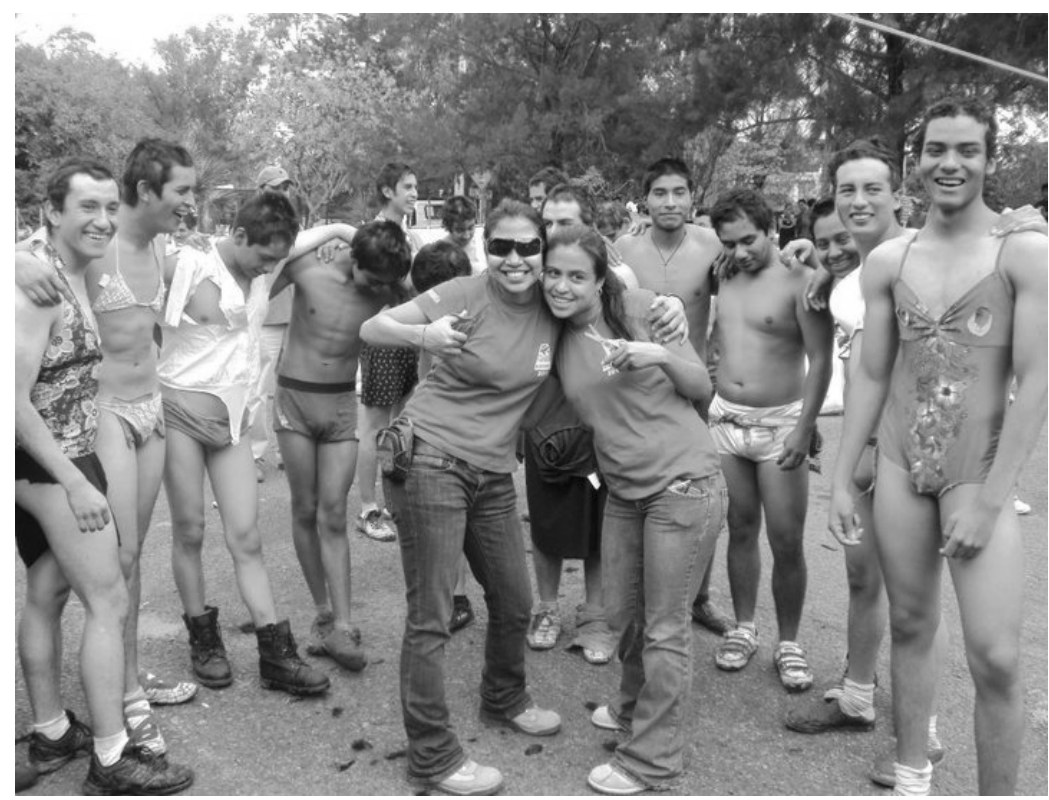

Figura 17. Estudiantes novatos año 2013, en la jornada de corte de cabello. Fuente: Otorgada por cortesía de estudiantes antiguos. 


\section{CAPÍTULO 8: ESTUDIO CUALITATIVO DE LAS NOVATADAS EN LA FACULTAD DE AGRONOMÍA}

El objetivo de la aplicación de las herramientas cualitativas fue reunir y ordenar todas las interpretaciones del fenómeno en cuestión para construir, paulatina y objetivamente una interpretación comprensible que pueda ser un recurso útil para la detener las jornadas de acoso entre estudiantes universitarios. Según se ha determinado en la presente investigación el bautizo en la Facultad de Agronomía es uno de los más violentos en el campus central de la Universidad de San Carlos de Guatemala. Considerando que es de carácter obligatorio podemos determinar que aproximadamente trescientos estudiantes de primer ingreso (según las estadísticas de los últimos cinco años otorgadas por el departamento de Control Académico de FAUSAC) son sometidos a crueles prácticas en las cuales son violentados física y psicológicamente.

A continuación, se presentan los resultados de las entrevistas a profundidad que fueron implementadas con estudiantes de primer ingreso del año 2013.

\subsection{Análisis de entrevistas realizadas}

Con el objetivo de acercarse al fenómeno de las novatadas de una manera objetiva se diseñaron e implementaron entrevistas a profundidad dirigidas a diversos sectores de la comunidad universitaria en FAUSAC. Entre los entrevistados destacan, para dar respuesta a los objetivos planteados, las dirigidas a estudiantes novatos, antiguos, profesores y profesionales egresados. 


\subsubsection{Entrevista a estudiantes novatos}

Los estudiantes novatos han expresado interés en responder a las preguntas formuladas en la presente Tesis Doctoral, sin embargo han pedido que sus nombres queden en el anonimato. A continuación los resultados de una entrevista a quien simplemente llamaremos Eugenia quien al ser entrevistada (año 2013) contaba con 18 años de edad.

Entrevistadora: ¿De todas las estaciones y prácticas hubo alguna que te molestara en especial?

“El estiércol que nos echaron en el pelo, porque pasé tres meses con ese olor. Así mismo que tuve un esguince muy fuerte en el tobillo y tuve necesidad de usar muletas durante dos meses, ello me atrasó mucho en los cursos, hubo días que no pude venir a clases”.

Entrevistadora: ¿Cómo te sentiste cuándo terminó el bautizo?

"Me sentí libre de haber salido de eso, porque yo estaba traumada ${ }^{32}$; me molestaba que tiraran bombas en las clases porque había que salir porque el aula se llenaba de humo y no me dejaba respirar bien. Pero luego me sentí muy mal y sobre todo cansada.”

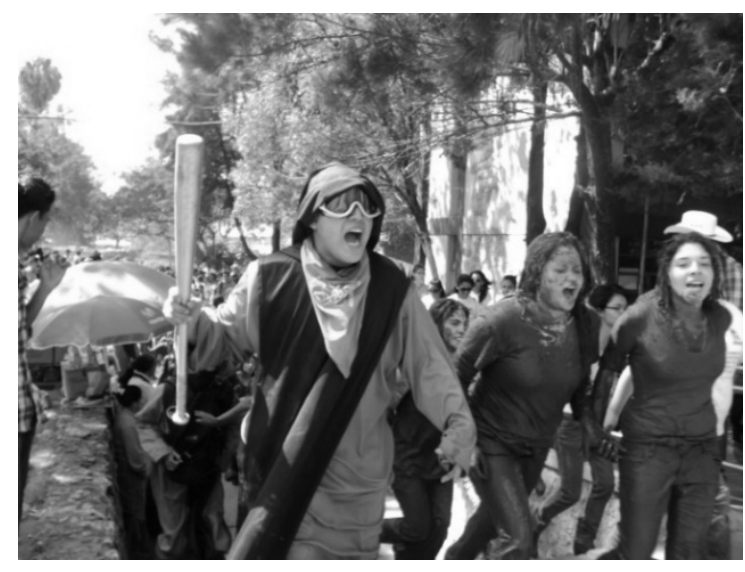

Figura 17. Estudiantes novatas realizando la última fase del bautizo.

Fuente: Fotografía tomada el día del evento, cortesía de una estudiante antigua.

\footnotetext{
${ }^{32}$ Traumada: Expresión muy utilizada cuando quiere hacer hincapié en un estado de profunda angustia o dolor.
} 
Entrevistadora: ¿Cuál será tu papel en el bautizo 2,014?

"Voy a participar porque me gustaría ver las cosas desde otra perspectiva. Por ejemplo, este año vi que hacían reuniones para ver como lo programan y organizan. Me da curiosidad pensar lo que planearán. Si tengo la oportunidad de bautizar a otras lo voy a hacer, pero procuraré no ser tan mala onda ${ }^{33}$ como lo fueron conmigo".

Entrevistadora: ¿ Si en tus manos estuviera: Regularlo, anularlo, permitir que continúe como hasta ahora, qué elegirías?

“Regularlo, porque a veces es muy pesado. Muchos creen que porque nosotras nos venimos a meter a la facultad somos varonilas $^{34}$, pero muchas no somos así. Tampoco estamos acostumbradas a hacer un ejercicio tan brusco como lo que nos obligaron a hacer. Yo eliminaría lo del estiércol en el cabello y lo del rodeo, así mismo lo que nos obligaron a comer. Me he puesto a pensar en lo mal que lo habrán pasado mis compañeras que estaban pasando en su período menstrual, afortunadamente no fue mi caso”.

Entrevistadora: ¿Bebes licor?, ¿qué te pareció que te obligaran a beber licor?

“Nunca había bebido porque mi religión no me lo permite por esa razón me desagradó mucho y me mareé rápidamente. No me gustó que me obligaran, pude ver como muchas de mis compañeras ya no actuaban normalmente, aunque reconozco que algunas otras hasta pidieron beber más de un vaso, seguramente les gustó”.

Entrevistadora: ¿Participaste en la fiesta organizada, después del bautizo?

“Me gustan los bailes, pero al hacer el último recorrido me doblé la pierna y se me inflamó, caminaba con mucha dificultad. Aunque me he bañé muchas veces, el mal olor del cabello (a ajo y cerdaza) no se me quitó, así que no tenía condiciones para participar También creo que ningún

\footnotetext{
${ }^{33}$ Mala onda: Expresión juvenil guatemalteca que significa comportarse de manera malintencionada y actuar con toda alevosía y ventaja.

${ }^{34}$ Hace referencia a que es una mujer con forma de vestirse y maneras de varón. Una chica masculina.
} 
muchacho hubiera querido bailar conmigo esa noche, por lo que mejor me fui a mi casa y traté de olvidar todo lo ocurrido”.

Entrevistadora: ¿Quieres hablar de algún tema más?

“Sí, me molesta mucho que el bautizo no haya sido de un solo día, sino que de semanas. Dos semanas antes del bautizo nos llevaron a la Finca Sabana Grande ${ }^{35}$. Allí nos metimos hasta los últimos rincones de la finca, conocimos los nacimientos de agua. Eso fue agradable, pero yo no iba preparada, no llevaba buen calzado y me salieron ampollas en los pies por el calor.

Posterior a ello, los trabajadores de la finca nos dijeron que los antiguos nos tenían una sorpresa. Ellos nos amarraron en parejas y nos obligaron a caminar contra la corriente del río que hay en la finca. Nos obligaron a hacer ejercicios tipo militares: sentadillas, cargar troncos, meternos al río para salir en otro lado. Allí hicimos cien sentadillas y fuimos a comer. Según nos comentaron después los autores de esta broma fueron los estudiantes de la Asociación de Estudiantes de Agronomía, a quienes no pude reconocer porque portaban capuchas. Durante quince días nos pasaron lanzando cohetillos en las aulas, gritándonos cosas e intimidándonos, doy gracias a Dios que hoy todo haya terminado, la verdad tengo ganas de llorar”.

Entrevistadora: Puedes hacerlo si deseas, agradezco sobremanera que hayas compartido conmigo esta experiencia, en verdad es muy importante.

\subsubsection{Análisis del discurso}

Cuando la estudiante fue entrevistada, había transcurrido una semana desde el día de su bautizo por lo que las declaraciones emitidas son sumamente sinceras y directas. Sobre todo el estado anímico permite comprobar que el daño emocional y físico fue fuerte. Sin embargo con el

\footnotetext{
${ }^{35}$ Finca Sabana Grande, finca de carácter agrícola bajo la administración de la Facultad de Agronomía, se encuentra ubicada en la zona Sur de Guatemala.
} 
paso del tiempo, la manera de pensar de algunos estudiantes (como lo es en el presente caso) cambia radicalmente. Pues conocedora de las declaraciones de la estudiante novata, quien expresa que su participación en la jornada del bautizo del siguiente año, será principalmente para cuidar que el bautizo de las nuevas no sea tan agresivo, los hechos demuestran algo distinto. Gracias al hecho que el bautizo fue sistematizado durante tres años (2013-2015) fue posible corroborar que la participación de la entrevistada fue muy activa y sobre todo agresiva y revanchista. Entre los estudiantes existe el lema "lo que sufrí en mi bautizo, tendrás que sufrir tú”.

Es importante analizar que las emociones colectivas, suelen contagiarse fácilmente y la euforia colectiva vivida por el grupo de estudiantes aquella jornada terminó contagiando a aquella muchacha que aseguraba no abusaría de sus compañeras novatas.

De la misma manera que se implementó la herramienta de investigación con las novatas, se invitó a algunos de los estudiantes varones a conversar relativo a la jornada recién pasada el bautizo. Es preciso indicar que muchos fueron los estudiantes invitados a conversar relativo al tema, pero solamente algunos de ellos aceptaron hacerlo. Esto confirma la cultura de silencio que se ha difundido entre estudiantes. Sin embargo algunos de ellos rompieron el silencio y decidieron hablar, como lo es el caso de $J o s e^{-36}$ de 18 años, expresando las ideas que se presentan a continuación.

Introducción: Inicialmente agradecí la oportunidad de poder entrevistarle, explicando generalidades acerca de la investigación realizada. Ello para promover un ambiente amigable que le permitiera hablar con franca libertad.

Entrevistadora: ¿Podrías hablarme acerca de tu experiencia durante la celebración del bautizo?

Entrevistado: "Siempre he estado involucrado en las actividades de la USAC porque mis padres han sido profesores en USAC. Cuando supieron que yo estudiaría aquí, mi padre me contó su propia experiencia, me comentó que él no se dejó bautizar. Yo decidí ser bautizado aunque reconozco que muchos compañeros antiguos me estuvieron amenazando y atemorizando, pero no estaba asustado

\footnotetext{
${ }^{36}$ Nombre ficticio, a petición del entrevistado.
} 
porque sabía que no podían abusar y hacerme mucho daño. Sin embargo mientras más se acercaba la fecha, me di cuenta que si eran capaces de cualquier cosa, porque nos tiraban morteros a los pies, y a eso si le tengo mucho miedo porque sé que nos pueden hacer perder un miembro del cuerpo. En algunas ocasiones me enfrenté con los antiguos y también con encapuchados, sabía que el día del bautizo lo recordarían y me buscarían para desquitarse. Mi padre fue estudiante en esta universidad durante el período de 1980 a 1986 durante el conflicto armado interno, me comentó que en aquella época secuestraban a los profesores. En estas actividades participaba todo tipo de personas. Pienso que ahora se corrompieron todos los ideales, pues más parecen pandilleros. Me di cuenta que contra ellos no puede decirse nada porque atacan en grupos y nos lastiman. El día del bautizo nos lanzaron botellas con diferentes líquidos malolientes, gasolina y hasta una bomba lacrimógena. Recuerdo que en esa oportunidad llegaron algunos enviados de los Derechos Humanos como observadores. Sin embargo no pudieron quedarse mucho tiempo porque les apedrearon el carro y tuvieron que retirarse. Pienso que estas personas no deberían venir porque no pueden hacer nada. No me parece conveniente que envíen a su gente más joven y solo vienen a que los asusten. Lo que más me molestó fue la humillación por la que nos hicieron pasar. Por ejemplo el hecho que me hayan obligado a revolcarme en el estiércol, vestirme de mujer, correr por el campus semidesnudo, esto es un abuso. También rechazo el hecho que nos pidieran dinero, para mí eso es una extorsión. A todos nos exigieron Q50.00 y además nos pidieron licor (para ellos). El día del bautizo de nuevo se nos exigió Q15.00 y bonos para entrar y salir de la facultad. Durante las semanas previas al bautizo inventaban cualquier excusa para cerrar el edificio y cobrar entrada y salida.”

Entrevistadora: ¿Cómo ves el papel de las autoridades de la facultad y de los profesores, durante celebración del bautizo?

Entrevistado: "Las autoridades tienen miedo, temen por su propia integridad física (pues los antiguos llegan con machetes, cadenas, pero llegan encapuchados a pesar que está prohibido el uso de capuchas. Pienso que existen muchas personas que se inscriben en la universidad solo para lucrar 
y provocar desórdenes de todo tipo porque es la manera en que les gusta actuar y vivir. En verdad pienso que el bautizo es una actividad muy lucrativa. Las autoridades deben reaccionar, si lo hacen pacíficamente, se arriesgan, pues los antiguos actúan violentamente”.

Entrevistadora: ¿Si en tuvieras la potestad de elegir entre la siguientes alternativas que decidirías? Anular el bautizo, ¿permitir que continúe como hasta ahora o regularlo?

Entrevistado: "Pienso que es más inteligente regularlo, me gustaría que fuera opcional, el que quiera bautizarse que lo haga y el que no que lo dejen en paz. El gran inconveniente es que para muchos estudiantes esto es un negocio y una oportunidad de hacer lo que en la calle no pueden hacer sin recibir algún tipo de castigo. Por eso muchos defienden esa actividad. Por ejemplo a una de mis compañeras, durante los cursos de vacaciones durante el año 2012 la quemaron con un mortero y decidió retirarse. Nunca más se supo de ella en la facultad, creo que se retiró a tiempo, pero también es injusto que lo haya hecho porque si llegó a la facultad es porque en realidad le gustaba la carrera. Seguramente las intenciones originales no eran quemarla, tal vez solamente querían asustarla, pero al final le provocaron un daño grande. Recuerdo que momentos antes del bautizo vi gente muy nerviosa, algunas chicas llorando y algunos compañeros temblando de miedo. La verdad es que nos habían intimidado mucho antes que llegara el evento, haciéndonos amenazas de todo tipo y por eso lograron su objetivo, teníamos mucho miedo. Un día antes nos metieron al auditórium, y nos encerraron allí con las luces apagadas. Allí nos dijeron: "El que no se bautice, pagará las consecuencias, nos llamaron a cada uno por nombre por megáfono, y solo con groserías”.

Algo que me sorprendió fue comprobar que una mujer encapuchada es peor que un hombre, es más agresiva, las mujeres nos maltratan más. Pienso que se aprovechan. La verdad nunca vi mujeres actuar de esa manera, con tanta violencia. En el caso de las muchachas nuevas tienen que aguantar ser acosadas sexualmente por los encapuchados”.

Entrevistadora: ¿Cómo te sentiste después del bautizo y cuál es tu decisión con respecto a lo que harás en el año 2014? 
Entrevistado: “Después del bautizo me sentí aliviado porque al fin había pasado, pero me sentí muy enojado porque tengo un carácter colérico, jamás dejo que nadie abuse de mí y esta ocasión tuve que permitirlo porque o veía una mejor alternativa. Con respecto a si participaré; considero que intentar cambiar el bautizo es imposible, todas las personas piensan en desquitarse. No voy a hacer el cambio solo, sin embargo hay algo que sí puedo hacer y es apadrinar a algún conocido o amigo de primer ingreso. Puedo ayudarle a que no lo maltraten tanto y a que soporte las bromas pesadas, insultos y golpes. Me gustaría que pararan los abusos, pero estoy consciente que no se puede hacer nada, así que solo puedo alejarme del grupo”.

Entrevistadora: ¿Qué opinas acerca de la identidad de los estudiantes sancarlistas?

Entrevistado: "No creo en ella porque mucha gente se cree Sancarlista solo para la época de los bautizos y la huelga y luego lo olvidan por completo, lo hacen solo para abusar. Estoy orgulloso de mi universidad, pero no creo que el bautizo sea la razón; al contrario considero que es algo vergonzoso. Tengo amigos que estudian en universidades privadas, pero se burlan de nosotros por la violencia que se vive en la universidad. A mí me da vergüenza que se de ese tipo de cosas en mi universidad”.

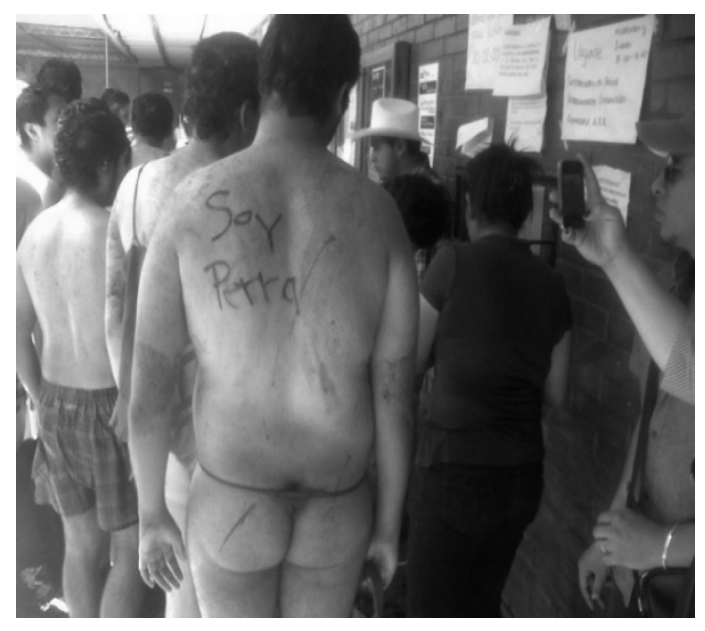

Figura 18. Escena captada durante la celebración del bautizo 2013.

Fuente: Fotografía tomada el día del evento. 


\subsection{Entrevista a profundidad dirigida al sector docente de FAUSAC}

El 80 \% sector docente en FAUSAC está conformado por profesores cuyas edades oscilan entre los 35-65 años de edad. Se tuvo la oportunidad de entrevistar a diez de ellos. Al pedirles que hablaran acerca de su experiencia durante el bautizo. Seis de los entrevistados expresaron que en aquel entonces se sintieron contentos de poder integrarse al estudiantado sancarlista. Señalan que no fueron los trámites administrativos formales para poder matricularse en la universidad y la obtención de un número de carnet lo que los identificó, sino el ritual mismo del bautizo. Sin embargo los vejámenes a los cuales fueron sometidos dejaron sentimientos negativos.

De acuerdo a conversaciones con trabajadores del sector administrativo los bautizos en la Facultad de Agronomía iniciaron en la década de 1980. Sin embargo en aquellas épocas los bautizos eran más simples, con menos actividades. Únicamente se les cortaba el cabello y se hacían algunos agujeros en la ropa, jamás se rasgaba la ropa interior de los novatos. Sin embargo hoy en día se hace gala de la fuerza bruta y tal parece que hay un desborde de creatividad en cuanto se trata de ridiculizar al prójimo.

Así por ejemplo el profesor Carlos López (Área Tecnológica), comenta lo siguiente:

“Ingresé a la Facultad como estudiante en el año de 1990 y recuerdo que antes únicamente se convocaba a los estudiantes de primer ingreso al parqueo de la facultad (el cual estaba preparado previamente para ello) se les cortaba el cabello (haciendo que el iniciado luciera cortes de cabello ridículos) y rasgaba la ropa (en el caso de los hombres). Mientras que las alumnas eran recibidas con una refacción, piñatas y dulces ofrecidos por las estudiantes antiguas. Eso aún era soportable y agradable. Para mí el bautizo fue una experiencia importante, porque con ella quedaba marcado que habías aceptado el reto de estudiar y graduarme en esta gloriosa universidad. Sin embargo en los últimos años, hemos visto como los estudiantes antiguos tratan muy mal a los estudiantes de primer ingreso. Lo más denigrante es tener que arrastrarse por el lodo. En lo personal estoy de acuerdo con 
el bautizo, pues eso nos identifica como sancarlistas, es una tradición pero en otro sentido no considero justo que los antiguos se ensañen con los nuevos, por esa razón me gustaría que el Consejo Superior Universitario regulara la actividad mediante un Punto Resolutivo . A pesar de ello considero que aún esto no sería suficiente, considero que existe la necesidad que todos nos comprometamos a velar por que se cumpla y no se sigan violentando los derechos humanos de los estudiantes de primer ingreso".

El peso de la opinión de los docentes es importante por cuanto son ellos son actores importantes en el ambiente estudiantil. Son los que interactúan más cercanamente con los estudiantes y de alguna manera comparten sus problemas y afectos.

Otro profesor entrevistado fue el maestro Miguel Ángel Cayax (Área Tecnológica) él manifiesta lo siguiente: "Es lamentable que los estudiantes sancarlistas sean señalados y reconocidos, fuera del campus, como estudiantes violentos, bochincheros, maleducados; en algunos casos hasta salvajes. Considero que eso es totalmente negativo. Me gustaría que las autoridades lograran permear el asunto. Que enfrentaran el problema de los abusos cometidos durante el bautizo, pero de manera diferente. Esto porque en el año 2012 las autoridades trataron de prohibir el bautizo, y lo único que lograron fue la confrontación. El papel de nosotros los docentes es valioso y determinante. Considero que deberíamos conversar con nuestros estudiantes y procurar sensibilizarlos para que las prácticas del bautizo sean menos violentas y denigrantes”.

Es importante señalar que en el claustro de la Facultad de Agronomía existen únicamente cuatro profesoras titulares entre 75 hombres.

Por esa razón se consideró importante conocer su opinión al respecto. Se tuvo la oportunidad de entrevistar a la profesora Mirna Ayala Lemus quien manifestó lo siguiente: “Es injusto que los estudiantes lleguen a la universidad con la ilusión de ser alguien en la vida y que sean recibidos con prácticas como rasgarles la ropa (incluso la interior) llenarlos de pintura, sustancias que queman la piel, cortarles el cabello, vestirlos de mujer (en el caso de los hombres) 
eso es triste. En lo personal odiaría que alguna de mis hijas tuviera que pasar por eso. Sin embargo reconozco que los rituales del bautizo poseen mucha importancia. En lo personal tuve la oportunidad de estudiar la maestría fuera del país y al igual que mis compañeros fui bautizada. Recuerdo que nos cubrieron los ojos con un pañuelo y nos condujeron a un lugar retirado dentro del campus. Allí nos esperaban los veteranos con bebidas alcohólicas las cuales nos ofrecieron. Yo no bebo y por eso rechacé la invitación y fue agradable comprobar que no hubo ningún problema con ello. Allí estuvimos, buen momento y los veteranos nos desearon buena suerte en las actividades académicas; reconozco que eso para mí fue agradable”.

Los profesores reconocen que en la actualidad el bautizo ha evolucionado. Las prácticas son cada vez más creativas y continuamente buscan nuevas maneras de anular la individualidad de los estudiantes y demostrar su "poder” sobre ellos.

También fue abordada en la entrevistada la profesora Mirna Herrera (Área Biológica) quien ha opinado extensamente acerca del tema. Ello se debe a que se ha constituido en la principal activista y opositora, según ella explica, de las prácticas violentas del bautizo en FAUSAC. Esta postura ha podido mantenerla y hacerla pública desde el cargo que ocupó en dos ocasiones como Presidenta del Claustro de Agronomía. Ella explica lo siguiente: "El bautizo en la Facultad de Agronomía atenta contra los Derechos Humanos de los estudiantes de primer ingreso porque son agredidos de todas maneras posibles: Hay antecedentes que muestran que han sido golpeados, humillados y sobre todo profundamente lastimados en el plano psicológico. Así por ejemplo en el año 2004, aproximadamente 25 estudiantes que portaban capuchas y sotanas (se presume que eran miembros del Sub-honorable de FAUSAC) cerraron uno de los edificios con los que cuenta la facultad y obligaron a los novatos a entrar al auditórium. Para inspirar mayor temor apagaron las luces y posteriormente entraron ceremoniosamente con velas encendidas en las manos.

Otros encapuchados que esperaban adentro lanzaron ametralladoras sobre los cuerpos de los estudiantes de primer ingreso. De ese suceso algunos alumnos resultaron quemados y ante esa 
situación se realizaron denuncias respectivas ante el Ministerio Público. Sin embargo las investigaciones no rindieron ningún fruto y todo quedó en la impunidad porque nunca logró identificar a los agresores, por cuanto portaban sotana y capucha. Esto fue un día antes a la celebración del bautizo porque el día de la actividad, todo subió de tono.

Durante el bautizo de ese año hubo estudiantes severamente lesionados con una sustancia que fue derramada en el cuerpo de los estudiantes de primer ingreso y que provocó quemaduras de segundo y tercer grado. Tengo muchos años como profesora en esta unidad académica y he comprobado como las actividades en el bautizo son cada vez más violentas; en tiempos antiguos no era así.

Por ejemplo en el año de 1977 cuando ingresé a FAUSAC como estudiante las mujeres no fuimos bautizadas. En el caso de los hombres básicamente les cortaban el cabello y los tiraban a la pileta. En general la celebración era un motivo de alegría, algo positivo.

En el año 2005 las autoridades académicas y administrativas de la facultad lograron PROHIBIR definitivamente el bautizo. Se pasó a las aulas y se advirtió a los alumnos que si celebraban las prácticas violentas del bautizo serían severamente castigados cancelándoseles la matrícula estudiantil. También se les advirtió que se les responsabilizaría, formal y legalmente, ante los Tribunales de Justicia del país por cualquier tipo de daño. Por esa razón se le pidió al presidente de la Asociación de estudiantes que comunicara ese mensaje y resultó ser una acción muy efectiva, ese año no hubo bautizo.

Posterior a esa administración (2003-2006) vuelve el bautizo en el año 2007 y las autoridades nuevamente fueron permisivas con todo tipo de prácticas violentas.

Como expresidenta del Claustro de FAUSAC presenté denuncias ante la Procuraduría de los Derechos Humanos (2005-2008). En esa ocasión pedimos su intervención para evitar los abusos y las irregularidades durante la práctica del bautizo. Esa fue la razón por la cual los miembros de la 
Procuraduría han venido como observadores. La conclusión a la que han llegado es que han constatado la violación de los derechos humanos, pero no han tomado ninguna acción concreta.

Considero que la Facultad de Agronomía es una de las unidades académicas más violentas porque las prácticas machistas ya son algo cultural. Una de las razones es que muchos de nuestros alumnos vienen de la Escuela Nacional Central de Agricultura e instituto Adolfo V. Hall ${ }^{37}$ y allí existe la tradición de bautizar de manera agresiva. Para ellos es fácil usar una capucha y al fin poder hacer lo que quieren.

En el caso de las estudiantes mujeres, hacen propias las prácticas masculinas, como por ejemplo el ingerir licor. Usar un vocabulario extremadamente vulgar y tomar actitud de ventaja y poca solidaridad y respeto para con sus compañeras de primer ingreso. Mi posición relativa al bautizo es la más extrema, rechazándolo en su totalidad. De hecho la celebración como tal está prohibida en ley este ha sido resultado de las gestiones realizadas por algunos miembros del Claustro. Mi argumento es que nada tiene que ver el bautizo con una bienvenida como tal. El concepto es totalmente diferente. Así pues para mi bautizo es pasar por un ritual difícil para ser parte de un grupo. Pero bienvenida es una fiesta, es un día de algarabía y de amistad.

Agronomía e Ingeniería son las dos unidades académicas donde hay alumnos más violentos y prueba de ello es algunos de ellos, usualmente, van armados. Definitivamente estamos viviendo en una sociedad muy violenta.

En una oportunidad en el año 2007 le pedí al señor Decano que tomara las medidas necesarias, pero me dijo "nosotros no podemos hacer nada”, entonces lo que hice fue recopilar los acuerdos de Junta Directiva y el Consejo Superior Universitario relativos a las prohibiciones existentes. Posteriormente compartí un comunicado con los estudiantes, pero no sirvió de nada. Mi gran duda es, si las autoridades académicas se niegan a hacerlo, entonces ¿Quién puede sancionar a los infractores? Planteo esta interrogante porque se ha comprobado, en repetidas ocasiones, que el

\footnotetext{
${ }^{37}$ El Instituto Adolfo V. Hall es una institución de educación media de corte militar.
} 
aplicar sanciones severas es la única estrategia que ha funcionado. Los estudiantes son muy hábiles y ven que no hay sanciones, por lo tanto no pasa nada y pueden seguir haciendo cuantos escándalos se les ocurran.

El costo de la capucha que los estudiantes usan durante estos eventos es de Q25.00 (aprox. \$3.00), está al alcance de cualquiera y todos están agrediendo con capucha, porque de este modo quedan en la impunidad. Eso es lo que significa la capucha: impunidad precisamente por eso debería prohibirse. Los estudiantes han hecho ver a las autoridades que al utilizar una capucha, ellos hacen lo que quieren”.

En este caso la profesora expresa una de las posiciones más extremas en contra de las prácticas celebradas durante el bautizo. En contraposición a la opinión de otros profesores, el bautizo debería ser completamente PROHIBIDO. A decir verdad en este extremo puede mencionarse que en realidad el bautizo en la USAC está prohibido, pero esa prohibición no se hace efectiva. Las razones pueden ser muy variadas, pero en el presente estudio no se ha indagado acerca de ellas, quedando la oportunidad de explorar más acerca del Gobierno Universitario y su funcionalidad dentro de la institución.

Otra de las opiniones vertidas es la del profesor José Pablo Prado Córdova (Subárea de Ciencias Sociales y Desarrollo Rural):

El doctor manifiesta que: "Siempre he estado visceralmente en contra del bautizo, pero reflexionando un poco más he llegado a la conclusión que las medidas extremas como la prohibición no son la solución. Esto porque al igual que en el tema de la prohibición de las drogas, crean un efecto de -rebote- y al final los resultados no son los deseados. Considero que lo que hay que hacer es conocer mejor el problema para poder entenderlo. Otra alternativa es buscar la manera de participar en la actividad. Ello podría lograrse metiéndole una programación a la actividad del bautizo. Es decir que si el bautizo dura de las 7:00 de la mañana a las 13:00 horas, lo ideal es que las autoridades regularan las fases del evento y que al final lo recuperaran. Esto significa que no se 
abandone a los estudiantes de primer ingreso a su suerte, sino que al final del evento haya una recuperación. En ese mismo momento el estudiante de primer ingreso se sentirá reconfortado porque observará que hay presencia del sector docente y de las autoridades; reconocerá la autoridad y psicológicamente habrá una recuperación inmediata. Es decir que el estudiante no quedará marcado. Esa sería la única alternativa que veo para que los estudiantes de primer ingreso no sigan siendo lastimados con tanta práctica violenta. También he considerado que la violencia demostrada durante la celebración del bautizo no es más que una manifestación del odio de clases. Es decir que considerando que a la USAC ingresan estudiantes de todo tipo de procedencias, grupos culturales y niveles económicos; existe una sola oportunidad de "homogeneizar” las condiciones particulares de cada estudiante, ella se da precisamente el día de la celebración del bautizo. Ese día existe la posibilidad de manifestar claramente el odio de clase a través del desborde de abusos y bromas de mal gusto. Así pues el estudiante indígena puede obligar a un novato no indígena a que se arrodille delante de él y que haga algún tipo de penitencia. Eso ya ha ocurrido en otras ocasiones, de la misma manera un estudiante de condición económica baja puede hacer lo mismo con uno de una clase económicamente acomodada”.

De los docentes entrevistados el cien por ciento manifestó, que a pesar que la práctica del bautizo es una tradición que permite que los estudiantes se identifiquen como estudiantes Sancarlistas, conlleva contenido de denigración y miedo en todas sus expresiones.

\subsection{Resultados de la entrevista dirigida a un egresado}

El profesional entrevistado ingresó a la Facultad de Agronomía como estudiante en el año de 1989, cuando fue bautizado. Actualmente reside en Bierbeek, Bélgica. El ingeniero entrevistado estuvo muy motivado a participar en el presente estudio por lo que los resultados de su entrevista son presentados a continuación. 


\section{Entrevistadora: Podría describir el día de su bautizo en FAUSAC?}

Ingeniero entrevistado: "La inscripción para estudiantes de nuevo ingreso tuvo lugar el día 16 de enero de 1989. Ese día, miembros de la Asociación de Estudiantes de Agronomía (A.E.A.) repartían volantes y preservativos entre los aspirantes. Los volantes anunciaban que el bautizo tendría lugar dos días más tarde; los estudiantes de nuevo ingreso teníamos que presentarnos a las 14 horas en el edificio T-9 de la Universidad de San Carlos.

Por suerte, dos compañeros de secundaria también entrarían a la FAUSAC y teníamos un amigo en común que ya cursaba el segundo año de la carrera. Este amigo se ofreció a llevarnos a la universidad en su vehículo ese día y nos aconsejó llevar una maleta con ropa limpia para después del bautizo. Así lo hicimos. Llegamos temprano al edificio de la FAUSAC. Aún no había muchos estudiantes de nuevo ingreso y, a medida que llegaban, debían reunirse en un rincón del edificio destinado para ello. Mientras llegaba la hora de inicio del bautizo, los estudiantes “antiguos” se paseaban alrededor del grupo de nuevos blandiendo y haciendo sonar sus tijeras y gritando. Los gritos eran intimidatorios pero el ambiente era festivo.

Finalmente, llegó el momento en que alguien (¿el presidente de la Asociación?) declaró iniciado el bautizo. Los antiguos se disputaban estudiantes nuevos. La idea era cortar el pelo de los nuevos de la forma más divertida y ridícula posible. El antiguo que lograra el mejor corte de pelo ganaría una botella de ron. Mi “padrino” de bautizo (que luego supe que tenía como apodo "Pedro Infante”) me cortó todo el pelo de la parte superior de la cabeza y dejó intacto el resto de tal forma que si me ponía una gorra, apenas se notaba el impacto que Pedro Infante trajo a mi peinado.

Cuando concluyó esta primera fase y el premio al mejor corte de pelo había sido otorgado a la pareja ganadora, pidieron que nos formáramos en dos filas. Saldríamos del edificio de la FAUSAC y lo debíamos hacer cogidos de la mano. Nos llevaron a la parte sur del campus, donde se encuentra el campo de prácticas de la facultad. Allí hay un tanque de agua para riego cuyo contenido había sido especialmente preparado para la ocasión: el agua era verduzca y el olor fétido. 
Un grupo de estudiantes antiguos se formó en dos filas que conducían a la orilla del tanque de riego. Uno por uno debíamos de correr entre estas dos filas de estudiantes antiguos para, al final, saltar al agua. Durante la carrera, los estudiantes nuevos recibían manadas, patadas y golpes con palos de parte de los estudiantes antiguos. La carrera terminaba con un empujón en la espalda que buscaba que el estudiante nuevo sumergiera la cabeza en el agua sucia del tanque de riego. Para asegurarse de que todos hubiesen metido la cabeza en el agua, de cuando en cuando alguien pasaba una vara a ras del agua.

La espera hasta que todos los estudiantes nuevos hubiesen saltado al tanque fue larga. Debíamos soportar frío porque para entonces ya habíamos sido desprovistos de camisas y únicamente vestíamos pantalón corto o ropa interior. Cuando todos los estudiantes nuevos estábamos en el tanque de riego, un estudiante antiguo dijo que debíamos cantar el himno nacional. Así lo hicimos. Luego, un estudiante nuevo fue designado para recitar la "jura a la bandera”. El resto debíamos repetir cada una de las estrofas, tal como se hace en cualquier acto cívico.

Luego, salimos del tanque y volvimos a formarnos en dos filas. Ahora haríamos un recorrido por otros edificios de la universidad. En cada facultad que se visitaba debíamos corear consignas ofensivas. Por ejemplo, al pasar por la facultad de veterinaria el grito era "animales huecos”, al pasar por la facultad de Ciencias Químicas y Farmacia, “putas” (en alusión a la población femenina dominante en esa facultad), etc. En esta última facultad, se nos dijo que debíamos perseguir a las muchachas y abrazarlas. Contra su voluntad, por supuesto. Esto causó que las mujeres que se encontraban en esos momentos en la cafetería, los jardines o los corredores de la facultad corrieran a refugiarse en donde pudieran.

Con este recorrido concluía el bautizo. Una vez de vuelta en la FAUSAC debíamos pasar a la A.E.A. a recibir una constancia de haber estado presente en el bautizo y una camiseta. Esta constancia, nos dijeron, debíamos tenerla todo el tiempo con nosotros porque en los siguientes días, estudiantes antiguos podían requerirla y, al no mostrarla, corríamos el riesgo de ser bautizados 
nuevamente. Y no en grupo, sino en forma individual. El bautizo en forma individual, o en grupos pequeños era peor. Amistades y familiares me lo habían advertido ya y yo, lo pude constatar días después al ver a dos estudiantes que no pudieron asistir el día señalado para el bautizo. Estos estudiantes no fueron llevados al tanque de riego, pero en su lugar, en un sitio a un costado del edificio, se llevó agua y revolvió la tierra para formar un lodazal. Los estudiantes nuevos debían revolcarse en el lodo. Minutos antes, algunos estudiantes antiguos habían orinado en el lodazal a sabiendas que éste había sido preparado especialmente para el bautizo”.

Entrevistadora: ¿Qué opina acerca del bautizo en FAUSAC?

Entrevistado: "No puedo decir que la pasé mal durante el bautizo. A pesar de los evidentes desmanes que en él se practican, la experiencia sirvió para formar un cierto sentido de pertenencia y para tener un primer contacto con quienes serían mis compañeros de estudios a partir de ese día. Esos son, digamos, los aspectos positivos.

Sin embargo, no se puede negar que en el bautizo se incurre en ciertas prácticas que solo se pueden calificar como abusos e, incluso, violaciones a los derechos humanos. Creo que no hay otra forma de calificar un acto en el que se corta el pelo a las personas, se les hace sumergirse en agua sucia, hay golpes, etc. Esas prácticas atentatorias a la integridad de las personas no son necesarias para lograr los aspectos positivos mencionados en el párrafo anterior.

En mi opinión, el bautizo, como otros eventos de la vida en sociedad, refleja a pequeña escala lo que somos. En el bautizo se puede observar rasgos que son totalmente contradictorios con lo que el movimiento estudiantil sancarlista predica y con la imagen que la USAC, en general, desea proyectar en la sociedad. La USAC, y especialmente su estudiantado, tradicionalmente se perfila hacia afuera como progresista, anti-militarista, opuesto a cualquier tipo de opresión, solidario con el pueblo, etc. Sin embargo, en el bautizo afloran características en los estudiantes que reflejan todo lo contrario. 
Un elemento central en el bautizo es la relación de opresor a oprimido que existe entre el antiguo y el nuevo. El primero tiene derecho a hacer lo que desee con el segundo sin rendir cuentas a nadie. Se arroga una superioridad que no está basada en méritos sino únicamente en el hecho de ser más antiguo. Como en el ejército. El nuevo tiene una actitud de sumisión y comúnmente no se rebelará aunque esté en desacuerdo. Como en el ejército. El nuevo debe mostrar su hombría aguantando los abusos sin chistar. Como en el ejército. Durante mi bautizo, se entonó el himno nacional y se recitó la jura a la bandera, tal como sucede en actos cívico-militares. En ningún otro momento de la vida universitaria tuve que volver a entonar el himno nacional.

En el transcurso del bautizo, antiguos garrote en mano hacen valer su autoridad y exigen de los nuevos gritar “como hombres”. Se puede agredir al estudiante de nuevo ingreso físicamente o en su dignidad (como cuando deben revolcarse en lodo) y todo ello es perfectamente aceptable. Se trata de prácticas que, me atrevo a asegurar, el estudiantado condenaría si supiera que son hechas por militares, finqueros, empresarios o cualquier otro grupo tradicionalmente opuesto a los ideales sancarlitas. En el bautizo, sin embargo, se puede. ¿Cuál sería la reacción de la Asociación de Estudiantes si se enterara que, por ejemplo, en una finca de caña los trabajadores son obligados a revolcarse en lodo y se les corta el pelo? Seguramente habría rechazo y protesta fuerte. En el bautizo, que además ocurre dentro del campus de la USAC, todo eso se puede. Contradictorio.

Quisiera resaltar otro aspecto que puede parecer menos importante y es el reforzamiento de ciertos estereotipos. Como gritar "animales” a los veterinarios, "putas” a las mujeres o tratar de “albañiles huecos” a los estudiantes de ingeniería. No es que el bautizo sea tan importante para definir los estereotipos que llevamos encima, pero la universidad no debería ser el lugar donde se celebran y se hace mofa de ellos. Cuando otras facultades tienen su bautizo y los estudiantes de nuevo ingreso pasan frente a la FAUSAC, la consigna es “campesinos huecos”. Y sobre eso, tengo 
una anécdota. Durante un tiempo trabajé en la región de Ixcán ${ }^{38}$, en un proyecto donde, entre otras cosas, se contemplaba la realización de un estudio de suelos. Se tomaron muestras de suelo y, a sugerencia de quienes trabajábamos en el proyecto, los análisis fueron encargados al laboratorio de suelos de la FAUSAC. El trabajo de campo se hizo entre diciembre y enero y en algún momento de enero debíamos llevar las muestras al laboratorio.

Nos acompañó un grupo de personas de la cooperativa donde trabajábamos. Era la temporada de bautizos. No recuerdo en qué facultad se organizó el bautizo ese día pero a los visitantes de Ixcán les pareció curioso ver aquel espectáculo. Divertido. Lo difícil fue explicar después porque al pasar frente a la FAUSAC aquellos estudiantes debían gritar “campesinos huecos”. ¿Y no se supone que la USAC se encuentra del lado de los campesinos? ¿Por qué los insulta? Ese fue el tema de conversación durante una buena parte del viaje de regreso a Ixcán.

En resumen, creo que el bautizo, aún con su carga de prácticas condenables, no llega a causar un gran impacto en quienes lo experimentan y que, al menos en mi experiencia y en otras que conozco, se puede recordar como algo divertido. Ello no significa que no haya que hacer cambios y no haya que adaptarse a los nuevos tiempos. La sociedad está urgida de romper con ciertas prácticas que recuerdan cosas que deberían quedar en el pasado. Aún si su impacto es puramente simbólico. El bautizo es una de esas prácticas que, creo, debe evolucionar hacia algo diferente. Las celebraciones de independencia con "bandas de guerra” y desfiles militares, sería otro ejemplo. El estudiantado debe ser más creativo y tratar de adaptarse a los nuevos tiempos. Se debe ver que la jocosidad no debe ser sinónimo de irrespeto a otros. Suena fácil, pero podría no serlo si repasamos algunos rasgos del "humor chapin". En muchos casos ese humor se basa en burlarse de alguien: de indígenas, de homosexuales, de mujeres, de negros, etc. Los chistes de velorio, son un ejemplo. Es todo un reto".

\footnotetext{
${ }^{38}$ El municipio de Ixcán se ubica en el departamento de Quiché. Esta es una de las regiones más pobres de Guatemala.
} 
Entrevistadora: ¿Opina que los bautizos en FAUSAC deberían prohibirse?

Entrevistado: "Creo que no. Eso sería aceptar que no existen formas de dar la bienvenida a los estudiantes, de manera amena sin faltar el respeto. Sería aceptar que no somos capaces de pasar un momento agradable sin pisotear la dignidad de otro. De hecho, el bautizo (o algo similar) existe en todas partes y no necesariamente está asociado a abusos o faltas de respeto”.

\subsection{La opinión de un profesional en el campo de la Psicología: Entrevista dirigida al Psicólogo de la Facultad de Agronomía}

El profesional entrevistado es Profesor Titular de FAUSAC y a la vez responsable de la Unidad de Psicología (desde hace veintidós años). Su principal labor es brindar asesoría y apoyo psicológico a los estudiantes que así lo requieran ${ }^{39}$. En esta ocasión se abordó con los siguientes cuestionamientos:

Entrevistadora: ¿Qué opina acerca de la celebración del bautizo dentro de la Facultad de Agronomía?

Entrevistado: "Esta es una actividad que ayuda a la identificación del estudiante de primer ingreso con la Facultad de Agronomía, sin embargo debido a las condiciones de violencia de la sociedad guatemalteca; la práctica ha salido de control. Es importante mencionar que no es tan fácil hablar de este fenómeno social porque aún dentro de la población estudiantil no existen denuncias; por lo menos en esta unidad de apoyo. Ello a pesar que es bien sabido que estas prácticas son sumamente agraviantes. Considero que esto se debe al nivel de intimidación al que son sometidos los estudiantes de primer ingreso. Dentro de las prácticas que puedo mencionar como más denigrantes es el forzar a los alumnos de nuevo ingreso a beber licor u otros brebajes que contienen algún tipo

\footnotetext{
${ }^{39}$ Se omite el nombre por petición del mismo profesional, sin embargo es importante hacer notar el hecho que aún a este nivel existen limitantes para hablar libremente relativo al tema.
} 
de alucinógeno. Considero que particularmente esta práctica es aberrante porque al momento de la celebración del bautizo los estudiantes de primer ingreso no están en sus cinco sentidos, de tal manera que cambia sustancialmente su percepción de lo que está ocurriendo.

De esa manera son mucho más vulnerables a los abusos. Especialmente esto es preocupante en el caso de las señoritas. Un hecho que me provoca gran confusión y enojo es el hecho que hace algunos años la Procuraduría General de Derechos Humanos se ha dado a la tarea de venir al campus universitario durante la celebración de este rito en calidad de “observadores”. Es decir en ese mismo momento se está legitimando el abuso, porque es la misma situación que si un grupo de ciudadanos pidan la presencia de la Procuraduría de Derechos Humanos durante los hechos delictivos (robos, extorsiones) para velar que se respeten los “derechos humanos” de los agredidos. Esta es una manera de legitimar la violencia, el hecho, esto es frustrante y triste. Sin embargo, durante el tiempo de servicio en esta unidad académica, nunca algún estudiante se ha acercado a quejarse o a pedir algún tipo de apoyo. Los únicos acercamientos que he tenido es de estudiantes que tienen comentarios que reprueban el bautizo, pero parece bien aceptado, o por lo menos tolerado".

\subsection{Entrevista con una profesional en el campo de la Sociología}

Se proyectaron dos de los videos filmados en donde los estudiantes de la Facultad de Agronomía bautizan a los novatos y otra en donde los bautizados exponen su opinión al respecto, posteriormente se le pide opinión relativa al bautizo, a lo cual la entrevistada responde:

“En este caso podemos realizar una comparación entre los estudiantes universitarios con la conducta de los mareros. En este caso la práctica del bautizo es requisito para poder ingresar a un grupo organizado. Los estudiantes entienden que es necesario pasar por un rito de iniciación. Otra 
analogía posible es lo que se hace dentro de los grupos Kaibil ${ }^{40}$ tienen que pasar por duras pruebas demostrando de esta manera su valentía y capacidades físicas. Y yo me pregunto cuál es el imaginario en las personas. Quizás sea el asegurar que pueden, que son fuertes. Es posible que busquen esa dignidad que se ha perdido colectivamente. En este sentido, vale la pena preguntarse, ¿quién falla? ¿¿Falla el sistema, falla la familia, la sociedad, la universidad? Considero que ese tipo de cuestionamientos es en los que hay que profundizar.

Es importante considerar que la universidad no llega cualquiera, llega solo el que ha vencido muchos retos, por ejemplo en los últimos años los exámenes de admisión se han convertido en el reto de muchos aspirantes a ser estudiantes sancarlistas. El ingresar a la universidad te hace sentir que eres conquistador de una meta. Todo lo que se haga, así sea irracional, tiene un valor y ese valor es la búsqueda de la identidad. Con respecto a la identidad puedo opinar que cuando el joven ingresa a la universidad hay un deseo de pertenecer.

\subsection{Entrevista dirigida a la Jefa de la Unidad de Salud del departamento de Bienestar Estudiantil}

El objetivo de entrevistar a la persona encargada de la Unidad de Salud fue el de tener acceso a información de carácter cuantitativo y cualitativo acerca de las emergencias atendidas durante la época de la celebración de los bautizos en las diferentes unidades académicas. Al respecto de ella la jefa de esta dependencia manifestó lo siguiente: "Definitivamente que la celebración del bautizo provoca mucha incomodidad a toda la población universitaria. Las actividades administrativas y docentes se ven interrumpidas y aunque esto es temporalmente ello representa grandes pérdidas económicas. Sin embargo en el caso de la unidad a la que represento puedo indicar que los médicos han atendido a estudiantes con quemaduras de primer y segundo

\footnotetext{
${ }^{40}$ Kaibil: Rango del que gozan militares guatemaltecos con formación y capacidades especiales para combatir en las condiciones excesivamente agrestes.
} 
grado, intoxicaciones por inhalación de gas pimienta e indigestión principalmente. El año pasado atendimos a estudiantes de Agronomía. Algunos presentaban un grado severo de intoxicación, otros con marcas en la piel por las esquirlas de los morteros lanzados y uno de ellos traía un golpe muy fuerte en la cabeza. A este alumno hubo necesidad de realizarle una sutura. En la unidad nos indignamos por lo sucedido y decidimos enviar una carta a las autoridades de esa unidad académica solicitándoles que tomaran cartas en el asunto.

Durante los bautizos los alumnos son sometidos a todo tipo de vejámenes. Sin embargo hay celebraciones de celebraciones y los más violentos siguen siendo, en primer lugar los de Agronomía, Ingeniería y Arquitectura”. Al consultar porqué razón cree que precisamente en estas unidades académicas están las prácticas más violentas, manifiesta que probablemente porque son muy “machistas”.

La profesional entrevistada manifiesta estar en total desacuerdo con esas prácticas, especialmente al referir la siguiente anécdota de la vida real: “Tengo muchos años de trabajar para San Carlos y en el año de 1979 conocí a un estudiante de nombre Francisco Palomo. Este muchacho quería graduarse de odontólogo y al ingresar a la unidad académica correspondiente fue bautizado de una manera muy cruel. Según fui informada una semana después del bautizo el muchacho se suicidó...” explica con una mueca de tristeza. Al preguntarle ¿por qué razón cree que el alumno llegó a ese extremo? explica que probablemente porque el muchacho era un poco afeminado y por el machismo del resto de los estudiantes, es sabido que se ensañan, especialmente, con alumnos que manifiestan este tipo de comportamiento.

La licenciada explica lo siguiente: "no quiero ni imaginarme qué le ocurría a uno de estos estudiantes gay, amanerado o afeminado en la Facultad de Agronomía, estoy segura que allí les iría muy mal”. Continúa explicando: “una de las situaciones que más me consterna es que posterior al bautizo hay muchos estudiantes, que andan buscando grifos para poder quitarse un poco el mal olor 
de las mezclas a ajo, vinagre, lodo, estiércol de vaca y todo tipo de sustancia que haya sido derramada en sus cuerpos”.

Finalmente manifiesta que si de ella dependiera, convertiría los bautizos en una verdadera bienvenida, similar a lo que organizan los estudiantes de farmacia quienes preparan un baile y comida para darle la bienvenida a los estudiantes de primer ingreso, esa unidad académica se distingue por ello. Indica que probablemente ocurra porque allí hay mayor población estudiantil femenina y generalmente las mujeres son menos agresivas aunque reconoce que suelen haber excepciones. Indica que le encantaría que las autoridades dejaran su papel de comodidad y en realidad tomaran las acciones necesarias para evitar este tipo de abusos.

Durante la fase de campo de la presente investigación incluían el reporte de la consulta externa de la Unidad de Salud de la Universidad de San Carlos de Guatemala de las emergencias atendidas durante ese día, allí figuran nombres y números de carnets de los estudiantes de la Facultad de Agronomía que fueron atendidos. 


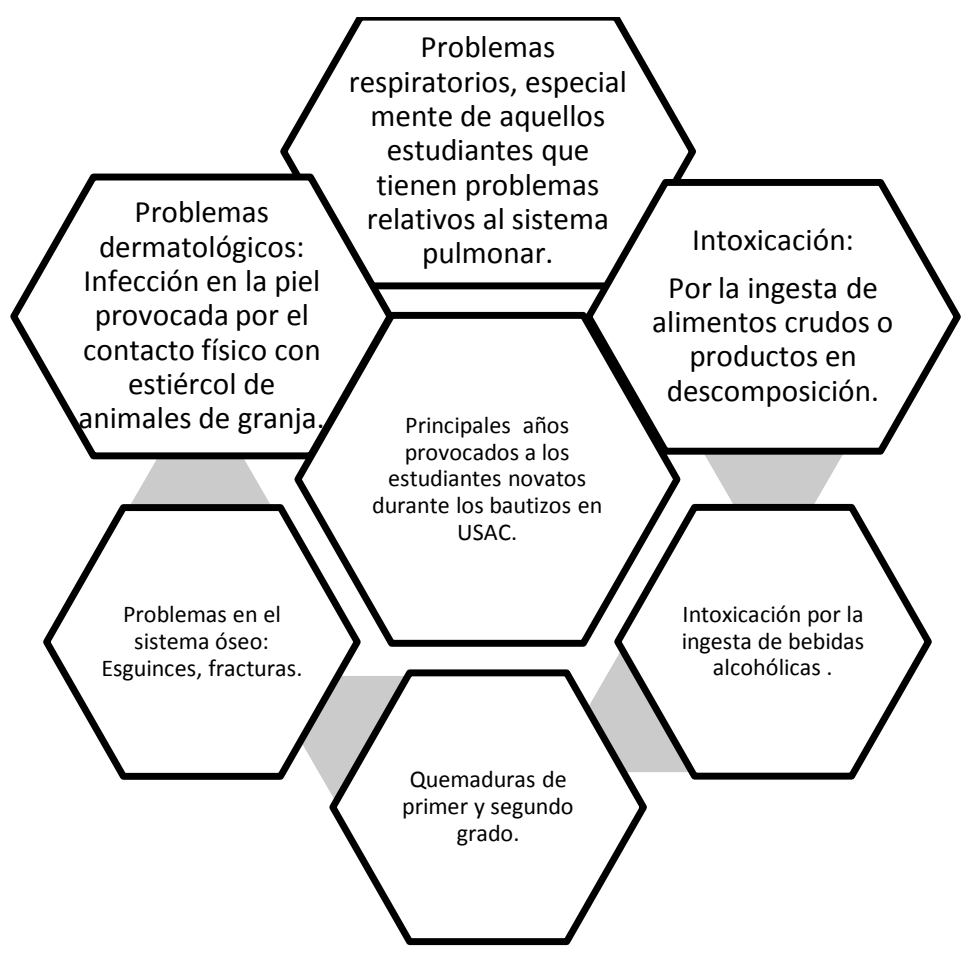

Figura 19. Daños provocados a los estudiantes novatos durante las jornadas de bautizo.

Fuente: Creación personal con información aportada por personeros de la Unidad de Salud de la Universidad de San Carlos de Guatemala, Guatemala. 
Otra de las herramientas de investigación implementadas fueron los grupos focales. En este caso se priorizó los grupos focales dirigidos a los principales actores en el fenómeno de las novatadas, en los siguientes apartados se presentan los resultados de los grupos focales trabajados con el sector docente y estudiantil.

\subsection{Grupo focal del sector estudiantil}

Descripción de la actividad: Para poder realizar la actividad se invitó con una semana de anticipación a un grupo de estudiantes quienes durante consultas personalizadas indicaron que deseaban participar en el evento. Se ubicó un salón de clases que tuviera las condiciones adecuadas con relación a que no hubiera ninguna interrupción durante la actividad. Los estudiantes que participaron representaron a diferentes cohortes estudiantiles dentro de la unidad académica, en el apartado correspondiente a la metodología se indica con mayor precisión características generales de los participantes.

Se contaba con una guía de preguntas generadoras (estructurada previamente) para que los estudiantes pudieran interactuar. Esta información también se presenta en la metodología. Las preguntas fueron de carácter abierto, pues allí incide la riqueza de los grupos focales en donde los

estudiantes pueden hablar con libertad y extenderse en las respuestas otorgadas. La función de la facilitadora fue únicamente conducir la actividad, para lograr los objetivos de la actividad, plantear las preguntas generadoras y conducir la reflexión y discusión entre los estudiantes.

Con el objetivo de sistematizar y resumir las principales respuestas de los estudiantes se han diseñado los siguientes esquemas: 


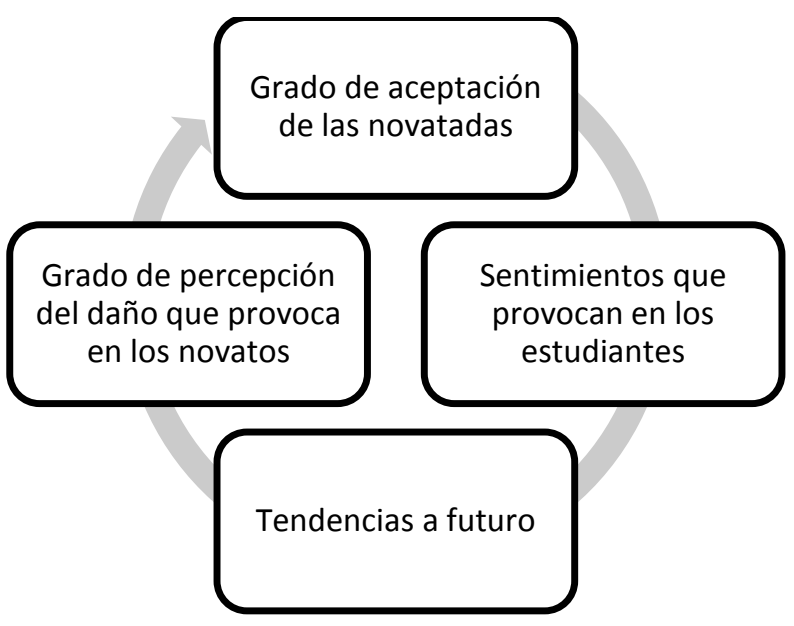

Figura 20. Estructura de las preguntas planteadas en el grupo focal. Fuente: Creación personal.

Los grupos focales significaron una oportunidad valiosa en la cual los estudiantes (de diferentes edades y grado de avance en la carrera) otorgaran de manera libre y relajada su perspectiva relativa a la celebración de los bautizos en FAUSAC. Por esa razón las preguntas debían ser de carácter abierto, porque ellas permitirían profundizar en las respuestas. Sin embargo era necesario dirigir la actividad para que esta mantuviera una estructura que diera respuesta a los objetivos planteados en la presente Tesis Doctoral. En general se orientó la discusión hacia la reflexión de aspectos relativos a: i) el grado de aceptación de las novatadas: porque es importante comprender si las novatadas en la Facultad de Agronomía en realidad aportan al desarrollo integral de los estudiantes sancarlistas, desde la perspectiva estudiantil. ii) Las tendencias a futuro: porque las novatadas han sido celebradas en la Unidad Académica objeto de estudio desde hace más de tres décadas. Es un hecho demostrado que las mismas han evolucionado y que el grado de violencia física y psicológica se ha incrementado, por lo que es importante evaluar la proyección de las mismas en el mediano y largo plazo.

De acuerdo a las principales respuestas obtenidas en los grupos focales se sintetizó la información presentada en la siguiente figura. 


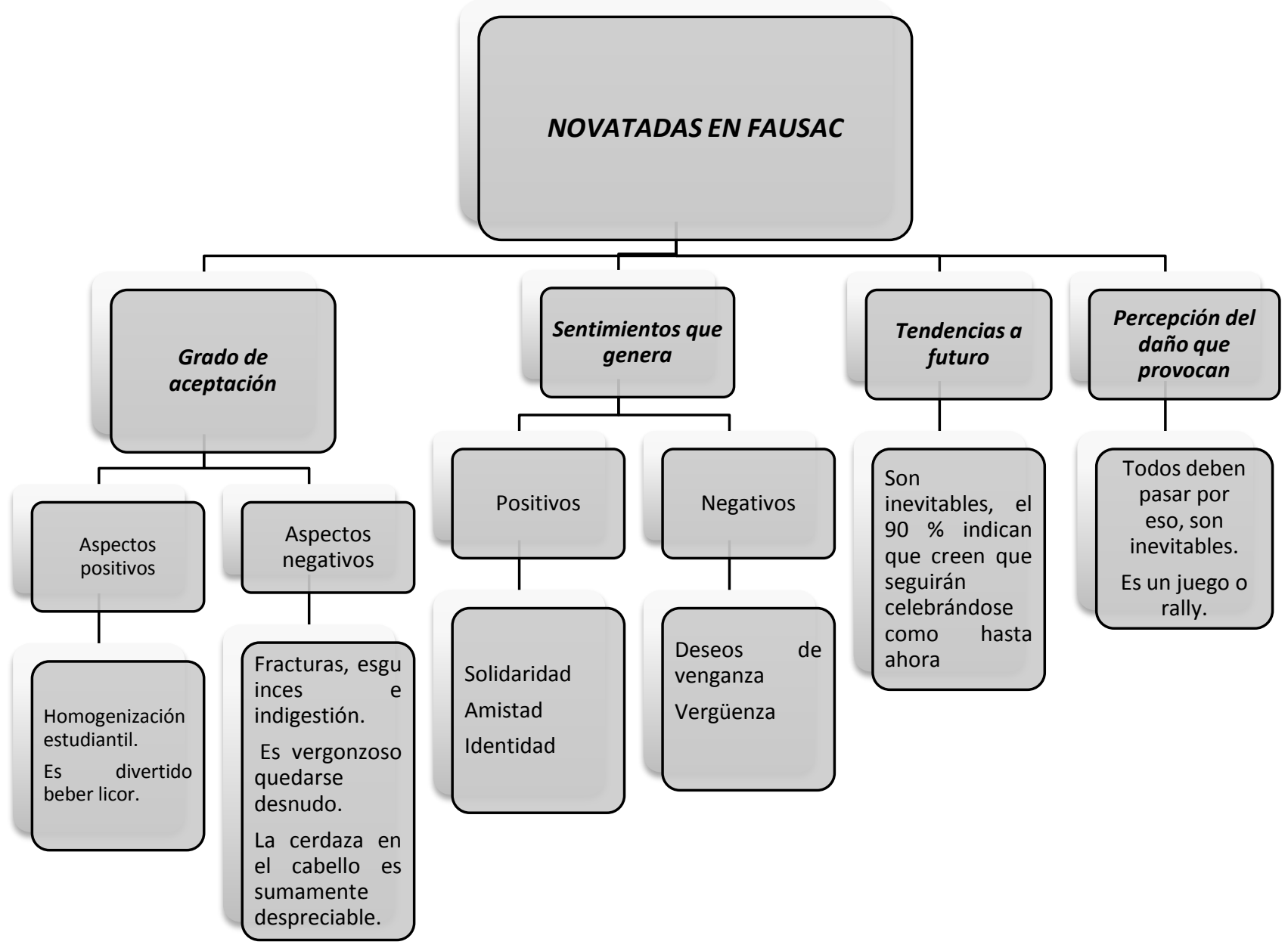

Figura 21.Resultados obtenidos en el grupo focal dirigido a estudiantes.

Fuente: Creación personal con datos obtenidos del grupo focal estudiantil, 2013. 


\subsubsection{Análisis del discurso}

Al inicio los estudiantes se mostraron un poco temerosos de hablar, pero mientras fue avanzando la jornada fueron relajándose y exponiendo con mucha seguridad sus ideas. Una de las principales quejas de los participantes fue que la celebración del bautizo no se limita al día del evento. Por el contrario inicia en algunas ocasiones a finales del año anterior cuando los estudiantes novatos deben asistir a recibir los llamados cursos propedéuticos. Allí inicia el acoso que continúa aún después de la celebración del evento en cuestión. Ello porque personajes encapuchados (en este momento no se sabe quiénes son) no permiten que nadie se escape de ser bautizado. Por esa razón identifican a los novatos que se negaron a ser bautizados colectivamente (porque ese día no se presentaron) y los identifican dentro de las aulas donde reciben clases y violentamente los sacan a los pasillos. En este caso no se ha reportado ninguna acción de los profesores al ser interrumpida la clase.

Allí son humillados, frente a sus compañeros, y se les hacen bromas pesadas, se les empuja, golpea y en muchas ocasiones se les rocía con sustancias en descomposición. Esta es una lección para la comunidad estudiantil. El mensaje es muy claro: Es mejor aceptar el bautizo tal como es y no exponerse, optando por la alternativa, que menos les exponga a la humillación pública.

Comentarios relativos a las actividades Pre-bautizo: Estas actividades son organizadas por el comité de bienvenida que se encuentra conformado por estudiantes encapuchados y estudiantes que son parte del comité de Orden, identificándose el día del evento con el uso de una playera llamada así: ORDEN. Cada año son elaboradas playeras en donde se lee la palabra orden. Así mismo en el frente de la playera hay un motivo serigráfico en el que se expone alguna caricatura que ridiculiza a las autoridades universitarias o docentes. 
Entre las actividades que cabe destacar es el uso de juegos pirotécnicos para intimidar a los estudiantes novatos. Los salones de clase son secuestrados momentáneamente por estudiantes encapuchados que portan, regularmente: cadenas, bates de béisbol, martillos, machetes y todo tipo de objetos lacerantes.

Una de las entrevistadas comentó como estuvo a punto de renunciar a su deseo de ser agrónoma porque se sintió asustada por la conducta violenta de sus compañeros. Se preguntaba qué había hecho mal para que sus futuros compañeros de aula la trataran de esa manera. Luego con la ayuda de sus compañeras de promoción, recobró la calma y pensó que "si otras ha soportado el dolor y humillación durante el bautizo, ¿por qué no había de hacerlo yo misma?

Una de las participantes en el grupo focal expresó: "El día del bautizo mi único deseo era que al fin ocurriera el bautizo y salir pronto de esa pesadilla. Deseaba que pronto terminara todo, habíamos tenido semanas muy difíciles en las que los encapuchados entraban a los salones interrumpiendo las clases para amenazarnos que debíamos presentarnos el día del bautizo. Lo que recuerdo es que todo lo que quería era que finalmente cumplieran sus amenazas y ya dejar de pensar en lo mismo pues muchas noches anteriores me despertaba pensando en el evento y no podía dormir”. Esta es la situación que viven los estudiantes novatos durante un mes aproximadamente pues es el tiempo que transcurre desde el inicio de las clases y el día en que generalmente es realizado el bautizo (segunda semana de febrero).

Otro estudiante expresó: "Venía decidido a todo, sabía que la iba a pasarla muy mal, pero me consolaba la idea que no estaría solo y que unos vecinos que también entrarían a la universidad pasarían por lo mismo, seguro que juntos lo lograríamos. Para nosotros se convirtió en todo un reto, pues ser estudiante de Agro, significa ser fuerte de carácter y aguantar cualquier cosa”. Otro estudiante hizo la siguiente reflexión: “pensaba que si otros soportaron, ¿por qué yo no había de hacer lo mismo?, pero mi forma de pensar cambió cuando durante el bautizo me rompieron la ropa interior, eso fue algo denigrante que aún no puedo superar”. Dentro de todas las prácticas realizadas 
durante el bautizo esta es la que según los entrevistados y participantes en grupo focal rechazan de manera tajante, en este sentido reconocen que los estudiantes antiguos "se pasan de listos" y que esto es totalmente innecesario. Al surgir el tema de la desnudez expuesta públicamente, les hicimos la siguiente pregunta: ¿qué opinan relativo a la denigración de carácter sexual en cuanto los obligan a fingir que están teniendo relaciones sexuales de todo tipo? La respuesta obtenida fue sorprendente, pues aseguraron (aunque se ha observado lo contrario) que en Agronomía no se realizan tales prácticas que a ellos como unidad académica se les señala como los más violentos dentro del campus universitario, pero que ese tipo de prácticas no se dan. Así mismo señalan a los estudiantes de Medicina y Odontología como los que gustan de implementar este tipo de "bromas o juegos”, como algunos les llaman.

También era importante explorar relativo a la “OBLIGATORIEDAD” de la participación en el bautizo, y las respuestas de los entrevistados fueron sorprendentes. Aseguraron que el bautizo no es obligatorio, como tampoco lo es ingerir bebidas alcohólicas durante el evento. Una de las estudiantes participante en el grupo focal comentó que durante la celebración del bautizo durante el año 2013, una de las estudiantes convulsionó por haber bebido licor. Sin embargo es testigo (porque ese año fue parte del comité de Orden) que la nueva no fue obligada. Así mismo manifestó: “Pienso que a algunas chavas no les dan libertad en sus casas y como los papás las cuidan tanto cuando vienen a la universidad vienen con la idea de hacer lo que les dé la gana y el bautizo es una buena oportunidad para ponerse una buena matraca ${ }^{41 ”}$. Aprovechando el tema de conversación se consultó si les preocupaba el hecho que algunas jovencitas al estar alcoholizadas fueran vulnerables a ataques de tipo sexual a lo que respondieron, que eso no sucedía. En esta oportunidad manifestaron que los "Verdes" cuidaban de las muchachas. Los novatos tienen claridad en que los encapuchados cumplen con una función positiva e importante el día del bautizo, identificando entre las más

\footnotetext{
${ }^{41}$ Expresión comúnmente empleada por los jóvenes guatemaltecos que hace referencia a una condición en la que la persona está alcoholizada.
} 
importantes: i) Velar para que personas ajenas a la facultad no participen en el bautizo. ii) Lograr que los estudiantes varones no participen, ni se involucren de ninguna manera, en el bautizo de las mujeres, pues esta es una actividad entre mujeres (a excepción de los mismos encapuchados de color verde). iii) Asegurar que las estudiantes de orden (quienes se identifican con una playera que mandan a elaborar especialmente para ese día) no se excedan en las prácticas dentro del bautizo. De esta manera los estudiantes entrevistados perciben que la función de los encapuchados es importante y determinante en el control de los límites a los cuales se puede llegar. A pesar de ello es inevitable cuestionarse: ¿ ¿Si los estudiantes encapuchados ejercen mecanismos de control sobre los antiguos que participan en el bautizo; ¿quién ejerce control sobre ellos? ¿Quién lleva la agenda, en el desarrollo de las actividades? ¿Existe un esquema claro a seguir? Mejor aún ¿Quién decide cuando detenerse si observan que hay novatos que están siendo lesionados? Es allí en donde subsiste uno de los mayores riesgos de la celebración.

Otro de los aspectos que los participantes expresaron como motivo de preocupación fue el uso de los juegos pirotécnicos ${ }^{42}$ antes, durante y después del bautizo. Esta es una acción que los estudiantes resienten mucho, pues lógicamente se ven amenazados en su integridad física. Uno de los problemas más graves es que uno de cada veinticinco estudiantes de la FAUSAC porta arma de fuego (según la percepción de los estudiantes participantes en el grupo focal). Esto conlleva mucho riesgo porque entre la cohetería, la algarabía y la euforia algunos estudiantes (aprovechando que ese día no hay ninguna autoridad presente) sacan sus armas de fuego y hacen descargas al aire libre, en esa situación la vida de los estudiantes, espectadores y aún los transeúntes corre riesgo.

\footnotetext{
${ }^{42}$ La comercialización de silvadores, bombas y otro tipo de juegos pirotécnicos están prohibidos en Guatemala por la Dirección General de Protección al Consumidor -DIACO-.
} 


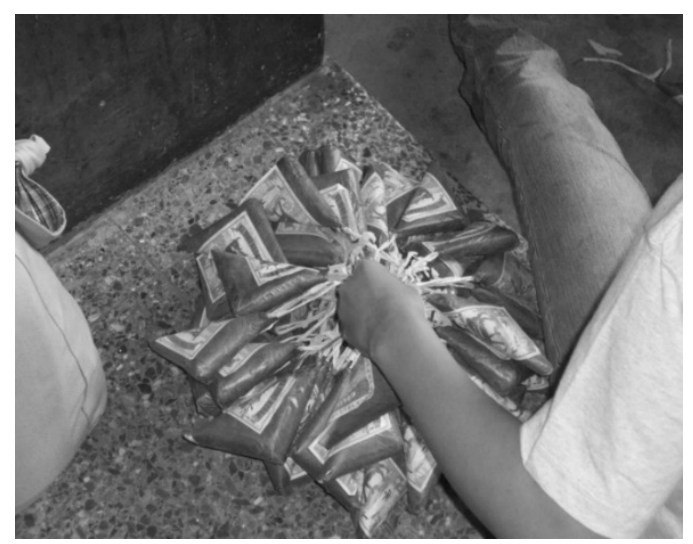

Figura 22. Estudiante antiguo preparando su “arsenal” para el día del bautizo.

Fuente: Fotografía otorgada por un estudiante antiguo.

Existe evidencia que una estudiante novatada del año 2014 se retiró de la Unidad Académica posterior a la celebración de su bautizo, porque según revelaron estudiantes de su promoción, sufrió quemaduras en las piernas al haber sido víctima de estos cohetillos.

\subsubsection{La Relación del poder y la subordinación}

Se determina de acuerdo a las entrevistas a profundidad y grupos focales que existe una clara relación de poder y subordinación entre los estudiantes novatos y los estudiantes antiguos. Por las múltiples acciones esta es perfectamente perceptible.

Algunas estudiantes que respondieron las encuestas, entrevistas personalizadas y grupo focal manifestaron que la presencia y actos intimidatorios de los Verdes, como se les llama comúnmente a los estudiantes encapuchados de Agronomía les provocaba especialmente miedo y desasosiego. Una de las participantes en el grupo focal indicó: "Sólo sé que de ellos puede esperarse cualquier cosa porque una sabe (aún antes de entrar a la universidad) que ellos (refiriéndose a los encapuchados) pueden hacer lo que quieran y nosotros tenemos que soportarlo si queremos ser sancarlistas”. 
Es importante reflexionar que esta manera de pensar cambia radicalmente cuando los estudiantes dejan de ser novatos y pasan a ser parte de los veteranos cuando culmina su propio bautizo. Uno de los estudiantes que participó en el grupo focal indicó: “Los verdes se portaron muy amables, en realidad la función de ellos es cuidar para que los antiguos que están bautizando no se pasen de vivos y sean demasiado masacres ${ }^{43}$ con los nuevos que se están bautizando”.

\subsection{Grupo focal de docentes}

Descripción de la actividad: El total de los profesores titulares fueron invitados a participar, sin embargo únicamente 07 de ellos aceptaron la invitación. La actividad se realizó en uno de los salones del edificio T-9 de la Facultad de Agronomía. Tuvo una duración de 2 horas aproximadamente, iniciando a las 09 de la mañana y culminando a las 11:00 horas. El objetivo de la actividad con docentes fue aportar información importante para responder al objetivo general de la investigación: Identificar, conocer y describir la opinión que los diferentes actores s de la Facultad de Agronomía tienen relativo a la celebración del bautizo o novatadas.

La percepción de los docentes es sumamente importante porque ellos interactúan diariamente con los estudiantes, comparten el mismo ámbito académico que es a la vez, también su ámbito laboral. Así mismo son en su mayoría egresados del a misma unidad académica por lo que la riqueza de su punto de vista radica en que gracias a él podemos conocer la evolución histórica de tales prácticas. Así mismo realizar algunas inferencias para identificar las tendencias en relación a la práctica.

Es importante hacer la observación que algunos de los profesores participantes en el grupo focal y las entrevistas a profundidad también han sido parte de la administración académica por lo

\footnotetext{
${ }^{43}$ Hace referencia a una manera excesivamente violenta, tal como ocurrió en durante el Conflicto Armado Interno en Guatemala. Esta expresión es comúnmente empleada en el vocabulario de los jóvenes universitarios.
} 
que la riqueza de su perspectiva radica en que han jugado roles importantes dentro de la Unidad Académica.

A continuación, se destacan los elementos más importantes que surgieron durante la reflexión realizada durante el evento.

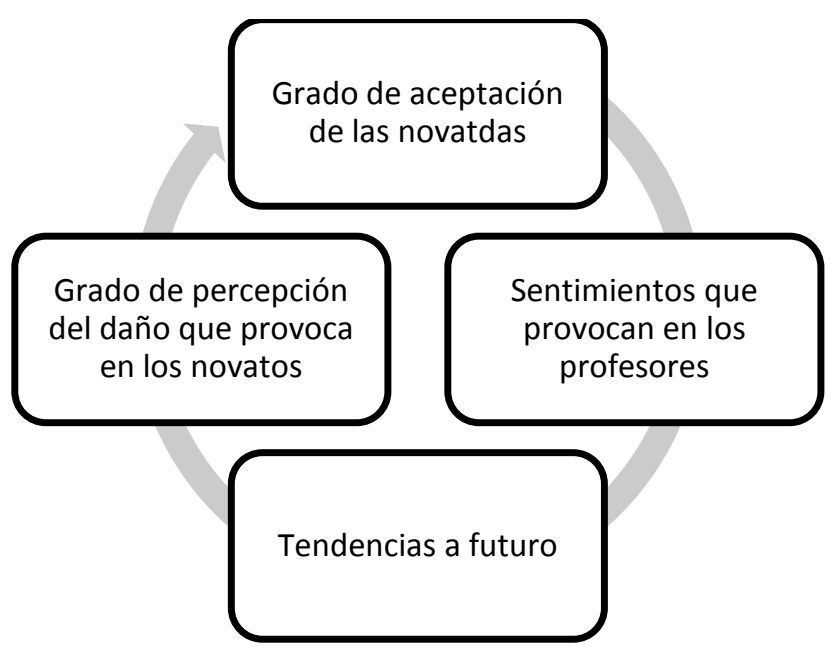

Figura 23. Estructura de las preguntas planteadas al grupo focal de los docentes.

Fuente: Creación personal de acuerdo a estudios preliminares realizados por la autora en el año 2012.

Las preguntas generadoras planteadas a los estudiantes y docentes fueron las mismas, con el objetivo de conocer los puntos de encuentro y desencuentro. Sobre todo es importante determinar el grado de aceptación de las novatadas, porque según las entrevistas personalizadas los profesores entrevistados manifestaron que es imperativo regular las prácticas de las novatadas. Esta es una segunda alternativa porque la inicial es prohibirlas y castigar severamente con la cancelación de la matrícula estudiantil a los infractores. Sin embargo reconocen que la práctica está muy arraigada y que será muy difícil lograrlo pues para ello es necesario que las autoridades universitarias tomen el asunto con seriedad.

A continuación, se presenta un esquema que sintetiza los principales hallazgos obtenidos en el grupo focal del sector docente. 


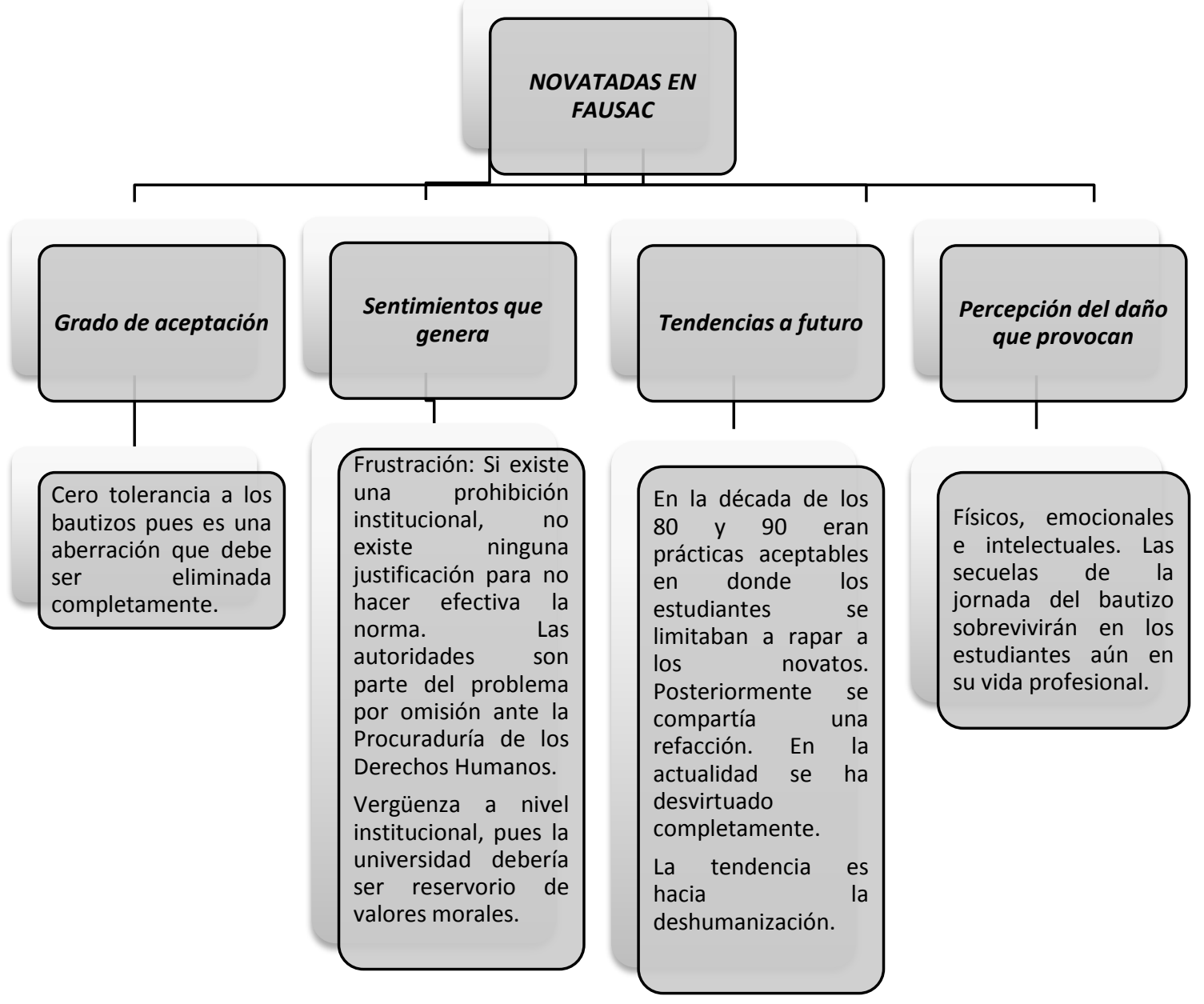

Figura 24. Síntesis de los resultados del grupo focal del sector docente.

Fuente: Creación personal con datos obtenidos durante la realización del grupo focal con docentes de la Facultad de Agronomía en el año 2013.

\subsubsection{Análisis del discurso}

Es evidente que mientras en el grupo de los docentes la tendencia es cero tolerancia a los bautizos, entre el grupo estudiantil goza de cierta aceptación. Principalmente porque lo consideran divertido, parte de una tradición y sobre todo retador. Hay que recordar que al ser humano le encantan los retos, especialmente durante la etapa juvenil. Sin embargo hay un elemento en común entre la percepción estudiantil y docente y es que ambos coinciden en que hay claras expresiones de violencia. 
Así mismo indican que la actividad ha involucionado con el paso del tiempo. Inició de manera tímida y amigable cuando los novatos eran obligados a sentarse o arrodillarse mientras les cortaban el cabello, posteriormente les rasgaban los pantalones y los obligaban a hacer un recorrido por el campus central universitario. También eran llevados a los campos agrícolas en donde se les obligaba a sumergirse en la pileta, pero esta contenía únicamente agua.

Al día siguiente se organizaba una fiesta vaquera en la cual participaba buen número de los estudiantes novatos bautizados el día anterior. Es necesario destacar que en las novatadas de las décadas de los 80 y 90 (según los docentes) eran mucho más manejables porque los estudiantes veteranos no usaban capucha por lo que en todo momento tenían claridad que podían ser juzgados por los excesos cometidos, tanto por los estudiantes novatos, como por sus mismos compañeros veteranos y algunos observadores del evento.

Sin embargo en la actualidad (aunque se ha mantenido el patrón inicial) se han involucrado nuevos factores y otras prácticas han surgido. Entre ellas destacan: i) El bautizo a las mujeres y todas las estaciones que ya se han descrito. ii) El uso de heces de origen animal (gallinaza, cerdada, estiércol de origen vacuno). iii) El obligar a los estudiantes a revolcarse en el lodo mezclado con cerdaza. iv) La utilización de juegos pirotécnicos como estrategia de intimidación sobre los estudiantes novatos. v) El uso de la capucha y sotana durante el bautizo. vi) La interrupción de clases a sabor y atojo de los veteranos. vii) La orden de las autoridades de suspender, oficialmente, las actividades docentes y administrativas el día del bautizo. Este ha sido un detonante en los excesos cometidos debido a que los estudiantes pueden tomar el poder en sus manos sin ser observados por ningún miembro del sector docente o administrativo. Algunos profesores consideran que esta decisión ha venido a incrementar los niveles de violencia en la práctica del bautizo. viii) El incremento en el uso de armas de fuego y los disparos al aire el día del evento. ix) El cortar completamente la ropa de los novatos, exponiendo su desnudez. ix) El vestir a los hombres con ropa de mujer y maquillarlos. xii) El obligar a las mujeres a ingerir alimentos mal sanos y finalmente 
xiii) El obligar a los estudiantes a beber licor. xiv) Los niveles de rivalidad que se han manifestado en contra de los estudiantes de Ingeniería.

Según los profesores, dentro de los elementos que dieron pie a la celebración en los inicios de la unidad académica y que aún se mantienen vigentes hoy en día son los siguientes: a) El corte

de cabello, b) El piletazo, c) El cantar el himno nacional dentro de la pileta, d) El recorrido final por las principales avenidas del campus central de la universidad y finalmente, e) Las consignas irrespetuosas gritadas ante el edificio de Rectoría.

Algunos los profesores participantes manifestaron su satisfacción a causa de que se estuviera realizando una investigación relativa al tema de los bautizos porque consideran que es necesario conocer con mayor propiedad los alcances que pueda tener esta celebración. Al final coincidieron que era necesario tomar medidas disciplinarias y que era necesario hacerlo pronto porque cada año se incrementaban los niveles de violencia. Así mismo lamentaron los niveles de permisividad de las autoridades de la Facultad.

\subsection{Un ciclo difícil de romper, otras unidades académicas que se unen a la celebración de la práctica del bautizo}

Con el objetivo de indagar acerca de la manera en que se proyecta la celebración de estas prácticas en el seno de la comunidad universitaria se abordó en una entrevista a profundidad a una estudiante de otra unidad académica. En este caso la entrevista fue dirigida a la señorita Vanessa Bran, estudiante de primer ingreso en el año 2013 a la unidad académica de Psicología.

Entrevistadora: ¿Podrías hablarme de tu experiencia durante la celebración del bautizo en la cual tuviste que participar?

Entrevistado: “Bueno, el sábado pasado (26 de Enero de 2013) nos citaron en las instalaciones del Centro Universitario Metropolitano -CUM- para participar en una actividad de reforestación en una 
finca. Nos dijeron que como actividad para darnos la bienvenida nos llevarían a sembrar arbolitos y de esta manera cooperar con la recuperación de las áreas boscosas en Guatemala. Accedimos creyendo que esa era una buena oportunidad para hacer algo positivo por el ambiente. Sin embargo, todo resultó un engaño. Al llegar nos colocaron en fila frente a uno de los edificios y frente a una motobomba nos bañaron completamente utilizando mangueras de gran presión. Pero eso no era todo, pues el agua tenía disuelto algún tipo de estiércol de vaca, esta situación pude identificarla por el mal olor que tenía el agua. Luego nos hicieron estar toda la jornada en el patio, bajo el sol, por lo que nuestra piel se quemó debido al estiércol disuelto en el agua. Cuando mis padres llegaron a recogerme a las tres de la tarde (pues esa había sido la hora convenida) se sorprendieron y enojaron mucho por lo que nos había hecho”.

Entrevistadora: ¿Qué piensas al respecto del bautizo en tu unidad académica?

Entrevistado: "Pues me parece muy negativo y sobre todo desagradable. Yo sabía que en Psicología no bautizaban y por eso estaba muy tranquila. Si me hubiera dicho que me iban a bautizar, tal vez hubiera ido preparada llevando ropa limpia para cambiarme luego del bautizo. Fue muy vergonzoso y humillante las cosas que nos hicieron, pienso que eso no era necesario y que solo lo hicieron por pura maldad”.

Vemos que a pesar de la crítica general y de las actas suscritas para rechazar el bautizo esta práctica está siendo aceptada y replicada en nuevas unidades académicas. Es el caso de la Facultad de Psicología, quien en por primera vez (no se ha documentado ninguna otra) se realiza la actividad de bautizo. Tal como en las otras unidades académicas las prácticas son violentas.

Para complementar la investigación etnográfica y entrevistas dirigidas a profesores y novatos acerca de la práctica del bautizo en la Facultad de Agronomía se aplicó un cuestionario a un grupo de 64 alumnos novatos del año 2013. Esta actividad se realizó una semana después de haber sido bautizados. A continuación se presentan algunas gráficas elaboradas con los resultados obtenidos. 


\section{CAPÍTULO 9: RESULTADOS DE LA APLICACIÓN DE HERRAMIENTAS DE INVESTIGACIÓN}

\subsection{Herramientas de carácter cuantitativo}

Aunque la presente Tesis Doctoral puede ser catalogada como una investigación de carácter Exploratorio (por lo que se han empleado algunas herramientas de la investigación cualitativa) también se han empleado algunas herramientas propias de la investigación cuantitativa. La información generada ha venido a complementar la información que es producto de la aplicación de entrevistas a profundidad, entrevistas a expertos y grupos focales.

\subsubsection{Características generales de los estudiantes encuestados}

Con el objetivo de conocer con mayor propiedad las opiniones que los novatos tienen acerca del bautizo, se aplicó un cuestionario a 64 de novatos del año 2013.

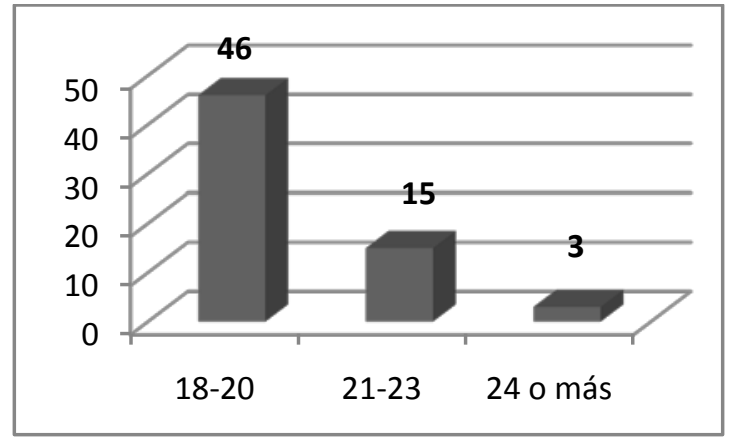

Figura 25.Edad de los estudiantes carnet 2,013 que fueron entrevistados Fuente: Elaboración propia.

La población estudiantil de FAUSAC es relativamente joven y el ambiente de la unidad académica es el típico para una institución educativa de educación superior en Guatemala. 
Gente joven embebida en actividades académicas y festivas. Es oportuno hacer la observación que las actividades deportivas y culturales no son muy usuales en esta unidad académica, siendo las fiestas vaqueras, jaripeos o bailes nocturnos los que constituyen las actividades más populares. Durante ese tipo de celebración un buen porcentaje de la población estudiantil ingiere licor, a pesar que según la normativa universitaria está prohibido.

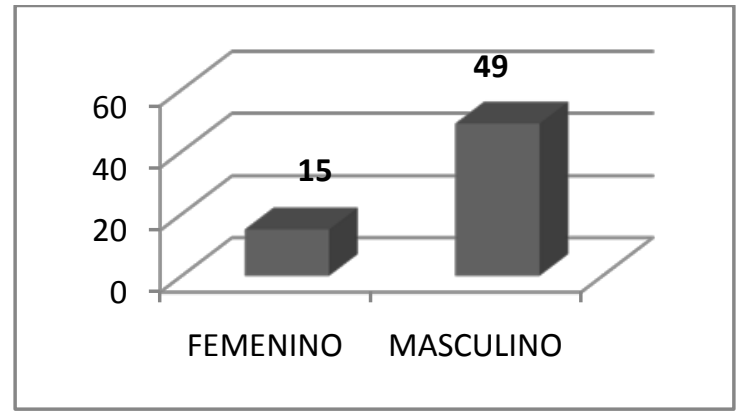

Figura 26. Género de los estudiantes carnet 2013 que fueron entrevistados.

Fuente: Elaboración propia.

El porcentaje de mujeres entrevistadas corresponde únicamente al 23 \% de la población entrevistada. Es conveniente hacer mención que hasta el año 2005 a esta unidad académica ingresaban menos del $10 \%$ de mujeres, sin embargo en la actualidad la población estudiantil femenina se incrementó al 45 \% .También se consideró importante determinar la especialidad que estudian los jóvenes entrevistados como vemos a continuación en la siguiente figura.

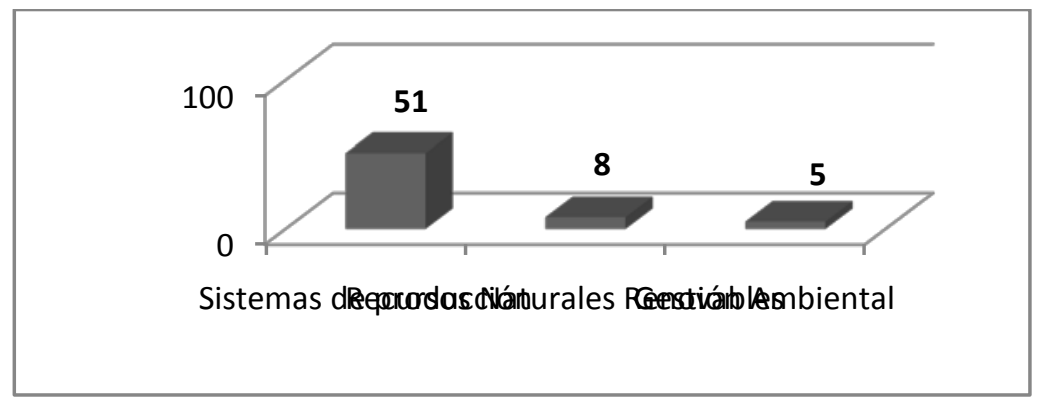

Ingeniero en Sistemas de Producción Agrícola.

Ingeniero en Recursos Naturales Renovables. Gestión Ambiental Local

Ingeniero en Gestión Ambiental Local.

Figura 27. Carrera que estudian los estudiantes entrevistados.

Fuente: Elaboración propia. 
Otra de las características de la Facultad de Agronomía es que la Carrera de Ingeniero en Sistemas de Producción Agrícola sigue siendo la que dispone de mayor aceptación en la población estudiantil. Por esa razón no fue casualidad encontrar en el grupo estudiantil entrevistado un mayor número de estudiantes matriculados en la misma.

\subsubsection{Percepción estudiantil relativa a la seguridad dentro del campus universitario}

La violencia que caracteriza a la sociedad guatemalteca, transversaliza a diferentes sectores de la población y el colectivo estudiantil sancarlista no es la excepción. Es así como queda documentado en los anexos IV, V, VII, VIII, IX, XI Y XII de una serie de abusos cometidos por estudiantes dentro del campus central de la Universidad de San Carlos de Guatemala.

A juicio de las investigadoras existe una estrecha relación entre la violencia manifiesta en la sociedad guatemalteca y la estudiantil. Por esta razón se incluyó dentro del cuestionario implementado algunas preguntas cómo las siguientes: ¿Qué opinión tiene acerca de los planes de seguridad implementados dentro del campus central de USAC? Las respuestas obtenidas fueron las siguientes:

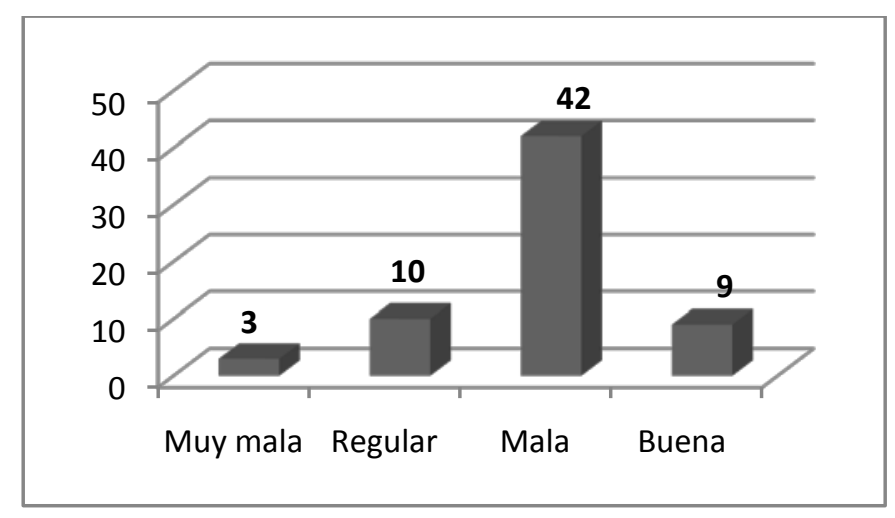

Figura 28.Percepción estudiantil relativa a la seguridad dentro del campus universitario. Fuente: Elaboración propia. 


\section{Aplicación de herramientas de investigación}

En esta gráfica puede apreciarse que según la opinión de los estudiantes el campus universitario de USAC es un lugar inseguro. En la última década se ha incrementado el número de asaltos a mano armada, robo de vehículos en los parqueos. También se ha informado a nivel general, información relativa a la amenaza de hombres que se dedican a abusar sexualmente de las estudiantes. Es conveniente señalar en este punto que aunque existe un programa de seguridad interna y algunos agentes de seguridad, éstos se dedican a resguardar los bienes materiales dentro de las aulas y oficinas (equipo de oficina y proyección multimedia, etc.). No existe un proyecto que considere la protección de la integridad física de los estudiantes.

Como ya se había hecho mención en otro apartado, la situación de ataques violentos es mucho más complicada cuando los protagonistas son los mismos estudiantes. Aunque existe una normativa claramente establecida acerca de la reglas de respeto y convivencia pacífica las autoridades administrativas no han podido intervenir ni mucho menos impedir enfrentamientos entre los mismos estudiantes. En muchas ocasiones éstas disputas giran en torno al manejo de las Asociaciones estudiantiles y el recurso económico que desde allí se maneja.

\subsubsection{Percepción de los estudiantes novatos relativa a su bautizo}

Cómo ya se ha explicado en el capítulo relativo de la metodología de investigación de la presente Tesis Doctoral, uno de los objetivos específicos planteados es describir la percepción que los estudiantes (novatos y antiguos) tienen relativa al bautizo. A continuación se presentan los

resultados obtenidos. La pregunta planteada fue ¿Cómo opinas que fue tu bautizo? categorizando las respuestas en la escala nominal de muy mala, mala, regular y buena. 
A diferencia de los resultados obtenidos en las entrevistas a profundidad en estas gráficas se puede observar que el $40 \%$ de los entrevistados considera que la experiencia del bautizo fue buena y otro $40 \%$ considera que fue regular.

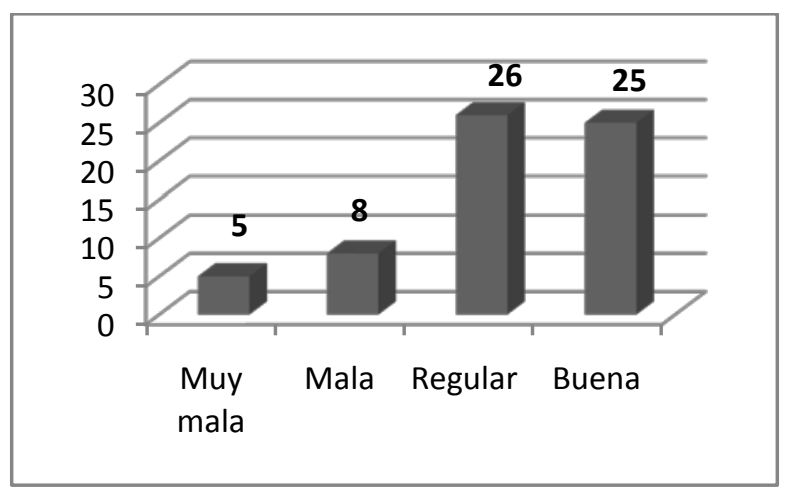

Figura 29. Percepción estudiantil respecto al bautizo al que fueron sometidos a inicio del año 2013. Fuente: Elaboración propia.

Se puede observar que existe un buen número de estudiantes de la Facultad de Agronomía que están muy acomodados a esta tradición sancarlista y han asimilado muy bien y considerado como normales las prácticas violentas y las bromas de mal gusto. Ni los excesos, ni el desborde de abusos han provocado que tengan una opinión negativa con respecto al ritual. Al cuestionarles acerca de cuál creen que es el principal objetivo del bautizo, opinaron de la manera siguiente:

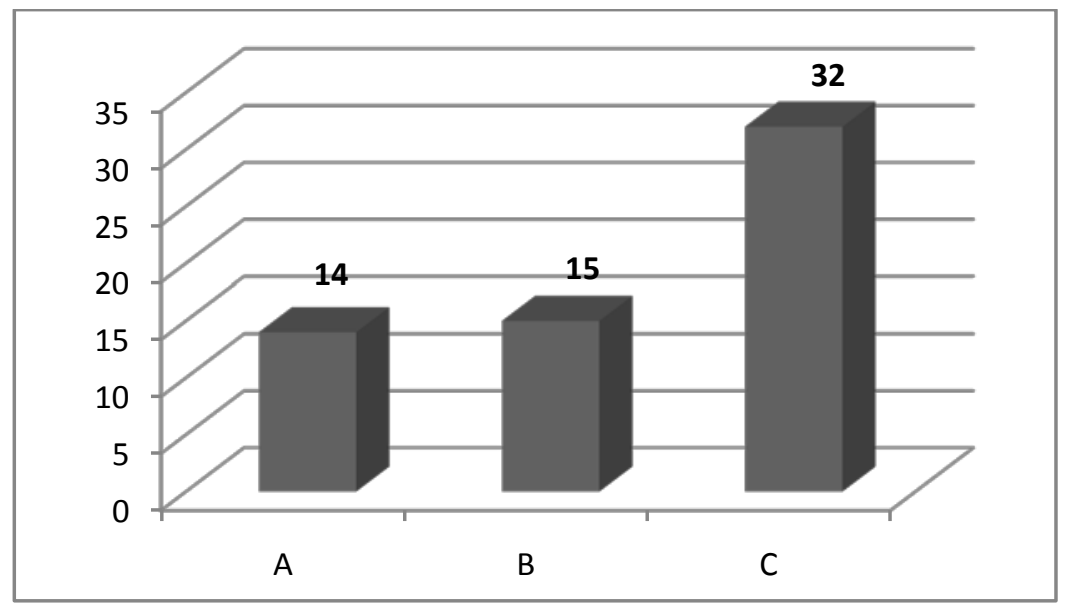

A: Una oportunidad de convivencia con los estudiantes antiguos.

B: Actividad indispensable para ser aceptado como sancarlista.

C: Oportunidad de revancha de los estudiantes antiguos sobre los novatos.

Figura 30.Percepción de los entrevistados con respecto al objetivo del bautizo. Fuente: Elaboración Propia. 
En la gráfica anterior se muestra que el $50 \%$ de los estudiantes opina que el bautizo es una oportunidad de revancha. De aprovecharse al máximo para lograr el desquite de los insultos, golpes y burlas de los cuales se fue víctima cuando se fue novato. De esa cuenta que la actividad sea tan intensa y popular. Esto al considerar que un estudiante promedio se tarda aproximadamente cinco años en graduarse, teniendo como mínimo cuatro oportunidades de participar en el ritual de bautizo de los novatos. De allí que surge la oportunidad para que la práctica vaya evolucionando y que las muestras de creatividad y actitudes poco solidarias provoquen el desborde y el caos.

Sin embargo existe un $24 \%$ de los estudiantes que considera que el bautizo es una oportunidad importante de convivencia estudiantil por lo que lo califican positivamente.

\subsubsection{Ponderación estudiantil de las prácticas del bautizo}

También se les cuestionó acerca de la opinión que tienen de las prácticas realizadas durante el bautizo. Nuevamente la pregunta y respuesta fue de carácter cerrada. Habiendo obtenido los resultados presentados en la siguiente gráfica.

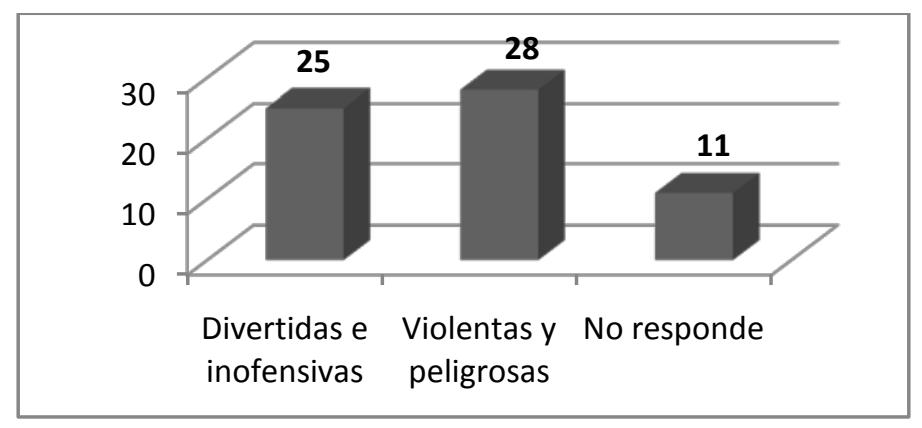

Figura 31.Perspectiva estudiantil relativa a las novatadas o bautizo.

Fuente: Elaboración propia.

Según puede observarse en la gráfica anterior, el $40 \%$ de los entrevistados considera que las prácticas del bautizo son divertidas e inofensivas. En este punto encontramos de nuevo 
contradicción con respecto al pronunciamiento de los profesores y estudiantes novatos entrevistados. Sin embargo existe un $44 \%$ que considera que por el contrario son violentas y peligrosas. Llama la atención encontrar un 22 \% de los entrevistados que no respondió a la pregunta planteada.

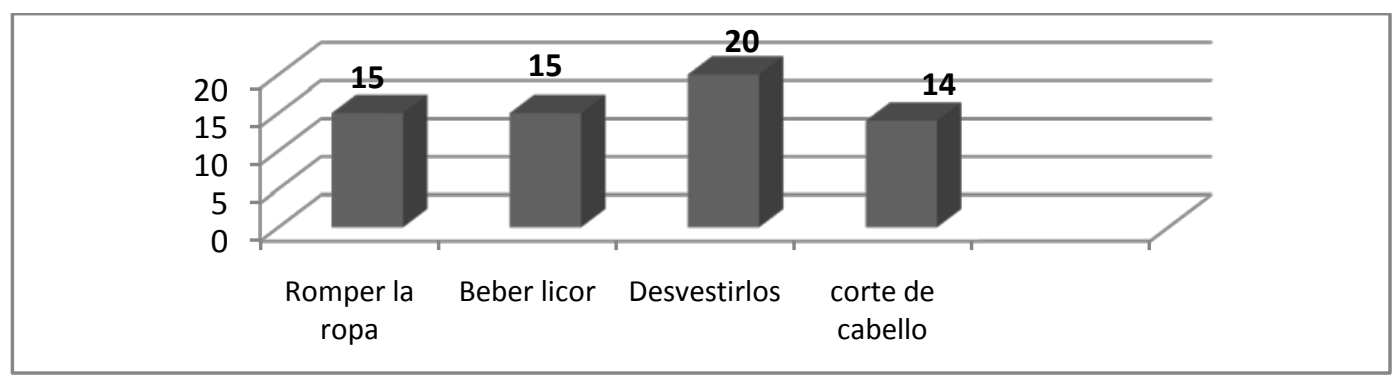

Figura 32. Prácticas más comunes durante la celebración del bautizo de los novatos 2,013. Fuente: Elaboración propia.

El corte de cabello fue la única práctica tradicional del bautizo por más de 20 años, sin embargo en los últimos diez años se han incorporado nuevas prácticas sumamente humillantes como el desvestir a los novatos y razgarles la ropa interior.

En algunas ocasiones se les obliga a vestir ropa interior y de baño de tipo femenino. Esto es únicamente en el caso de los varones, a las mujeres se les permite conservar la ropa, pero esta queda totalmente inservible después de pasar por las estaciones que tienen como ingrediente principal cerdaza y otras sustancias desagradables.

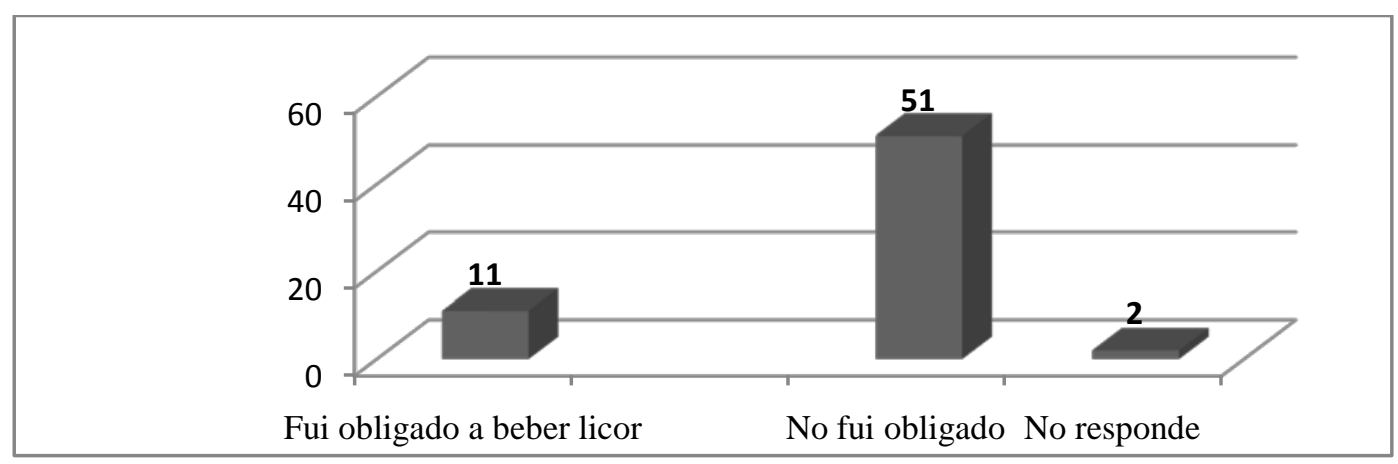

Figura 33.Número de novatos que fueron obligados a beber licor durante el bautizo. Fuente: Elaboración propia. 


\section{Aplicación de herramientas de investigación}

Aunque un buen número de estudiantes universitarios ingieren, por su propia voluntad, licor existe un porcentaje que (por razones de salud o religiosas) no lo hacen. Sin embargo el día del bautizo son obligados a hacerlo. Según reveló la encuensta el $18 \%$ de los entrevistados fueron obligados a beber licor. Ello constituye un riesgo muy grave porque los efectos del licor sobre una persona que no tiene la costumbre de hacerlo podrían ser muy extremos y hacerlo sumamente vulnerable.

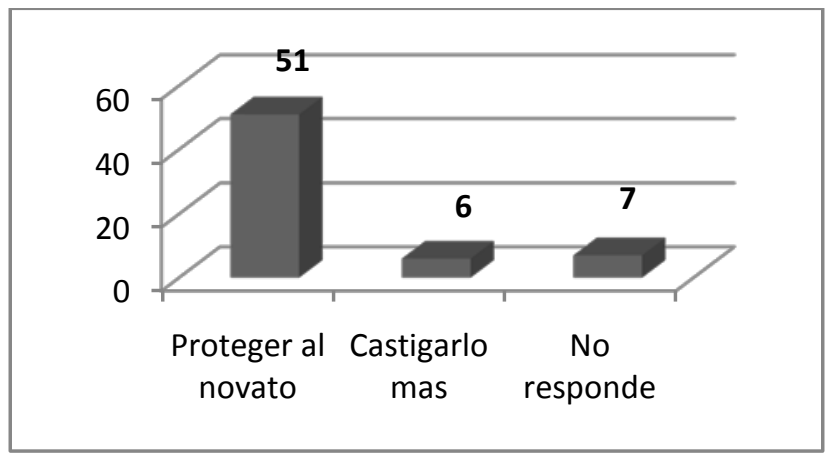

Figura 34.El papel de los padrinos durante la celebración del bautizo. Fuente: Elaboración propia.

Existe un $80 \%$ de los entrevistados que opinan que el papel de los padrinos es positivo, pues de alguna manera permiten soportar de mejor manera las prácticas dentro del bautizo, ello coincide con lo expresado por los estudiantes que participaron en los grupos focales y entrevistas a profundidad. Durante los bautizos existe la tradición que cada novato tiene la oportunidad de adquirir un padrino. Generalmente este es vecino, amigo o familiar. Este es quien tiene el derecho, exclusivo, de bautizarlo de la manera que considere conveniente, vedando la participación de otros estudiate antiguos. Por esta razón los novatos se esfuerza por tener su propio padrino o madrina. 


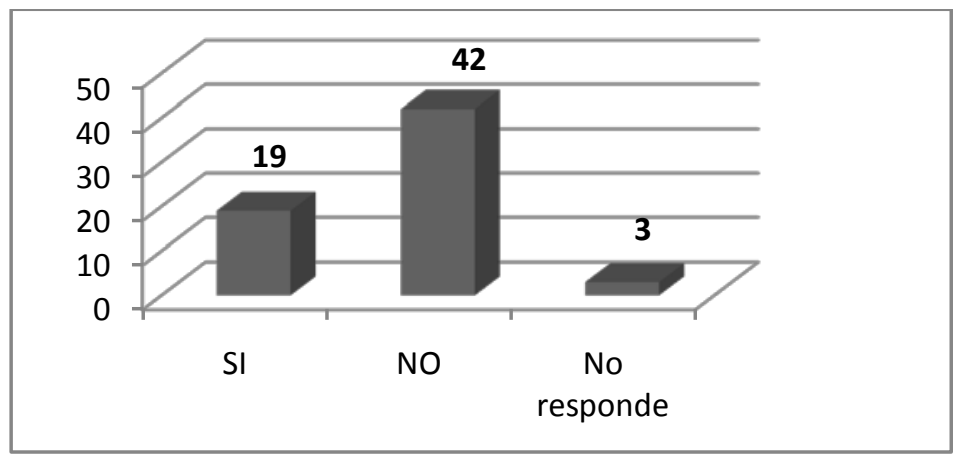

Figura 35.Estudiantes lesionados durante el bautizo.

Fuente: Elaboración propia.

El 30 \% de los estudianes entrevistados manifestaron haber sufrido algún tipo de lesión o daño físico. Según se determinó en la entrevista dirigida con la representante de la Unidad de Salud de la universidad las lesiones más comunes son: intoxicaciones por inhalación de gases e ingesta de alimentos descompuestos o brevajes de todo tipo y quemaduras cutáneas de primer y segundo grado.

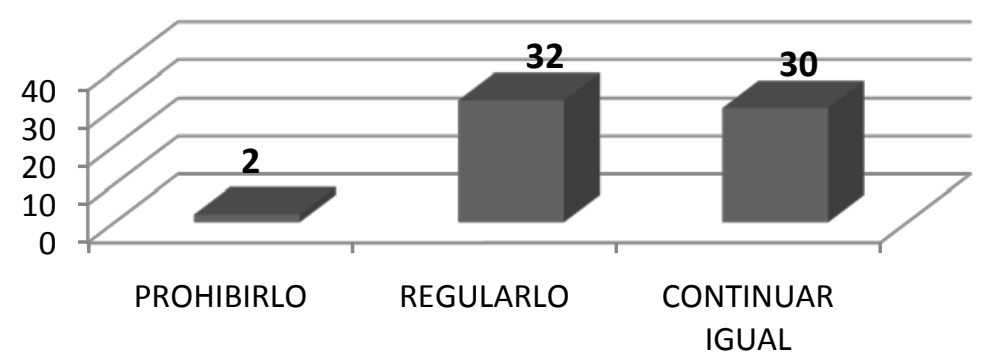

Figura 36.Percepción estudiantil con respecto a la continuidad del bautizo. Fuente: Elaboración propia.

A pesar de todos los vejámenes sufridos durante la celebración del bautizo apenas un 2 \% de los entrevistados opinan que debería ser prohibido en su totalidad, considerando que lo más conveniente es regularlo (50\% de los entrevistados). Ello apenas en un punto porcentual por encima de aquellos que opinan que debería seguir practicándose tal como se ha hecho hasta el día de hoy. 
Este resultado es contrapuesto a la opinión de los profesores entrevistados quienes opinan que la práctica tal como se realiza hasta el día de hoy trae consigo consecuencias negativas para la universidad.

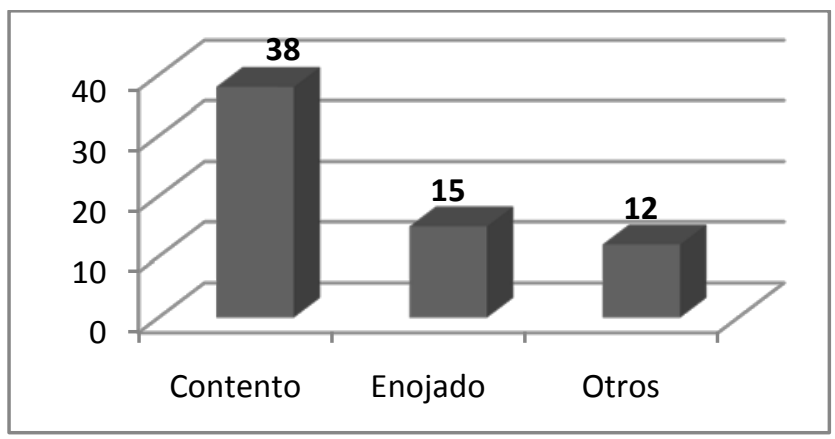

Figura 37.Estado anímico de los novatos posterior a la celebración del bautizo. Fuente: Elaboración propia.

Es interesante concluir, a la luz de los resultados obtenidos, que un $60 \%$ de los estudiantes novatos encuestados manifestaron sentirse contentos posterior a la realización del bautizo y apenas un $24 \%$ manifestó sentirse enojado.

\subsubsection{Análisis de los resultados del estudio cuantitativo}

Aizpún y García-Mina (2013) manifiestan que solamente haciendo investigaciones puede conocerse a profundidad las múltiples implicaciones de las novatadas y comprender que no tienen nada de divertido. Extremo que queda demostrado con las leyes que han sido promulgadas en Francia (1999-2000) y España (2014) en donde se establece que las novatas están literalmente prohibidas y son consideradas como un delito que debe perseguirse.

Finalmente y en este sentido es necesario considerar que otros estudios como el de Abramovay (2005) demuestran que sin duda alguna la violencia es uno de los elementos que tienen incidencia directa en la baja calidad del proceso enseñanza-aprendizaje. Así mismo que todos somos 


\section{Aplicación de herramientas de investigación}

víctimas, porque nuestras vidas cotidianas se ven alteradas por instituciones educativas que se han convertido en verdaderos campos de batalla.

Otra de las dificultades que hubo que sortear fue el vencer el llamado Código del Silencio. Este consiste en que aquellos estudiantes que hablan del bautizo para quejarse de él, son unos llorones, o afeminados, aquellos que no aguantan nada y por lo tanto deben buscar matricularse en otra Unidad Académica, menos en Agronomía. Principalmente se dice de ellos que no están preparados para ser agrónomos de la universidad de San Carlos y se les dice que deberían ir a estudiar a las universidades privadas. Esto demuestra también, tal como dice Leflaive (2003), que es necesario reconocer el carácter integral de las novatadas y comprender que también es un pulso de poder político. Así mismo que más allá de fortalecer la identidad de los estudiantes promueve el clasismo. El pulso de poder se da entre autoridades (permisivas como hemos visto) y los estudiantes que esconden su identidad detrás de una sotana y capucha.

Afortunadamente se contó con la participación de los actores en las novatadas y fueron decenas de estudiantes novatos, veteranos, autoridades académicas, egresados y especialistas en diversas ramas de las Ciencias Sociales quienes participaron en las entrevistas, grupos focales y cuestionarios.

De esta manera podemos aseverar que se trianguló suficiente información que permiten validar las conclusiones a las que se ha llegado.

El ser bautizado al ingresar a la Facultad de Agronomía puede ser considerado como un rito de paso en donde se transita de un estado de ser un aspirante a universitario a ser un estudiante sancarlista.

Para ser aceptado e incorporado como tal deben demostrarse ciertas cualidades. Por ejemplo que se posee la capacidad de soportar el malestar provocado por el estiércol de diversos animales de granja que es untado deliberadamente sobre el cabello y cuerpo; demostrar que se tiene la suficiente 


\section{Aplicación de herramientas de investigación}

hombría para echarse un par de $\operatorname{tragos}^{44}$ a demostrar fortaleza física al momento de sumergirse a las 07 de la mañana en el agua fría en el estanque entre mezclas de ajo y otros ingredientes nauseabundos y posteriormente el revolcarse en una mezcla de lodo y estiércol.

Como en los ritos de paso de las sociedades primitivas de las cuales nos hablan los antropólogos y sociólogos. Este caso es Van Gennep (1986) quien nos hace ver que la persona pasa de una situación de menor valía a una muy superior. Sin embargo debe transitar durante cierto espacio de tiempo entre dos mundos. Según el autor lo verdaderamente interesante no es el detalle del rito, sino más bien su significación esencial. Emplea la expresión pasar el umbral cuando se cruzan dos mundos, dos espacios, dos modos de comportarse o dos modos de vida. El anterior o antiguo (el que se deja) y el posterior (el nuevo y que se adquiere).

Desde la perspectiva antropológica puede caracterizarse, a la perfección, el bautizo de los estudiantes de Agronomía como un rito de paso. Pues este cumple con los tres momentos que identifica y de los cuales nos habla Vann Gennep, siendo estos:

i) El momento de la separación. Este se da cuando se hace una categorización entre novatos y antiguos. Se materializa cuando los novatos son encerrados en el auditórium de la facultad y son instruidos (o amenazados) por los veteranos acerca de la manera en que deben conducirse durante la supuesta celebración. En este momento son despojados de su identidad individual, ya no son llamados por su nombre propio, sencillamente son nuevos, pero de una manera peyorativa. Podemos hacer una analogía cuando los prisioneros entraban a los campos de concentración nazis y eran despojados de todo tipo de objeto personal (documentos, joyas, fotografías, libros, anteojos) y simplemente eran llamados hafting [prisionero].

Por esa razón se les corta el cabello, se les despoja de la ropa y de todo tipo de elementos que pueda distinguirlos. En ese momento todos son iguales, no hay lugar para advertir condiciones de posicionamiento social o pertenencia a un grupo cultural indígena o ladino (algo aún muy

\footnotetext{
${ }^{44}$ En el lenguaje de los jóvenes universitarios guatemaltecos, significa beber licor.
} 


\section{Aplicación de herramientas de investigación}

practicado en el ámbito guatemalteco), tampoco para hacer distinción por la condición económica o aspecto físico. Este breve espacio es apreciado por los novatos especialmente, según revelaron en los grupos focales, entrevistas a profundidad y encuestas. Esto demuestra que aún dentro de la comunidad universitaria existen élites y distinciones de todo tipo por lo que cuando por alguna razón se logra esa condición de igualdad, prevalece un estado de comodidad. Durante la celebración del bautizo el colectivo será llevado al límite de resistencia física y tolerancia para, supuestamente, comprobar su valía. El siguiente momento es el denominado:

ii) El momento del margen. Este también es identificado como el momento de la transición. En este espacio pueden ubicarse las nueve estaciones que las novatadas de la Facultad de Agronomía deben superar. Cada una de ellas representa un reto, cada una contiene su propio dolor, pero cada una las acerca más al momento triunfal en donde pueden finalmente agregarse al grupo de las veteranas. En el caso de los varones el corte de cabello y despojarlos de la ropa simboliza despojarlos de su condición profana o impura (como se considera en los rituales religiosos).

iii) El momento de la agregación. Este es el tercer momento, según el autor este asegura la incorporación a una nueva categoría social. Es verdad que aunque la actividad del bautizo sea sumamente violenta y saturada de prácticas grotescas al culminar el recorrido final por el campus universitario y dejar en libertad a los novatos todo concluye. Por lo menos para aquellos que fueron bautizados porque para los fugitivos, aún quedan momentos difíciles por vivir.

Finalmente, el punto cúspide del ritual lo constituyó la fortaleza moral para exhibirse con la cabeza rapada (en el caso de los novatos) y enlodadas hasta el cabello (en el caso de las novatas) por el campus universitario semidesnudo. Desde la perspectiva de los ritos de paso religiosos, se transita de un estado de inferioridad a uno de superior valía. Tal es el caso del simbolismo que tiene 


\section{Aplicación de herramientas de investigación}

para el pueblo Malinké ${ }^{45}$ de África Occidental la ablación o mutilación de los genitales en las adolescentes africanas. Aunque el ritual está catalogado por como: una salvajada e injusticia, para los miembros de este grupo cultural es una práctica importante que aporta a las virtudes que toda mujer debe poseer al llegar al matrimonio. Al respecto se hace la observación que este es simplemente un análisis desde la perspectiva antropológica por lo que no emitiremos opinión relativa a un tema tan controversial que es caso juzgado y cuyo estudio requiere especial y oportuna atención.

Dentro de las novatadas existen algunas actividades que son cuestionadas desde la perspectiva de la salud. Así por ejemplo en muchas ocasiones los estudiantes novatos se ven obligados a consumir alcohol dentro del ritual de bienvenida. Esta es una práctica bastante común entre los estudiantes universitarios, sin embargo durante el evento, echarse un par de tragos es considerado necesario para poder transitar del estatus de menor a mayor. Existe la consigna que todos los agrónomos beben licor y aquel no lo haga está fuera del grupo porque carece de la calidades para ser parte del mismo. Así mismo es una manera de mostrar el poder del grupo sobre el individuo. Muchos estudiantes novatos ven la oportunidad de ingerir licor por primera vez sin ser juzgados por sus padres o el resto de la comunidad, por lo que se escudan en que es parte del bautizo. Por esta razón posterior a las jornadas de bautizo puede observarse a muchos estudiantes que ambulan por los jardines entre los edificios en estados de ebriedad. Otros alumnos han comentado que prefieren ser bautizados en estado de ebriedad porque saben que lo que les espera es difícil por lo que es mejor estar un poco sedado pues no sentirán frío, miedo, vergüenza o dolor.

En otro sentido, algunos estudiantes han manifestado que a través de la celebración del bautizo se han descubierto a sí mismos, han completado la imagen que acerca de sí mismos desean tener. A pesar que existe un sector estudiantil y docente que rechaza las prácticas del bautizo por ser

\footnotetext{
${ }^{45}$ Los malinké, también denominados como mandinga o mandé conforman un grupo étnico del África occidental. En la actualidad existen cerca de trece millones residiendo en diferentes países del oeste de África, en Gambia, Guinea, Guinea-Bissau, Senegal, Malí, Sierra Leona, Liberia, Burkina Faso y Costa de Marfil.
} 
consideradas innecesarias, humillantes y salvajes existe otro sector que lo reconoce e identifica como una etapa en la vida estudiantil que es necesario vivir porque ella permite sentirse parte de algo importante.

\subsection{Análisis de los resultados del estudio cualitativo}

Las entrevistas a profundidad, recreadas en un ambiente de confianza y cordialidad, permitieron el análisis y reflexión individual acerca de la experiencia de los estudiantes durante las novatadas. El estudiante promedio de la Facultad de Agronomía muestra un temple severo, que le es necesario para sobrevivir en un ambiente hostil, en el cual difícilmente se cuestionará acerca de eventos que lo hacen sentirse vulnerable. La concertación de las entrevistas fue un hecho afortunado, desde la perspectiva que otorgó la oportunidad del auto-análisis e introspección de cada uno de los entrevistados. Dentro de los principales hallazgos encontrados podemos señalar los descritos en los siguientes apartados.

\subsection{1. ¿Los bautizos refuerzan la identidad de los estudiantes como sancarlistas?}

Uno de los argumentos formulados con mayor frecuencia a favor de la celebración del bautizo o novatadas es que refuerzan la identidad como sancarlista. En el evento los estudiantes se reconocen a sí mismos como necesitados de pasar por este rito de paso para poder obtener calidades que le invisten como estudiantes sancarlistas.

Ante esta aseveración es importante cuestionarse ¿Qué significa ser un estudiante de la Universidad Estatal de Guatemala? ¿Cuáles son las normas y valores que caracterizan a los profesores, estudiantes y egresados de la institución? Definitivamente estos son cuestionamientos 


\section{Aplicación de herramientas de investigación}

que exigen un esfuerzo investigativo particular, pero por ahora aportaremos algunos hallazgos que son producto del trabajo de campo realizado. Según pudo determinarse en los resultados de los grupos focales y entrevistas dirigidas a especialistas; en épocas del Conflicto Armado Interno el estudiante sancarlista fue perseguido, humillado $\mathrm{y}$ en algunas ocasiones secuestrado $\mathrm{y}$ posteriormente asesinado. Esto porque se identificaba con las demandas del campesinado y sectores urbanos pobres que se organizaban en contra de los gobiernos militares que ejercían una dictadura sobre el pueblo. Fue durante esas épocas en donde se reforzó el uso de la capucha porque ella permitía proteger la identidad de los estudiantes activistas.

Sin embargo este argumento también ha sido formulado en las novatadas de importantes instituciones educativas europeas, tal como nos muestra Leflaive, quien nos indica que es un error considerar a las novatadas, como un simple instrumento de integración social, que suple el papel que le corresponde a la escuela y parece no cumplir (Leflaive, 2003).

La reflexión en este punto es que si el bautizo, fiestas vaqueras, borracheras, desórdenes y hacer todo lo que se venga en gana, es la marca de los estudiantes de la universidad estatal, se ha fallado como comunidad educativa. Han fallado las autoridades académicas, administrativas y cuerpo docente lo que evidencia la necesidad de cambiar el sistema. Así mismo es indispensable iniciar la búsqueda y reforzamiento de los verdaderos valores como estudiantes que alardean ser del pueblo, por el pueblo y para el pueblo. Como pregonaba las antiguas protestas estudiantiles en las décadas de los años 1980-1990 cuando el Conflicto Armado Interno recrudecía.

El demostrar la valentía, la fuerza física y la decisión de querer ser sancarlista y estudiar en la Facultad de Agronomía son los factores que los novatos señalan como principal motivación para soportar las humillaciones del bautizo. Saben que han sido puestos a prueba y que todo mundo los

observa y querrá saber si han sido capaces de superar retos que los veteranos han superado (supuestamente) en el pasado. He aquí un elemento de suma importancia. Aunque la hipótesis original del presente trabajo de investigación era justamente que "la violencia expresada en la 
celebración de los bautizos era reflejo de la violencia de la sociedad a la cual pertenecía”; posterior a la revisión de interesantes trabajos de investigación hubo necesidad de plantearla de una manera diferente. Esto porque no todos los estudiantes que abusan de sus compañeros han sido bautizados; ni tampoco todos los estudiantes que son bautizados continúan con tal práctica, renunciando el supuesto derecho ganado.

Zimbardo (1971) explica que personas comunes y corrientes, gente buena puede fácilmente perpetrar hechos malvados como respuesta natural a las condiciones a las cuales son sometidos. A este fenómeno Zimbardo ha dado por llamarle Efecto Lucifer. Siendo este un intento por comprender los procesos de transformación que actúan cuando las personas buenas o normales hacen algo malvado o vil (Haslam y Reicher, 2004).

\subsubsection{La percepción estudiantil relativa al maltrato físico y psicológico}

Las encuestas realizadas los estudiantes novatos demuestran que la realización del bautizo goza de buen grado de aceptación. Sin embargo al entrevistarlos individualmente, se obtuvieron resultados diferentes. En un ambiente de mayor confianza algunos de los estudiantes se atrevieron a reconocer que fueron víctimas de maltrato físico y psicológico. Así mismo reconocieron que hay algunos eventos negativos dentro del bautizo que difícilmente podrán ser olvidados. En este sentido es importante mencionar que una de las prácticas más resentidas por los novatos es el que los hayan desnudado completamente. Hay que recordar que en algunos casos las veteranas se dieron a la tarea de cortar la ropa interior de sus compañeros novatos.

Existen otras prácticas como: el obligarles a ingerir alimentos en descomposición y el revolcarse en estiércol de animales de granja que fueron señaladas como un exceso y muestra del salvajismo y abuso de poder que los estudiantes antiguos pueden ser capaces. En todas las 


\section{Aplicación de herramientas de investigación}

novatadas documentadas (2013-2015) surgieron elementos nuevos que fueron incorporándose como una "marca de promoción”. Algunos estudiantes entrevistados comentaron que el año en que se cometieron mayores abusos fue el año 2013. Explicaron que hubo mayor participación de estudiantes antiguos y muchos más estudiantes que sufrieron lesiones leves y moderadas. Hubo más intoxicados, las muchachas se quejaron, más. En algunas otras ocasiones se iban incorporando actividades que involucraban el empleo de cadáveres de animales de todo tipo.

Cada uno introduce una nueva broma, la tendencia es la eterna búsqueda de un tipo de bromas que humillen y pongan al novato ante un mayor reto. A pesar de ello hay algunas prácticas y efectos coincidentes. Así por ejemplo en todas las ocasiones, sin excepción, se pudo observar estudiantes: vomitando, deambular mareados, caminar cojeando y más triste aún, fue posible observar algunas muchachas llorando. Al acercarse y consultarles fue posible descubrir que tenían algún tipo de daño en las extremidades inferiores, principalmente, provocado al tropezar y caer en el suelo durante los recorridos que son obligadas a hacer.

El daño fue evidente y este extremo puede corroborarse visualizando algunos videos filmados y subidos a la Web por estudiantes ${ }^{46}$. Aunque filmar estas acciones, hubiese sido conveniente para fines de la investigación y deducción posterior de responsabilidades, fue imposible principalmente porque resultó grotesco y una falta de respeto para los novatos que estaban siendo dañados de esa manera. Así mismo los estudiantes Encapuchados y de Orden, suelen arrebatar cámaras fotográficas, de video y todo tipo de evidencia que algunos espectadores quieran conservar. Esta actitud demuestra que los agresores saben que las supuestas bromas, son en realidad acciones que ponen en riesgo la integridad física de los novatos. Así mismo están conscientes que cometen un delito y que pueden ser juzgados por los tribunales correspondientes.

\footnotetext{
${ }^{46}$ Existen más de veinte videos libres en el sitio Youtube. Para encontrarlos únicamente hay que escribir en el buscador: Bautizo Agronomía, USAC. Algunos de ellos se encuentras en el disco compacto anexo a la presente Tesis Doctoral.
} 
Es valioso recordar en esta ocasión que durante las jornadas de celebración del bautizo de los novatos de los años de 2005 y 2006; decenas de estudiantes de la FAUSAC sufrieron quemaduras de tercer grado, en diversas partes del cuerpo. Ello ocurrió cuando deliberadamente los estudiantes antiguos rociaron sobre su cuerpo un tipo de tinta indeleble. Según se estableció en investigaciones posteriores esta era del tipo de tinta que es usada durante los procesos electorales. Durante las jornadas del bautizo de los años 2013 y 2014 nuevamente fueron reportados estudiantes intoxicados y con quemaduras de primer y segundo grado en distintas partes del cuerpo.

Otro aspecto importante por analizar y la respuesta al as pruebas que son sometidos los novatos: Entre las múltiples pruebas a las que fueron sometidas los novatos de la Facultad de Agronomía se encuentran el corte de cabello, ingerir bebidas alcohólicas y alimentos mezclados con ajo, cebolla, y cualquier sustancia de carácter nauseabundo. Estas prácticas fueron bien toleradas, pero existe una que fue legítimamente rechazada y fue la relativa a despojarlos de la ropa, obligándolos a exhibir su desnudez. La sociedad guatemalteca es sumamente machista, así que el haber obligado a los novatos a vestir (tal como se observa en algunas fotografías) ropa interior de mujer fueron acciones consideradas, por los novatos entrevistados, como excesivamente humillantes.

Según quedó documentado fotográficamente en algunos casos se llegó al extremo de escribir obscenidades con lápiz labial en el cuerpo de los novatos. Tal como se demuestra en la siguiente declaración de Esdras $^{47}$ (estudiante novato de 18 años de edad): “Mi experiencia del bautizo fue desagradable, vergonzosa y humillante. Lo único que puedo decirle es que me llenó de mucha ira y enojo. Aún hoy en día reconozco a los antiguos me bautizaron y me dejaron casi desnudo y escribieron sobre mi espalda que era hueco ${ }^{48}$. Al verlos hoy en día, no los soporto. No

\footnotetext{
${ }^{47}$ El nombre es ficticio, a solicitud del entrevistado, quien temeroso de futuras represalias, pidió que sus declaraciones quedaran en el anonimato.

${ }^{48}$ En el medio guatemalteco esta palabra hace referencia a tener preferencia sexual por personas del mismo género.
} 


\section{Aplicación de herramientas de investigación}

me imagino trabajando con ellos en un grupo en algún curso, menos aun siendo su amigo. No les perdonaré que me hayan rasgado la ropa interior dejándome como una prostituta, viviré para esperar el momento de poder desquitarme, les irá mal, lo aseguro”.

El extremo de haber rasgado la ropa interior (en el caso de los varones) es el más sentido y peor tolerado. De hecho es el que incita a muchos a la venganza. Proyectan la impotencia de poder defenderse de los antiguos (puesto que el bautizo es de carácter obligatorio) en el futuro que promete el "desquite” con los estudiantes de nuevas generaciones, tal como lo expresó Manuel (novato de 19 años) en la entrevista: "No importa cuántas cosas malas haya tenido que soportar, porque total.... Agronomía es para los “hombres” y hay que aguantar. Eso sí... el próximo año me voy a desquitar con los nuevos, que se preparen porque no voy a tener piedad de ninguno de ellos, lo peor para mí, ya pasó; solo me resta esperar”.

De manera muy sincera, reconocieron sentirse atrapados por un sistema que ya está establecido y que parece funcionar para conveniencia de algunos. Recordemos que también hay un elemento de poder y económico implícito en tales prácticas. Todo indica que los veteranos defienden a capa y espada su derecho de bautizar y las autoridades administrativas y sector docente parecen tolerarlo.

Esto desde la perspectiva que el día del evento se suspenden las actividades académicas y administrativas, dejando de esta manera el campo libre para los desórdenes y excesos. Incluso uno de los estudiantes entrevistados expresó su repudio a las prácticas violentas, pero indicó que no tenía la menor esperanza que la situación fuera a cambiar y menos aún de ser él un elemento de tal cambio. De esta manera que lo único que podía hacer era participar en calidad de padrino para tratar de proteger a algún novato que gozara de su simpatía.

De este modo queda anulada la hipótesis que fue planteada con respecto a que los estudiantes rechazan la práctica del bautizo. Algo diferente ocurre en el sector docente en donde los profesores entrevistados manifestaron preocupación por los abusos cometidos en contra de los 


\section{Aplicación de herramientas de investigación}

novatos. Así mismo la representante de la Unidad de Salud que fue entrevistada expresó su frustración a causa de la carencia de medidas disciplinarias contundentes. Explicando que cada año durante la época de los bautizos un buen número de estudiantes (especialmente de las carreras de Agronomía, Ingeniería y Arquitectura que han demostrado ser las más violentas en este tipo de eventos) son atendidos por presentar problemas de intoxicación y quemaduras en la piel entre las más comunes.

\subsubsection{Cuestionamiento acerca de la obligatoriedad del bautizo}

En las entrevistas a profundidad los estudiantes se atrevieron a cuestionar acerca del carácter obligatorio y sistemático del bautizo: Aunque algunos de sus principales defensores señalan que el bautizo es un simple juego y recalcan que es “opcional”, estudios preliminares realizados por la autora han comprobado el carácter obligatorio y sistemático del evento. Esto demuestra que es un fenómeno social que requiere de especial atención. El bautizo de los novatos de Agronomía se practica, religiosamente, desde hace más de treinta años y ha evolucionado, según hemos podido ver en los resultados de las encuestas y entrevistas dirigidas a veteranos. Es importante hacer la observación que el carácter obligatorio del bautizo se expresa en el castigo que se otorga a aquellos novatos que no asistan y participen en su propio bautizo. Posterior a la celebración del evento se organiza un "bautizo particular" para aquellos que no hubieren asistido el día del evento. Los estudiantes novatos son asaltados en cualquier pasillo o sacados con violencia, de los salones de clase y son agredidos física y psicológicamente por un grupo de los estudiantes antiguos que se han autonombrado como "organizadores del evento". Esto a la vista de los docentes que nada pueden hacer para evitar tal abuso. 


\section{Aplicación de herramientas de investigación}

Algunos de los entrevistados expresaron que el bautizo es opcional, pero esto es simplemente una estrategia para evadir a las autoridades. Comprobado está, que aquellos novatos que desobedezcan la orden de presentarse el día de su bautizo serán castigados severamente por los veteranos. Humillados en público de una manera que seguramente no podrán olvidar el resto de su vida estudiantil y probablemente también de la profesional.

\subsubsection{Reflexión relativa a la obligatoriedad de la denuncia}

Una de las interrogantes que aún quedan por responder es la siguiente: ¿Por qué no se hacen efectivas las denuncias de los abusos cometidos durante las jornadas de bautizos?: Existe evidencia que en casos extremos (jornadas 2006 y 2007) estudiantes de la Facultad de Agronomía resultaron con quemaduras de primer y segundo grado como consecuencia de las jornadas de bautizos.

Así mismo, la Unidad de Salud resguarda los reportes anuales de estudiantes intoxicados por ingesta de alimentos putrefactos. En otros casos se reportaron estudiantes con extremidades fracturadas o bien con esguinces severos. A pesar de ello al dialogar con las autoridades correspondientes se determinó que no existen denuncias formales de tales actos, siendo importante reflexionar ¿A qué se debe que no existan denuncias de este tipo? Recordemos que antes se ha hablado que existe una cultura o Código de Silencio en donde el que hable de los bautizos, debe hacerlo para defenderlos. Por esta razón la participación en los grupos focales, y entrevistas a profundidad fue escasa. Esto es comprensible porque para iniciar no es sencillo hablar de un tema que, para muchos, provoca todo tipo de evocación de recuerdos dolorosos.

Con respecto a la Denuncia, podemos señalar que entre los estudiantes se han fortalecido códigos secretos de comportamiento. Entre ellos está el Código de la No Denuncia o Código del 


\section{Aplicación de herramientas de investigación}

Silencio. Aquellos estudiantes que denuncia son tachados de traidores, afeminados, cobardes, miedosos y otro tipo de apelativos peyorativos. Sin embargo existen algunos documentos que dan cuenta de cómo algunos estudiantes se han armado de valor y han denunciado los abusos sin obtener, lamentablemente, ningún tipo de reacción de las autoridades, tal como el caso que se expone a continuación:

El caso de la denuncia presentada por el estudiante Mauricio Delgado Pacay ${ }^{49:}$ : EL día 10 de Febrero del año 2012 en el Centro Universitario de Cobán, departamento de Alta Verapaz en Guatemala, se celebró el denominado "bautizo” de los estudiantes novatos. El estudiante ya mencionado denunció ante la Junta Directiva del Centro Universitario que fueron encerrados por encapuchados en un aula en donde les lanzaron juegos pirotécnicos al cuerpo obligándolos a beber licor. Relató que uno de los principales problemas fue que varios estudiantes resultaron con quemaduras y problemas respiratorios por el grado de contaminación del aire. La principal molestia del estudiante fue que los estudiantes que se negaban a ingerir licor recibieron fuertes golpe de estudiantes encapuchados. $^{50}$

La decisión de las autoridades del Centro Universitario, fue: “ofrecerle una disculpa en nombre del Centro Universitario y acordar que se realizaría una investigación para sancionar a los responsables”. Al darle seguimiento el suceso, pude comprobar que no hubo tal investigación y que menos aún se dio con los responsables, esto porque los agresores resguardaron su identidad al utilizar una capucha. Finalmente el incidente quedó en la impunidad, celebrándose nuevamente durante los ciclos 2013 y 2014.

Volviendo a la reflexión generada durante las entrevistas en el campus central mencionaremos que al consultar a una de las estudiantes entrevistadas acerca de la razón por la cual

\footnotetext{
${ }^{49}$ Estudiante regular de la carrera de Agronomía del Centro Universitario de la USAC ubicado en el departamento de Alta Verapaz.

${ }^{50}$ Según consta en Acta 07-2012 del Consejo Directivo del Centro Universitario de USAC EN Cobán, Alta Verapaz.
} 
no había denunciado a las autoridades de la facultad el hecho de haber sido agredida de tal manera, respondió lo siguiente: “No tiene ningún sentido quejarse porque no me harán caso. Así mismo aunque lo hicieran, a ¿A quién podría señalar? , si eran muchos los que nos acosaban el día del bautizo”. Al hacer la misma pregunta a otro de los alumnos en los grupos focales respondió: “No tiene ningún sentido quejarse con el Decano, porque seguramente no hará nada, todo mundo le teme a los Verdes, son muy agresivos, hemos sabido que aún al Decano lo han encerrado en su propia oficina”.

El estudiante se refiere al suceso acontecido en una de las jornadas de desorden surgidas días previos al bautizo del año 2013. En aquella oportunidad, personas encapuchadas ${ }^{51}$ cerraron la entrada principal en donde se encuentra el sector administrativo, inclusive el Decano. Esto con el objetivo de evitar que interviniera en la encerrona de los novatos. La denuncia de los abusos vividos por los estudiantes novatos durante los bautizos es aún una tarea pendiente. Ella es determinante para iniciar a cobrar conciencia y sobre todo comprender que el bautizo no tiene nada de jocoso. Muchos de los estudiantes que fueron abordados relativo este tema, prefirieron no hablar, evadiendo el tema, diciendo que simplemente es un “juego, una tradición”. Muchos otros se escudan diciendo que es "una manera de lograr que todos sean iguales que el día del bautizo no haya ninguna distinción relativa al género, condición social, grupo cultural o diferencias de cualquier índole.

Sin embargo al profundizar en la investigación y proporcionarles un ambiente más relajado, lejos de la mirada de sus compañeros (esto se logró en las entrevistas a profundidad) se obtienen historias desgarradoras que describen vejaciones, humillaciones en el ámbito sexual, golpes, intoxicación por ingesta de alimentos malsanos y bebidas alcohólicas. Algunos de los entrevistados señalaron que fueron “dañados física y psicológicamente”, pero esto no es fácil reconocer, por lo menos, públicamente. En otro sentido diremos que hoy en día los bautizos son mucho más

\footnotetext{
${ }^{51}$ En vista que cubren sus rostros, no puede asegurarse su identidad. Sin embargo el sector estudiantil asegura que no se permite a infiltrados, de tal suerte que aseguran se trata de estudiantes veteranos.
} 


\section{Aplicación de herramientas de investigación}

elaborados, con mayores actividades que buscan la degradación del novato y sobre todo que muestran el grado de deshumanización de los victimarios. 


\subsubsection{El grado de organización del evento}

Con respecto a la organización del evento, es oportuno hacer la observación que para el caso del bautizo de las novatas hubo una planificación previa. Este hecho quedó demostrado al haber identificado y descrito las nueve estaciones que fueron programadas y que cada novata debía superar. Una condición un tanto diferente y menos elaborada ocurrió en el caso de los novatos. Evento en el que se observaron únicamente tres estaciones. En ellas existía claridad únicamente en que los estudiantes debían ser intimidados, rapados, desnudados y ridiculizados. Las actividades dentro del bautizo de los novatos fueron improvisadas por la masa pues ni aún los estudiantes encapuchados (cuyo supuesto rol debía ser el regular la actividad) pudieron contrarrestar los desbordes colectivos. Una de las grandes preocupaciones a futuro es la siguiente ¿Quién es la persona que conduce la actividad?, ¿Hasta dónde puede conducir el desborde de emociones y euforia durante la celebración?, ¿A quién puede señalarse como responsable en caso del homicidio culposo de alguno de los novatos? Todas estas preguntas habrá que responderlas en algún momento. Por las limitaciones del estudio no es posible darles respuesta, sin embargo queda abierta una brecha importante de investigación.

\subsubsection{El tiempo empleado para el bautizo}

Afortunadamente, para la salud mental e integridad física de los novatos, la celebración del bautizo se realiza en un solo día durante el período comprendido entre las 06 de la mañana y las 12: 00 horas, aproximadamente. Sin embargo la actividad es sumamente intensa y muchos momentos difíciles tuvieron que ser superados en corto período de tiempo. Es importante considerar que a pesar de que el bautizo como tal dura menos de 7 horas, este tiempo es suficiente para ejecutar todo 


\section{Aplicación de herramientas de investigación}

tipo de salvajada que ponga en riesgo, la vida misma de los novatos. Es necesario recalcar que la intimidación a los novatos ocurre permanente y sistemáticamente desde el primer día de actividades. Aun cuando inician a participar en cursos propedéuticos. Ello incrementa el nivel de angustia de los estudiantes.

\subsubsection{Reflexiones realizadas por los estudiantes en torno a la práctica del bautizo}

Las prácticas son deshumanizantes pues para cometer acciones aberrantes como: desnudar, cortar el cabello, obligar a arrastrarse en estiércol; es necesario despojar al otro de su humanidad. Solamente considerándole diferente (y en la mayoría de casos inferior) es posible provocar tanto daño al otro. Existen fuerzas superiores, dentro de los estudiantes, que son las que promueven la manifestación de un comportamiento totalmente errático y violento, en contradicción de lo que se espera (naturalmente) de un estudiante universitario.

Considerando que dentro de las prácticas de las novatadas (o bienvenida como han ideado llamarle para burlar la prohibición de las mismas) existen algunas que son aceptadas porque estimulan la inversión de energía y creatividad, bien podrían sustituirse por jornadas deportivas bien organizadas y con participación de estudiantes antiguos y sobre todo autoridades de la unidad académica que velen por la seguridad y respeto de los Derechos Humanos de los estudiantes de primer ingreso. Como podremos ver en el siguiente esquema, las respuestas fueron muy variadas, sin embargo revelan la percepción clara y firme que los estudiantes tienen acerca de su propio bautizo. 


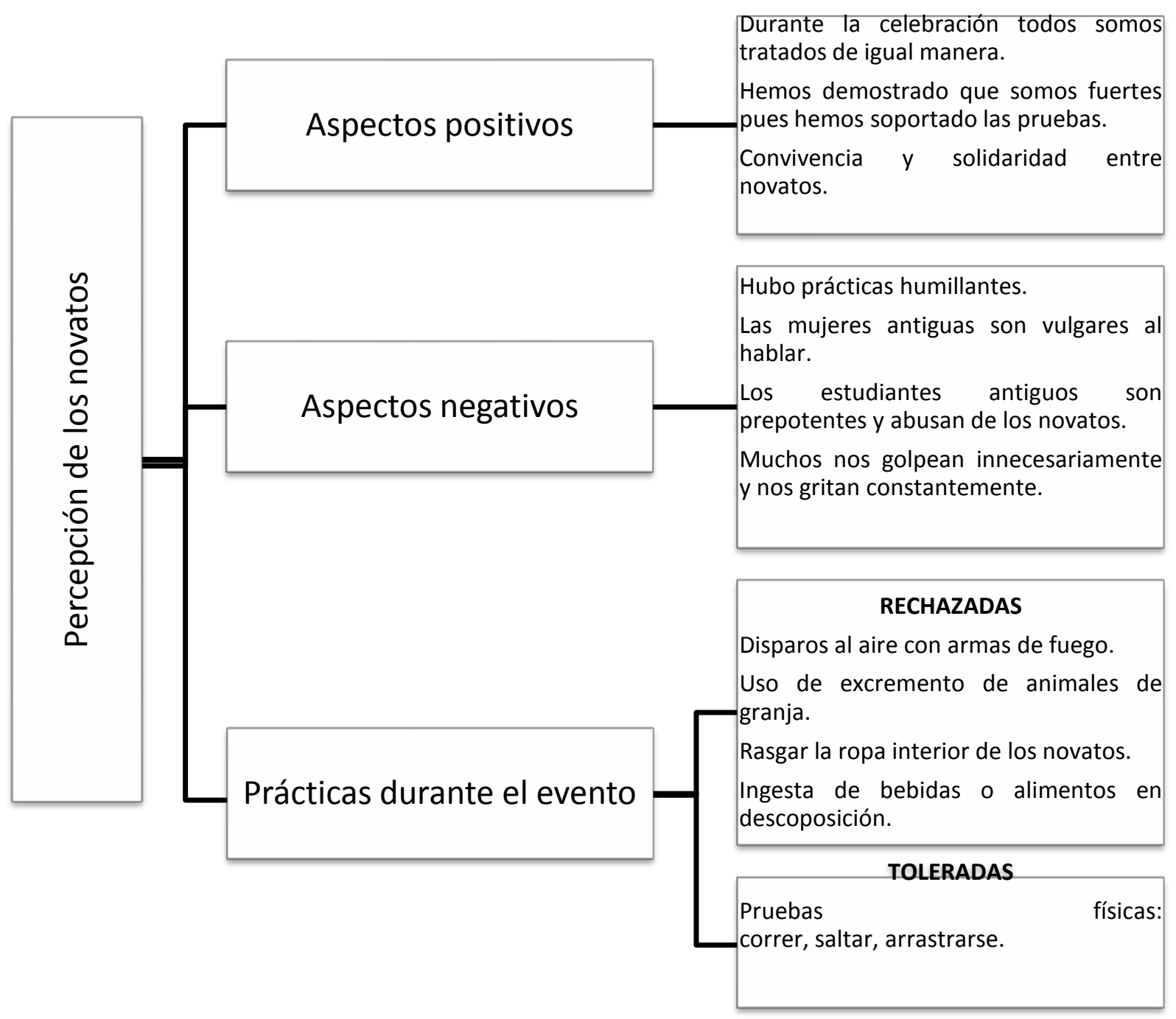

Figura 38. Percepción de los estudiantes novatos acerca de la celebración del bautizo. Fuente: Creación personal con resultados de las encuestas.

La humillación de la cual son víctimas los estudiantes novatos cuando son obligados a despojarse de su ropa y quedarse en ropa interior es una forma de violencia en términos de los rituales de bautizo en USAC. Cuando los alumnos externan su "dolor interno, la violencia psicológica” demuestran que durante la práctica existe todo tipo de maltrato.

Las entrevistas también fueron realizadas entre estudiantes antiguos, habiendo obtenido como respuestas más frecuentes las que se presentan en el siguiente esquema. 


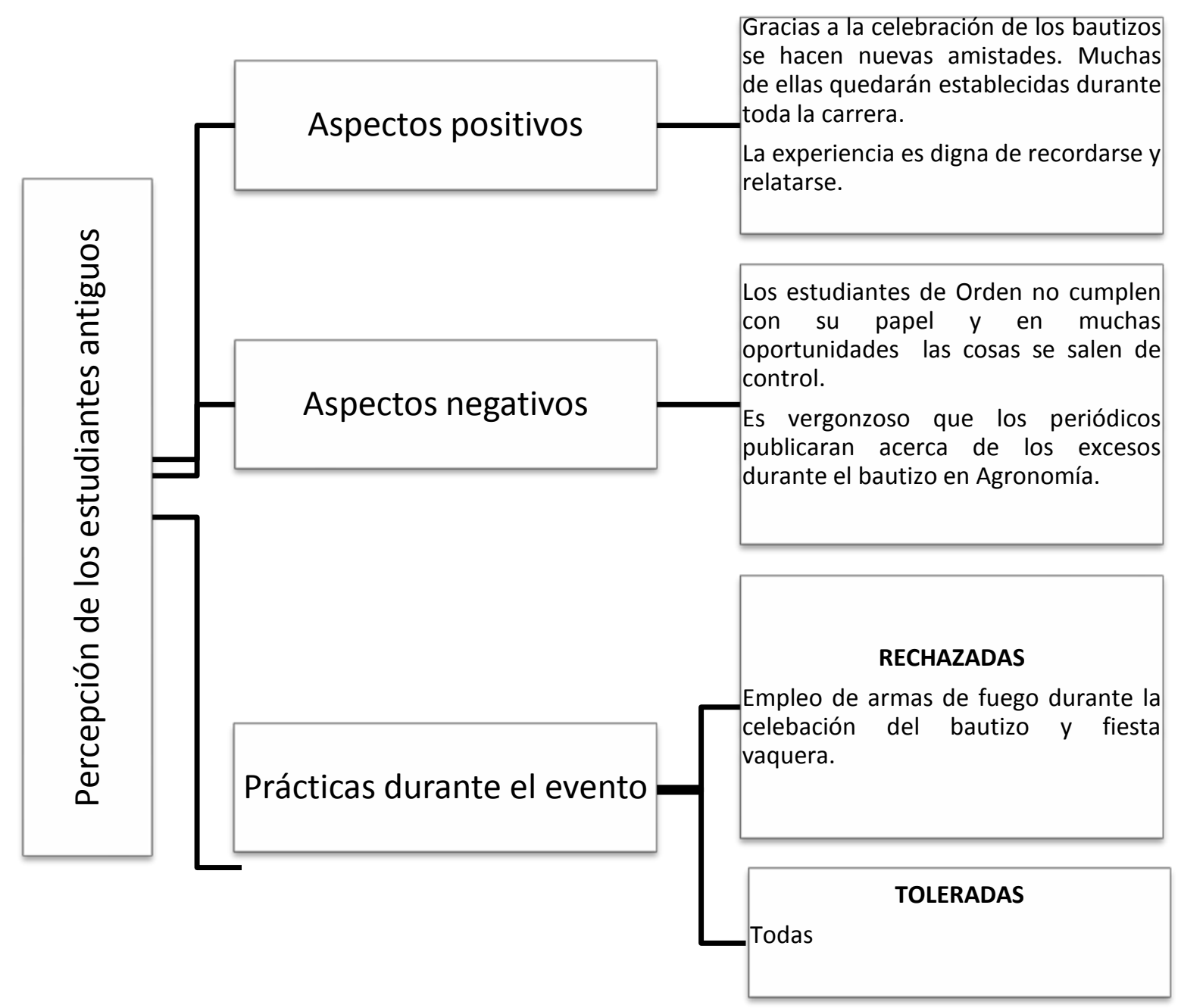

Figura 39. Percepción de los estudiantes antiguos acerca de la celebración del bautizo.

Fuente: Creación personal con resultados de las entrevistas personalizadas.

Las opiniones de los estudiantes novatos y antiguos coinciden en aspectos tales como: i) Permiten la homogenización de colectivo estudiantil. Esto revela que los estudiantes estiman y privilegian los espacios en los cuales son tratados sin ninguna distinción. Podemos reflexionar entonces que dentro de la Facultad de Agronomía es un grupo en donde se hacen distinciones de clase.

ii) La celebración de los bautizos promueven la solidaridad entre estudiantes. En este tema es importante reflexionar que los estudiantes novatos son solidarios con otros novatos que padecen los 
suplicios del bautizo; pues en ninguna de las acciones de los estudiantes antiguos hacia los novatos puede observarse alguna acción solidaria.

\subsubsection{Del drama de la cultura moderna y la deshumanización de los estudiantes}

Conviene analizar estas acciones desde "el drama de la cultura moderna”, como anota Boff en su obra: San Francisco de Asís, Ternura y convivialidad. En donde señala que la raíz de todos los males de los tiempos modernos y la crisis cultural es la carencia de ternura de unos para con los otros, así mismo para con la naturaleza y más aterrador aún, para con nuestro propio futuro (Boff, 1981). No es de extrañar que un filósofo tan agudo como Martin Heidegger haya considerado a Fürsorge [ternura] y la Sorge [solicitud] como el fenómeno estructurador de la existencia.

Las prácticas deshumanizantes son producto de la carencia de esa delicadeza que permite fascinarse y apasionarse por la naturaleza y por todas las expresiones de la creación, entre ellas y en un lugar muy especial los seres humanos. Desde esa perspectiva, es sorprendente descubrir que durante las prácticas del bautizo de los novatos en FAUSAC no logra visualizarse ningún tipo de solidaridad y compasión hacia los novatos. Son simplemente estudiantes agrediendo a sus compañeros, aquellos que en un futuro serán sus colegas, socios o quizás sus esposas, esposos o bien sus jefes.

Otro de los argumentos que señala Boff como los causantes del drama de la cultura moderna son los elevados niveles de represión del Eros. De la manifestación de los instintos más naturales del hombre que amenazan con desbordar en todo tipo de acciones, independientemente del valor que pueda dársele a cada una de ellas. 


\section{Aplicación de herramientas de investigación}

En un ambiente puramente académico, es el Logos (la razón) quien se ha encargado de construir un sistema "inflexible” las reglas, la disciplina, la homogenización de los estudiantes(Freud, 1921).

Todos los alumnos deben responder a la medida de lo que se espera de ellos, los estándares académicos siempre serán el cristal con que serán vistos. En este sentido el desempeño académico y el cumplir con las reglas, las normas al pie de la letra son lo más importante y permitirá distinguir a un "buen estudiante" de uno que no lo es o que probablemente nunca llegue a serlo. Todo un año académico en donde es Logos quien moldea y regula el ambiente; el total de las actividades, hasta que llega el día tan esperado, (el Día del Bautizo) en donde es Eros, y su fuerza destructora quien puede manifestarse. Es allí en donde no hay reglas, en donde la razón (el Logos) es relegada a segundo plano, en donde la autoridad la constituyen los mismos estudiantes, de tal manera que hay un desborde de emociones, de violencia, del Pathos (la capacidad de ser afectado y de afectar): la afectividad, que es lo concreto y primario en el ser humano.

La razón, según el filósofo Jean Ladriére, citado por Boff (1981), no es el primero ni el último momento de la existencia humana, sino que está abierta hacia abajo y hacia arriba. Abajo, nace de algo más antiguo, más profundo y elemental y primitivo: la afectividad. Hacia arriba, se abre a la experiencia espiritual, que es el descubrimiento del yo dimensionado hacia la totalidad y de la totalidad presente en el yo, no como pura contemplación, sino como experiencia de que, por detrás de lo real, no hay únicamente estructuras, sino sentido gratificante, simpatía y ternura.

Es Eros quien predomina y gobierna el día del bautizo, no tiene porqué ser precisamente malo, violento o reprochable por las prácticas extremas que en él se avizoran. Esto porque el Eros está ligado con la fantasía, con la creatividad, con la irrupción de lo nuevo, lo sorprendente y lo maravilloso. El Eros produce fascinación, atracción y hechizo.

Si ese Eros es disciplinado por el Logos, grandes cambios podrían esperarse el día de la celebración del bautizo para que pueda ser en verdad una celebración. A efecto de ellos uno de los 


\section{Aplicación de herramientas de investigación}

docentes entrevistados sugirió que el institucionalizar la actividad al establecer una agenda, haciendo referencia que los profesores y autoridades administrativas participaran en la actividad, podrían disminuirse las prácticas violentas evitando así el repudio y rechazo de la opinión pública hacia la institución.

\subsection{9. ¿Pueden las prácticas del bautizo conducir al suicidio?}

Aunque en algunos sectores aún sigue argumentándose que el bautizo es un simple juego entre estudiantes; existen antecedentes de un estudiante que cometió suicidio, justamente un día después de haber sido bautizado en la Universidad de San Carlos de Guatemala. A continuación referiremos la siguiente historia referida en una de las entrevistas a profundidad.

La directora de la Unidad de Salud de -USAC- describió la experiencia en la cual un estudiante de primer ingreso a la Facultad de Odontología decidió suicidarse un día después de haber sido bautizado. Según manifiesta la profesional entrevistada, considera que la decisión del estudiante muy probablemente haya sido tomada debido a que fue objeto de crueles vejámenes aún más que sus compañeros. Esta situación particular pudo deberse a que el estudiante ya referido manifestaba en sus maneras y forma de actuar un carácter acentuadamente afeminado.

El acoso a hombres y mujeres homosexuales (aunque no aseguramos que haya sido el caso del estudiante) es bastante común en el medio guatemalteco en donde se rechaza frontalmente la feminidad en los hombres y todo tipo de tendencias de carácter homosexual. Esto ocurrió en la década de 1980 y aunque es un hecho aislado, da cuenta del nivel de psicosis que algunas prácticas dentro del bautizo provocan en los novatos.

Durante las jornadas de bautizo del año 2015 los incidentes no se hicieron esperar y fue alertado el cuerpo de Bomberos Voluntarios debido a que se escucharon múltiples disparos al aire, 


\section{Aplicación de herramientas de investigación}

en algunos casos utilizando armas de grueso calibre, hubo un estudiante herido. Este hecho fue documentado gracias a las publicaciones en diversos medios de comunicación, ver ANEXOS VI, VII y VIII.

Este último hecho provocó que muchas personas ajenas a San Carlos se pronunciaran en contra de la celebración del bautizo. Entre ellas los vecinos de las colonias aledañas al campus universitario. Así mismo radioescuchas de Radio Sonora y algunos sitios de internet.

Detrás de la superficie civilizada, abierta y liberal de la vida cotidiana en las universidades, con su opaca pero encantadora atmósfera, hay otro mundo de relaciones de poder entre los estudiantes más jóvenes y sus compañeros mayores. Allí la humillación es permitida y todas las prácticas son permeadas por una sexualidad “prohibida”, por ello la insistencia de desnudar a los novatos y aún de rasgarles la ropa interior, dejando expuestos (en el caso de los varones) el área genital.

El ambiente estudiantil sancarlista se ha convertido, de acuerdo a la definición de campo de Bourdieu y Passseron (2003), en un espacio físico e ideológico de fuerzas y luchas. El día del Bautizo es la oportunidad para que algunos estudiantes antiguos que por no poseer alguna cualidad distintiva, logren hacerse notar. Pareciera que mientras más violentos y crueles son con los novatos, mayor será el grado de prestigio que ganarán. Así mismo también es una oportunidad de homogenización en donde el estudiante antiguo de escasos recursos económicos puede humillar al estudiante acaudalado. O la estudiante antigua que no es precisamente agraciada puede arremeter en contra de alguna novata que se distinga por su belleza física. Esta aseveración se plantea acerca de los resultados obtenidos en las entrevistas personalizadas.

Vale la pena preguntarse acerca de la razón por la cual los estudiantes antiguos “reproducen” las prácticas militares que tan duramente juzgan y han rechazado durante décadas, por lo menos en el discurso. En este punto es conveniente recordar que Guatemala es un país que durante treinta y seis años vivió un conflicto armado interno en donde decenas de estudiantes 


\section{Aplicación de herramientas de investigación}

sancarlistas fueron secuestrados, torturados y asesinados. En tales condiciones se marcó un distanciamiento claro entre las clases militares guatemaltecas y los estudiantes de la universidad estatal. Prueba de ello es que durante dos de las celebraciones estudiantiles más importantes en USAC (Huelga de Dolores y elecciones de Reyes Feos universitarios) los militares siempre han sido objetos de dura crítica y ridiculización. Pese a ello durante la celebración del bautizo, sobreabundan las prácticas de corte militar. La manera prepotente y autoritaria en que los estudiantes antiguos mandan a los novatos a realizar ejercicios físicos (correr, sentadillas, despechadas, saltos) hasta el cansancio; la utilización del lenguaje humillante y vulgar hasta los castigos a los que son sometidos. La ridiculización y castigo de aquellos que no logren superar las pruebas asignadas, son la clara y contradictoria reproducción de aquello que se rechaza, reafirmándolo y manteniéndolo vigente.

\subsection{La inversión del poder el día del bautizo}

El día del Bautizo es el día en que el poder se invierte en que la autoridad oficial desaparece como por arte de magia y el escenario es óptimo para desencadenar el tropel hormonal de excesos. Toda la energía física y creativa (aunque para proponer estaciones de bautizo humillantes) se hace presente durante esa jornada; esperada pacientemente durante todo un año. Un solo día al año la ley y el orden quedan atrás y "todo es permitido, por cuanto no podrá ser observado, perseguido y castigado”. La autoridad está lejana, descansando en casa, haciendo cualquier cosa; menos señalando las acciones de los alumnos. Mientras más ajenas se encuentran las autoridades administrativas y docentes de la actividad mayor es la oportunidad y motivación de dar rienda suelta a los deseos de los jóvenes. Es un momento en donde deberán aprovechar porque a la jornada siguiente todo volverá a la normalidad y cualquier falta al orden, disciplina sería inmediatamente “reprimida y castigada”. Para poder comprender de mejor manera el fenómeno de las novatadas es 
necesario explorar el entorno institucional, determinando cuáles son las fuerzas que en esa institución interactúan. Cómo se maneja el poder, quienes, y de qué manera implementan la normativa institucional. Por esta razón presentamos a continuación los esquemas que permiten conocer la organización universitaria, desde la perspectiva de la toma de decisiones.

Según el Instituto de Problemas Nacionales de la USAC -IPNUSAC- el poder en la universidad se entiende en el siguiente esquema: 


\section{El poder en la Universidad de San Carlos de Guatemala}

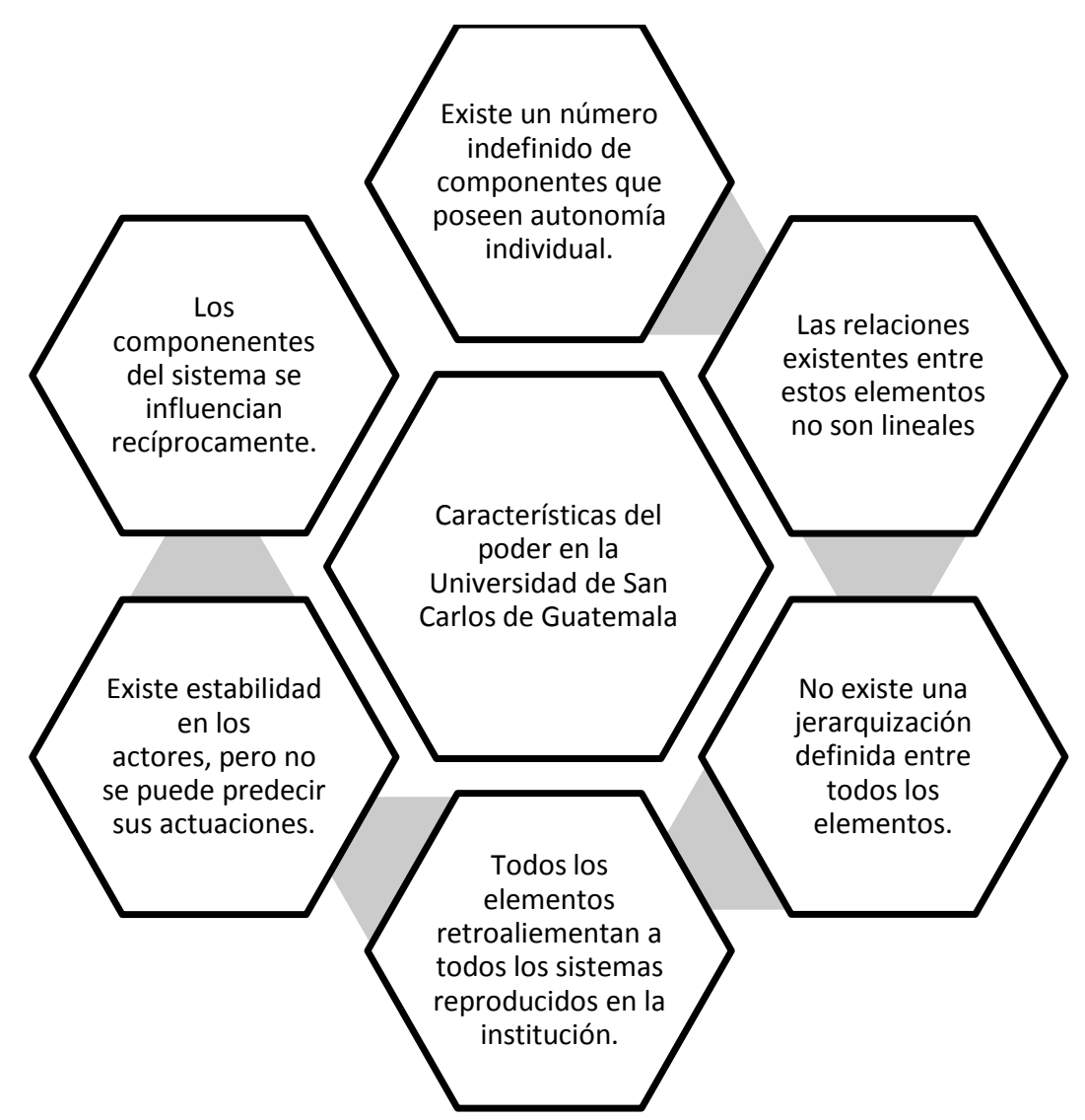

Figura 40.El poder en la Universidad de San Carlos de Guatemala.

Fuente: Creación personal con datos otorgados en el Instituto de Problemas Nacionales de USAC -IPNUSAC 


\section{Aplicación de herramientas de investigación}

La Autonomía de la Universidad de San Carlos de Guatemala es una de las características más relevantes de esta institución de educación superior. Para poder conseguirla se realizaron una serie de luchas que culminaron en el año de 1945 cuando se emitió la Constitución Política de la República de Guatemala, aprobándose al unísono la Ley Orgánica ${ }^{52}$ y la Ley de Colegiación Obligatoria para los egresados de esta casa de estudios.

$\mathrm{Al}$ respecto se concluye que existen grandes contradicciones políticas en el ejercicio del poder dentro de la institución, reflejado con ello que existen actores bien posicionados que no están dispuestos a renunciar a lo que consideran ya como territorio ganado. Existen estudiantes empoderados (las Asociaciones Estudiantiles en muchas ocasiones se han convertido en verdaderas trincheras en el campo de batalla) que están bien organizados con objetivos que van mucho más allá de lo académico. Al respecto podemos mencionar que en el sector docente es muy popularizada la convicción que “el estudiante viene a la universidad a estudiar”; muy diferente a lo que algunos estudiantes (se les considera así por cuanto tienen matrícula estudiantil vigente) se han dedicado cuando por medio de Asociaciones lícitas e ilícitas se ven involucrados en negocios ilegales como la venta de estupefacientes y en algunas ocasiones de armas de fuego. En algunas ocasiones se ha observado que estudiantes abandonan sus estudios para dedicarse de lleno a las actividades políticas siendo parte de la Asociación de Estudiantes Universitarios.

Los objetivos de la presente Tesis Doctoral están enfocados principalmente al análisis y reflexión de algunas expresiones de violencia entre iguales en el campus de la Universidad, por lo que el tema de los fenómenos que acontecen en el seno de las organizaciones universitarias queda fuera del tema principal de investigación. Sin embargo existe la oportunidad de agotarlo en futuras oportunidades, pues muchos de los fenómenos dentro de universitarios están supeditados por el poder de las mismas Asociaciones Estudiantiles.

\footnotetext{
${ }^{52}$ Promulgada según Decreto Legislativo Número 131 y posteriormente modificada en 1947 según Decreto Legislativo Número 325, vigente a la fecha.
} 


\subsection{La impunidad durante la celebración de los bautizos}

Es importante entender que la libertad académica y la Autonomía Universitaria es mal comprendida por muchos estudiantes, quienes asumen que Autonomía es "hacer lo que se quiere porque la San Carlos es sagrada, no entra la Policía Nacional y puedes hacer lo que deseas”. Para algunos de ellos (miembros de las Asociaciones especialmente) es muy fácil comprar una sotana y una capucha y desde la impunidad desafiar a las autoridades académicas y administrativas.

La Abogada y Notaria Sandra Castañeda ${ }^{53}$, opina que el uso de las capuchas durante el conflicto armado interno (décadas 1960-1996) fue instaurado como una necesidad para proteger la identidad de los estudiantes universitarios que consecuentes con las luchas del pueblo protegían su identidad. Está bien documento el hecho que durante el la época de guerra en Guatemala, cientos de estudiantes universitarios cayeron abatidos por las balas del Ejército de Guatemala quienes buscaban reprimir las voces de protesta en contra de los gobiernos autoritarios.

Algunas de las prácticas entre estudiantes universitarios son adoptadas con mucha mayor facilidad que otras y el uso de las capuchas durante la celebración del Desfile Bufo (durante la Semana Santa o Semana Mayor) y los bautizos han sido popularizados en el $100 \%$ de las Unidades Académicas y Escuelas no Facultativas. Cada unidad académica se distingue por el uso de una capucha de distinto color, en el caso se la Facultad de Agronomía es de color verde oscuro. El uso de la capucha representa cierto status y para poder utilizarla se hace necesario cumplir con los requisitos que los dirigentes (reconocidos popularmente como “Los Verdes”) determinan. No existe claridad relativa a estas condiciones, pero entre las relevantes están: i) Ser estudiante regular de FAUSAC. ii) Estar dispuesto a someterse a la autoridad de Los Verdes. iii) Cumplir con las atribuciones que les sean concedidas (generalmente éstas son distribuidas de manera arbitraria).

\footnotetext{
53 Profesora universitaria en Facultad de Agronomía y Centro de Estudios del Mar, ex miembro de la Asociación de Estudiantes Universitarios durante la época del Conflicto Armado Interno en Guatemala.
} 


\section{Aplicación de herramientas de investigación}

Aunque los estudiantes que se usan capuchas aparecen en escena en diferentes momentos del ciclo académico, el tema de interés en la presente investigación es durante la celebración de la novatada o bautizo por lo que las reflexiones realizadas giraron en torno a ello.

Los estudiantes encapuchados tienen la potestad de organizar, dirigir y regular las actividades dentro del bautizo. Es claro que aunque existe una agenda (pues algunas actividades están claramente organizadas) esta es extremadamente flexible. Está comprobado que cada año que se realiza el bautizo se incorporan nuevos elementos a sabor y antojo de quienes lo organizan. Prueba de ello fue que durante la celebración del bautizo en la Facultad de Agronomía, durante el año 2013 se llevaron cadáveres de tres lechones, que los estudiantes novatos tuvieron que acariciar y besar como una de las pruebas a las que fueron sometidos. Es común que en algunos años los estudiantes se dirijan a los basureros municipales o clandestinos y vayan de cacería, atrapando a alguna ave de rapiña que también se ha convertido en símbolo durante la celebración de los bautizos y desfile bufo.

La orientación que los estudiantes encapuchados le den a la actividad del bautizo es determinante y aunque (según los entrevistados) la función principal de estos personajes durante el bautizo es "regulación y control”, es conveniente hacerse la pregunta ¿quién regula lo que los encapuchados deciden y hacen? Desde nuestra perspectiva, allí está el mayor riesgo. 


\section{CONCLUSIONES Y LÍNEAS DE AVANCE}

Las novatadas son unos hechos extraordinarios que, cuando ocurren a menudo, se vuelven perversamente cotidianas puesto que los que participan en ellas, se desensibilizan de su inhumanidad

HANK NUWER

Inicialmente es importante mencionar que realizar la presente Tesis Doctoral constituyó un desafío porque el ritual del bautizo en la Universidad de San Carlos es un fenómeno que provoca diversidad de opiniones y que presenta algunas dificultades metodológicas para su abordaje. Una de las más importantes se debe a que; aunque la actividad es de carácter público, en su desarrollo no tolera la participación de ningún tipo de persona que represente autoridad sobre la acción estudiantil.

Por esa razón en la celebración acontecida durante la segunda semana de febrero de los años 2013, 2014 y 2015 hubo necesidad de apoyarse en estudiantes veteranos que proporcionaron relatos, entrevistas, fotografías y sobre todo anécdotas vividas durante la celebración del bautizo. La participación de los propios protagonistas del suceso fue imperativa. Si bien es cierto fue posible observar el ritual; fue a una distancia prudencial, considerando la actitud amenazante e intimidatoria de los estudiantes encapuchados, armados con cadenas, martillos, machetes, bates de béisbol. Y más aún de algunos otros que portaban armas de fuego.

Así mismo fue necesario superar el desaliento y desinterés mostrado por algunos miembros del Claustro, quienes (al compartir la idea de la investigación) manifestaron que dedicar una Tesis Doctoral a un juego o broma como lo son los bautizos era perder el tiempo, una tarea sumamente infructífera. Explica Leflaive (2003) que el ritual de bautizo, al igual que la violencia doméstica inició a hacerse visible hasta que fue políticamente correcto el denunciarla y condenarla. Es necesario provocar cambios pues durante mucho tiempo la práctica ha sido perfectamente admitida 
y hasta resultaba divertida, hasta que los veteranos iniciaron a extralimitarse en sus prácticas provocando daños físicos y emocionales de carácter permanente en los novatos.

A la luz de los resultados obtenidos, podemos concluir que el fenómeno de las novatadas en la Universidad de San Carlos de Guatemala exige mayor atención de la comunidad científica universitaria. Es imperativo que las organizaciones académicas y administrativas se pongan al servicio de la búsqueda de rutas críticas por recorrer, que permitan detener la ola de abusos en contra de los estudiantes novatos. La responsabilidad es de todos y las acciones propuestas deben ser de carácter integral y permanente.

Los efectos de las novatadas son de diversa índole: físicos, psicológicos, económicos y hasta políticos. La riqueza de la información recopilada en la presente Tesis Doctoral reside en los múltiples enfoques en que fue abordado el fenómeno en cuestión. La opinión de los principales actores es fundamental porque al comparar las diferentes versiones pueden encontrarse puntos intermedios que permiten identificar un hilo conductor. En este caso puede determinarse que aunque muchos argumentan que el bautizo es un elemento que "identifica" al estudiante sancarlista este no es del todo cierto porque muchos de los actores principales opinan que la supuesta solidaridad y compañerismo, se ve desvanecida ante el desborde de maltratos, insultos y golpes que los antiguos propinan a los novatos. Considerándolo contrariamente como una simple y vana expresión de violencia y salvajismo.

Según Pierre Bourdieu (2003) en el sistema escolar y universitario son lugares donde se fabrica algo más que un título. La riqueza es muy superior por cuanto se fabrican formas de pensar, de actuar, son lugares en donde se reproducen las estructuras sociales. Desde esta perspectiva la situación es sumamente preocupante porque los estudiantes que durante las jornadas del bautizo son los que protagonizan tan crueles escenas de violencia, serán los mismos que tendrán que hacer aportes sustanciales en la búsqueda a la solución de muchos de los principales problemas de la sociedad guatemalteca. ¿Cómo podría un profesional que se ha deshumanizado (mediante su 
participación activa en este tipo de prácticas) responder integralmente a las necesidades de una población que lo necesita?, nadie puede dar lo que no tiene. Al respecto es justo aclarar que no todos los estudiantes participan y que tal como puede comprobarse en los comentarios expresos en las redes sociales más populares en el medio guatemalteco; un sector importante de la población estudiantil de -USAC- rechaza y condena estas prácticas.

Para atender las necesidades de la población guatemalteca, golpeada por la violencia, corrupción a todo nivel y desempleo, se requerirá de sensibilidad, humanidad y todo tipo de valores éticos y morales. Todas esas calidades humanas parecían tan ajenas e inalcanzables el día de la novatada. Es primordial preguntarse entonces si la actitud de los estudiantes, ¿fue provocada por un estado de excitación momentáneo o bien es reflejo de una pérdida gradual de valores humanos y deshumanización que los marcará por siempre? Es necesario profundizar en este tipo de investigación. Por ahora hemos aportado a través de la presente Tesis Doctoral, información que será útil para poder profundizar en este tipo de estudio.

Durante la celebración de la novatada, la improvisación fue en todo momento un detonante del efecto de masa y la ausencia total de todo tipo de autoridad durante el evento fue el elemento catalizador del desborde y los excesos. Al respecto algunos entrevistados opinaron que si las autoridades administrativas y docentes tomaran el control de la actividad, es decir la regularán, probablemente las prácticas serían menos violentas. En este punto es interesante plantearse el pulso entre el gobierno estudiantil- versus el gobierno académico y cuestionarse ¿por qué las autoridades no han podido o no han querido intervenir?

Vale la pena preguntarse (al igual que la pregunta que incomodaba a los supervivientes de los campos de exterminio de Auschwitz), pero ¿hubo un final feliz? Los sobrevivientes de los campos de Auschwitz, según Paz (2010) no lograron reincorporarse plenamente a una vida normal. Es más, parecía que se dudaba acerca de qué cosas tendrían que haber hecho para haber sobrevivido. Parecía que se les cuestionaba. ¿Esa misma interrogante es válida para los novatos 
recién bautizados? En este punto se debe reflexionar con profundidad acerca del tema de la violencia colectiva, cómo y porqué ocurren tales atrocidades.

Se pregunta Hacker (1973, p. 357) cómo “El pueblo alemán, supercivilizado y supercultivado, había inmolado a millones de ciudadanos en el corazón de Europa; lo había hecho sin compasión y con crueldad, sirviéndose de métodos técnicos y orgánicos modernos”. De la misma manera el sector académico podría preguntarse, ¿Cómo el estudiantado de la Facultad de Agronomía ha llegado a hacer gala de tales niveles de violencia y odio hacia sus propios compañeros?, es acaso la fuerza de la tradición, la manera en que pretende justificarse lo injustificable. Al respecto el mismo autor recopila algunas de las principales tesis relativas a la violencia entre las cuales destacan: i) La violencia es el problema cuya solución presenta ella misma. ii) Los problemas que solo pueden resolverse con violencia deben ser planteados de nuevo. iii) La violencia es contagiosa como el cólera; debe su virulencia la apariencia de justificación, que la hace epidémica (Hacker, 1973, p.15). La violencia no puede ser justificada desde ningún punto de vista y los argumentos de solidaridad, identidad y juego, son cada vez menos consistentes.

Así mismo vale la pena preguntarse, pero ¿hubo un final feliz? ¿Estuvieron los novatos a gusto al haber participado en tal hazaña? ¿Pueden decir que están orgullosos de que esos eventos sean publicados en los diarios? ¿O preferirían haberlo no vivirlo? Esta pregunta fue planteada en el cuestionario aplicado a un grupo de estudiantes, en donde se explora acerca si quisieran continuar con las prácticas del bautizo, anularlo o simplemente modificarlo. Según los resultados obtenidos el 50 \% de los encuestados indicaron que lo ideal sería normarlo, el 49 \% opinó que debía continuar tal como hasta el día de hoy se celebra.

Es en este punto en donde las autoridades administrativas y académicas deben tomar decisiones y actuar con denuedo. Se deben dar a conocer los resultados de la presente Tesis Doctoral y diseñar mecanismos para detener los abusos y excesos cometidos durante la celebración de las novatadas. Este es el reto más grande, para que tal como expresó uno de los profesores 
entrevistados sea posible quitarle al agua al pez sin que este se muera, a través de normar la actividad introduciendo una agenda dirigida por el sector docente y administrativo. Esto sería el equivalente a institucionalizar una práctica que no ha podido ser eliminada desde la estrategia de la prohibición. Ni la amenaza de expulsión de carácter permanente ha sido suficiente.

Los suicidios acontecidos en fechas posteriores al bautizo, los estudiantes intoxicados, agredidos física y psicológicamente deberían constituirse en una voz de alerta a lo que podría ocurrir en un futuro no lejano, en donde la situación podría tornarse más preocupante. ¿Hace falta que ocurra alguna tragedia para reaccionar serena, pero contundentemente?

La Procuraduría de los Derechos Humanos en Guatemala, a través del representante de la Defensoría de la Juventud (Lic. Abner Paredes) han declarado que, institucionalmente, están en contra de la celebración de las novatadas. Así mismo que han pedido en algunas ocasiones a las autoridades de USAC que envíe un informe integral para conocer más del fenómeno y emprender las acciones legales que sean necesarias. Lamentablemente ese informe no ha llegado, según expone el Defensor (Paredes, 2015).

La tendencia a la celebración del bautizo en nuevas unidades académicas es a incrementarse, lo cual es muy lógico porque los estudiantes organizadores del evento obtienen grandes beneficios. Así por ejemplo suelen exigir a los novatos una suma de dinero considerable bajo el argumento que es para financiar la fiesta de bienvenida (generalmente los estudiantes novatos no participan en ella). Así miso exigen bebidas alcohólicas que deben ser entregadas el día del bautizo. En este sentido podemos concluir que no es una actitud que demuestre solidaridad el obligar a financiar una fiesta en la que no se participará.

No existen reglas claras ni mucho menos tarifas establecidas, por esa razón la exigencia económica podría incrementarse cada año a sabor y antojo de los organizadores. Esta situación conduce el dos conclusiones razonables: i) Habrá resistencia estudiantil en el momento de promover la eliminación o erradicación de la celebración del bautizo porque existe la motivación de obtener 
un recurso económico con el cual no se contaría de ninguna otra manera. Ya algunos estudiantes novatos han calificado esta exigencia de dinero como una extorsión.

ii) El 50 \% de los novatos no se sienten identificados con la celebración del bautizo ni opinan que esta aporte a su desarrollo como profesionales.

Es justo hacer la observación que aunque todos los novatos son bautizados, algunos no sufren agresiones tan marcadas. Generalmente ello ocurre en los casos que cuentan con un estudiante antiguo que acepta ser su padrino. En la mayoría de los casos este es un vecino, antiguo amigo de estudios o hasta familiar. Este tipo de estudiantes fueron los que mostraron (durante las entrevistas focalizadas y cuestionarios) aceptar en mayor grado la celebración en bautizo. No es lo mismo ver que desnudan y lapidan a un compañero, que sentirlo en carne propia.

Algunos estudiantes novatos inclusive, mencionan que fue una experiencia "inolvidable, digna de ser contada a sus hijos”. Al comparar las diferentes opiniones y lecturas del fenómeno en sí; pueden encontrarse puntos de encuentro, puntos intermedios en donde los relatos adquieren especial importancia porque logran permitirnos llegar a algunas conclusiones.

Dentro de las opiniones más comunes resaltan aquellas que justifican el bautizo como un evento por el que necesariamente hay que pasar, de tal manera que es mejor pasarla bien aunque haya mucho que sufrir. Ello demuestra que los estudiantes novatos se han acostumbrado y aceptado como normal los abusos y excesos cometidos. En el mismo sentido, el $49 \%$ de los estudiantes antiguos entrevistados expresaron dentro de las virtudes del bautizo se encuentra la capacidad de homogenizar al grupo. Es durante este evento, el momento en que no hay posición económica, grupo cultural, etc. Estos son los estudiantes que abogan por la celebración de los bautizos argumentando que ello les permitirá ser solidarios con otros sancarlistas por ello se apegan a aquellas actividades que consideran una tradición, defendiéndolas de la manera que les sea posible.

Aunque algunas de las prácticas dentro del bautizo fueron bien toleradas por los novatos existieron muchas que fueron etiquetadas como sumamente violentas. Según los resultados 
obtenidos durante el trabajo de campo realizado; los estudiantes coinciden en que el campus universitario es inseguro. Porque en él, especialmente en épocas de bautizos y celebración de la Huelga de Dolores, hay manifestaciones claras de violencia. En ellas hay un contenido deshumanizante. Existen fuerzas superiores, dentro de los estudiantes, que son las que promueven la manifestación de un comportamiento totalmente errático y violento, en contradicción de lo que se espera (naturalmente) de un estudiante universitario. Hacker, (1973, p.19) opina que "la más terrorífica dimensión de la brutalización moderna no es el constante recrudecimiento de la violencia individual y colectiva, sino su creciente regularización y su práctica habitual”.

En un sentido más amplio podemos concluir que la violencia manifiesta dentro del bautizo es reflejo de la misma condición que transversaliza la realidad social contemporánea del guatemalteco. En Guatemala existen algunos sectores populares que se han acostumbrado a la violencia. Diecinueve homicidios al día han provocado que el guatemalteco promedio ya no se escandalice por el horror de la muerte.

De la misma manera existen otros eventos violentos que la misma historia denuncia; de una realidad post-guerra con cientos de problemas no resueltos. Con decenas de demandas sociales que exigen el cambio en la estructura económica y política del país. Es así como cada estudiante (por lo menos aquellos procedentes del área rural y de un estrato económico bajo) lleva dentro de sí las demandas no resueltas y la frustración de una Paz, Firme y Duradera (Acuerdos de Paz, 1996) que no han provocado cambios sustanciales.

De manera integral la violencia manifiesta durante la celebración del bautizo revela la misma condición en la cotidianeidad del estudiante universitario. Actor social de gran importancia en la sociedad guatemalteca en quien, según el imaginario colectivo, puede esperarse una contribución concreta e inmediata en su servicio profesional, pero que finalmente es un guatemalteco más. Uno privilegiado sí, por pertenecer al escaso porcentaje que tiene oportunidad de 
acceso a la educación superior, pero finalmente reflejo de lo que acontece en cada uno de los hogares guatemaltecos a los que pertenece.

La Universidad no existe solo para sí misma, tiene un deber que cumplir. De esta manera el sector académico profesional tiene responsabilidad directa en la formación de los estudiantes. Esta debe darse de forma integral, no olvidando que como dice Supple (1993) citado por Burguet (2001) que los profesores tienen la responsabilidad de ayudar a sus estudiantes a llegar a ser personas. Los esfuerzos académicos de un profesor universitario deben estar encaminados a la formación de profesionales íntegros de frente a los retos de la sociedad guatemalteca moderna.

En este mismo sentido conviene analizar estas acciones desde, el drama de la cultura moderna, como anota Leonardo Boff en su obra San Francisco de Asís, Ternura y convivialidad. En donde señala que: "la raíz básica de nuestra crisis cultural reside en la aterradora falta de ternura y de solicitud de los unos para con los otros, y de todos para con la naturaleza y para con nuestro propio futuro” (Boff, 1981, p.31).

Las prácticas deshumanizantes son producto de la carencia de esa delicadeza que permite fascinarse y apasionarse por la naturaleza y por todas las expresiones de la creación, entre ellas y en un lugar muy especial los seres humanos. Desde esa perspectiva, es sorprendente descubrir que durante las prácticas del bautizo de los novatos en FAUSAC no logra visualizarse ningún tipo de solidaridad y compasión hacia los novatos. Son simplemente estudiantes agrediendo a sus compañeros, aquellos que en un futuro serán sus colegas, socios o quizás sus esposas, esposos o bien sus jefes.

Otro de los argumentos que señala Boff (1981) como los causantes del “drama de la cultura moderna” son los elevados niveles de represión del Eros. De la manifestación de los instintos más naturales del hombre que amenazan con desbordar en todo tipo de acciones, independientemente del valor que pueda dársele a cada una de ellas. Según Freud (1921) una civilización se construye solo disciplinando este Eros, no reprimiéndolo. 
En un ambiente puramente académico, es el Logos (la razón) quien se ha encargado de construir un sistema inflexible las reglas, la disciplina, la homogenización de los estudiantes. Todos los alumnos deben responder a la medida de lo que se espera de ellos, los estándares académicos siempre serán el cristal con que serán vistos. En este sentido el desempeño académico y el cumplir con las reglas, las normas al pie de la letra son lo más importante y permitirá distinguir a un buen estudiante de uno que no lo es o que probablemente nunca llegue a serlo.

Todo un año académico en donde es Logos quien moldea y regula el ambiente; el total de las actividades, hasta que llega el día tan esperado (el Día del Bautizo) en donde es Eros, y su fuerza destructora quien puede manifestarse. Es allí en donde no hay reglas, en donde la razón (el Logos) es relegada a segundo plano, en donde la "autoridad" la constituyen los mismos estudiantes, de tal manera que hay un desborde de emociones, de violencia, del Pathos (la capacidad de ser afectado y de afectar): la afectividad, que es lo concreto y primario en el ser humano.

La razón, según el filósofo Ladriére citado por Boff (1981), no es el primero ni el último momento de la existencia humana, sino que está abierta hacia abajo y hacia arriba. Abajo, nace de algo más antiguo, más profundo y elemental y primitivo: la afectividad. Hacia arriba, se abre a la experiencia espiritual, que es el descubrimiento del yo dimensionado hacia la totalidad y de la totalidad presente en el yo, no como pura contemplación, sino como experiencia de que, por detrás de lo real, no hay únicamente estructuras, sino sentido gratificante, simpatía y ternura. Sin embargo ese Eros que predomina y gobierna el día del bautizo, no tiene porqué ser precisamente malo, violento o reprochable por las prácticas extremas que en él se avizoran. Esto porque el Eros está ligado con la fantasía, con la creatividad, con la irrupción de lo nuevo, lo sorprendente y lo maravilloso. El Eros produce fascinación, atracción y hechizo. Según Leonardo Boff los antiguos decían que era un daimon, que habita en él una fuerza demoníaca: la vulcanicidad de los elementos en ebullición (Boff, 1981, p. 28). 
Si ese Eros es disciplinado por el Logos, grandes cambios podrían esperarse el día del bautizo para que pueda ser en verdad una celebración. A efecto de ellos uno de los docentes entrevistados sugirió que el "institucionalizar la actividad al establecer una agenda”, haciendo referencia que los profesores y autoridades administrativas participaran en la actividad, podrían disminuirse las prácticas violentas evitando así el repudio y rechazo de la opinión pública hacia la institución.

En otro sentido las entrevistas a profundidad realizadas dan cuenta de sucesos extremos como la referida por la directora de la Unidad de Salud de la USAC, quien ha referido la experiencia en la cual un estudiante de primer ingreso a la Facultad de Odontología decidió suicidarse un día después de haber sido bautizado. Esto debido a que fue objeto de vejámenes particularmente por manifestar un carácter afeminado. Esto es bastante común en el medio guatemalteco en donde se rechaza frontalmente la feminidad en los hombres y todo tipo de prácticas de carácter homosexual. Esto ocurrió en la década de 1980 y aunque es un hecho aislado, da cuenta del nivel de psicosis que algunas prácticas dentro del bautizo provocan en los novatos.

De la misma manera las quemaduras en la piel de los novatos que fueron provocadas por haberlos cubierto con la tinta indeleble, durante el bautizo de los novatos en el año 2005 que fuera utilizada durante el proceso de elecciones. Durante las jornadas del presente año los incidentes no se hicieron esperar y fue alertado el cuerpo de bomberos voluntarios debido a que se escucharon múltiples disparos al aire, en algunos casos utilizando armas de grueso calibre, hubo un estudiante herido. Este hecho fue documentado gracias a las publicaciones en diversos medios de comunicación.

Todas estas situaciones han sido documentadas y publicadas en los diarios de mayor circulación en el país, así mismo han sido notas de programas radiales y televisivos. Ello ha desencadenado una ola de repudio que finalmente provoca un daño irreparable a la imagen que el pueblo guatemalteco tiene de la universidad estatal y de sus estudiantes. En las redes sociales 
existen sitios implementados para hacer escuchar la voz de las denuncias realizadas por estudiantes agraviados. En este sentido podemos concluir que estos medios de comunicación han sido una vía de escape para romper con el Código del Silencio. Nuevamente el anonimato es el elemento clave. En un primer momento son los estudiantes antiguos que esconden su identidad detrás de una capucha para cometer todo tipo de abusos; posteriormente son los estudiantes novatos agraviados quienes se escudan en el anonimato facilitado por las redes sociales para exponer su repudio y rechazar radicalmente las prácticas durante el bautizo ${ }^{54}$.

Aunque la atmósfera que envuelve la vida cotidiana de los universitarios de San Carlos es de jovialidad y un desborde de energía positiva por alcanzar grandes sueños, es innegable que también existe en ese medio un mundo de relaciones de poder entre estudiantes. Es allí en la universidad en donde inician a perfilarse los grandes políticos y demagogos que incursionarán en las instituciones de Estado de Guatemala. Dejaremos por un lado a los dirigentes estudiantiles con sus particulares objetivos y estrategias y nos enfocaremos en otro tipo de relación de poder y es aquella que se da entre los estudiantes veteranos y los novatos. Es claro que existe gran interés por someter, mediante humillaciones sistemáticas y constantes, a los estudiantes de primer ingreso. La pregunta es ¿por qué razón el sistema educativo lo permite?

Durante las jornadas de bautizo en la Universidad la humillación es permitida y se han documentado todo tipo de excesos y actitudes radicalmente violentas. Otro elemento que puede distinguirse es el ímpetu por ridiculizar y exponer simbólicamente prácticas sexuales. Toda la energía de los jóvenes se ve expresada en juegos que denotan una sexualidad reprimida. Por ejemplo existe una urgencia que conlleva a la insistencia de desnudar a los novatos y aún de rasgarles la ropa interior, dejando expuestos, en muchas ocasiones partes el área genital. El

\footnotetext{
${ }^{54}$ En Guatemala es muy popular el uso de la redes sociales de comunicación y ha surgido decenas de sitios virtuales en donde se denuncian todo tipo de actos de corrupción, prácticas violentas y hechos que no pueden hablarse abiertamente por otros medios. Entre ellos destaca en Facebook el denominado: Soy 502, en donde puede visualizarse dentro de los archivos jornadas dedicadas a la discusión, reflexión y repudio de los bautizos en USAC.
} 
ambiente estudiantil sancarlista se ha convertido, de acuerdo a la definición de campo de Pierre Bourdieu, en un espacio físico e ideológico de fuerzas y luchas (Bordieu y Passeron, 2003). El día del bautizo es la oportunidad para que algunos estudiantes antiguos que por no poseer alguna cualidad distintiva, logren hacerse notar. Pareciera que mientras más violentos y crueles son con los novatos, mayor será el grado de prestigio que ganarán. Así mismo también es una oportunidad de homogenización en donde le estudiante antiguo de escasos recursos económicos puede humillar al estudiante acaudalado. O la estudiante antigua que no es precisamente agraciada puede arremeter en contra de alguna novata que se distinga por su belleza física. Esta aseveración se plantea acerca de los resultados obtenidos en las entrevistas personalizadas.

Seguir las normas de la pandilla y el cabecilla: Es claro que durante la celebración de las novatadas existen (aunque esto no es reconocido abiertamente por los participantes) cabecillas o líderes. Entre ellos puede señalarse a los encapuchados de cada unidad académica y a los estudiantes de orden. Según explica Zimbardo (1971) cuando se actúa grupalmente como sucede dentro de las pandillas pueden hacerse cosas realmente horrorosas, sin que eso sea considerado malo, únicamente se siguen las reglas establecidas.

El catalizador de la maldad durante la celebración de las novatadas en FAUSAC es principalmente el efecto de masa, el deseo incontrolable de hacer lo que los demás hacen, sin ningún tipo de cuestionamiento. El estudiante promedio que participa en las novatadas considera que es normal ser agresivo, normal golpear a sus compañeros, obligarlos a hacer cosas que él nunca haría. La conciencia individual se ve anulada frente a los impulsos del colectivo de estudiantes antiguos que disfrutan del participar en las novatadas argumentando que es simplemente una expresión de la identidad sancarlista.

Las acciones cometidas en contra de los estudiantes novatos pueden considerarse como violencia porque tal como expone Hacker (1973, p. 95) la violencia es la manifestación abierta, manifiesta, “desnuda”, casi siempre física de la agresión. En las múltiples estaciones diseñadas para 
el bautizo de novatos y novatadas hay violencia porque hay contacto físico, porque hay empujones, codazos, golpes a diferentes partes del cuerpo. Hay contacto físico entre los antiguos y novatos. Por lo tanto también el daño es físico.

Un elemento cuyo análisis es importante es preguntarse acerca de la razón por la cual los estudiantes antiguos "reproducen” (durante la celebración del bautizo) las prácticas militares que tan duramente han juzgado y han rechazado durante décadas, por lo menos en el discurso. En este punto es conveniente recordar que Guatemala es un país que durante treinta y seis años vivió un conflicto armado interno en donde decenas de estudiantes sancarlistas fueron secuestrados, torturados y asesinados. En tales condiciones se marcó un distanciamiento claro entre las clases militares guatemaltecas y los estudiantes de la universidad estatal. Prueba de ello es que durante dos de las celebraciones estudiantiles más importantes de USAC (Huelga de Dolores y elecciones de Reyes Feos universitarios) las prácticas de los militares siempre han sido objetos de dura crítica y ridiculización.

Sin embargo durante la celebración del bautizo, sobreabundan las prácticas de corte militar. La manera prepotente y autoritaria en que los estudiantes antiguos mandan a los novatos a realizar ejercicios físicos (correr, sentadillas, despechadas y saltos) hasta el cansancio; la utilización del lenguaje humillante y vulgar hasta los castigos a los que son sometidos. La ridiculización y castigo de aquellos que no logren superar las pruebas asignadas, son la clara y contradictoria reproducción de aquello que se rechaza, reafirmándolo y manteniéndolo vigente.

Cuando hablamos de identidad es importante hacer la diferenciación entre dos tipos de identidad. La que se posee, naturalmente, como individuo y que nos diferencia de todos los demás y la que poseemos de manera colectiva. La identidad individual es justamente la que, intencionalmente, se ve dañada durante algunas prácticas de este rito de iniciación. Tal es el caso de no llamar a los estudiantes de primer ingreso, sino simplemente nuevos. Por los pasillos, en los 
patios y lugares públicos se grita a son de burla: nuevos....nuevos....nuevos, como si serlo fuera humillante.

$\mathrm{Al}$ respecto también es importante observar que el corte de cabello es una de las prácticas más populares (desde el origen hasta el día de hoy) dentro de las novatadas en FAUSAC. Es imperativo analizar que este constituye un ritual de bienvenida sumamente común en las prisiones y cuarteles militares. Según Zimbardo (2002) el corte de cabello es un clásico ritual de degradación. El corte de cabello es considerado como una práctica humillante. No conformes con cortarlo, lo hacen de una manera que ridiculiza al que porta tal o cual estilo de corte.

Uno de los profesionales entrevistados relató cómo fue obligado a entonar el Himno Nacional de Guatemala y recitar la Jura a la Bandera sumergido en las frías aguas de una pileta ubicada dentro de los campos agrícolas de la Facultad de Agronomía. Posterior a eso, nunca más tuvo que entonar el Himno Nacional de Guatemala, durante su vida estudiantil. Esto demuestra que dentro de la Universidad Estatal no existen muchos espacios cívicos en donde se fomente el amor a la nación como tal. Volvemos en esta oportunidad a la reflexión acerca que el estudiante sancarlista necesita afianzar su identidad colectiva. Es aquí en donde la comunidad académica debe estar organizada y fortalecer valores cívicos, morales y humanos dentro del estudiantado. Al estar ausente este tipo actividades, los estudiantes se ven atraídos por otro tipo de prácticas (ideadas y organizadas por otros estudiantes) que de alguna manera suplen esa necesidad.

El sector docente y todos aquellos que representan algún tipo de autoridad sobre los estudiantes exigen, buen comportamiento, esfuerzo constante, méritos y virtudes que en muchas ocasiones la institución misma no ostenta.

Otro profesional entrevistado señaló que en una de sus visitas al campus (muchos años después) pudo, casualmente, observar el bautizo de los novatos estando acompañado de un grupo de campesinos de un departamento del interior del país. Extrañados se preguntaban ¿por qué razón los estudiantes veteranos de Ingeniería (al pasar frente a los edificios de Agronomía) incitaron a gritar a 
los estudiantes de Agronomía: “campesinos..., campesinos... ${ }^{55 ” ? ~ ¿ E s ~ q u e ~ a c a s o ~ s e r ~ c a m p e s i n o ~ e s ~}$ algo de lo que haya que avergonzarse?, ¿'No se supone que los estudiantes de la Universidad de San Carlos de Guatemala están para servir al pueblo de Guatemala, por cuanto su estudio es pagado con los impuestos del pueblo? Según expresó el profesional entrevistado, esta fue una de las grandes dudas del grupo de campesinos, quienes evidentemente se vieron ofendidos.

Otra de las contradicciones serias es que si el bautizo de los novatos logra, reafirmar la identidad sancarlista, permitiendo a los novatos ser parte del grupo porqué razón los entrevistados reconocen haber sido, por el contrario, dañados en su autoestima. Los mismos involucrados rechazan la práctica y en algunos casos se muestran avergonzados que sea ese uno de los distintivos de los estudiantes sancarlistas. Sin embargo se reconoce que la presente Tesis Doctoral es de carácter exploratorio, sin embargo apertura una nueva línea de investigación en donde habrá que retomar muchos de los hallazgos de la presente. Una manera de poner sobre la mesa un tema que debía haberse tratado desde hace tiempo, pero que por diversas razones no se ha hecho. Entre esas razones se encuentra el conocido, Código del Silencio. Este hace que los detractores de las novatadas sean tratados como cobardes o bien inmerecedores de estudiar en la Tricentenaria Universidad de San Carlos de Guatemala, como muchos llaman orgullosamente.

Otra de las razones del silencio es que nadie quiere hablar de las debilidades institucionales y es obvio que el sistema se ha acomodado. Ha aportado todas las condiciones para que los estudiantes puedan comprar una capucha que tiene un mínimo costo y poder delinquir a su sabor y antojo, durante los bautizos, fiestas de bienvenida o como quiera llamárseles. La sociedad universitaria en su conjunto ha sido sumamente permisiva, pero hay que reflexionar en que eso tiene un costo: Decenas de estudiantes dañados física y emocionalmente por generaciones y en muchas ocasiones para toda la vida.

\footnotetext{
55 Al decir campesinos agregaron la palabra "hueco", que en el medio guatemalteco es considerado un
} término sumamente ofensivo, sinónimo de la carencia de hombría. 
Otro de los aspectos importantes que se visualizan en es el pulso de poder existente entre el sector estudiantil sancarlista y las autoridades institucionales, como veremos a continuación.

En las novatadas un grupo de estudiantes deshumanizan y humillan a los novatos. Desde ese momento deja de ser un juego o algo que sea digno de recordarse o celebrarse. El cortarles el cabello, rociarlos de sustancias incluso corrosivas, es inaceptable desde ningún punto de vista. Los estudiantes antiguos han perdido el norte de la moral, tal como los estudiantes universitarios que fueron parte del experimento referido por Zimbardo en la prisión de Stanford. Sin embargo el sistema lo permite por lo que parece que las cosas marchan bien para los estudiantes. En la actualidad (Agosto del año 2015) no existe el menor indicio que las prácticas violentas dentro de las novatadas sean suprimidas y la pregunta obligada es ¿Hasta dónde se permitirá a la creatividad de la maldad hacer de las suyas? Es necesario que para que las autoridades actúen con denuedo ¿es necesario que a sus oficinas llegue la noticia de víctimas mortales? Los suicidios acontecidos en fechas posteriores al bautizo, los estudiantes intoxicados, agredidos física y psicológicamente deberían constituirse en una voz de alerta a lo que podría ocurrir en un futuro no lejano, en donde la situación podría tornarse más preocupante. ¿Hace falta que ocurra alguna tragedia para reaccionar serena, pero contundentemente?

Según Bourdieu (2003), en el sistema escolar y universitario son lugares donde se fabrica algo más que un título. La riqueza es muy superior por cuanto se fabrican formas de pensar, de actuar, son lugares en donde se reproducen las estructuras sociales. Desde esta perspectiva la situación es sumamente preocupante porque los estudiantes que durante las jornadas del bautizo son los que protagonizan tan crueles escenas de violencia, serán los mismos que tendrán que hacer aportes sustanciales en la búsqueda a la solución de muchos de los principales problemas de la sociedad guatemalteca. Ese esfuerzo requerirá de sensibilidad, humanidad y todo tipo de valores éticos y morales que parecían tan ajenos e inalcanzables el día de la novatada. Una de las preguntas que queda en el tintero para nuevas investigaciones es si ¿̇la actitud de los estudiantes fue provocada 
por un estado de excitación momentáneo o bien es reflejo de una carencia total de valores que los marcará por siempre? Esta pregunta es válida, pero no es posible responderla con la información recopilada en la presente Tesis Doctoral, por lo que podrá ser abordada en nuevos esfuerzos por sistematizar el fenómeno de los bautizos en USAC.

La improvisación fue en todo momento un detonante del efecto de masa y la ausencia total de todo tipo de autoridad durante el evento fue el elemento catalizador del desborde y los excesos. Al respecto algunos entrevistados opinaron que si las autoridades administrativas y docentes tomaran el control de la actividad, es decir la regularán, probablemente las prácticas serían menos violentas. En este punto es interesante plantearse el pulso entre el gobierno estudiantil- versus el gobierno académico y cuestionarse ¿por qué las autoridades no han podido o no han querido intervenir? 


\section{Líneas de Avance}

Es importante reconocer que entre el sector docente, autoridades administrativas y alumnos existen posiciones encontradas relativas a la celebración del bautizo. Las soluciones están al alcance de la mano, pero se hace indispensable la participación de todos. Según el Informe Mundial de la Salud (2002) un requisito básico para abordar las expresiones de violencia es hacerlo de manera integral. Para ello es que todas las personas trabajen juntas en asociaciones de todo tipo y a todos niveles. Es inevitable pensar que existe un conflicto y por lo tanto es necesario abordarlo.

Dentro de las acciones concretas que proponemos enumeramos por su orden de importancia las siguientes:

a) Que las autoridades académicas y administrativas organicen y proporcionen las condiciones necesarias para que representantes (elegidos por los mismos colectivos que representan) dialoguen relativo a la problemática de los bautizos. Dentro de los temas primordiales deben considerarse: los resultados de la presente Tesis Doctoral y otros que en el futuro se realicen, relativos al tema. El problema que representa la permisividad institucional con esta práctica y la pasividad de diferentes sectores de la comunidad sancarlista.

b) Es vital que las autoridades universitarias reconozcan públicamente, que el problema existe, identificando los focos de violencia (relativo a actores, tiempos, grupos vulnerables). En estos grupos de reflexión es indispensable la participación del sector estudiantil, padres de familia, docentes, autoridades y egresados. Estas jornadas deben ser realizadas con el acompañamiento de representantes de los Derechos Humanos en Guatemala, profesionales del Derecho y especialistas en Ciencias Sociales. Tal es el caso de Psicología, Antropología y algunas otras en el ámbito de Humanidades. En especial se requiere de la participación de especialistas en el Manejo de Conflictos. Esto parecería extremo, pero considerando la diversidad de opiniones y conflicto de intereses, este extremo se hace, más que necesario. 
c) Producto de las reflexiones de este grupo élite, debe editarse y publicarse un COMUNICADO dirigido a la población sancarlista. El objetivo principal de este es lograr la sensibilización de los principales actores en los bautizos de USAC.

d) Crear un sitio Web, en donde la comunidad sancarlista pueda exponer su opinión relativa a los bautizos, rompiendo de esta manera con la impunidad y Código del Silencio.

Se ha determinado que la estrategia de denunciar los abusos cometidos es una manera de sensibilizar a la población. Evidenciar el daño físico, psicológico, económico y moral que provocan los bautizos es una estrategia para aportar información que puede ser útil en la toma de decisiones administrativas. El promover una Cultura de Denuncia es un factor clave para detener los abusos. Tal como reza el título de la investigación realizada por Aizpún y García-Mina (2013): Novatadas, conocer para comprender; comprender para actuar. Se considera que con la presente Tesis Doctoral se ha realizado un aporte sustancial al conocimiento del fenómeno de las novatadas en la Universidad de San Carlos de Guatemala. Sin embargo aún existe mucho camino por recorrer, pues es necesario continuar con jornadas de análisis y reflexión. Es importante escuchar la voz de los estudiantes novatos, de aquellos que probablemente para no sentirse excluidos prefieren callar y no denunciar una serie de abusos a los que han sido sometidos.

e) Es necesario continuar profundizando en la línea de investigación relativa a las dinámicas estudiantiles y los retos que deben afrontarse dentro de campus universitario, considerando el incremento de la población estudiantil. El sistematizar y documentar las denuncias constituirán el material necesario para otras acciones reguladas por el normativo interno y las leyes vigentes en el país. Así mismo este permitiría la identificación de grupos vulnerables. Este sitio debe ser creado, administrado y actualizado por especialistas en el tema informático, Psicología y Ciencias Sociales. f) Aunque no se trata de buscar culpables, pues culpables somos todos por acción u omisión, es imperativo que los profesionales que han participado en las jornadas de reflexión promuevan la generación de una Propuesta o iniciativa de Ley que prohíba la celebración de novatadas. Aunque 
se les llame bautizos, bienvenidas o como se idee en llamarlos, las acciones que están catalogadas como rito de iniciación y que conlleven violencia física, humillación y maltrato a los novatos debe ser inaceptable ${ }^{56}$.

Esta propuesta representa romper con una tradición fuertemente arraigada entre los estudiantes sancarlistas por lo que genera polémica entre la comunidad académica. Se estima que el regular (en un primer momento) para luego eliminar la práctica del bautizo en la universidad representará grandes dificultades. Sin embargo éstas son justificadas desde la perspectiva que gracias a la implementación de estas medidas pueden obtenerse grandes cambios, logros y beneficios en el bienestar del estudiantado sancarlista. La clave para provocar estos cambios está en el logro de consensos entre los principales actores. Ese representa el mayor reto por cuanto la comunicación entre el estudiantado sancarlista, autoridades y sector docente no ha sido (según delata la historia) el más conveniente.

El estudiantado sancarlista ha mostrado que cuando en desacuerdo con algunas medidas tomadas administrativamente, procede a la toma de las instalaciones del campus universitario, perjudicando todo el proceso educativo.

Aunque el camino por recorrer en el control de las novatadas en San Carlos es difícil, es necesario recorrerlo, de cara a los nuevos retos que supone el ser profesional egresado de la única universidad estatal. El incorporarse a la sociedad de una manera asertiva, adecuada y sobre todo respetuosa con el otro.

g) Es indispensable incluir en las agendas del Consejo Superior Universitario y Juntas Directivas de las Unidades Académicas en donde se celebra el bautizo el análisis de la realidad que se vive. Sobre

\footnotetext{
${ }^{56}$ Para el caso guatemalteco, iniciativa de ley es la "aquella facultad, que es otorgada por la norma con el objeto de que determinados entes puedan someter a consideración del Congreso de la República un proyecto de ley que se presuma es acorde a las necesidades del ordenamiento jurídico del país”. Esta facultad está encomendada exclusivamente a los diputados del Congreso de la República, Organismo Ejecutivo, Corte Suprema de Justicia, Tribunal Supremo Electoral y a la Universidad de San Carlos de Guatemala. Sin embargo la aprobación está sujeta a la decisión de la mayoría absoluta de los diputados del congreso (que en la actualidad son 158) por lo que en este caso sería ochenta diputados.
} 
todo debe considerarse que es necesario aprender a convivir, pues además de ser indudablemente uno de los objetivos del sistema educativo, es uno de los retos principales del siglo XXI (Jares, 2002). 


\section{REFERENCIAS}

Abramovay, M. (2005). Victimización en las escuelas: ambiente escolar, robos y agresiones físicas. Revista Mexicana de Investigación Educativa, vol. 10, num. 26 Julio-Sept, 833-864.

Aguirre, G. (1947). La medicina indígena: América indígena. México: Porrúa.

Aizpún, A. y García-Mina, A. (2013). Novatadas: Comprender para actuar. Madrid: Editoriales Universitarias Españolas.

Alonzo, S. (2012). Evaluación de los valores y actitudes de los estudiantes de Ingeniería de la Universidad de San Carlos de Guatemala. Tesis para obtener el grado de Ingeniero Industrial. Facultad de Ingeniería. Guatemala: Universidad de San Carlos de Guatemala.

Alvarez, V. (2002). Conventos, aulas y trincheras. Universidad y movimiento estudiantil en Guatemala: la ilusión por conservar. Guatemala: Facultad Latinoamericana de Ciencias Sociales.

Arendt, H. (2005). Sobre la violencia. Madrid: Alianza Editorial, S.A.

Avilés y Monjas. (2005). Estudio de incidencia de la intimidación y el maltrato entre iguales en la educación secundaria obligatoria mediante el cuestionario CIMEI (Avilés, 1999) Cuestionario sobre intimidación y maltrato entre iguales-. anales de psicología vol.21 No. 1, 21-74.

Avilés, J. (2006). Bullying: el maltrato entre iguales. Agresores, víctimas y testigos en la escuela. Salamanca: Amaru Ediciones.

Bandura, A. (1986). http://www.policyscience.net/ws/bandura.pdf. Recuperado el 03 de Abril de 2013

Bandura, A. (1987). Teoría del aprendizaje social. Madrid: Espasa Calpe.

Baridón, D. (2012). Estudio de la violencia escolar en los centros de educación media de Juan Lacaze, Uruguay. Tesis para obtener el grado de doctor en Desarrollo Psicológico, Aprendizaje y Educación: perspectivas contemporáneas. Madrid: Universidad Complutense de Madrid.

Barragán, L. , Valadez, L., Garza, I., Barragán, A., Lozano, A., Pizarro, H. y Martínez, B. (2010). Elementos del concepto de intimidación entre iguales que omparten los protagonistas con los estudiosos del tema. Revista Mexicana de Investigación Educativa, vol. 15, núm. 45, abril-julio., 553-559.

Barreda, H. (2010). Efectos negativos que exidten en la legislación guatemalteca de no considerar como droga a las bebidas alcohólicas, las cuales son causantes del Síndrome de Dependencia del alcohol. Guatemala: Facultad de Ciencias Jurídicas y Sociales, Universidad de San Carlos de Guatemala.

Boff, L. (1981). San Francisco de Asís, ternura y vigor. Cantabria: Editorial al terrae.

Bordieu, P. (2003). Intelectuales, política y Poder. Buenos Aires: Editorial Universitaria de Buenos Aires.

Bordieu, P. y Passeron, J.C. (2003). Herederos: estudiantes y cultura. Buenos Aires: Argentina, Siglo XXI. 
Brenneman, R. (20 de 01 de 2014). La Mara de Cristo: Iglesias y pandillas en Centro América. El Faro Académico, págs. 1-2.

Burguet, A. (22 de 07 de 2015). http://www.juntadeandalucia.es/. Obtenido de http://www.juntadeandalucia.es/educacion/webportal/abaco-portlet/content/fa29ee02-577b451d-8b4a-2c8a6644d842

Carlisky, N. (2000). Resignación o desafío: un enfoque transdisciplinario sobre la sociedad actual. Buenos Aires: Grupo Editorial Lumen.

Centro de Investigaciones Económicas Nacionales. (2010). Prevención de la violencia-un diagnóstico preliminar. Guatemala.: CIEN.

Chagas, R. (2005). Los maestros frente a la violencia de los alumnos. Revista mexicana de investigación educativa. vol.10, número 027, octubre-diciembre., 1071-1082.

Collins, R. (2005). Interaction Ritual Chains. Metodología en Ciencias Sociales, 227-245.

Congreso de la República. (1992). Ley contra la Narcoactividad: Decreto 48-92. Guatemala.

Congreso de la República de Guatemala. (1973). Código Civil Guatemalteco, Decreto 17-1973. Guatemala.

Congreso de la República de Guatemala. (1992). Código Procesal Penal: Decreto Número 51-92. Guatemala.

Congreso de la Republica de Guatemala. (2009). Ley de Armas y Municiones . Guatemala.

Dómenech, M. e Iñiguez, L. (2002). La Construcción social de la violencia. Athenea Digital, 1-10. Obtenido de http://www.raco.cat/index.php/Athenea/article/viewFile/34105/33944

Durkheim, D. (1976). Las formas elementales de la vida religiosa. Distrito Federal: Colofón, S.A.

Durkheim, E. (1967). La división del trabajo social. Buenos Aires: Schapire.

Ehagüe, J. y Conquero, B. (02 de 10 de 2014). Mayor presencia policial contra las novatadas. La Razón, págs. 1-2.

Eliade, M. (2000). Nacimiento y renacimiento: El significado de la iniciación en la cultura humana. Barcelona: Kairos, S. A.

España, O. (2008). Educación Superior en Centro América. Guatemala: OSCADEL.

Fernández, V. (2007). Estudio del pensamiento del profesor de educación física en las etapas de la escuela primaria y secundaria. Tesis para optar por el título de Doctor en Didáctica y Organización Escolar. Universidad Complutense de Madrid. Madrid, España.

Freud, S. (1921). Obras completas de Sigmound Freud: Más allá del principio del placer. Psicología de las masas y análisis del yo y otras obras. Buenos Aires: Amorroru.

García, E. (2009). El ruido como barrera comunicacional y contaminante en la ciudd universitaria, Zona 12. Tesis para optar por el título de Licenciado en Ciencias de la Comunicación. Universidad de San Carlos de Guatemala. Guatemala.

García, J. (2010). Reseña de "El Efecto Lucifer. El porqué de la maldad" de Zimbardo Ph. Vol. 11, número 1. Teoría de la Educación. Educación y Cultura, 440-441.

Garrido,C. ; Herrero, C.; Masip, J. (2001). www.uky.edu. Obtenido de http://www.uky.edu/ eushe2/Pajares/GarridoEtAl2005.pdf. 
Gil-Verona, et al. (2002). Psicobiología de las conductas agresivas, vol. 18, número 2, diciembre. anales de psicologia, 293-303.

Gobierno de Guatemala. (2015). Presupuesto Ciudadano 2015. Guatemala: Ministerio de Finanzas Públicas.

Gobierno de Guatemala. Comisión Presidencial Coordinadora del Ejecutivo en Materia de Derechos Humanos. (2006). Política Nacional de Derechos Humanos. Guatemala.

González-Ortega, Enrique Echeburúa y Paz de Corral. (2008). Variables significativas en las relaciones violentas de parejas jóvenes: Una Revisión, Vol. 16, número 2. Psicología Conductual, 207-225.

Grondona, A. (2010). La Sociología de Émile Durkeim: ¿Una definición "comunitarista" de lo social?, número 55. Papeles de CEIC, 1-22.

Grupo de Apoyo Mutuo -GAM- Guatemala. (2014). Informe de monitoreo de violencia y situación de los Derechos Humanos de Enero a Junio 2014. Guatemala: GAM.

Guatemala, Alcohólicos Anónimos de. (2004). Cómo aprender a vivir. Guatemala: Impresos Novell.

Guatemala, Congreso de la República. (1993). Constitución Política de la República de Guatemala. Guatemala: Congreso de la República de Guatemala.

Guatemala. Congreso de la República. (1993). Constitución Política de la República. Guatemala.

Guatemala. Instituto Nacional de Estadística. (2013). Caracterización estadística: República de Guatemala. Guatemala.

Gubrium, J. \&. (2002). Handbook of Interview Research: Context and Method (Manual de la etrevista de investigación, método y contexto), Vol. vii. California: Wiley Inter Sciense.

Hacker, F. (1973). Agresión. Distrito Federal: Ediciones Grijalbo, S.A.

Haslam, A. \& Reicher, S. (2004). Visión crítica de la explicación de la tiranía basada en los roles: pensando más allá del experimento de la prisión de Stanford, vol 19, número 2. Revista de Psicología Social, 115-122.

Hendry, J. (1999). The ritual round. In Other people's world: An introduction to cultural anthropology. New York: New York, University Press.

Hurtado, P. (07 de 04 de 2011). Los 312,967 universitarios ignotos. El Periódico, págs. 1-2.

Jares, X. (2002). Aprender a Convivir. Revista Interuniversitaria de formación del profesorado, número 44., 79-92.

Jiménez, A. (2007). El maltrato entre escolares (Bullying) en el primer ciclo de educación secundaria obligatoria: valoración de una intervención a través de medios audiovisuales. Memoria para optar al grado de doctor . Huelva: Universidad de Huelva.

Le Bon, G. (2004). Psicología de las masas: Estudio sobre la Psicología de las multitudes. Buenos Aires: Virtual.

Leflaive, G. (2003). El bizutage: ritual y reproducción. RDTP, LVIII, número 2., 93-140. Obtenido de http://rdtp.revistas.csic.es/index.php/rdtp/article/viewFile/152/153

López-Yarto, L. (1997). Dinámica de grupos (cincuenta años después). Bilbao: Descleé de Brouwer, S.A. 
Markez, et al. (2006). La violencia colectiva: Un problema de salud pública pendiente de ser investigado. Norte de Salud Mental, número 25., 45-59.

Markez, et al. (2009). Violencia y salud mental: Salud mental y violencias, estructural, social y colectiva. Epidemiología de la violencia colectiva, número 42, p. 157.

Markez, I., Fernández, A. y Pérez-Sales,P. (2009). Violencia y salud mental: salud mental y violencias, institucional, estructural, social y colectiva. Madrid: Asociación Española de Neuropsiquiatría.

Martín, M. . (2003). Violencia doméstica contra la mujer. Lo aberrante de la cotidianidad: del estereotipo sexista a la violación de los Derechos Humanos. Tesis para la obtención del título de Doctor en Ciencias Políticas y Sociología. Facultad de Ciencias Políticas . Madrid.

Matute, A. Programa de Naciones Unidas para Guatemala. (2010). Informe Estadístico de la Violencia en Guatemala, 2007. Guatemala: Magna Terra Editores, S.A.

Mayos, G. (17 de 06 de 2015). El "Efecto Rashomon", análisis filosófico para el centenario de Akira Kurosawa. Obtenido de www.ub.edu: http://www.ub.edu/histofilosofia/gmayos/PDF/EfectoRashomon.pdf

Menninger, K. (2012). La apatía en sí misma una manifestación de agresividad. Experimentos Psicosociales, No. 7, 377-378.

Miles, M. , Huberman, A. \& Saldaña, J. (1994). Qualitative Data Analysis: A Methods Sourcebook (El manual de codificación para investigadores cualitativos). Los Ángeles: Sage.

Montenegro, J. (28 de Abril de 2013). Cada año la USAC recibe 10,000 nuevos estudiantes. Guatemala, Ciudad Guatemala.

Morales, et al. (2007). Psicología Social. Madrid: Mac.Graw-Hill/Interamericana de España, S.A.

Muñoz, J.M. \& Vásquez, S. (2002). Procesos colectivos y acción social. XII Congreso Colombiano de Psicología (págs. 1-63). Medellín: Sociedad Colombiana de Psicología.

Organización de las Naciones Unidas. (1992). Manifiesto de Sevilla: preparar el terreno para la construcción de la paz. París.

Organización Panamericana de la salud para la Organización Mundial de la Salud. (2002). Informe mundial sobre la violencia y la salud: resumen. Washington.

Ortega y Gasset, J. (1966). Obras completas. Tomo II. Madrid: Revista de Occidente.

Ortega y Gasset, J. (2009). La rebelión de las masas. Madrid: Alianza Editorial, S.A.

Ortega, J. (15 de 01 de 2014). Por tercer año consecutivo, San Pedro Sula es la ciudad más violenta del mundo. Consejo Ciudadano para la Seguridad pública, Justicia Penal A.C., págs. 1-2.

Ortega, J. (06 de Julio de 2015). www.seguridadjusticiaypaz.org.mx. Obtenido de www.sciencespo.fr/opalc/sites/sciencespo.fr.opalc/files/ciudades\%20violentas\%202014.pdf

Ortega, R. Del Rey, R. \& Mora-Merchán, J. (2001). Violencia entre escolares. Conceptos y etiquetas verbales que definen el fenómeno del maltrato entre iguales, vol. 41, agosto. Revista Interuniversitaria de Formación del Profesorado, 95-113. 
Oseguera, A. (2008). De ritos y antropólogos. Perspectivas teóricas sobre el ritual indígena en la Antropología realizada en México, vol. 15, número 42. Cuicuilco, Volumen 15, Número 42, 97-118.

Palomero, J. y Fernández, M. (2001). La violencia escolar: Un punto de vista global, número 41. Revista Interuniversitaria de Formación del Profesorado, 19-38.

Paz, F. (2010). En el corazón de la zona gris. Una lectura enográfica de los campos de Auschwitz. Madrid: Trotta, S.A.

Piñuel, I. (02 de 10 de 2014). ¿El nuevo "Bullying"? La Razón.

Prieto, M. (2005). Violencia escolar y vida cotidiana en la escuela secundaria. Revista Mexicana de Investigación Educativa, vol. 10, número 27., 1005-1026.

Programa de Naciones Unidas para el Desarrollo. (2008). Guatemala: ¿Una economía al servicio del desarrollo humano? Guatemala: Edisur.

Programa de Naciones Unidas para el Desarrollo. (2012). Guatemala: ¿un país de oportunidades para la juventud? Informe . Guatemala: PNUD.

Programa de Naciones Unidas para el Desarrollo, Guatemala. (2007). Informe estadístico de la Violencia en Guatemala. Guatemala: Magna Terra Editores, S. A.

Ramos, M. \&. (2011). Bullying en el nivel superior. XI Congreso Nacional de Investigación Educativa (págs. 1-11). Guadalajara: Universidad de Guadalajara.

Ramos, M. Tesis Doctoral para optar por el título de Psicólogo Social. (2008). Violencia y victimización en adolescentes escolares. Sevilla: Universidad Pablo de Olavide.

Reguera, M. (2001). Transmisión social de la agresividad y la violencia en los adolescentes. Tesis para optar por el título de Doctor en Ciencias Políticas y Sociales. Universidad de Salamanca. Madrid.

República, G. C. (2008). Decreto Ley 22: Ley contra el femicidio y otras formas de discriminación contra la mujer. Guatemala.

Roldán, J. Tesis de grado para obtener el título de Maestro en Artes en la carrera de Maestría Regional de Formación de Formadores Docentes de Educación Primaria. (2010). Acoso escolar o efecto Bullying en las escuelas normales. Guatemala: Universidad de San Carlos de Guatemala.

Scandroglio, et al. (2008). La Teoría de la Identidad Social: una síntesis crítica evidencias y controversias, vol. 20, número 1. Psicothema, 80-89.

Seijo, L. (12 de 05 de 2007). "Ojo por ojo sigue siendo bastante popular entre la población". Prensa Libre, págs. 1-2.

Soto, R. (2011). Cadena de rituales de interacción, Randall Collins, número 7. El Alma Pública, 2328.

Spitzer, T. (2004). Miradas diversas sobre la disciplina y violencia en centros escolares. Capítulo de Violencia estudiantil y género en la Universidad Autónoma de Chapingo. México: Editorial Universidad de Guadalajara.

UNESCO. (1992). El Manifiesto de Sevilla sobre la violencia: preparar terreno para la construcción de la paz. Barcelona. 
UNESCO. Morín, E. (1999). Los siete saberes necesarios para la educación del futuro. París: Organización de las Naciones Unidas para la Educación, la Ciencia.

Universidad de San Carlos de Guatemala. (1994). La Autonomía Universitaria. Guatemala: Editorial Universitaria.

Universidad de San Carlos de Guatemala. (2000). Recopilación de leyes y reglamentos de la Universidad de San Carlos de Guatemala. Guatemala: Editorial Universitaria.

Universidad de San Carlos de Guatemala. (2003). Plan Estratégico USAC- 2022. Guatemala: Editorial Universitaria.

Universidad de San Carlos de Guatemala. (2007). Resumen Ejecutivo "Caracterización de la cultura organizacional de la Universidad de San Carlos de Guatemala". Guatemala: Universitaria.

Universidad de San Carlos de Guatemala. (2007). Resumen Ejecutivo: Caracaterización de la Cultura Organizacional de la Universidad de San Carlos de Guatemala. Guatemala: Universitaria.

Valles, M. (2003). Técnicas cualitativas de investigación social: Reflexión metodológica y práctica profesional. Madrid: Síntesis, S.A.

Van Gennep, A. (1986). Los Ritos de Paso. Madrid: Taurus.

Van Helsig, J. (1998). Las Sociedades Secretas y su poder en el siglo XX. Gouda: Ewertverlag S.L.

Velasco, D. (2011). Texto para uso académico:Pierre Bordieu. Vida-obra-conceptos. Madrid: Editorial Elipses.

Villareal, M. Tesis para obtener el grado de doctor en Filosofía con especialidad en Psicología. Universidad Autónoma de Monterrey. (2009). Un modelo estructural del consumo de drogasy conducta violenta en adolescentes escolarizados. Monterrey.

Winton, A. (2011). Grupos violentos en Centroamérica: la institucionalización de la violencia, número 3. Desacatos No. 37, párrafo 1.

Wirth, O. (07 de 07 de 2015). www.actiweb.es. Obtenido de www.actiweb.es/bibliotecamasonica/archivo9.pdf

Zamanillo, T. (2002). Teoría y práctica del aprendizaje por interacción de grupos pequeños. Tesis para optar por el título de Doctor en Sociologia, Facultad de Sociología. Universidad Complutense de Madrid. Madrid.

Zamorano, A. (2013). Asesinos por naturaleza: Una lectura primigenia de la violencia en el cine, vol. 10, número 22. Revista de Investigación Social, 259-282. 


\section{ANEXOS}

\section{ANEXO I: Acta del Consejo Superior Universitario de USAC}

ACTA NÚMERO CERO SEIS GUION DOS MIL DOCE (06-2012). En la ciudad de Guatemala a las nueve horas del día miércoles veintiocho de marzo del año dos mil doce, reunidos en el Salón de Sesiones del Consejo Superior Universitario, para celebrar sesión ORDINARIA,

\subsection{Plan de Seguridad en la Universidad de San Carlos de Guatemala.}

El Consejo Superior Universitario procede a considerar lo relacionado al Plan de Seguridad en la Universidad de San Carlos de Guatemala, para lo cual se conoce el informe presentado por la Dirección General de Administración, relacionado con los recientes acontecimientos ocurridos en el campus central, como consecuencia de los actos de la Declaratoria de la Huelga del año 2012. Luego de varias intervenciones de sus miembros y deliberación al respecto, emiten algunas consideraciones, entre ellas: que se incluya como punto de agenda a tratar en las próximas sesiones ordinarias, lo referente al tema de la Seguridad en esta Casa de Estudios dentro de la estructura del Punto Sexto; que se solicite a la Dirección de Asuntos Jurídicos del seguimiento a los hechos ocurridos en la Facultad de Ciencias Económicas y la Facultad de Ciencias Jurídicas y Sociales y presente los cargos correspondientes de conformidad con lo establecido en las normas, leyes y reglamentos universitarios a este Órgano de Dirección; que se contrataron agentes de seguridad para resguardar en lugar y/o recintos universitarios fuera del campus universitario y el personal de vigilancia que se encontraban en dichos lugares y/o recintos serán traslados al campus central; que es importante contratar especialistas en seguridad; que es importante coordinar en el tema de seguridad con el Ministerio de Gobernación y el Ministerio Público; que la Dirección General de Administración determine y presente una propuesta de control de portación de armas en el campus central; que es importante lanzar una campaña publicitaria donde informe a la comunidad universitaria sobre el tema de seguridad; que es importante agregar cámaras de seguridad dentro y fuera de los edificios de esta Universidad; que debe contarse con un grupo élite de seguridad, sobre todo en casos de emergencia; que se nombre una comisión que de el seguimiento al tema de seguridad; y que las puertas de acceso a esta Casa de Estudios sean reinstaladas. Al respecto el Consejo Superior Universitario tomando en consideración los argumentos expuestos por sus miembros, ACUERDA: Nombrar una Comisión Específica, con el propósito de dar seguimiento al tema de seguridad en la Universidad de San Carlos de Guatemala, así como a las consideraciones manifestadas en este Órgano de Dirección al respecto, conformada de la manera siguiente: Dr. Lauriano Figueroa Quiñónez, quien fungirá como Coordinador; Lic. Carlos René Sierra Romero, Ing. Herbert René Miranda Barrios, Sr. José Roy Morales Coronado y el Director General de Administración. Dicha Comisión deberá presentar a este Órgano de Dirección, un informe y propuesta respecto al tema de seguridad en esta Casa de Estudios, para conocimiento y consideración. 


\section{ANEXO II: Principales ritos de iniciación}

\begin{tabular}{|c|c|c|c|c|}
\hline No. & Nombre & Simbolismo u objetivo & Prácticas más comunes & Fin perseguido \\
\hline 1 & $\begin{array}{ll}\text { Rito } & \text { de } \\
\text { pubertad } & \end{array}$ & $\begin{array}{l}\text { Que los jóvenes tengan } \\
\text { acceso a los secretos de } \\
\text { la comunidad y la } \\
\text { sexualidad. }\end{array}$ & $\begin{array}{ll}\text { Separación de } \\
\text { madres, hermanas, } \\
\text { abuelas: privándolos } \\
\text { de dormir, comer o } \\
\text { beber. } \\
>\text { Felación } \\
>\text { Pruebas corporales } \\
\text { crueles r para } \\
\text { comprobar } \\
\text { fortaleza } \\
\text { resistencia }\end{array}$ & $\begin{array}{lr}\text { Asegurar } & \text { las } \\
\text { destrezas } & y \\
\text { habilidades } & \text { que } \\
\text { garanticen } & \text { la } \\
\text { seguridad } & y \\
\text { protección de } & \text { la } \\
\text { comunidad. } & \\
& \\
\text { Desarrollar } & \text { la } \\
\text { identidad } & y \\
\text { cohesión del grupo. }\end{array}$ \\
\hline 2 & $\begin{array}{l}\text { Rito de } \\
\text { acceso al } \\
\text { matrimonio }\end{array}$ & $\begin{array}{l}\text { Comprobar que la pareja } \\
\text { de novios tengan las } \\
\text { virtudes necesarias para } \\
\text { entrar en unión } \\
\text { matrimonial. }\end{array}$ & $\begin{array}{l}\text { Corroboración de la } \\
\text { virginidad, especialmente en } \\
\text { caso de la mujer }\end{array}$ & 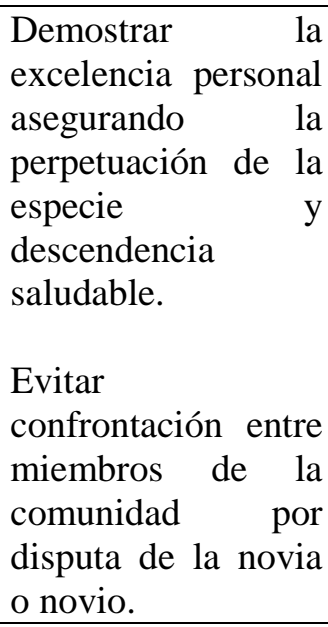 \\
\hline
\end{tabular}

Fuente: Creación personal con información de varios autores.

\section{ANEXO III: El acoso entre estudiantes y las redes sociales}

El uso del Facebook como red social se ha popularizado entre los estudiantes de la Facultad de Agronomía.

Caricatura alusiva al bautizo de la Facultad de Agronomía, publicado en el muro de una estudiante antigua, un día previo al bautizo en el año 2012 (que fue realizado el 14 de Febrero en el cual se realiza la celebración del Día del Cariño y la Amistad). 


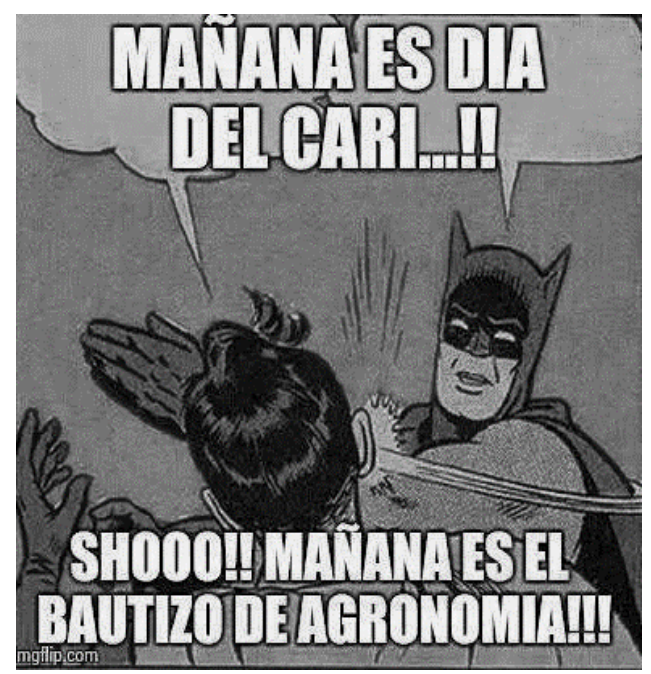

Fuente: Muro de Facebook en el muro de estudiantes antiguos de la Facultad de Agronomía.

ANEXO IV: Estudiantes encapuchados secuestraron a las autoridades de FAUSAC

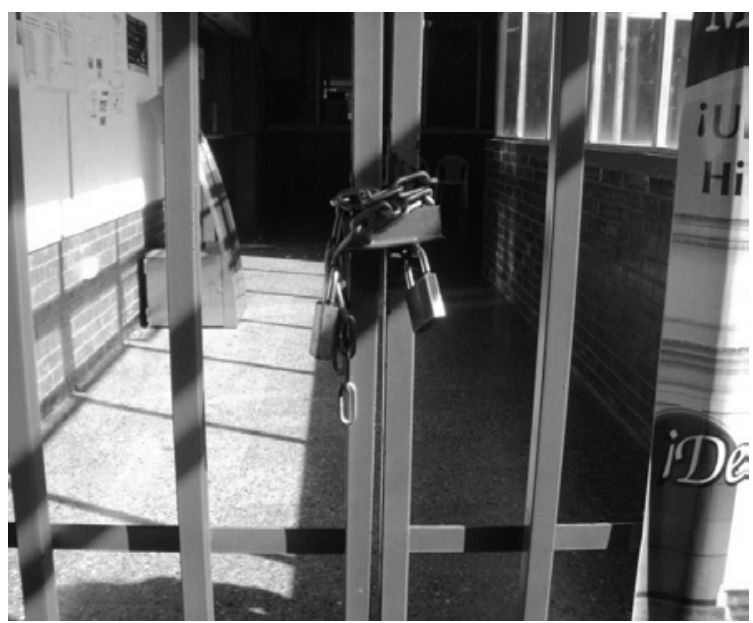

Fuente: Creación personal, fotografía tomada el día del evento. 


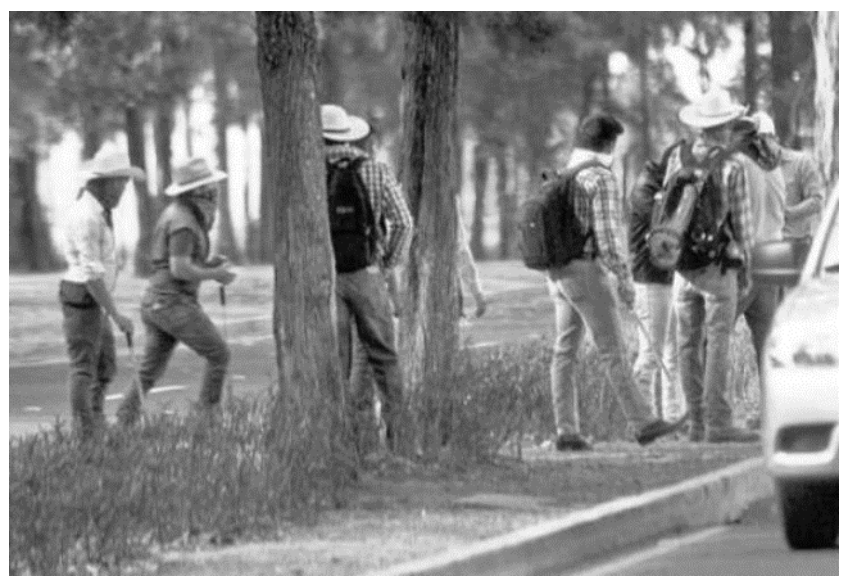

Fuente: Diario Prensa Libre.

ANEXO VI: Legislación a nivel mundial relativa a Derechos Humanos

\begin{tabular}{|l|l|l|}
\hline \multicolumn{1}{|c|}{ Institución } & \multicolumn{1}{|c|}{ Instrumento legal } & Año/ lugar de promulgación \\
\hline \multicolumn{1}{|c|}{$\begin{array}{l}\text { Organización de } \\
\text { Naciones Unidas }\end{array}$} & $\begin{array}{l}\text { Declaración Universal de los } \\
\text { Derechos Humanos }\end{array}$ & 1948 \\
\hline $\begin{array}{l}\text { Organización de } \\
\text { Naciones Unidas }\end{array}$ & Manifiesto de Sevilla & Sevilla, España/ 1986 \\
\hline $\begin{array}{l}\text { Congreso de la } \\
\text { República de Guatemala }\end{array}$ & $\begin{array}{l}\text { Constitución Política de la } \\
\text { República de Guatemala }\end{array}$ & Guatemala/1986 \\
\hline $\begin{array}{l}\text { Congreso de la } \\
\text { República de Guatemala }\end{array}$ & Decreto Ley 17-1973 & Guatemala/1973 \\
\hline $\begin{array}{l}\text { Congreso de la } \\
\text { República de Guatemala }\end{array}$ & $\begin{array}{l}\text { Decreto Ley 22-2008: Ley de } \\
\text { feminicidio y otras formas de } \\
\text { violencia contra la mujer. }\end{array}$ & Guatemala/2008 \\
\hline $\begin{array}{l}\text { Congreso de la } \\
\text { República de Guatemala }\end{array}$ & $\begin{array}{l}\text { Decreto Ley 15-2009: Ley de } \\
\text { armas y municiones. }\end{array}$ & Ciudad de Guatemala/2009 \\
\hline
\end{tabular}

Fuente: Elaboración personal. 


\section{ANEXO VII: Nota de Prensa relativa a abusos cometidos en el año 2015}

Publicado en febrero 12, 2015

Los estudiantes que ayer fueron ingresados en la emergencia del Hospital Roosevelt, dejaron el centro asistencial durante la madrugada, el examen toxicológico determinó intoxicación por exceso de alcohol; los vejámenes a los que fueron obligados los universitarios dejan al descubierto que los bautizos continúan impunes en la Universidad San Carlos de Guatemala (Usac).

La rectoría de la Universidad de San Carlos prohibió los bautizos en sus sedes. (Foto Prensa Libre: Hemeroteca PL). En conclusión el exceso de alcohol y el ejercicio que realizaron los estudiantes fue la causa de la intoxicación, revela el informe médico. Similares prácticas se efectúan en las facultades de Ingeniería, Agronomía y Arquitectura esta casa de estudios, pese a que fueron prohibidas mediante un acta del Consejo Superior Universitario en el 2011. En el caso de los estudiantes, tres hombres y dos mujeres egresaron anoche y la madrugada de hoy del centro asistencial. Una sexta estudiante fue trasladada a un hospital privado, pero se ignora su estado de salud.

Bautizos o novatadas, un abuso que queda en la impunidad

Aunque se les llame “tradición”, “broma” o “bienvenida”, los bautizos no son más que un abuso de poder de un grupo hacia una o más personas como condición para ser admitidas socialmente. Tras haberse sumergido en una pila con sangre de animal mezclada con ajo, los estudiantes de primer ingreso deben saltar al fango maloliente donde hay un zopilote muerto, como parte de las penitencias del "bautizo" en el Centro Universitario del Suroriente, en 2013, las cuales pueden verse en YouTube.

En Ingeniería obligaron a los “nuevos” a correr en ropa interior y a algunos les pusieron prendas íntimas femeninas; por supuesto, no sin antes ser rapados.

Las damas no se escaparon, como ocurrió en Veterinaria y Zootecnia, donde después de repetir un discurso humillante, bajo la vigilancia de los “padrinos”, debían revolcarse sobre lodo y estiércol, todo entre gritos e insultos.

Estudiantes graban vejámenes contra los estudiantes de primer ingreso

A los estudiantes los bañan con orina y estiércol de animales

\section{ANEXOVIII: Nota Periodística acerca de las denuncias realizadas por los bautizos}

Universitarias denuncian abusos durante bautizos

La Procuraduría de los Derechos Humanos (PDH) documenta una denuncia presentada por familiares de "un grupo de mujeres estudiantes de primer ingreso a la Universidad de San Carlos, las que habrían sido abusadas sexualmente hace una semana”, informó Abner Paredes, de la Defensoría de la Juventud. 


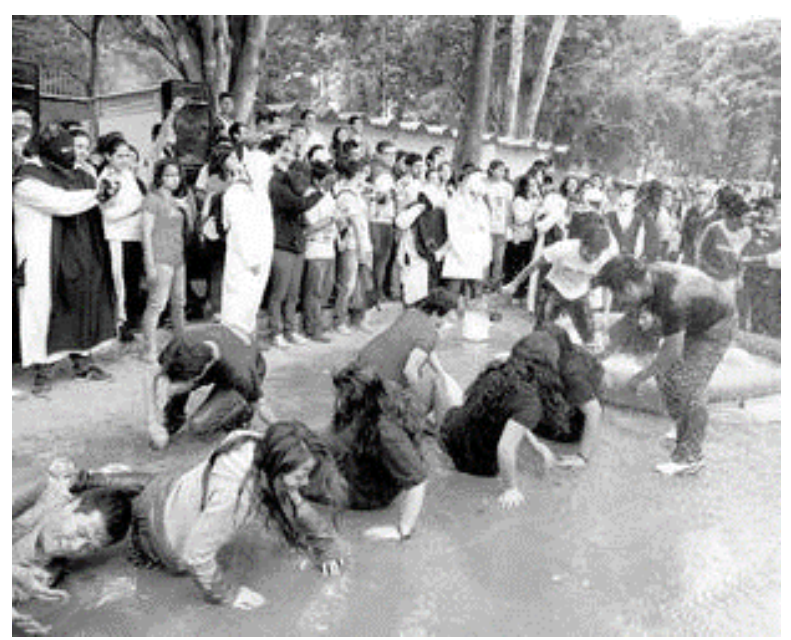

Este caso, aclaró, no se relaciona con el de los estudiantes que se intoxicaron el pasado miércoles por haber ingerido bebidas alcohólicas y posiblemente drogas, de los que cinco fueron llevados al Hospital Roosevelt.

"Verificamos la información, porque este tipo de casos es grave. Tuvimos contacto con el Ministerio Público para realizar las investigaciones y determinar la verdad de los hechos”, agregó Paredes.

El defensor de la juventud no ofreció detalles de la cantidad de víctimas, el día del suceso y a la facultad que pertenecen, aduciendo: "No puedo adelantar aspectos que se están compaginando, pero la veracidad de lo que sucedió, está en la denuncia”.

"Estamos contra los bautizos en la Usac, desde hace tres años le venimos pidiendo a las autoridades que nos envíen un informe de los mismos y aún lo estamos esperando”, prosiguió.

\section{Bautizos}

Aunque el rector Carlos Alvarado anunció que los bautizos quedaban prohibidos, ayer unos 600 estudiantes de primer ingreso de la facultad de Medicina de la Universidad de San Carlos, tuvieron el "bautizo de bienvenida".

Este es un requisito que imponen los alumnos antiguos para aceptar a los nuevos como miembros de familia universitaria. La actividad fue realizada en el complejo deportivo Los Arcos, en la zona 14. Se buscó la postura del rector, pero no contestó las llamadas a su celular

Los hombres pasaron por una piscina inflable con distintos líquidos en estado de descomposición, debieron tirarse al suelo para realizar una práctica de atletismo. Algunos se desmayaron, pero al volver en sí, como castigo, dieron una vuelta a la pista atlética.

A las mujeres les tiraron bolsas que supuestamente contenían orines, heces y desperdicios; algunas no soportaron los olores y vomitaron, siendo auxiliadas por sus padrinos y madrinas quienes les proporcionaron agua pura para calmar los efectos.

Para diferenciar a los hombres les cortaron el pelo con tijera y luego disputaron con los antiguos un partido de futbol. Finalmente recibieron una playera y se realizó una fiesta.

"Para evitar malos entendidos dejamos entrar a los padres de familia, para que ellos mismo se den cuenta que no estamos violando los derechos humanos, ni mucho menos los obligamos a ingerir bebidas embriagantes”, expresó una de las dirigentes estudiantiles apodada Bob Esponja.

Luego agregó que dentro de las dinámicas está echarles gelatina al pelo de las mujeres y reconoció que se hizo un cobro para otorgar la playera y organizar la fiesta de bienvenida.

MP acciona La fiscal general, Thelma Aldana, informó que el Ministerio Público (MP) averigua el caso de los estudiantes intoxicados, durante una actividad realizada el miércoles en el campus de la la Universidad de San Carlos de Guatemala. Aldana dijo que se recabó la información pertinente para determinar si los organizadores del evento son estudiantes o no, para así deducir 
responsabilidades. La fiscal repudió los hechos e hizo un llamado a los organizadores de estas actividades, para que reflexionen y que no pierdan el control de ellas. Entre las primeras diligencias, los fiscales hicieron un reconocimiento del lugar en donde ocurrieron los hechos y tomaron declaración de las víctimas. El MP también recaba evidencia acerca de los supuestos agresores y se espera el informe médico legal del Instituto Nacional de Ciencias Forenses, para determinar el químico que pudieron haber ingerido los estudiantes. Al principio se indicó que a los universitarios se les habían proporcionado medicamentos, aunque después se aseguró que los 15 afectados sufrieron una intoxicación por bebidas alcohólicas.

Noticias Siglo XXI Guatemala

- "Nosotros estamos en contra de los bautizos en la Usac y desde hace tres años le venimos pidiendo a las autoridades un informe de ellos”.- Abner Paredes, Defensor de la PDH.

\section{ANEXO IX: La Procuraduría de los Derechos Humanos investiga acerca de abusos}

\section{POR EDWIN PITÁN Y JOSÉ MANUEL PATZÁN}

14 de Febrero de 2015 a las 00:00h

Ábner Paredes, de la Defensoría de la Juventud de la PDH, dijo que el miércoles último recibieron la denuncia del supuesto abuso.

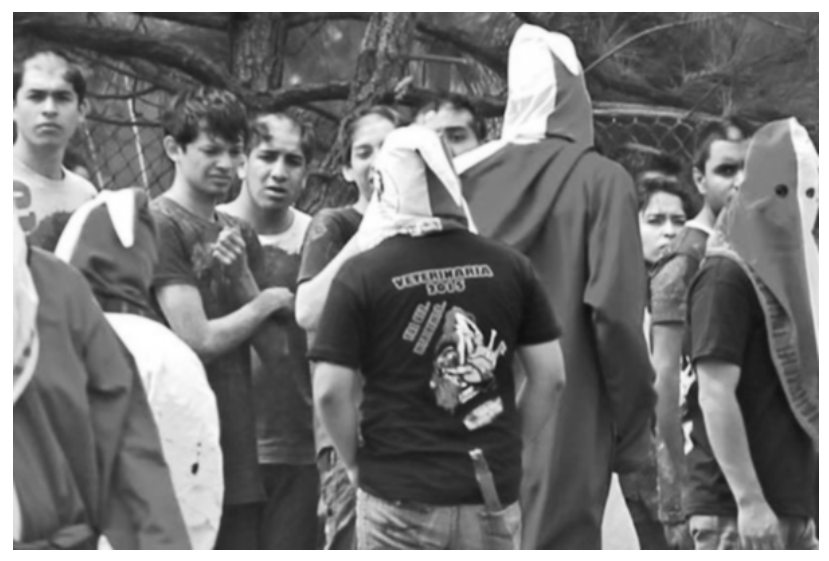

Encapuchados vigilan, a estudiantes de nuevo ingreso, a quienes les cortaron el pelo, en un "bautizo", ayer.

"Efectuamos el proceso de averiguación para establecer la veracidad de los hechos. Recibimos la denuncia de una fuente anónima”, explicó.

Agregó que esta semana la PDH recibió 10 denuncias por abusos en "bautizos".

AEU niega agresiones

El presidente de la Asociación de Estudiantes Universitarios (AEU), Guillermo Prera, negó que hayan recibido denuncias de la mencionada agresión sexual, y aseguró que fiscales del Ministerio Público tomaron la declaración. 
"El día en que se intoxicaron los cinco universitarios se habló del abuso contra algunas estudiantes, pero no ocurrió. Solo hubo afectados por beber alcohol. Hablamos con los representantes de los subcomités, y se informó que no hubo agresiones”, declaró.

La denuncia anónima establece que el abuso sexual habría sido cometido el miércoles último, aunque todavía no se aclara por quién y en qué sector del campus, por temor.

Supuestamente ocurrió el mismo día en que cinco estudiantes se intoxicaron en un "bautizo" para ingresar en el Comité de Orden de la Huelga de Dolores.

\section{Intimidaciones}

Autoridades de la Escuela de Historia y Trabajo Social de la Usac denunciaron ayer en la PDH y el Consejo Superior Universitario (CSU) que integrantes del Comité de Orden de la Huelga de Todos los Dolores los amenazaron de muerte por no haber permitido que ocuparan el edificio S-1.

"No tengo conocimiento de amenazas contra estudiantes de Historia. Ellos están en su derecho de denunciar", indicó Prera.

\section{Desafían prohibición}

Pese a la prohibición de "bautizar" a estudiantes de primer ingreso de la Usac, ayer se efectuó otra de estas actividades. Con la presencia de padres de familia, y por momentos supervisión de representantes del CSU, que prometió velar por que no se cometan abusos, desde las 6 horas. Unos 600 estudiantes de Medicina llegaron al Centro Universitario Metropolitano, zona 11, y corrieron tomados de la mano alrededor de las instalaciones.

Horas después, los participantes abordaron unos nueve buses urbanos retirados de su ruta y se dirigieron al Club Universitario Los Arcos, zona 13. Ahí fueron introducidos en una piscina y luego rodaron en lodo.

Los organizadores aseguraron que la participación fue "voluntaria”.

\section{Tenían machetes}

En un recorrido que Prensa libre efectuó por el campus de la Usac, zona 12, se observó que pese al anuncio de las autoridades universitarias sobre mantener mejor control de esas actividades, varios estudiantes de la Facultad de Agronomía permanecían afuera armados con palos y machetes. El CSU presentará informes al respecto. 


\section{ANEXO X: Comunicado de Consejo Superior Universitario}

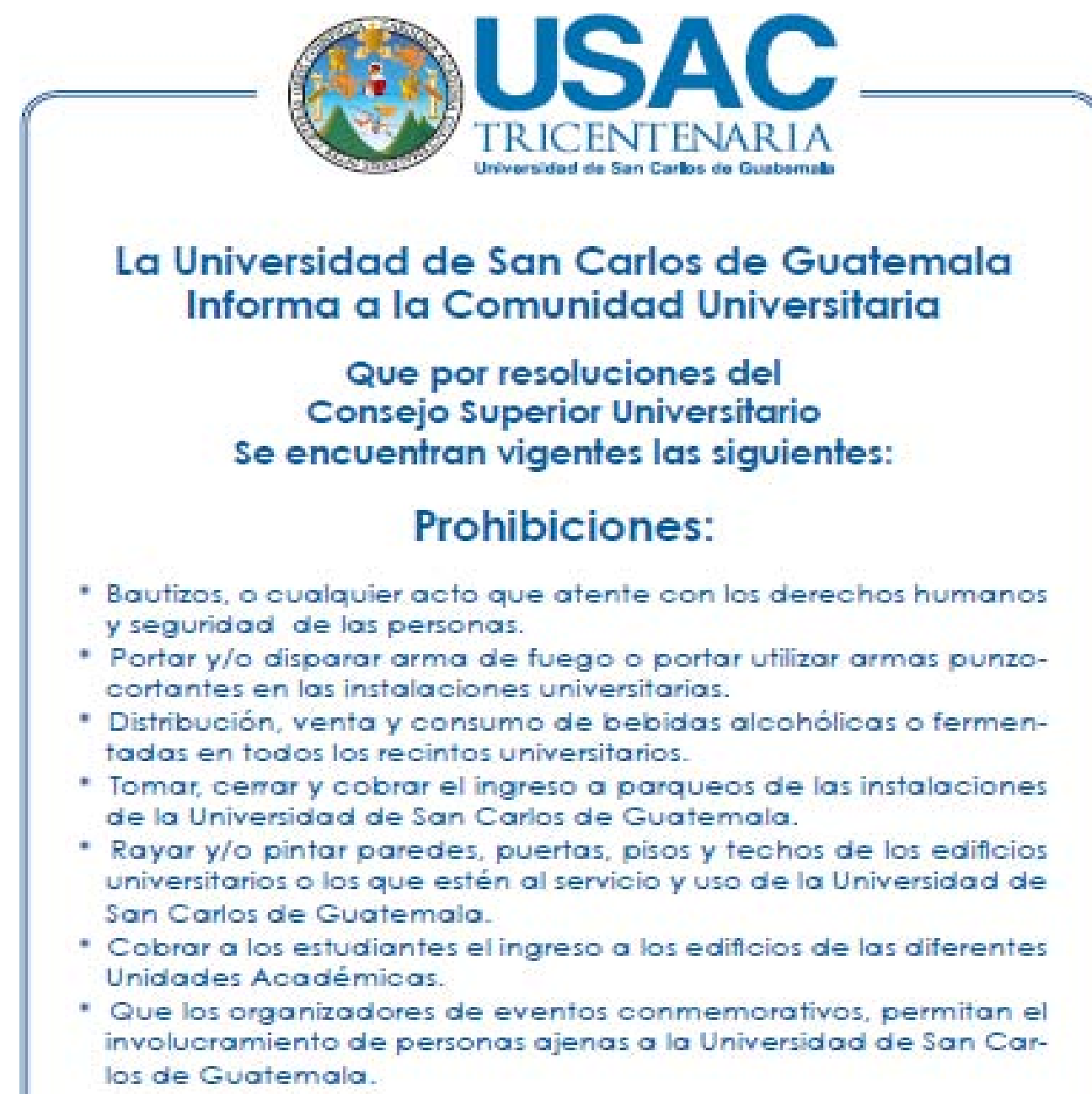

La Universidad de San Carlos de Guatemala Informa a la Comunidad Universitaria

\author{
Que por resoluciones del \\ Consejo Superior Universitario \\ Se encuentran vigentes las siguientes: \\ Prohibiciones:
}

- Bautizos, o cualquier acto que atente con los derechos humanos y seguridad de las personas.

- Portar y/o disparar arma de fuego o portar utilizar armas punzocortantes en las instalaciones universitarias.

- Distribución, venta y consumo de bebidas alcohólicas o fermentadas en todos los recintos universitarios.

- Tomar, cerrar y cobrar el ingreso a parqueos de las instalaciones de la Universidad de San Carlos de Guatemala.

- Rayar y/o pintar paredes, puertas, pisos y techos de los ediflcios universitarios o los que estén al servicio y uso de la Universidad de San Carlos de Guatemala.

- Cobrar a los estudiantes el ingreso a los ediflcios de las diferentes Unidades Académicas.

- Que los organizadores de eventos conmemorativos, permitan el involucramiento de personas ajenas a la Universidad de San Carlos de Guatemala.

\section{Sanciones:}

Las sanciones contempladas en las Leyes y Reglamentos Universitarias $\mathbf{y}$ el Derecho Común, en todas las actividades, rescatando el auténtico contenido de crítica libre, mordaz e ingeniosa que tantas generaciones de ilustres sancarlistas le imprimieron a esta tradición universitaria. y que la sociedad siempre vio con respeto. 
ANEXO XI: Bitácora de abusos cometidos durante los bautizos

\begin{tabular}{|c|c|c|c|c|c|c|c|c|}
\hline $\begin{array}{l}N \\
o .\end{array}$ & Lugar & $\begin{array}{l}\text { Unidad } \\
\text { Académica }\end{array}$ & Fecha & Agresores & Víctima & $\begin{array}{l}\text { Fuente de } \\
\text { información }\end{array}$ & Acciones & $\begin{array}{l}\text { Castigo/ } \\
\text { Sancionados }\end{array}$ \\
\hline 1 & $\begin{array}{l}\text { Cobán, } \\
\text { Alta } \\
\text { Verapaz }\end{array}$ & $\begin{array}{l}\text { Carreras de } \\
\text { Agronomía } \\
\text { y Geología }\end{array}$ & 2012 & $\begin{array}{l}\text { Personas } \\
\text { encapuchadas } \\
\text {, supuestos } \\
\text { estudiantes } \\
\text { antiguos. }\end{array}$ & $\begin{array}{l}\text { Mauricio } \\
\text { Delgado }\end{array}$ & 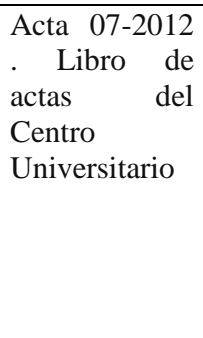 & $\begin{array}{l}\text { Golpes en el } \\
\text { cuerpo por } \\
\text { haberse } \\
\text { negado a } \\
\text { beber licor, } \\
\text { quemaduras } \\
\text { en el cuerpo } \\
\text { con juegos } \\
\text { pirotécnicos. }\end{array}$ & 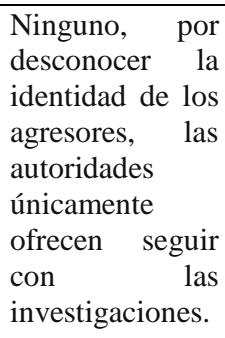 \\
\hline 2 & $\begin{array}{l}\text { Campus } \\
\text { Central }\end{array}$ & $\begin{array}{l}\text { Ciencias } \\
\text { Químicas y } \\
\text { Farmacia }\end{array}$ & 2005 & $\begin{array}{l}\text { Encapuchado } \\
\text { s del comité } \\
\text { de Huelga de } \\
\text { Ingeniería }\end{array}$ & $\begin{array}{ll}\text { Julio } & \\
\text { Romero } \quad \text { y } \\
\text { Julio } & \\
\text { Bautista } & \end{array}$ & $\begin{array}{l}\text { Acta } 09-2005 \\
\text { del libro de } \\
\text { actas del } \\
\text { Consejo } \\
\text { Superior } \\
\text { Universitario }\end{array}$ & $\begin{array}{l}\text { Fueron } \\
\text { hospitalizados } \\
\text { por haber sido } \\
\text { golpeados con } \\
\text { bates y palos } \\
\text { por los } \\
\text { agresores }\end{array}$ & Ninguno \\
\hline 3 & $\begin{array}{l}\text { Campus } \\
\text { Central }\end{array}$ & $\begin{array}{l}\text { Facultad de } \\
\text { Agronomía }\end{array}$ & 2010 & $\begin{array}{l}\text { Encapuchado } \\
\text { s de } \\
\text { Agronomía }\end{array}$ & $\begin{array}{l}\text { Secretario } \\
\text { Académico } \\
\text { de la } \\
\text { Facultad. }\end{array}$ & $\begin{array}{l}\text { Relato de las } \\
\text { secretarias de } \\
\text { la Unidad. }\end{array}$ & $\begin{array}{l}\text { Los } \\
\text { estudiantes } \\
\text { encapuchados } \\
\text { irrumpieron } \\
\text { violentamente } \\
\text { en las oficinas } \\
\text { de la } \\
\text { autoridades } \\
\text { académicas, } \\
\text { exigiendo } \\
\text { abandonaran } \\
\text { sus puestos de } \\
\text { trabajo pues } \\
\text { habría lectura } \\
\text { de boletín } \\
\text { estudiantil. }\end{array}$ & $\begin{array}{lr}\text { Ninguno, por } \\
\text { desconocer la } \\
\text { identidad de los } \\
\text { agresores. }\end{array}$ \\
\hline
\end{tabular}

Fuente: Creación personal. 


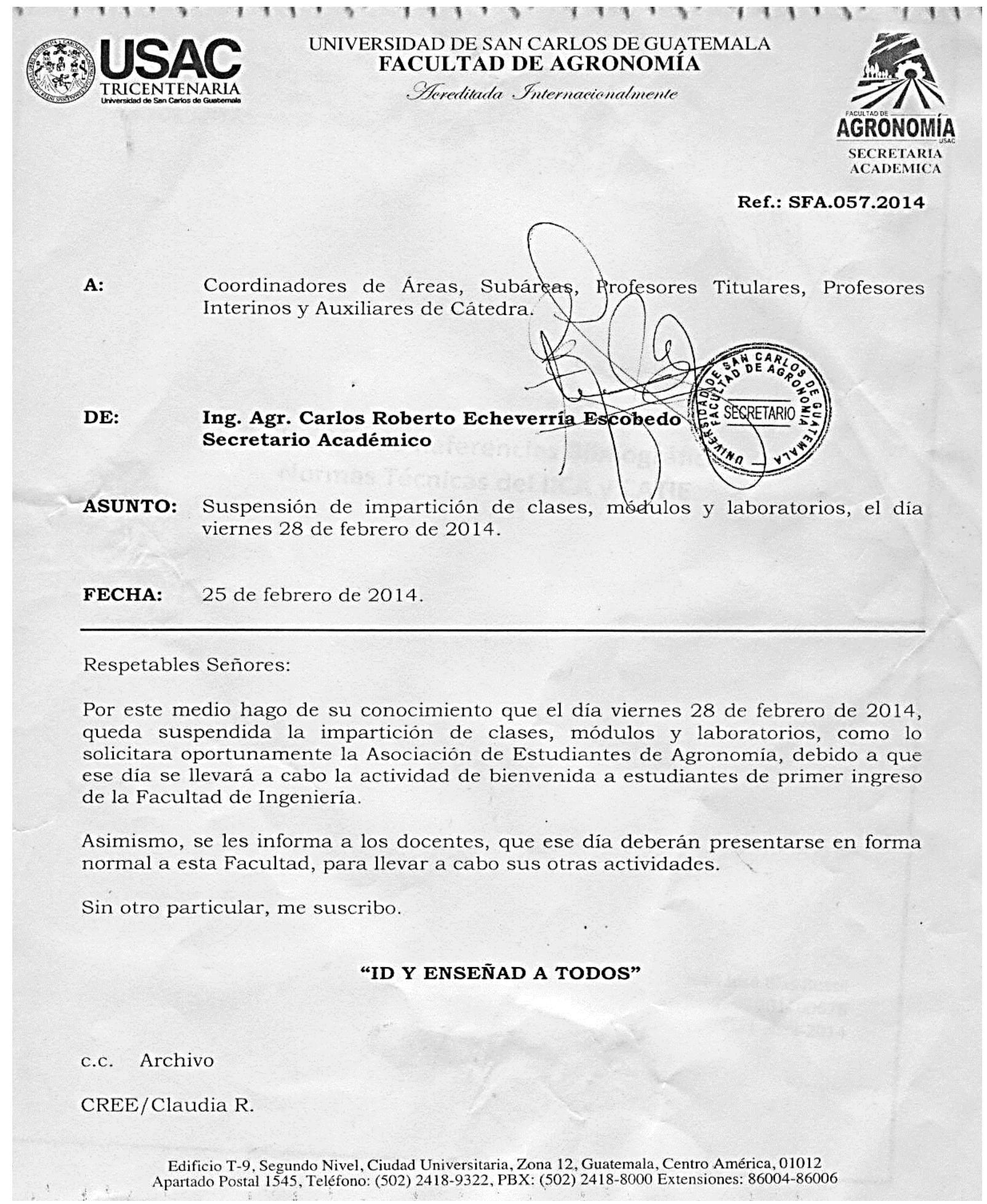




\section{ANEXO XIII: Nota anónima escrita como reacción a las jornadas de Bautizo en}

\section{FAUSAC.}

\section{CARTA ABIERTA AL ESTUDIANTE DE AGRONOMIA}

Amanece y se escucha el estruendoso sonido de los cohetillos, el ensordecedor estallido de las bombas, agudos chiflidos, gente corriendo de un lado a otro, un verdadero bullicio, una aparente fiesta. Pero si se observa con mayor atención puede notarse inmediatamente que todo ese revuelo, toda esa energía no es otra cosa mas, que el día del bautizo en la Facultad de Agronomía.

Somos universitarios, parte de un $2.8 \%$ privilegiado que tiene la oportunidad de una educación superior, como buenos sancarlistas sabemos bien que el bautizo es una "tradición"por la que todas y todos hemos pasado, tradición que lamentablemente ya no cumple con su cometido inicial, darle a los nuevos una bienvenida... No discutiré la legitimidad de esta práctica, se sabe además que el CSU la ha prohibido... Sin embargo sí es mi intención hacer un llamado a la reflexión, a que hagamos un análisis sobre nuestro actuar ese día y a no reproducir los patrones de violencia de la sociedad guatemalteca. Compañera, compañero la violencia solo genera mas violencia.

Ese día alcanzan su momento máximo la adrenalina, la aparente valentía y con ello una serie de vejámenes hacia las personas que se ven obligadas a participar en este "rito" de iniciación. El argumento barato con el que se excusa esta práctica es que TODOS pasamos por el bautizo, es una tradición, que te convierte en parte de la facultad, te da derecho a bautizar el año siguiente, te hace dejar de ser nuevo y demás mentiras que sus defensores mas fuertes harán resonar al poner en duda la manera en que se realiza el bautizo. Sin embargo eso no nos da el derecho de hacer pasar a los compañeros por situaciones que pongan en riesgo su integridad física, psicológica y moral.

Este dia representa un atentado para la integridad física de todos, sean "antiguos" o "nuevos" debido al comportamiento de personajes estúpidos e inconsientes que disparan al aire como sucedió el año pasado (2013) lo mas alarmante es que la persona que realizo estos disparos estaba en compañia de un "dirigente estudiantil" peor aun este dirigente es un acérrimo defensor del bautizo y usuario de esas excusas baratas ya mencionadas..

El año pasado durante el bautizo se mostró un comportamiento preocupante, personas ebrias, improperios y lo peor es la cantidad de excremento esparcido por el suelo y sobre los cuerpos de las y los compañeros.

No existe libertad sin reglas. No pretendo hacer un debate sobre la realización o no del bautizo, la libertad, el consumo de licor, ni ninguna otra cosa. Lo único que pretendo es hacerles el llamado a la reflexión; recuerden: No hagas a los demás lo que no quieres que te hagan a ti.

Como buenos sancarlistas demostremos que somos mejores personas que el año pasado, que el mes pasado e incluso mejores que el día anterior, recuerden:

"El respeto al derecho ajeno es la paz" paz que tanto necesitamos ya sea como sociedad o como individuos.

Somos agrónomos, ejercemos una profesión noble, hagamos honor a ello.

"La agricultura es la profesión del sabio, la ocupación de todo hombre libre y la mas adecuada al sencillo" Cicerón.

Fuente: Fue distribuida anónimamente en las instalaciones de FAUSAC. 
ANEXO XIV: Fotografía de estudiantes encuestados

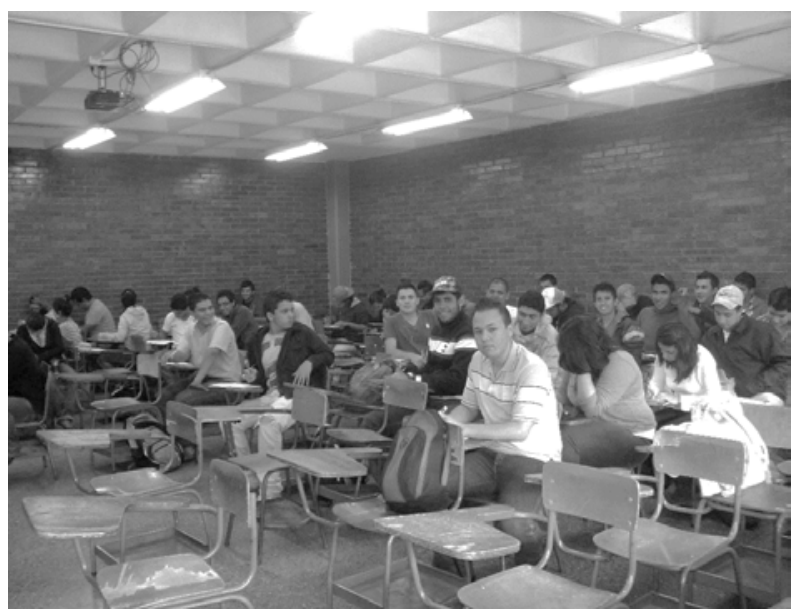

Fuente: Creación personal

ANEXO XV: Cuestionario aplicado a los estudiantes novatos de FAUSAC

\section{CUESTIONARIO SOBRE INTIMIDACIÓN Y MALTRATO ENTRE IGUALES}

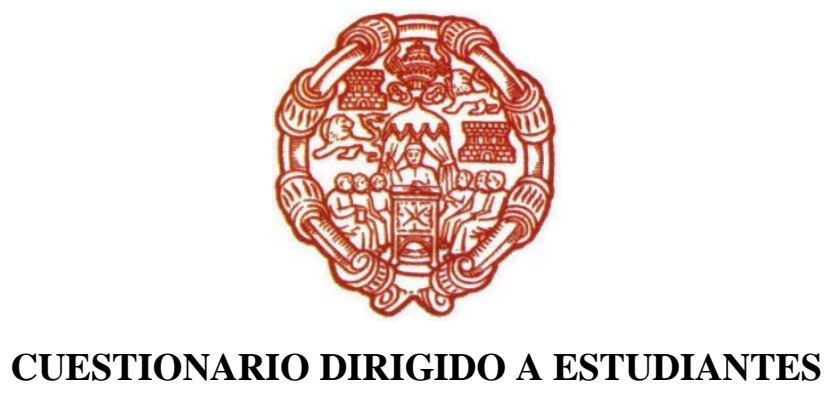

Universidad Pontificia de Salamanca, España.

Universidad de San Carlos de Guatemala

Facultad de Agronomía

Subárea de Ciencias Sociales y Desarrollo Rural

ESTUDIO DE LAS DINÁMICAS ESTUDIANTILES EN LA UNIVERSIDAD DE SAN CARLOS DE GUATEMALA EN LA ÉPOCA CONTEMPORÁNEA 
Estimado Estudiante: El presente cuestionario es una de las herramientas empleadas en la investigación de campo de estudios relativos a las prácticas estudiantiles de los sancarlistas. El único objetivo del mismo es documentar tu opinión relativa a la práctica del bautizo en tu unidad académica. Por lo anteriormente expresado no escribas tu nombre en el presente cuestionario. Anticipadamente agradecemos el tiempo que empleas en responder el mismo.

EDAD:

GÉNERO:

$\begin{array}{lll}\text { CARRERA QSTUDIA ACTUALMENTE EN } & \text { FAUSAC: }\end{array}$

1. Escribe dentro del paréntesis una $\mathbf{X}$ en el tipo de prácticas que mejor identifiquen al estudiante sancarlista ante la sociedad guatemalteca.

A. El bautizo de estudiantes de primer ingreso

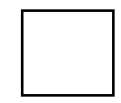

B. El compromiso social en la búsqueda de la solución a los principales problemas del país.

2. ¿Ha presenciado o escuchado acerca de hechos violentos y/o delictivos dentro de las instalaciones del campus central de USAC?

SI

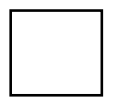

NO

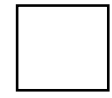

3. ¿ ¿Te sientes seguro dentro del campus universitario durante el día?

SI

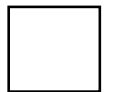

NO

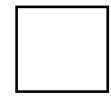

¿Te sientes seguro dentro del campus universitario durante la tarde y noche?

SI

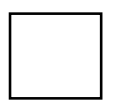

NO

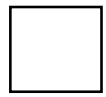

5. ¿Consideras que la seguridad dentro del campus universitario es?

6. Describe tu expertencia durante el bautizo.

MUY MALA

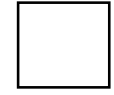

REGULAR

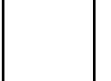

MALA
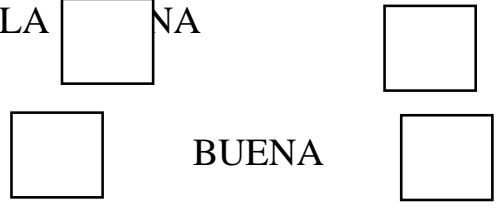
7. ¿Cuál piensas que es el objetivo de la celebración del bautizo (elije una sola respuesta)?

a) Una excelente oportunidad de convivencia con otros estudiantes

b) Una acción indispensable para ser aceptado como estudiante sancarlista

c) Una oportunidad de revancha de los estudiantes antiguos sobre los novatos
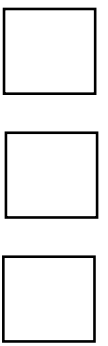

8. ¿Las prácticas durante la celebración del bautizo son?

- Divertidas e inofensivas

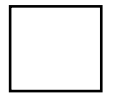

- Violentas y peligrosas

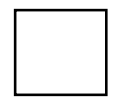

9. Enumera según el orden de importancia, las tres prácticas más populares durante la celebración del bautizo

1.

2.

3.

10. ¿Cuál fue el papel de los padrinos?

- Protegerlo del ataque de terceros y hacer su bautizo menos desagradable

- Someterlo a los más duros tratos

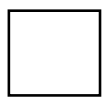

11. ¿Durante la celebración del bautizo fuiste obligado a beber licor?

SI

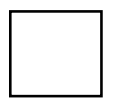

NO

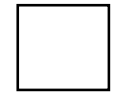

12. ¿Si fuiste obligado a beber licor durante la celebración del bautizo, qué opinas acerca de ello?

Fue buena idea, me ayudó a tolerar la jornada del bautizo

Fue negativo porque era mejor estar lúcido, el estar alcoholizado me hizo más vulnerable. 
13. ¿Las prácticas durante la celebración del bautizo son?

Ligeramente violentas

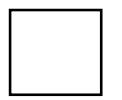

Moderadamente violentas

Excesivamente violentas

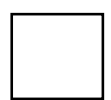

14. ¿Sufriste algún tipo de lesión física (problemas estomacales, esguinces, fracturas, etc.) producto de las prácticas durante la celebración del bautizo?

SI

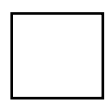

NO

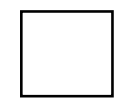

15. Si tuvieras la posibilidad de elegir qué harías?

Prohibir el bautizo de los estudiantes de FAUSAC

a) Implementar normativos para regular las prácticas del bautizo y evitar excesos y abusos.

b) Continuar con la celebración del bautizo como hasta la fecha.

16. Describe cómo te sentiste durante la celebración del bautizo.

a) Contento porque pude participar de una actividad tradicional en mi facultad.

b) Enojado: por las bromas realizadas y los abusos.

17. ¿Finalmente, cuál es el sentimiento que prevalece en ti al finalizar la celebración del bautizo?

a) Me siento bien porque ya soy sancarlista

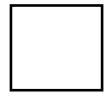

b) Siento mucha frustración y enojo

c) Me siento triste y avergonzado

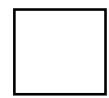

18. ¿Participarás el próximo año en el bautizo de los novatos? 
- $\mathrm{SI}$

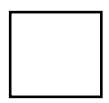

- $\mathrm{NO}$

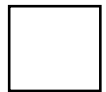

19. Si has respondido que sí, indica la razón.

a) Es una práctica que nos distingue como sancarlistas

b) Es una excelente oportunidad para tomar revancha con los novatos

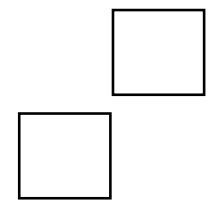

20. Finalmente podemos concluir que la celebración del bautizo es?

- MUY MALA REGULAR

$\square$

MALA $\square$
BUENA

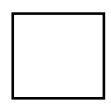




\section{ANEXO XVI: Guía práctica para la implementación de grupo focal}

OBJETIVO GENERAL: Conocer, describir y analizar la experiencia de la celebración del ritual de iniciación denominado "bautizo en la Facultad de Agronomía de la-USAC”.

La herramienta será aplicada al azar a estudiantes de la Facultad de Agronomía (aquellos que acepten participar). El único requisito es ser estudiante regular de la Facultad de Agronomía y haber sido bautizado.

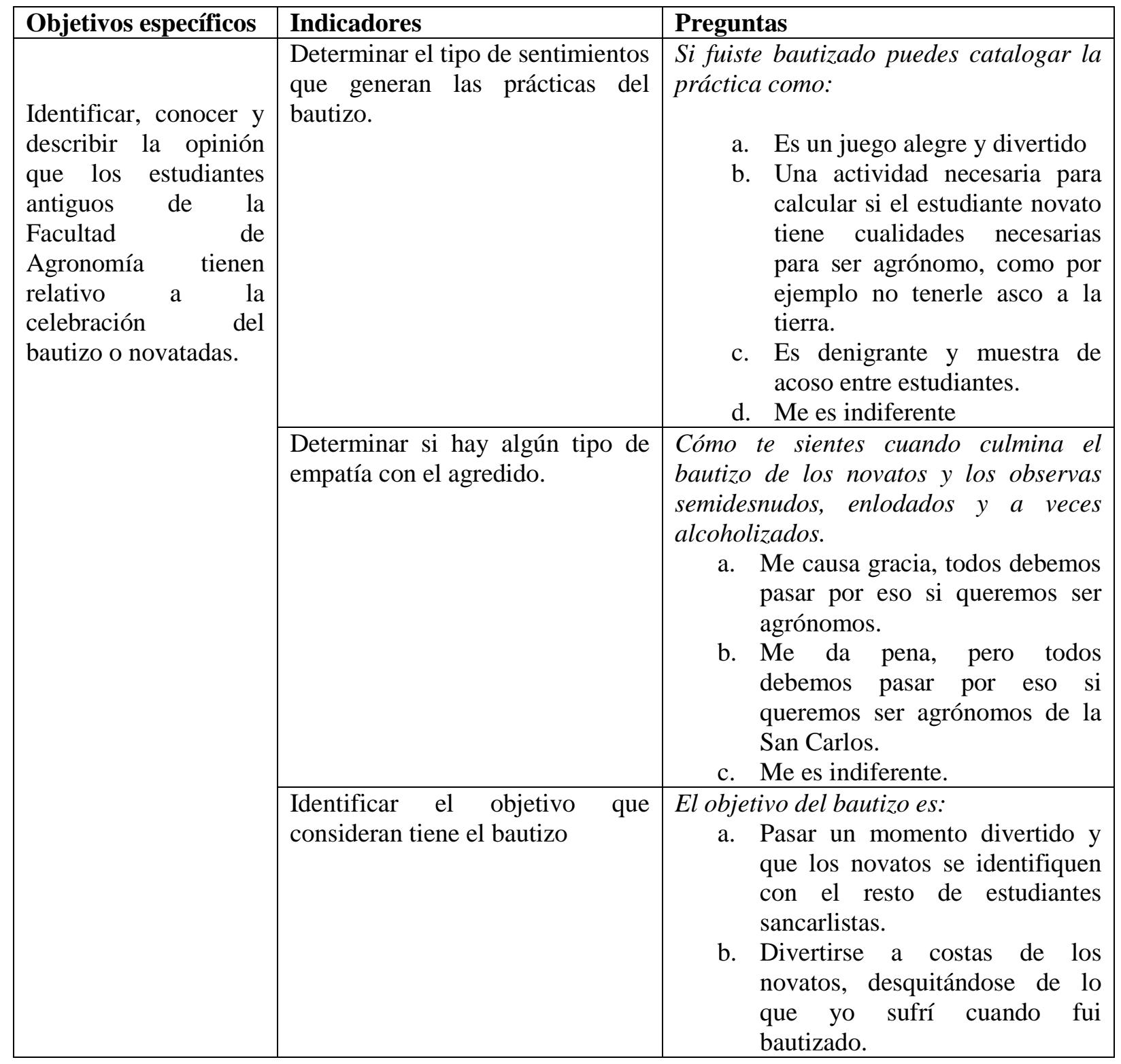




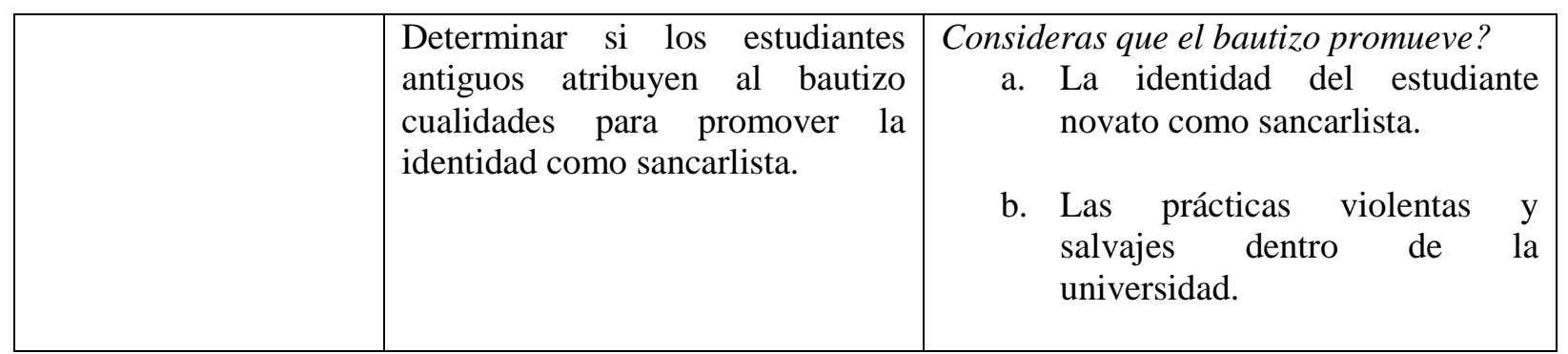

Fuente: Creación personal.

ANEXO XVII: Guía práctica para la implementación de grupo focal

GUÍA PRÁCTICA PARA LA IMPLEMENTACIÓN DEL GRUPO FOCAL CON PROFESORES DE FACULTAD

\section{DE AGRONOMÍA}

OBJETIVO GENERAL: Conocer, describir y analizar la experiencia de la celebración del ritual de iniciación denominado "bautizo en la Facultad de Agronomía de la -USAC".

\begin{tabular}{|c|c|c|}
\hline Objetivos específicos & Indicadores & Preguntas \\
\hline \multirow{3}{*}{$\begin{array}{l}\text { Identificar, conocer y } \\
\text { describir la opinión que los } \\
\text { estudiantes antiguos de la } \\
\text { Facultad de Agronomía } \\
\text { tienen relativo a la } \\
\text { celebración del bautizo o } \\
\text { novatadas. }\end{array}$} & \begin{tabular}{lr}
\multicolumn{2}{l}{ Determinar el tipo } \\
de sentimientos \\
que generan las \\
prácticas & del \\
bautizo. &
\end{tabular} & $\begin{array}{l}\text { Considera que la práctica del bautizo en la Facultad } \\
\text { de Agronomía es: } \\
\text { a. Una tradición sancarlista que garantiza la } \\
\text { identidad y cohesión al grupo estudiantil. } \\
\text { b. Una salvajada y una oportunidad de acoso } \\
\text { entre universitarios. }\end{array}$ \\
\hline & $\begin{array}{lr}\text { Determinar } & \text { si está } \\
\text { dispuesto } & \text { a } \\
\text { participar } & \text { para } \\
\text { regular } & \text { tales } \\
\text { prácticas. } & \end{array}$ & $\begin{array}{l}\text { Considera que su papel como profesor ante tales } \\
\text { prácticas debe ser: } \\
\text { a. Mantenerse al margen como hasta ahora } \\
\text { porque es una práctica puramente } \\
\text { estudiantil. } \\
\text { b. Participar de alguna manera pues es } \\
\text { necesario regularlo para que no haya } \\
\text { lesionados. }\end{array}$ \\
\hline & $\begin{array}{l}\text { Determinar si } \\
\text { reconocen que } \\
\text { hay algún tipo de } \\
\text { daño físico en los } \\
\text { bautizados. }\end{array}$ & $\begin{array}{l}\text { Señale si ha conocido algún tipo de lesión (entre las } \\
\text { alternativas siguientes) en los estudiantes novatos } \\
\text { durante la celebración del bautizo: } \\
\text { a. Quemaduras en la piel que van de leves a } \\
\text { graves } \\
\text { b. Problemas estomacales por ingesta de } \\
\text { productos malsanos } \\
\text { c. Estudiante alcoholizados }\end{array}$ \\
\hline
\end{tabular}




\begin{tabular}{|l|l|l|}
\hline $\begin{array}{l}\text { Determinar si } \\
\text { considera que el } \\
\text { bautizo es un } \\
\text { problema que hay } \\
\text { que resolver en el } \\
\text { corto o mediano } \\
\text { plazo. }\end{array}$ & $\begin{array}{l}\text { Considera que es importante abordar el tema del } \\
\text { bautizo institucional y sistemáticamente. } \\
\text { a. Sí, porque es necesario una cultura de } \\
\text { prevención a la violencia y velar por la } \\
\text { proyección positiva de la institución. } \\
\text { No, porque la práctica está ya arraigada y } \\
\text { nada de lo que se haga podrá cambiarlo. } \\
\text { c. Me es indiferente. }\end{array}$ \\
\hline
\end{tabular}

Fuente: Creación personal.

\section{ANEXO XVIII: Bautizo a joven de 15 años puede frustrar carrera de ocho futbolistas}

El bautizo, como se define la "bienvenida" en el fútbol en la que se rapa a los novatos que se integran al equipo, puede frustrar la carrera de ocho jugadores del Xelajú guatemalteco, entre ellos dos brasileños, un costarricense y un hondureño, por un proceso penal por violencia contra menores.

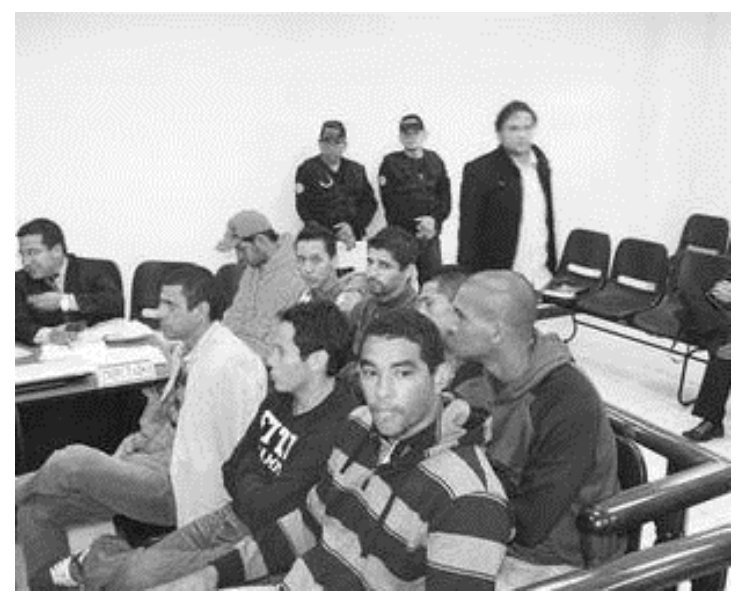

El escándalo afecta a los brasileños Israel Silva y Juliano Rangel, el costarricense Sergio Morales, el hondureño José Alberto Mendoza y los guatemaltecos Kevin Arreola, Julio Estacuy, Edgar Chinchilla y Milton Leal, todos titulares del Xelajú.

Un fallo emitido la semana pasada por el Juzgado Segundo de Primera Instancia Penal señala que Morales, Rangel y Mendoza son investigados por agresión sexual y el resto por el delito de maltrato en contra de personas menores de edad.

El querellante es Mario Humberto Rodas, de 15 años, quien resultó lesionado en diciembre pasado al negarse a ser 'bautizado' por los citados jugadores, que tienen prohibición de salir del país.

Dwight Anthony Pezzarrosi García, exjugador guatemalteco que pasó por equipos de Chile, España, Argentina, Inglaterra y Guatemala, aseguró que el rito del bautizo es "normal", y se da desde hace mucho tiempo en varios países. 
"Esta práctica es bastante común dentro de los equipos de Guatemala y en el extranjero, pero no en todos es igual y no trasciende. El objetivo es darle una bienvenida con un poco de humor al jugador nuevo para romper el hielo", dijo el exjugador del Racing de Ferrol y el CD Numancia de España entre 2002-2003 y 2005-2006.

La tradición, según sus propias palabras, es rapar "al nuevo" o hacerle un corte de cabello tosco, así como gastarle bromas, algunas veces pesadas pero sin que la situación se salga de control.

Pezzarossi, actual Comisionado Presidencial para el Deporte en Guatemala, aclaró que los bautizos no trascienden porque son entre jugadores.

"Los tiempos han cambiado y todos los jugadores no están obligados a que les guste o a quedarse callados, pueden quejarse si son maltratados y más aún si son menores de edad", expresó.

Como consecuencia de la denuncia entablada por la madre del joven Rodas, el brasileño Silva vio frustrado su pase al Saprissa costarricense, pero al igual que sus compañeros seguirá jugando con el Xelajú hasta que se termine la investigación, posiblemente en marzo próximo, y se defina si se cambian las medidas judiciales, que puede ser hasta imponerles cárcel.

"Entiendo la situación del caso de ese joven y más de la madre, pero también el de los compañeros futbolistas involucrados, porque para mí no es extraño 'el bautizo' dentro del fútbol aunque sí es complicado porque se salió de contexto", dijo Pezzarossi, quien jugó en Argentinos Juniors y el Palestino chileno.

"Mientras yo estuve (en el balompié) no tuve ningún inconveniente con algún muchacho que comenzaba en la era del fútbol profesional", aseguró el exjugador del Santiago Wanderers chileno y el Bolton Wanderers inglés.

De acuerdo con la denuncia presentada por el joven jugador del Xelajú, el costarricense Sergio Morales lo agarró de los genitales hasta por cinco minutos al negarse a ser rapado.

Sin embargo, el grupo lo terminó rapando aunque debido a los golpes que recibió, Rodas terminó en el hospital y los ocho jugadores denunciados penalmente. 